\title{
Improving Microbial Safety of Locally Grown Produce in West Virginia Area
}

\author{
KaWang Li \\ West Virginia University, kwli@mix.wvu.edu
}

Follow this and additional works at: https://researchrepository.wvu.edu/etd

Part of the Food Microbiology Commons

\section{Recommended Citation}

Li, KaWang, "Improving Microbial Safety of Locally Grown Produce in West Virginia Area" (2021). Graduate Theses, Dissertations, and Problem Reports. 8238.

https://researchrepository.wvu.edu/etd/8238

This Dissertation is protected by copyright and/or related rights. It has been brought to you by the The Research Repository @ WVU with permission from the rights-holder(s). You are free to use this Dissertation in any way that is permitted by the copyright and related rights legislation that applies to your use. For other uses you must obtain permission from the rights-holder(s) directly, unless additional rights are indicated by a Creative Commons license in the record and/ or on the work itself. This Dissertation has been accepted for inclusion in WVU Graduate Theses, Dissertations, and Problem Reports collection by an authorized administrator of The Research Repository @ WVU.

For more information, please contact researchrepository@mail.wvu.edu. 


\title{
Improving Microbial Safety of Locally Grown Produce in West Virginia Area
}

\author{
Ka Wang Li \\ Dissertation submitted to the \\ Davis College of Agriculture, Natural Resources, and Design \\ at West Virginia University \\ Doctor of Philosophy in \\ Animal and Food Sciences \\ Cangliang Shen, Ph.D., Chair \\ Brett P. Kenney, Ph.D. \\ Kristen, Matak, Ph.D. \\ Jacek, Jaczynski, Ph.D. \\ Department of Animal and Nutritional Sciences
}

Morgantown, West Virginia

2021

Keywords: Foodborne pathogen, Surrogate, Farmers' market, Produce, Sanitation, West Virginia Copyright $2021 \mathrm{Ka}$ Wang Li 


\section{ABSTRACT \\ Improving Microbial Safety of Locally Produced Food in West Virginia Area}

Ka Wang Li

There is a growing concern regarding the microbial safety of farmers' markets as fresh produce consumption in the United States is gaining popularity. The CDC reported 46\% of foodborne illnesses are related to fresh produce. Consuming fresh produce raw removes a processing step, increasing the risk of cross-contamination, leading to illness. However, this risk can be mitigated by washing produce with antimicrobial solutions during post-harvest processes. To reduce the microbial load on fresh produce, the triple-wash process, where the produce is rinsed with water twice and lastly an antimicrobial solution (WWA). WWA is recommended by the WVU Extension Service Small Farm Center, but its efficacy has yet to be evaluated.

The objectives of this project were: 1.) to evaluate the two triple-wash procedures (WAW/WWA) with commercial antimicrobials to inactivate foodborne pathogens and surrogate bacteria on cucumbers, tomatoes, and spinaches; 2 .) to evaluate the two triple-wash procedures with SaniDate-5.0 on microbial quality of butternut squashes; 3 .) to determine the economic feasibility of the triple-wash application in a processing plant, and 4.) to assess how produce growers handle containers and evaluate the survival of Salmonella and Listeria monocytogenes on various commonly used produce container surfaces under refrigerated and room conditions.

Results showed Triple-wash by WWA with antimicrobials achieved additional reductions $(P<0.05)$ of pathogens by 0.38-0.56 $\log _{10}$ CFU/cucumber, 0.71 -1.48 $\log _{10}$ CFU/tomato, 0.35 $1.07 \log _{10} \mathrm{CFU} / \mathrm{g}$ spinach, and 0.7-2.0 $\log _{10} \mathrm{CFU} / \mathrm{squash}$ than the WAW procedure The estimated annual operating cost of the triple-wash process with SaniDate-5.0 ranges from $\$ 487.05$ to $\$ 1,977.33$ for growers producing $1,000-5,000$ squashes. Pathogens decreased slower $(P<0.05)$ at $3.2^{\circ} \mathrm{C}$ on pressed-card and wood surfaces than at $22.5^{\circ} \mathrm{C}$ on a plastic surface. At $22.5^{\circ} \mathrm{C}$, Salmonella and L. monocytogenes reduced $(P<0.05)$ to $<1.30 \log$ (detection limit) after 3 days, and 12 days on plastic, respectively.

Collectively, results indicate that WWA can achieve additional pathogen reduction, SaniDate-5.0 could be used as an alternative antimicrobial agent in the triple-wash process for small local produce growers. It showed the WWA method was an economically feasible approach for produce growers to improve microbial safety during postharvest processing of squash. 


\section{ACKNOWLEDGEMENTS}

This calls for a celebration, to express my gratitude to those who supported me alongside this long, fruitful, and at times treacherous education. Without your assistance, this journey would be nothing but a dream.

Thank you to my advisor and mentor, Dr. Cangliang Shen, for his vision, guidance, and patience. Without his knowledge and experience, as well as continuous support, completing these studies in a timely manner would be virtually impossible. Thank you for letting me partake in this precious opportunity.

Thank you to my committee members, Dr. Brett P. Kenney, Dr. Kristen Matak, and Dr. Jacek Jaczynski. It is truly humbling to learn alongside the experts in the field of food science. Thank you for the kindness, acceptance, and numerous technical assistances. Thank you to Dr. Zachary Freedman for his input and contribution in the early parts of my study.

Thank you to the faculty and staff in the Animal and Nutritional Sciences Department at West Virginia University for their continuous support. It is their dedicated hard work so our operations could be as frictionless as it is.

Thank you to the fellow undergraduate and graduate colleges, who decided to clear out their busy schedule, offer helping hands at times when lab-work gets unwieldy, and took the effort to cultivate our friendship. I wish our bonds will remain unscathed for the test of time.

Thank you to the friends and colleges from as near as next door to as far as the opposite side of the globe, thank you for showing me the beauty in diversity, this journey would not be the same without them.

This dissertation is dedicated to everyone who treasures liberty. 


\section{TABLE OF CONTENTS}

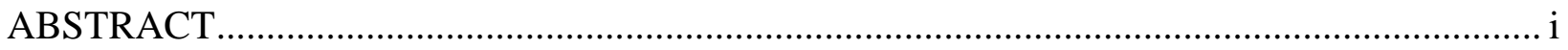

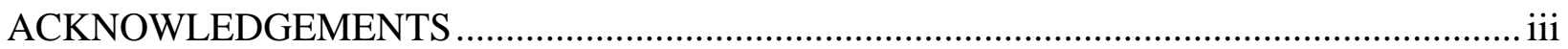

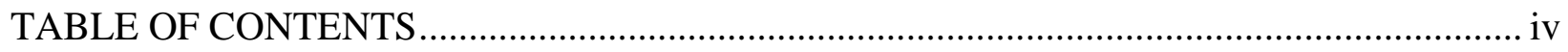

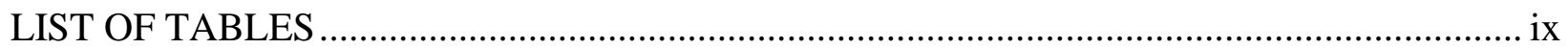

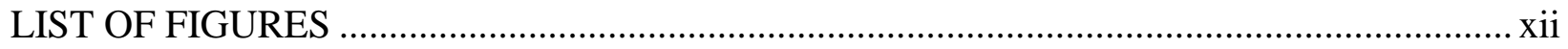

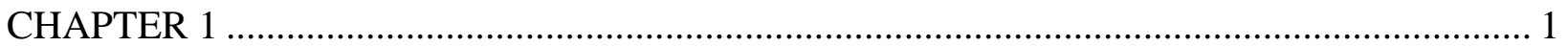

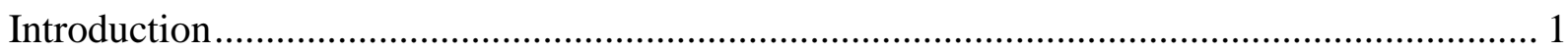

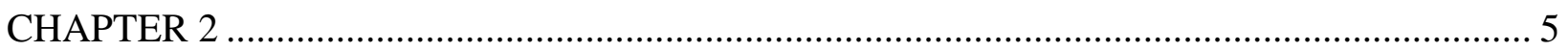

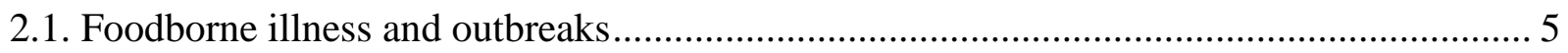

2.2. Foodborne pathogen and recent outbreaks ................................................................. 5

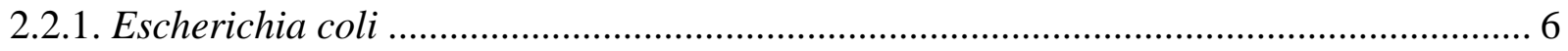

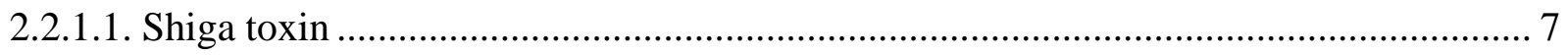

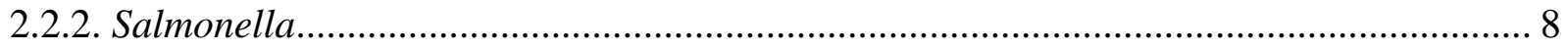

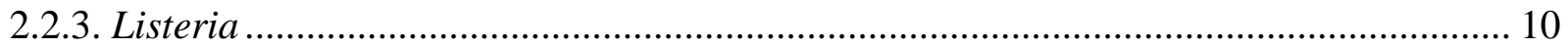

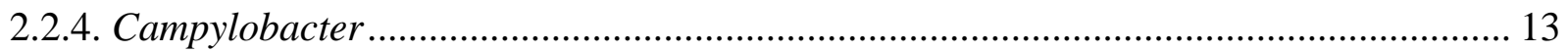

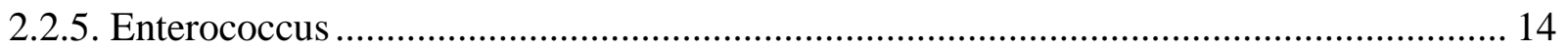

2.3. Surrogate Roles in Food safety studies ........................................................................ 15

2.3.1. Enterococcus faecium as a Pathogen Surrogate............................................................ 16

2.4. Microbial Safety in Farmers' Markets Produce ................................................................ 19

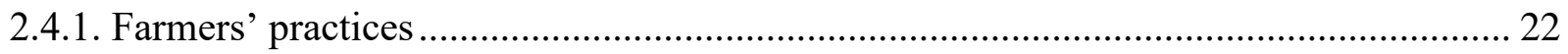

2.4.2. The Food Safety Modernization Act.............................................................................. 24

2.4.3. Pathogen survival on food contact surfaces ................................................................. 26

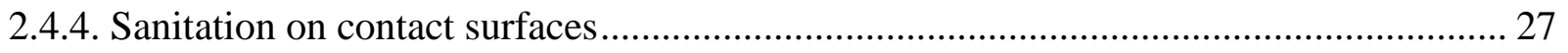

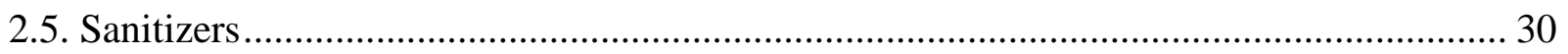




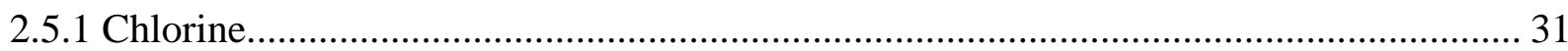

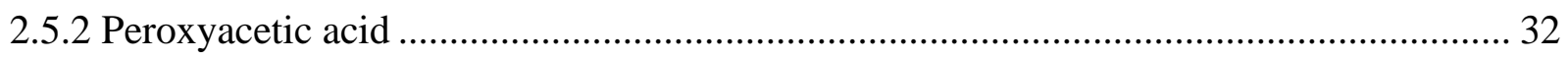

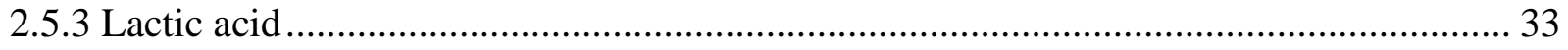

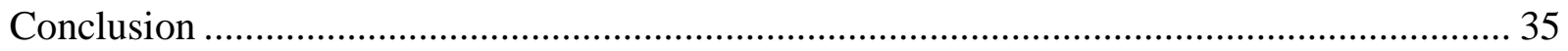

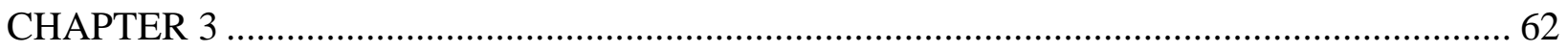

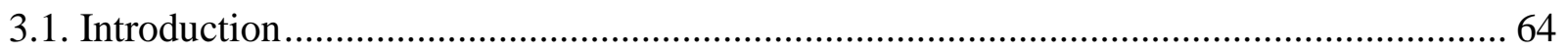

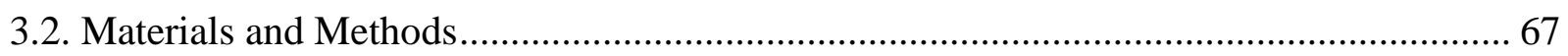

3.2.1. Fresh produce sample preparation and background microflora elimination ............... 67

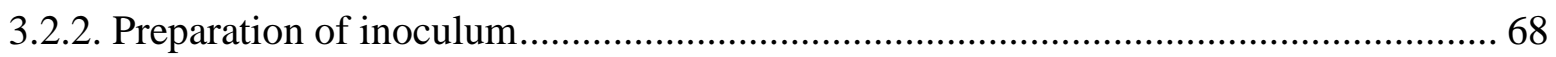

3.2.3. Inoculation of fresh produce samples ……………................................................... 69

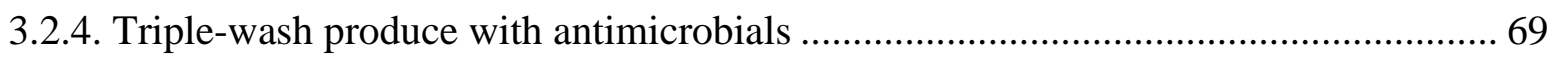

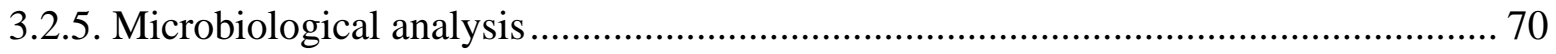

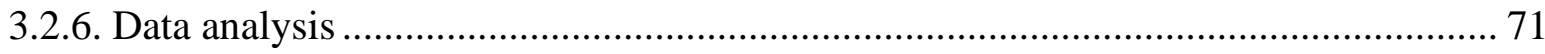

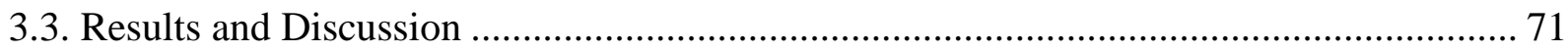

3.3.1. Comparison of WAW and WWA procedures ........................................................... 71

3.3.2. Efficacy of triple-wash with antimicrobials against Salmonella ................................ 72

3.3.3. Efficacy of triple-wash with antimicrobials against $L$. monocytogenes ..................... 73

3.3.4. Comparison of Salmonella verse Surrogate E. faecium............................................... 74

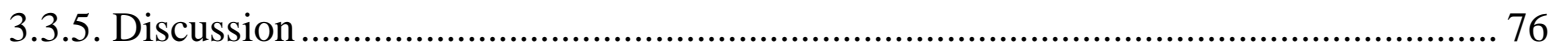

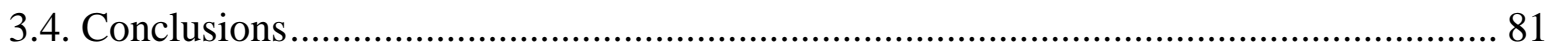

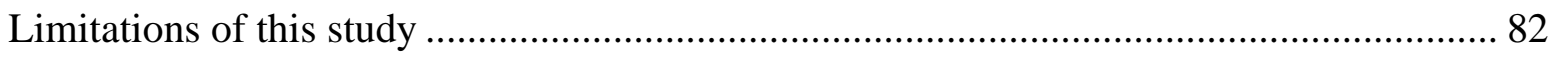

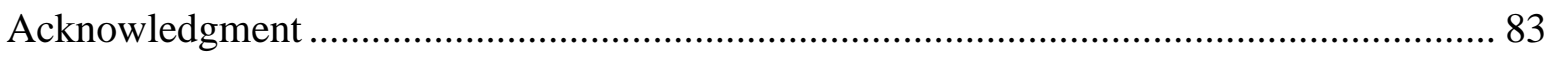

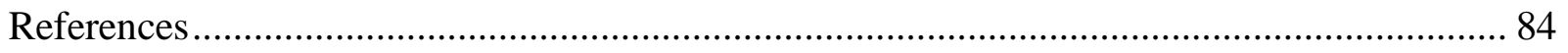

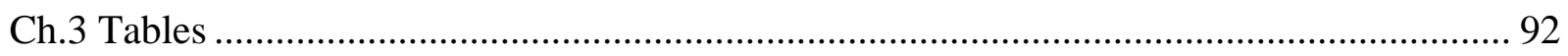

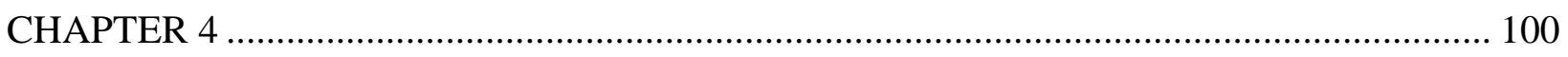




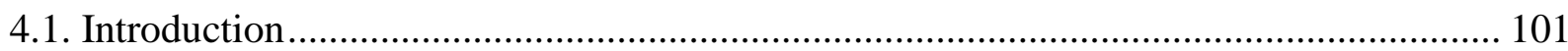

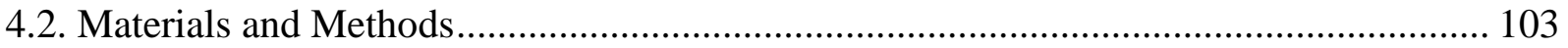

4.2.1. Preparation of inoculum...................................................................................... 103

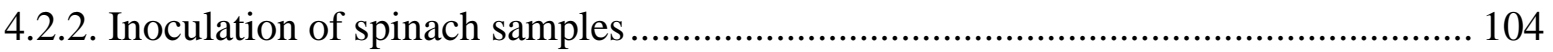

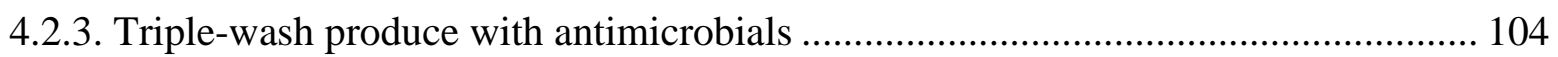

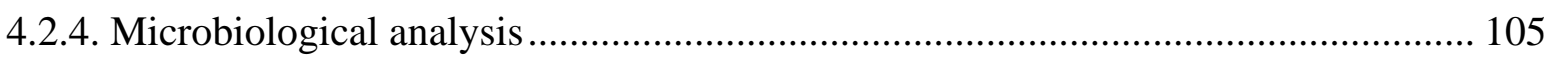

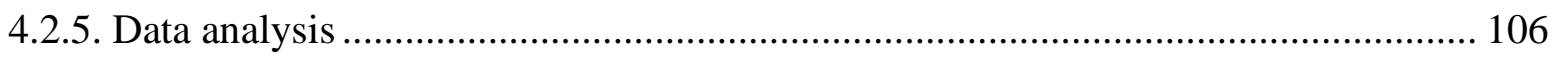

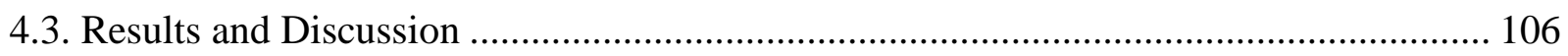

4.3.1. Three-step wash by WAW verse WWA procedures ............................................... 106

4.3.2. Three-step wash with antimicrobials against Salmonella ......................................... 107

4.3.3. Three-step wash with antimicrobials against $L$. monocytogenes ................................ 108

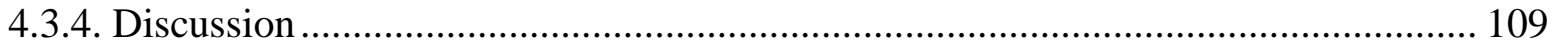

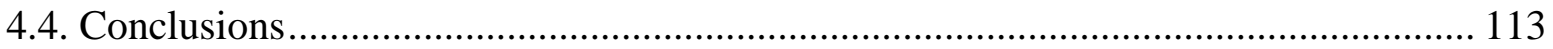

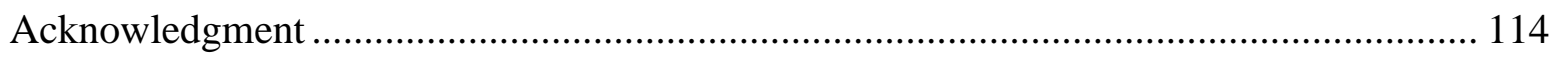

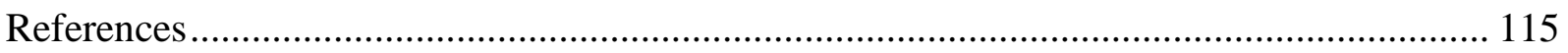

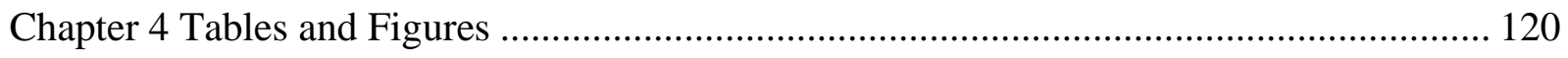

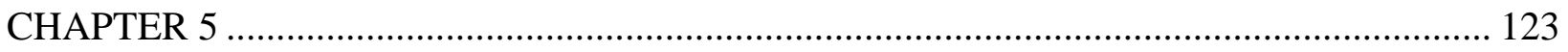

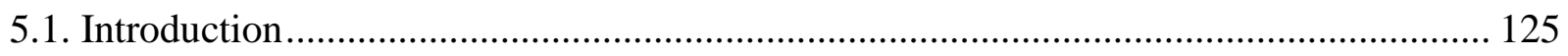

5.2. Materials and Methods............................................................................................ 127

5.2.1. Preparation of inoculum and inoculation of squashes ............................................ 127

5.2.2. Triple wash squashes with antimicrobials in lab condition ...................................... 128

5.2.3. Triple wash squashes in a processing plant ............................................................ 129

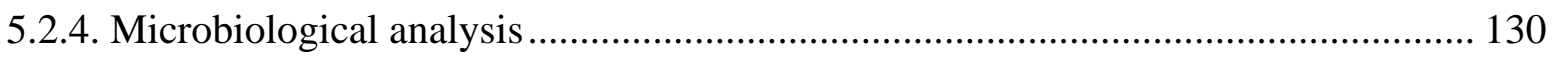

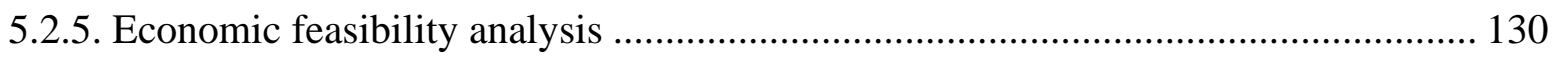

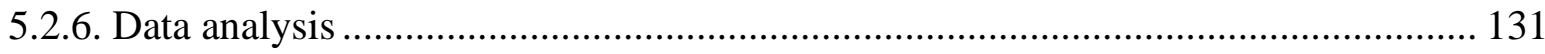


5.3. Results and Discussion

5.3.1. Laboratory study: antimicrobial effect of treatments during the triple-wash process

5.3.2. Plant onsite study: evaluate the shelf-life stability of washed squashes

5.3.3. The operating cost of triple-wash on squashes

Acknowledgment

References

Chapter 5 Tables and Figures 146

CHAPTER 6 153

6.1. Introduction. 155

6.2. Materials and Methods. 157

6.2.1. Survey of handling produce containers at KY and WV farmers' markets 157

6.2.2. Preparation of inoculum. 158

6.2.3. Storage material inoculation and microbiological analysis 159

6.2.4. Data analysis 160

6.3. Results and Discussion 161

6.3.1. Assessing vendor's handling of produce containers 161

6.3.2. Salmonella and L. monocytogenes survival on various container surfaces 162

6.3.3. Modeling of pathogen survival during storage 165

6.4. Conclusions. 169

Acknowledgment. 170

References.. 171

Chapter 6 Tables and Figures . 175

CHAPTER 7 184 


\section{LIST OF TABLES}

Table number Title

Table 3.1

Table 3.2

Table 3.3

Table 3.4

Table 3.5
Survival and reduction of Salmonella Typhimurium and Tennessee on cucumbers ( $\left.\log _{10} \mathrm{CFU} / \mathrm{cucumber}\right)$ by triple wash procedure water dip-antimicrobial dip-water dip (WAW) or water dip-water dip-antimicrobial dip (WWA) in water, sodium hypochlorite (SH, 100 ppm, pH 8.2), ASH (SH, 100 ppm, pH 6.8 adjusted by citric acid), lactic and citric acid blend (LCA, Veggiexide $\AA 2.5 \%$ ), a PAA and hydrogen peroxide mixer (SD, SaniDate-5.0, 0.0064, 0.25 and 0.50\%).

Survival and reduction of Salmonella Typhimurium and Tennessee on tomatoes ( $\log _{10} \mathrm{CFU} /$ tomato) by triple wash procedure water dip-antimicrobial dip-water dip (WAW) or water dip-water dip-antimicrobial dip (WWA) in water, sodium hypochlorite (SH, 100 ppm, pH 8.2), ASH (SH, 100 ppm, pH 6.8 adjusted by citric acid), lactic and citric acid blend (LCA, Veggiexide ${ }^{\circledR}, 2.5 \%$ ), a PAA and hydrogen peroxide mixer (SD, SaniDate-5.0, 0.0064, 0.25 and 0.50\%).

Survival and reduction of Listeria monocytogenes on cucumbers ( $\log _{10} \mathrm{CFU} /$ cucumber) by triple wash procedure water dipantimicrobial dip-water dip (WAW) or water dip-water dipantimicrobial dip (WWA) in water, sodium hypochlorite $\mathrm{SH}$, 100 ppm, pH 8.2), ASH (SH, 100 ppm, pH 6.8 adjusted by citric acid), lactic and citric acid blend (LCA, Veggiexide ${ }^{\circ}, 2.5 \%$ ), a PAA and hydrogen peroxide mixer (SD, SaniDate-5.0, 0.0064, 0.25 and $0.50 \%)$.

Survival and reduction of Listeria monocytogenes on tomatoes ( $\log _{10}$ CFU/tomato) by triple wash procedure water dipantimicrobial dip-water dip (WAW) or water dip-water dipantimicrobial dip (WWA) in water, sodium hypochlorite ( $\mathrm{SH}$, 100 ppm, pH 8.2), ASH (SH, 100 ppm, pH 6.8 adjusted by citric acid), lactic and citric acid blend (LCA, Veggiexide ${ }^{\circledR}, 2.5 \%$ ), a PAA and hydrogen peroxide mixer (SD, SaniDate-5.0, 0.0064, 0.25 and $0.50 \%$ ).

Survival and reduction of Enterococcus faecium on cucumbers ( $\log _{10} \mathrm{CFU} /$ cucumber) by triple wash procedure water dipantimicrobial dip-water dip (WAW) or water dip-water dipantimicrobial dip (WWA) in water, sodium hypochlorite ( $\mathrm{SH}$, 100 ppm, pH 8.2), ASH (SH, 100 ppm, pH 6.8 adjusted by citric acid), lactic and citric acid blend (LCA, Veggiexide ${ }^{\circ}, 2.5 \%$ ), a

Page

92 
PAA and hydrogen peroxide mixer (SD, SaniDate-5.0, 0.0064, 0.25 and $0.50 \%$ ).

Table 3.6 Survival and reduction of Enterococcus faecium on tomatoes

$\left(\log _{10} \mathrm{CFU} /\right.$ tomato) by triple wash procedure water dipantimicrobial dip-water dip (WAW) or water dip-water dipantimicrobial dip (WWA) in water, sodium hypochlorite $(\mathrm{SH}$, 100 ppm, pH 8.2), ASH (SH, 100 ppm, pH 6.8 adjusted by citric acid), lactic and citric acid blend (LCA, Veggiexide $®, 2.5 \%$ ), a PAA and hydrogen peroxide mixer (SD, SaniDate-5.0, 0.0064, 0.25 and $0.50 \%$ ).

Table 3.7 A comparison of the reduction of Salmonella and surrogate Enterococcus faecium on cucumbers ( $\log _{10} \mathrm{CFU} /$ cucumber) by triple wash procedure water dip-antimicrobial dip-water dip (WAW) or water dip-water dip-antimicrobial dip (WWA) in water, sodium hypochlorite ( $\mathrm{SH}, 100 \mathrm{ppm}, \mathrm{pH} 8.2), \mathrm{ASH}(\mathrm{SH}$, 100 ppm, pH 6.8 adjusted by citric acid), lactic and citric acid blend (LCA, Veggiexide ${ }^{\circledR}, 2.5 \%$ ), a PAA and hydrogen peroxide mixer (SD, SaniDate-5.0, 0.0064, 0.25 and 0.50\%).

Table $3.8 \quad$ A comparison of the reduction of Salmonella and surrogate Enterococcus faecium on tomatoes ( $\log _{10} \mathrm{CFU} /$ tomato) by triple wash procedure water dip-antimicrobial dip-water dip (WAW) or water dip-water dip-antimicrobial dip (WWA) in water, sodium hypochlorite (SH, 100 ppm, pH 8.2), ASH (SH, 100 ppm, pH 6.8 adjusted by citric acid), lactic and citric acid blend (LCA, Veggiexide ${ }^{\circledR}, 2.5 \%$ ), a PAA and hydrogen peroxide mixer (SD, SaniDate-5.0, 0.0064, 0.25 and $0.50 \%$ ).

Table 4.1 Physical and chemical parameters of antimicrobial treatments in this study

Table $5.1 \quad$ Cost of SaniDate-5.0 at different concentrations

Table 5.2 Reduction of Salmonella Typhimurium and Tennessee on butternut squashes $\left(\log _{10} \mathrm{CFU} / \mathrm{squash}\right)$ by triple-wash procedure water dip-antimicrobial dip-water dip (WAW) or water dip-water dip-antimicrobial dip (WWA) in sodium hypochlorite ( $\mathrm{SH}, 100$ ppm), lactic and citric acid blend (LCA, Veggiexide ${ }^{\circledR}, 2.5 \%$ ), a PAA and hydrogen peroxide mixer (SaniDate-5.0, 0.0064, 0.25 and $0.50 \%$ ).

Table 5.3 Reduction of Listeria monocytogenes on butternut squashes $\left(\log _{10}\right.$ CFU/squash) by triple-wash procedure water dip-antimicrobial dip-water dip (WAW) or water dip-water dip-antimicrobial dip (WWA) in sodium hypochlorite (SH, 100 ppm), lactic and citric 
acid blend (LCA, Veggiexide ${ }^{\circledR}, 2.5 \%$ ), a PAA and hydrogen peroxide mixer (SaniDate-5.0, 0.0064, 0.25 and 0.50\%).

Table 5.4 Cost comparison of triple wash at different production scales. Total cost is calculated by assuming water and treatments are reused throughout the whole washing section.

Table 5.5 Cost comparison of triple wash at different production scales when water and antimicrobial treatments are refreshed every 60 or 180 squashes.

Table 6.1 Type of containers for presenting and transporting produce at farmers' market

Table 6.2 Wash and/or sanitize produce containers between farmers' market 176 visits

Table 6.3 Temperature of storing containers with produce before transport to farmers' market

Table 6.4 Awareness of foodborne pathogens contaminated on fresh produce

Table 6.5 Parameters (mean \pm standard error) of models estimated for the survival of Salmonella on plastic, pressed-card, and wood surfaces after storage at $3.2^{\circ} \mathrm{C}(22.9 \% \mathrm{RH})$ for 21 days.

Table 6.6 Parameters (mean \pm standard error) of models estimated for the survival of Salmonella on plastic, pressed-card, and wood surfaces after storage at $22.5^{\circ} \mathrm{C}(50.4 \% \mathrm{RH})$ for 21 days.

Table 6.7 Parameters (mean \pm standard error) of models estimated for the 181 survival of Listeria monocytogenes on plastic, pressed-card, and wood surfaces after storage at $3.2^{\circ} \mathrm{C}(22.9 \% \mathrm{RH})$ for 21 days.

Table 6.8 Parameters (mean \pm standard error) of models estimated for the 182 survival of Listeria monocytogenes on plastic, pressed-card, and wood surfaces after storage at $22.5^{\circ} \mathrm{C}(50.4 \% \mathrm{RH})$ for 21 days. 


\section{LIST OF FIGURES}

Figure number Title Page

Figure 4.1 Reductions of Salmonella Typhimurium and Tennessee on spinaches $\left(\log _{10} \mathrm{CFU} / \mathrm{g}\right)$ after three-step washing using the procedure of WAW (water dip + antimicrobial dip + water dip) or WWA (water dip + water dip + antimicrobial dip) with or without antimicrobials of sodium hypochlorite ( $\mathrm{SH}-100 \mathrm{ppm})$, lactic/citric acid blend (LCA, 2.5\%), and a mixture of hydrogen peroxide and peroxyacetic acid (SaniDate-5.0, 0.0064, 0.25 and 0.50\%).

Figure 4.2 Reductions of Listeria monocytogenes on spinaches $\left(\log _{10}\right.$ $\mathrm{CFU} / \mathrm{g}$ ) after the three-step washing using the procedure of WAW (water dip + antimicrobial dip + water dip) or WWA (water dip + water dip + antimicrobial dip) with or without antimicrobials of sodium hypochlorite (SH-100 ppm), lactic/citric acid blend (LCA, 2.5\%), and a mixture of hydrogen peroxide and peroxyacetic acid (SaniDate-5.0, 0.0064, 0.25 and 0.50\%).

Figure 5.1 Triple-wash process inlucding step 1-manually brush with produce bursher (A), step 2-soft cloth towlers scrub (B), step 3melt rinse container with mesh and immerse into the SaniDate5.0 solution $(\mathrm{C})$.

Figure 6.1 Survival of Salmonella and Listeria monocytogenes on plastic, pressed-card, and wood surfaces during storage at $3.2^{\circ} \mathrm{C}(22.9 \%$ $\mathrm{RH})$ and $22.5^{\circ} \mathrm{C}(50.4 \% \mathrm{RH})$ for 21 day 


\section{CHAPTER 1}

\section{Introduction}

Fresh produce including fruits and vegetables is an important component of a healthy and balanced diet. The demand for locally produced food has created growth opportunities for farmers' markets in the USA, its national count increased from 1,755 in 1994 to 8,771 in 2019 (USDA AMS, 2020). With 93 farmers' markets operating at over 112 locations throughout West Virginia, full-time produce growers generate an average annual revenue of approximately $\$ 40,000$, and over half a million customers are served annually through West Virginia’s Farmers' markets (Li et al., 2018). However, fruits and vegetables that are consumed raw, are increasingly being recognized as important vehicles for the transmission of foodborne pathogens. The Centers for Disease Control and Prevention (CDC) concluded nearly half of foodborne illnesses are caused by pathogens on fresh produce in the United States (CDC, 2019). Ensuring fresh produce safety at farmers' markets is crucial for long-term growth in the local foods sector in WV. The West Virginia Small Farm Center suggested produce growers use a three-step wash procedure to eliminate pathogens from produce surfaces if their produce is consumed raw or grown close to the ground since 2017. The triple-washing process (two water rinses, followed by an antimicrobials dip) has been recognized as an effective approach for inactivating pathogens from food surfaces and improving food safety in farm production environments (Strohbehn et al., 2013). Recent studies demonstrated that the mixture of peroxyacetic acid and hydrogen peroxide (SaniDate-5.0) effectively reduced Salmonella and Listeria monocytogenes on cucumbers, tomatoes, and butternut squash (Leifert et al., 2008; Li et al., 2020), and local produce growers have shown interest in incorporating SaniDate-5.0 into 
their post-harvest processing to reduce microbial load, extend product shelf-life, as well as the cost of applying this sanitation approach in, small-scale, local produce grower settings.

Fresh produce needs to be handled properly to reduce the risk of foodborne pathogen cross-contamination from sources such as humans, animals, and the environment through growing, harvesting, processing, shipping, and handling. During post-harvest storage, produce that is stored in unsensitized containers could serve as a potential pathogens reservoir and thereby harbor and transfer foodborne pathogens such as Salmonella spp. and L. monocytogenes (Cossentine et al., 2004; Higbee et al., 2001; Killinger \& Adhikari, 2014; Randall et al., 2011). Material used in the storage containers, i.e., wood, pressed-card, or plastic, are subject to weathering or has rough surfaces that can provide a niche for pathogen survival. The role of storage container material as a potential source of pathogen contamination at local farmers' markets is not well-understood, especially for pathogen survival rate on various material surfaces, therefore: the objectives of this research project were:

1.) To evaluate the two triple-wash procedures with commercial antimicrobials including an $\mathrm{H}_{2} \mathrm{O}_{2}$-peroxyacetic-acid blend, a lactic/citric acid blend, and chlorine water to inactivate foodborne pathogens and surrogate bacteria on cucumbers, tomatoes, and spinaches.

2.) To evaluate the two triple-wash procedures with an $\mathrm{H}_{2} \mathrm{O}_{2}$-peroxyacetic-acid mixture (SaniDate-5.0) to improve microbial safety and quality of butternut squashes

3.) To determine the feasibility of the triple-wash application in a processing plant.

4.) To assess how small produce growers handle storage containers and evaluate survival of Salmonella and Listeria monocytogenes on various produce container surfaces commonly used at farmers' markets, under storage conditions at refrigerated and room temperature. 
References

CDC. (2019, June 17). CDC and Food Safety: Fruit and Vegetable Safety. https://www.cdc.gov/foodsafety/newsletter/fruit-veggie-3-20-19.html

Cossentine, J. E., Sholberg, P. L., Jensen, L. B. J., Bedford, K. E., \& Shephard, T. C. (2004). Fumigation of Empty Fruit Bins with Carbon Dioxide to Control Diapausing Codling Moth Larvae and Penicillium expansum Link. Ex Thom Spores. HortScience, 39(2), $429-432$.

Higbee, B. S., Calkins, C. O., \& Temple, C. A. (2001). Overwintering of codling moth (Lepidoptera: Tortricidae) larvae in apple harvest bins and subsequent moth emergence. Journal of Economic Entomology, 94(6), 1511-1517.

Killinger, K., \& Adhikari, A. (2014). Assessment of sanitation techniques for tree fruit storage bins. https://www.centerforproducesafety.org/amass/documents/researchproject/345/CPS\%20F inal\%20Report\%20Killinger.pdf

Leifert, C., Ball, K., Volakakis, N., \& Cooper, J. M. (2008). Control of enteric pathogens in ready-to-eat vegetable crops in organic and 'low input' production systems: A HACCPbased approach. Journal of Applied Microbiology, 105(4), 931-950. https://doi.org/10.1111/j.1365-2672.2008.03794.x

Li, K., Chiu, Y.-C., Jiang, W., Jones, L., Etienne, X., \& Shen, C. (2020). Comparing the Efficacy of Two Triple-Wash Procedures With Sodium Hypochlorite, a Lactic-Citric Acid Blend, and a Mix of Peroxyacetic Acid and Hydrogen Peroxide to Inactivate Salmonella, Listeria monocytogenes, and Surrogate Enterococcus faecium on Cucumbers and 
Tomatoes. Frontiers in Sustainable Food Systems, 4, 19.

https://doi.org/10.3389/fsufs.2020.00019

Li, K., Khouryieh, H., Jones, L., Etienne, X., \& Shen, C. (2018). Assessing farmers market produce vendors' handling of containers and evaluation of the survival of Salmonella and Listeria monocytogenes on plastic, pressed-card, and wood container surfaces at refrigerated and room temperature. Food Control, 94, 116-122. https://doi.org/10.1016/j.foodcont.2018.06.036

Randall, P., Sholberg, P., Judd, G., \& Cossentine, J. (2011). Acetic Acid Fumigation of Fruit Storage Bins to Control Diapausing Codling Moth Larvae. HortScience, 46(12), 16341639.

Strohbehn, C., Mendonca, A., Wilson, L., Domoto, P., Smith, M., Brehm-Stecher, B., \& Shaw, A. (2013). On-farm Food Safety: Cleaning and Sanitizing Guide. Human Sciences Extension and Outreach Publications. https://lib.dr.iastate.edu/extension_families_pubs/102

USDA AMS. (2020). National Count of Farmers Market Directory Listings. https://www.ams.usda.gov/sites/default/files/media/NationalCountofFarmersMarketDirec toryListings082019.pdf 


\section{CHAPTER 2 \\ Literature Review}

\subsection{Foodborne illness and outbreaks}

According to a survey from FAO and WHO, annual global produce production increased from 500 million to nearly 3 billion tons from 1980 to 2004 (FAO \& WHO, 2008). From 1970 to 2017, supply of fresh produce in the U.S. increased dramatically from 154.4 to 202.6 pounds per capita availability (USDA-ERS, 2020). Fresh produce is vulnerable to foodborne pathogen contamination since it is often consumed raw without a "killing" step, even with interventions to reduce the microbial contamination from farm to the table. Foodborne illness remains a challenging public health issue, causing approximately 9.4 million cases in the United States annually (Scallan et al., 2011). The Centers for Disease Control and Prevention (CDC) defines a foodborne outbreak as two or more people contracting the same disease by consuming the same product (CDC, 2018a). From 1996 to 2010, the U.S. Food and Drug Administration (FDA) reported 131 outbreaks associated with over 20 different fresh produce commodities in the U.S. resulting in 14,350 illnesses, 1,382 hospitalizations, and 34 deaths (U.S. FDA, 2016a). In 2014, the CDC's FoodNet Surveillance Program identified 19,542 cases of Foodborne infection, 4,445 hospitalizations, and 71 deaths (CDC, 2015a). A USDA ERS report determined the cost of 15 major foodborne illnesses in the U.S. increased from $\$ 15.5$ billion (2013) to $\$ 17.6$ billion (2018). Salmonella, Toxoplasma, Listeria, Norovirus, and Campylobacter accounted for $\$ 15.7$ billion in 2018, about $90 \%$ of the total costs (USDA ERS, 2021).

\subsection{Foodborne pathogen and recent outbreaks}

The Interagency Food Safety Analytics Collaboration (IFSAC;2020), consists of CDC, FDA, and USDA, identified 3,981 outbreaks related to Salmonella, Escherichia coli O157, Listeria, or Campylobacter through 1998 to 2018. Of which 1,459 outbreaks could be assigned 
to a single food category: 905 was confirmed or suspected to be caused by Salmonella, 255 by E. coli O157, 44 by Listeria, and 255 by Campylobacter, respectively. Salmonella illnesses were the most evenly distributed among various food commodities across the four pathogens, while $E$. coli O157, Listeria, and Campylobacter were mostly attributed to few food categories (IFSAC, 2020).

\subsubsection{Escherichia coli}

Escherichia coli is a Gram-negative, rod-shaped bacterium., E. coli is a facultative anaerobic, non-spore-forming, mesophilic bacterium belonging to the family

Enterobacteriaceae. E. coli replicates rapidly ( $20 \mathrm{mins})$ under optimal conditions $\left(37^{\circ} \mathrm{C}\right)$ and can be found in the lower intestines of warm-blooded animals including human and ruminants and environment samples (Bertoldi et al., 2015; CDC, 2016a; Jay et al., 2005).

There are well-recorded pathogenic E. coli strains, including Shiga toxinproducing E. coli (STEC), Enteropathogenic E. coli (EPEC), Enterohemorrhagic E. coli (EHEC), Enteroinvasive E. coli (EIEC), Enteroaggregative E. coli (EAEC), Enterotoxigenic E. coli (ETEC) and Diffusely Adherent E. coli (DAEC). All pathotypes represent collections of strains that have similar virulence factors and cause similar diseases (Jang et al., 2017; Robins-Browne et al., 2016). Gerba (2009) had captured the relationship between intestinal pathogenic E. coli in Figure 2.1. de Oliveira Elias et al. (2019) reported that the most severe diseases recorded during produce-associated outbreaks are caused by EHEC, which includes the Shiga-toxin-producing $E$. coli (STEC) or verocytotoxin-producing E. coli (VTEC) serotypes. Their related diseases include bloody diarrhea, thrombotic thrombocytopenic purpura, hemorrhagic colitis, and hemolyticuremic syndrome (de Oliveira Elias et al., 2019). 
E. coli O157:H7, a STEC, as well as six other serogroups: O26, O45, O103, O111, O121, and $\mathrm{O} 145$, are responsible for more than 160,000 cases of foodborne illnesses annually in the United States (Bertoldi et al., 2015; CDC, 2016a). These pathogens can contaminate fresh produce during production where water is contaminated with infected animal feces and crosscontaminations from equipment, surfaces, and/or handlers (Yeni et al., 2016). The infectious dose was as low as 2 cells as reported by Hara-Kudo (2010) or less than 700 cells (Hara-Kudo \& Takatori, 2011; Tuttle et al., 1999).

In recent years, over 75\% of E. coli $\mathrm{O} 157: \mathrm{H} 7$ illnesses were related to vegetable crops, such as leafy greens, and red meat products especially beef (IFSAC, 2020). Romaine lettuce contaminated with E. coli $\mathrm{O} 157: \mathrm{H} 7$ appears to be a recurring item in multistate outbreaks, resulting in 167 cases in 27 states with 85 hospitalizations in early 2020 (CDC, 2020a). Previously, romaine lettuce contaminated with E. coli O157:H7 caused 16 hospitalizations in 2019, and 96 hospitalizations with five deaths in 2018 (CDC, 2019b, 2019a). In 2015, an E. coli O157:H7 outbreak linked to a food truck serving several farmers' markets in Seattle, WA, resulted in 6 illnesses and 3 hospitalizations (Food Safety News, 2015). In 2011, strawberries contaminated with Escherichia coli O157:H7 sold at a farmers' market in Oregon sickened 16 people and caused one death (Food Safety News, 2011).

\subsubsection{Shiga toxin}

Several species of Shigella including Shigella flexneri, boydii, sonnei, and dysenteriae are gram-negative bacilli that cause shigellosis, with symptoms including fever, stomach pain, hemorrhagic colitis, and hemolytic-uremic syndrome (CDC, 2020f; Melton-Celsa, 2014). Disease transmission by fewer than 100 CFUs, Shigellosis mainly affects children in developing countries through fecal to oral transmission or human to human transmission from contaminated 
water, food, or feces (Bennish et al., 2020; CDC, 2020d; Khan et al., 2013). Out of S. flexneri, boydii, sonnei, and dysenteriae, S. dysenteriae type 1 is the only species reported to generate Shiga toxin, an exotoxin that leads to the most severe shigellosis, and has the highest mortality rate out of the four species (Bennish et al, 2020; Khan et al., 2013).

Shiga toxin-producing Escherichia coli (STEC) is a subset of serotypes inside of Enterohaemorrhagic Escherichia coli (EHEC), a pathotype of E. coli that produces Shiga-like toxin I and II (Stx 1 and Stx 2) that molecularly relate to that from Shigella dysenteriae type 1 (Schüller, 2011). Scheutz et al. subtyped three Stx1 (Stx1a, Stx1c, and Stx1d) and seven Stx2 (Stx2a, Stx2b, Stx2c, Stx2d, Stx2e, Stx2f, and Stx2g) by PCR sequencing (Scheutz et al., 2012). The Stx(s) enter the intestine, bind with the glycosphingolipid Gb3, halt protein synthesis within the cell and induce apoptosis; they can alter gene or protein expression in epithelial, endothelial, mesangial cells, and monocytes (Melton-Celsa, 2014). Stx(s) damage the microcirculation, causing infarction of the mucosa, that leads to bleeding into the bowel and bloody diarrhea (Johannes et al., 2010).

\subsubsection{Salmonella}

The CDC estimated Salmonella spp. was responsible for a million foodborne illnesses annually in the United States (CDC, 2012a). It was the leading cause of death by foodborne illness in the United States (Scallan et al., 2011). Previous outbreaks in the United States, with produce as delivery vehicle, included tomatoes, sprouts, cantaloupes, etc. (James M. et al., 2006a).

First isolated in 1885 from swine cholera (FDA-NSTA, 2009), Salmonella has more than 2500 serotypes identified since 2015 (CDC, 2015c); these serotypes are divided into six subspecies (Su \& Chiu, 2007), and most are identified as S. enterica which is commonly 
recognized as a foodborne pathogen (Le Minor \& Popoff, 1987). Salmonella is a Gram-negative, rod-shaped, motile, facultative anaerobe, with diameters around 0.7 to $1.5 \mu \mathrm{m}$ and length 2 to 5 $\mu \mathrm{m}$ (Doyle \& Buchanan, 2013; U.S. FDA, 2014a). The most common reservoirs for nontyphoidal salmonellae are cattle poultry, mainly chickens and turkeys, pigs, and wild animals. For typhoid and enteric fevers-inducing strains like Salmonella enterica serovar Typhimurium, there is no significant animal reservoir since their mode of spreading mainly involves fecal-oral transmission typically with fecal contaminated water (Chaudhuri et al., 2018; Giannella, 1996).

The infectious dose of Salmonella is dependent on the status of the immune system, serotype, and the composition of food as the delivery vehicle, but records show that salmonellosis can be caused by less than 10 vegetative cells (D'aoust et al., 1985). Hara-Kuda (2010) analyzed 11 Salmonella outbreaks and concluded the infectious dose could be as low as 363 MPN (Most Probable Number) (Hara-Kudo \& Takatori, 2011).

Salmonella infections can be acquired through mainly the consumption of contaminated food and water (Morris \& Potter, 2013). In healthy individuals, defensive mechanisms against Salmonella includes gastric acid, short-chain fatty acids produced by normal intestinal microflora (Giannella, 1996). Salmonellosis occurs when Salmonella cells invade the digestive tract spreading from the intestines to other body parts. Salmonella colonizes the ileum and colon after ingestion, and then they invade the epithelium cells in the small intestine and multiply intracellularly. They spread through lymph nodes via circulation and cause an inflammatory response that could lead to ulcers responsible for damaging the intestine, causing gastroenteritis, including diarrhea, fever, and abdominal cramps with a short onset period of 12 to 72 hours after infection which could also last as long as 4 to 7 days (Giannella, 1996; James M. et al., 2006a). Giannella (1996) summarizes the invasion process as shown in Figure 2.2. Severe cases of the 
infection usually occur in infants, elderly, and immune-compromised patients, which leads to detrimental diarrhea that requires the patient to be hospitalized even after antibiotic treatment. Patients with less severe infections can recover in less than a week when rehydrated (Coburn et al., 2007).

Although the majority of Salmonella infections are from poultry products, a CDC study reported that fresh produce has been associated with approximately $50 \%$ of illnesses caused by contaminated produce. Over $75 \%$ of illnesses were attributed to food groups including chicken, seeded vegetables such as tomatoes, pork, eggs, and turkey (IFSAC, 2015, 2020; Painter et al., 2013). A study in 2014 reported that one Salmonella spp. cells were isolated on fresh herbs from 13 farmers' markets located on the west coast of the U.S. (Levy et al., 2015). Since 2013 the CDC has recorded multiple outbreaks related to Salmonella present on pre-cut fruits and melons, papayas, coconuts, spouts, and cucumbers; these foods caused more than 1700 reported cases, more than 400 hospitalizations, and 8 deaths (CDC, 2020b). In 2020, Salmonella Enteritidis in peaches caused a multistate outbreak, infecting 101 people from 17 states, leading to 28 hospitalizations (CDC, 2020g). In the same year, Salmonella Javiana in cut fruit lead to an outbreak of 165 cases in 14 states, with 73 hospitalizations (CDC, 2020c). Salmonella Newport in red, white, and yellow onions caused 1,127 cases and 167 hospitalizations from 48 states in 2020 (CDC, 2020e). Salmonella Carrau in pre-cut melons caused 137 cases and 38 hospitalizations from 10 states in 2019 (CDC, 2019d).

\subsubsection{Listeria}

Each year L. monocytogenes is estimated to cause 1400 hospitalizations and 250 deaths in the United States and was reported to be one of the leading causes of death from foodborne illness in the U.S.(19\%) followed by Salmonella spp. (28\%) (Scallan et al., 2011). Listeria spp. 
contains six species with 17 serotypes; 13 serotypes represent L. monocytogenes, 2 serotypes represents L. innoca. L. innoca is considered to be a non-pathogenic variant of L. monocytogenes (James M. et al., 2006b). Non-pathogenic species of Listeria can be indicative of poor hygienic practices, or as an indicator organism for L. monocytogenes (Gurtler et al., 2017). L. monocytogenes is a Gram-positive, non-spore-forming, psychrotrophic, facultative anaerobic motile short rod (Farber \& Peterkin, 1991). They are 0.4 to $0.5 \mu \mathrm{m}$ in diameter and 0.5 to $2 \mu \mathrm{m}$ in length. (Schuchat et al., 1991). L. monocytogenes can cause listeriosis, an invasive illness in humans. Once the bacterium enters the host's monocytes, macrophages, or polymorphonuclear leukocytes, it reproduces and spreads directly from cell to cell in the host, without needing to spread interstitially to reach other cells. Protein groups on the L. monocytogenes cell surface enable its survival in phagocytic cells and enhance its spread from cell to cell (FDA, 2012). $L$. monocytogenes was first demonstrated to transmit via contaminated food in 1983 and can be found in the environment, as well as domestic livestock, ruminants, wild animals, and birds (FAO \& WHO, 2008; Schlech et al., 1983).

The psychrotrophic property of L. monocytogenes allows it to survive during storage; grow at a refrigerated temperature as low as $-0.4^{\circ} \mathrm{C}$; and reach a typical infective dose of around $3 \log _{10} \mathrm{CFU} / \mathrm{g}$ for listeriosis or 5.28 to $9 \log _{10} \mathrm{CFU} / \mathrm{g}$ to result in gastroenteritis (Chan \& Wiedmann, 2009; Gurtler et al., 2017). L. monocytogenes respond to cold stress by decreasing metabolic rates, increasing unsaturated fatty acids in membrane lipids, increasing cold shock protein expression, and import of cryoprotective compounds (Bucur et al., 2018). It is known that temporary temperature abuse from improper handling can increase the growth rate of $L$. monocytogenes (Bibek Ray \& Arun Bhunia, 2013). 
L. monocytogenes can be isolated from many environmental samples including water, soil, decaying vegetation, and animal feces (Farber \& Peterkin, 1991). Food-borne outbreaks of listeriosis have been related to contaminated unpasteurized milk and their products in 2016 and 2017, causing 10 hospitalizations and 3 deaths (CDC, 2018c, 2018b); ready-to-eat deli meats caused 12 cases with hospitalizations and one death over four states, in 2020, and 10 cases with hospitalizations and one death over five states in 2019 (CDC, 2019f, 2021a); packaged salads produced at Ohio caused 19 cases over nine states, 19 hospitalizations, and one death (CDC, 2016b); cantaloupes from Colorado caused 147 cases in 28 states, with 143 hospitalizations and 33 deaths (CDC, 2012b). Other food vehicles include caramel apples, bean sprouts, Enoki mushrooms, and more (CDC, 2020d; Garner \& Kathariou, 2016; USFDA, 2016; Zhu et al., 2017).

The U.S.-FDA indicated that $5 \%$ of vegetables and salads, and 5.7\% of RTE meats contain L. monocytogenes (Hitchins, 1996). Due to several outbreaks in the 1980s, the U.S. FDA and the USDA FSIS regulated that RTE foods are classified as adulterated if L. monocytogenes is detected at $>1$ cell $/ 25 \mathrm{~g}$ food samples (U.S. FDA, 2004). The IFSAC reported over $75 \%$ of $L$. monocytogenes associated illnesses were attributed to dairy and fruits and $90 \%$ of illnesses were attributed to non-meat food categories (IFSAC, 2020).

Listeriosis symptoms for healthy adults are mainly diarrhea and fever, which would cause abortion and stillbirth on pregnant patients and meningitis, pneumonia for newborns (Gaschignard et al., n.d.; James M. et al., 2006b; Okike et al., 2013). Pregnant women are about 13 times more likely to contract listeriosis than the general population (Silk et al., 2012) symptoms include meningitis, septicemia, abortion, and stillbirths (CDC, 2017). The most effective way to prevent the disease is to avoid high-risk foods during pregnancy. These foods 
include 1.) unpasteurized milk and its products such as soft cheese; 2.) raw or slightly cooked spouts; 3.) Cut melons that are left at room temperature for more than 4 hours; 4.) ready-to-eat foods including deli meats, cold cuts, lunch meats, hot dogs, or fermented sausages and; 5.) Fish products including cold-smoked fish (CDC, 2019e).

\subsubsection{Campylobacter}

Campylobacter is a microaerophilic curved Gram-negative rod that has corkscrew motility and is carried in the intestine of many warm-blood animals, especially poultry (Laughlin et al., 2019; Oyarzabal et al., 2017). It is a commensal organism colonized in the intestinal tract (cecum) of poultry. Cecum and colon are the main reservoirs of Campylobacter spp. which can leak or rupture during processing and cause contamination to the carcass (Berrang et al., 2001). Chantarapanont et al, (2003) showed that the chicken skin provides a favorable environment for survival of Campylobacter spp., even under frozen conditions, and can form viable but nonculturable cells under poor growth conditions (Chantarapanont et al., 2003). Campylobacter is commonly thermophilic, they can grow between 37 and $42^{\circ} \mathrm{C}$ with an optimum temperature of $41.5^{\circ} \mathrm{C}$. Its microaerophilic nature limits growth to low oxygen concentrations (between $3 \%$ to $15 \%$ ). In laboratory settings Campylobacter spp. is isolated with 5\% oxygen, $10 \%$ carbon dioxide, and 85\% nitrogen (Oyarzabal et al., 2017). Campylobacter is sensitive to dry conditions; optimal water activity $\left(a_{\mathrm{w}}\right)$ of Campylobacter growth is 0.997 , growth is inhibited when $a_{\mathrm{w}}$ is lower than 0.987 and concentrations of sodium chloride $(\mathrm{NaCl})$ are above $2 \% \mathrm{w} / \mathrm{v}$ or $\mathrm{pH}$ is below 4.9 (Silva et al., 2011).

Campylobacter spp. have been known to cause diseases in animals since the early $20^{\text {th }}$ century, but they were not recognized as a foodborne pathogen until the 1980s (Silva et al., 2011). The CDC reported 1.5 million cases of Campylobacter infections annually in the U.S, and 
cases are more common in the summer (CDC, 2019h). Over half of non-dairy Campylobacter illnesses were attributed to Chicken (58.3\%) and up to $70 \%$ of human campylobacteriosis can be attributed to the consumption of poultry products or unpasteurized milk and unchlorinated waters (Acheson \& Allos, 2001; CDC, 2019g; IFSAC, 2020). According to the CDC, the infectious dose of Campylobacter is as low as a few cells. Campylobacteriosis causes diarrhea, bloody diarrhea, fever, stomach cramps, nausea, vomiting, and complications including irritable bowel syndrome, arthritis, and Guillain-Barré syndrome. It has an incubation period of 2-5 days and possibly extends to one week (CDC, 2019h). Campylobacteriosis is generally self-limited and lasts a week or less; antimicrobial treatments, including fluoroquinolone and azithromycin, can be used to decrease the duration of symptoms and bacterial sheeding (Laughlin et al., 2019).

The CDC revealed that Campylobacter outbreaks are not commonly reported due to the high frequency of this infection with an average of 30 outbreaks annually in recent years. In 2008, Campylobacter contamination in bagged raw peas caused 18 people to become sick at five south-central Alaska farmers' markets (Gardner et al., 2011). Recent Campylobacter foodborne outbreaks include instances related to consumption of unpasteurized milk in Utah caused 99 cases with 10 hospitalizations, and one death were reported (Davis, 2016); undercooked chicken livers served in Ohio and Oregon caused two presumptive cases and three confirmed cases of campylobacteriosis (CDC, 2015a); and contaminated tap water near the border of Arizona and Sonora, Mexico caused 26 cases of Guillain-Barré syndrome (Jackson et al., 2014).

\subsubsection{Enterococcus}

Enterococcus is a genus for a group of lactic acid bacteria (LAB) that contains both commensal and pathogenic microorganisms. Enterococci are Gram-positive, non-spore-forming, facultative anaerobic cocci that appear in a single formation, pairs, or chains. They are 
ubiquitous in the environment and can be found in the guts of animals (Bennett et al., 2015). They grow optimally at a temperature of $35^{\circ} \mathrm{C}$, although most species can grow at temperatures of 10 to $45^{\circ} \mathrm{C}$ (Franz et al., 1999).

Enterococcus spp. can be adapted to the fermentation activity of cheese and dry sausages due to their tolerance for a high concentration of salts (up to $40 \%$ bile salts) and a wide $\mathrm{pH}$ range of 4.6 to 9.9 (Foulquié Moreno et al., 2006). When meat is improperly processed or stored, Enterococci, including E. faecalis and E. faecium, cause spoilage in processed meats (Franz et al., 1999). Enterococcus infects the human body and causes urinary tract infections, sepsis, endocarditis, and wound infection (Oprea \& Zervos, 2007; Poh et al., 2006). Enterococci lack some virulence factors and are not as intrinsically virulent as other foodborne pathogens. Resistance to a variety of antibiotics raises concern. Vancomycin-resistant enterococci are one of the leading causes of nosocomial infections (Caballero et al., 2017; A. Khan et al., 2019). From 2009-2015, the CDC reported one Enterococcus faecalis outbreak, causing 13 cases of illness (Dewey-Mattia et al., 2018).

Recent data reported by the IFSAC revealed that outbreaks and sporadic infections caused by the four priority pathogens were generally demographically similar, attributing illnesses to each of 17 food categories. They emphasized that interventions to reduce illnesses from these pathogens need to target a variety of food categories, including Salmonella in multiple food categories, E. coli $\mathrm{O} 157$ in vegetables and beef, Listeria in dairy and fruits, and Campylobacter in multiple food categories, especially in chicken (IFSAC, 2020).

\subsection{Surrogate Roles in Food safety studies}

Foodborne pathogens are generally handled in biosafety level 2 (BSL-2) facilities by trained personnel. For organizations without access to BSL-2 laboratories or who wish to study a 
pathogen in food processing environments, surrogate microorganisms are an alternative to the respective pathogens for intervention treatments studies, researchers can determine inactivation kinetics, while preventing introduction of pathogen contamination in food processing facilities. Based on this constraint, a proper surrogate should be non-pathogenic, behaves similarly during inactivation and susceptibility to injury, possess comparable kinetics to target pathogen, is simple to prepare and genetically stable (FDA, 2018).

When selecting an appropriate surrogate strain for fresh produce studies, Busta et al. (2013) recommended an ideal strain should have stable and consistent growth patterns, is easy to cultivate to high populations with stability until usage, is inexpensive to enumerate, can be differentiated from background microflora, does not induce spoilage, has similar attachment characteristics, and similar susceptibility to injury to that of the target pathogen.

Regression analysis can be used to validate a surrogate bacteria in a tested temperature range. Ceylan and Bautista evaluated Pediococcus acidilactici ATCC 8042 and Enterococcus faecium NRRL B-2354 as thermal surrogate microorganisms for Salmonella in low-moisture pet food products. Inoculated samples were treated at $76.7,82.2$, and $87.88^{\circ} \mathrm{C}$. After enumeration, log-transformed plate counts were plotted against time for each temperature. D-values indicated P. acidilactici 8042 was more heat resistant than the Salmonella control but less heat resistant than E. faecium B-2354, validating the use of P. acidilactici 8042 and E. faecium B-2354 as surrogates for Salmonella in dry pet food products that are thermally processed at 76.7 to $87.88^{\circ} \mathrm{C}$ (Ceylan \& Bautista, 2015).

\subsubsection{Enterococcus faecium as a Pathogen Surrogate}

Enterococcus faecium NRRL B-2354 is commonly used and recommended as a surrogate bacterium for Salmonella Enteritidis PT 30 in validation of almond thermal processing in (Jeong 
et al., 2011). Previously known as Pediococcus NRRL B-2354 and Micrococcus freudenreichii, E. faecium NRRL B-2354 (ATCC 8549) was reclassified with the NRRL and ATCC designations (Ma et al., 2011)

Kopit et al. evaluated the safety of E. faecium NRRL B-2354 based on its genomic and functional characteristics, including detection of virulence factors; biofilm formation and adherence, antibiotic susceptibility; survival at low $\mathrm{pH}$; high temperature, and in the presence of ethanol. Researchers reported that strain- and application-specific evaluations of E. faecium NRRL B-2354 as a conservative surrogate was needed. (Kopit et al., 2014)

Bianchini et al. (2014) validated E. faecium NRRL B-2354 as a surrogate in the extrusion of carbohydrate-protein meals in place of Salmonella spp. by processing contaminated meal mixtures containing chicken meal, rice flour, potassium chloride, and potassium sorbate at $73.78^{\circ} \mathrm{C}$ resulted in a $5-\log$ reduction of the surrogate, $80.38^{\circ} \mathrm{C}$ resulted in brought the E. faecium counts to below detection limits $(<10 \mathrm{CFU} / \mathrm{g})$. For comparison, a cocktail included Salmonella enterica Branderup NVSL 96-12528, Salmonella enterica Oranienburg NVSL 96-12608, Salmonella enterica Typhimurium ATCC 14028, Salmonella enterica Enteritidis IV/NVSL 9413062, and Salmonella enterica Heidelberg/ Sheldon 3347-1 was treated with the same extrusion procedure. The control treatment showed a 5 -log reduction was achieved at $60.6^{\circ} \mathrm{C}$, and below detection limits at $68.8^{\circ} \mathrm{C}$, showing the surrogate was more heat resistant than Salmonella spp., which suits as a safer, conservative alternative for these validation studies.

Ceylan and Bautista validated E. faecium NRRL B-2354 against a seven-strain cocktail of Salmonella Anatum, Montevideo, Senftenberg 775w, Tennessee, Schwarzengrund, Infantis, and Mbandaka during thermal processing of dry pet food with moisture levels of 9.1, 17.9, and $27.0 \%$, heated at 76.7 and $87.88^{\circ} \mathrm{C}$. At $9.1 \%$ moisture, D-values for the Salmonella spp. and E. 
faecium NRRL B-2354 were 6.54 and $11.66 \mathrm{~min}$ at $76.7^{\circ} \mathrm{C}, 2.66$ and $4.08 \mathrm{~min}$ at $82.2^{\circ} \mathrm{C}$, and 1.07 and $1.69 \mathrm{~min}$ at $87.8^{\circ} \mathrm{C}$ respectively. Findings suggested the thermal inactivation characteristics of E. faecium NRRL B-2354 were suitable to use as a conservative surrogate for Salmonella spp. in dry pet food. (Ceylan \& Bautista, 2015)

Enache et al. compared the heat resistance and survival of Salmonella Tennessee with $E$. faecium NRRL B-2354 by dry inoculation using talc to remove moisture after growth in growth media (on a plate or in broth), before being introduced into a model peanut butter matrix. The matrix was then heated to $85^{\circ} \mathrm{C}$ to determine thermal death time. Researchers found no significant difference in thermal resistance when using plate-cultured or broth-cultured Salmonella, but found E. faecium had greater heat resistance when cultured in the broth compared to cells grown on agar. Regardless of what cell type was used for dry inoculum preparation, E. faecium had significantly $(\mathrm{P}<0.05)$ greater heat resistance than Salmonella Tennessee, as the researchers concluded that E. faecium is an appropriate conservative surrogate for Salmonella under the tested conditions (Enache et al., 2015).

Jeong et al. (2011) evaluated E. faecium NRRL B-2354 as a surrogate for the thermal inactivation of Salmonella Enteritidis PT30 with moist air, convection heating for almonds. The results showed at various time, temperature, and humidity levels, thermal inactivation on $E$. faecium was reduced by $0.6 \log$ and $1.4 \mathrm{log}$, lower than the $3 \log$ and $5 \log$ reduction on Salmonella Enteritidis, showing E. faecium could function as a conservative moist-air heating surrogate for Salmonella Enteritidis PT 30 on almonds.

To be applied in food safety studies, surrogates need to be validated by obtaining growth and resistance data for a microorganism and evaluating the efficacy of an intervention or inactivation process before experimental studies. Ideal surrogates behave similarly to the targeted 
pathogen in their inactivation kinetics, growth parameters, and survivability under given conditions as determined with appropriate statistical analyses, and are nonpathogenic and genetically stable.

\subsection{Microbial Safety in Farmers' Markets Produce}

The natural microflora on fresh produce is usually nonpathogenic, but produce can be contaminated with bacteria, yeasts, and molds during growth, harvest, post-harvest processing and handling, and transportation from human, animal, or environmental sources (Ahvenainen, 1996; Sánchez et al., 2012). During processing, produce is prone to mechanical damage, which may increase tissue senescence, reducing their resistance to microbial spoilage and product shelflife (Trias et al., 2008). The microbiological quality of produce varies widely based on the types of commodity. Methods used in microbiological quality studies may not be directly comparable, but they show types of commodities and tests conducted. The common evaluation methods use different microbiological measurements as an indicator of microbial quality and cleanliness of the sample, including aerobic plate count, total/fecal coliforms, generic E. coli, and common foodborne pathogens.

There are few publicly available studies contrasting the microbial quality of produce sourced from grocery stores and farmers' markets. Roth et al. (2018) compared the microbial quality of tomatoes, leafy greens, berries, and spinach from 9 farmers' markets (301 samples) and 12 supermarkets (100 samples) in Florida between 2016 to 2017. Farmers' market produce showed a higher total coliform prevalence at 50.8\% (153 of 301) and 34\% (34 of 100) of supermarket produce. Farmers' market leafy greens $\left(2.3 \log _{10} \mathrm{CFU} / \mathrm{g}\right)$ and spinach $\left(2.4 \log _{10}\right.$ $\mathrm{CFU} / \mathrm{g}$ ) also had higher total coliform counts than their supermarket counterparts, at $1.1 \log _{10}$ $\mathrm{CFU} / \mathrm{g}$ and $0.70 \log _{10} \mathrm{CFU} / \mathrm{g}$, respectively. Generic E. coli was detected in $2.3 \%$ (7 of 301) of 
farmers' market produce, and none in supermarket samples. Generic E. coli was detected in 5.8\% of spinach, $2.6 \%$ of leafy greens, and $2.2 \%$ of tomatoes samples from farmers' markets, averaging at $<1 \log _{10} \mathrm{CFU} / \mathrm{g}$. L. monocytogenes was found in spinach $(3.9 \%, 2$ of 52$)$ and leafy greens $(2.6 \%, 2$ of 77$)$ from farmers' market. Salmonella was detected in one farmers' market tomato and one supermarket berry sample. No E. coli $\mathrm{O} 157: \mathrm{H} 7$ was detected.

Scheinberg et al. (2017) surveyed leafy green produce from Pennsylvania farmers' markets in 2017. E. coli was detected in $28 \%$ of kale (15 of 54), $29 \%$ of lettuce (15 of 52), and $17 \%$ of spinach samples ( 8 of 46 ). Listeria spp. were found in $2 \%$ of kale ( 1 of 54 ), $4 \%$ of lettuce ( 2 of 52) samples, and 7\% of spinach samples (3 of 46). Authors concluded that food safety training and public health oversight would be beneficial for farmers' market vendors.

Levy et al. (2015) surveyed 13 farmers' markets in Los Angeles and Seattle; 133 fresh herbs (basil, cilantro, and parsley) were sampled for microbial quality. They reported that 112 of 133 fresh herbs samples were coliform positive. Thirty-two samples were generic E. coli positive, with up to 3.15 and $4.15 \log _{10} \mathrm{CFU} / \mathrm{g}$ for coliform and E. coli, respectively. Based on guidelines for microbial quality of RTE foods established by the Public Health Laboratory System of the United Kingdom (PHLS), 16 samples out of 133 contained more than $2 \log _{10}$ CFU/g of generic E. coli, which was unsatisfactory (Gilbert et al., 2000).

Wood et al. (2015) collected 68 Romaine lettuce from five farmers' markets in Vancouver, Canada for the level of aerobic bacteria, total coliforms, and E. coli. in 2015. The mean aerobic plate count (APCs) of lettuce samples was $6.3 \log _{10} \mathrm{CFU} / \mathrm{g}$ and ranged from 4.8 to $7.8 \log _{10} \mathrm{CFU} / \mathrm{g}$. While $72 \%$ (49) of samples contained coliforms at a mean of $1.9 \log _{10} \mathrm{CFU} / \mathrm{g}$, $13 \%$ (9) of the lettuce contained approximately $0.7 \log _{10}$ CFU/g E. coli, highlighting the potential concerns for microbial safety in farmers' market produce. 
Pires et al. (2020) evaluated food safety risks associated with consuming fresh produce; authors purchased produce from 44 farmers' markets in Northern California to assess the prevalence of Salmonella and E. coli. Researchers did not find Salmonella on 128 produce samples while E. coli was found in $40(31.3 \%)$ out of 128 fresh produce samples, with the contamination ranging from 0 to $2.96 \log _{10} / \mathrm{mL}$, with an overall average of $0.13 \log _{10} / \mathrm{mL}$.

Iturriaga, et al. (2007) studied the impact of relative humidity and storage temperature on Salmonella growth in tomatoes. Tomatoes were inoculated with $3.8 \log _{10} \mathrm{CFU} /$ tomato Salmonella Montevideo. Inoculated tomato samples were stored at 22 or $30^{\circ} \mathrm{C}$ for 10 days, at various levels of relative humidity $(60,75,85$, or $97 \%)$. Results showed high relative humidity (97\%) promoted the growth of Salmonella and the biofilm formation. Salmonella could survive for 10 days with around $2 \log _{10} \mathrm{CFU}$ increased population on the surface of tomatoes. Even when relative humidity decreased to $60 \%$, Salmonella maintained between 3.5 to $4.5 \log _{10}$ CFU/tomato throughout the experimental period.

Colás-Medà et al., (2017) studied L. monocytogenes and Salmonella on fresh-cut pears for their survival against refrigerated conditions (consistent $\left.4^{\circ} \mathrm{C}\right)$ and temperature abuse $\left(4^{\circ} \mathrm{C}\right.$ for the first 3 days, $8^{\circ} \mathrm{C}$ for the rest of the study) for 8 days. Storage conditions had no effect $(P>0.05)$ on each pathogens, L monocytogenes showed a 1.5-2.0 $\log _{10} \mathrm{CFU} / \mathrm{g}$ increase in population, and Salmonella showed a slight decline of $0.5 \log _{10} \mathrm{CFU} / \mathrm{g}$. This experiment showed the psychrophilic properties of L. monocytogenes and the bacteria preserving nature in refrigerated environments. Controlling storage temperature was shown to be ineffective in reducing microbial load on fresh produce.

Application of antimicrobials is not the only efficient way to decontaminate fresh produce by inactivating the pathogen cells. An alternative method includes detaching pathogen 
cells from fresh produce's surface with the use of ultrasound. Jose et al. (2014) tested the adherence and inactivation of Salmonella Enteritidis and E.coli on green peppers and melons with organic acid and ultrasound. By using the combination of $40 \mathrm{kHz}$ Ultrasound, $1 \%$ lactic acid, and $1 \%$ acetic acid at a 2-minute duration, ultrasound caused a similar reduction of both pathogens on produce $\left(1.8 \log _{10} \mathrm{CFU} / \mathrm{cm}^{3}\right.$ reduction). But combining ultrasound with organic acid showed a synergistic effect $\left(2.1-3.0 \log _{10} \mathrm{CFU} / \mathrm{cm}^{3}\right)$.

Although most outbreaks reported are focused on the food items, sanitizing contaminated food contact surfaces also needs to be considered, since cross-contamination could occur when clean produce comes in contact with a contaminated surface (Yi et al., 2020).

\subsubsection{Farmers' practices}

Fresh produce in outdoor markets is more difficult to control when compared to grocery stores. Multiple variables contribute to this difficulty, including sanitation, temperature control, and worker hygiene. Limited access to power, toilets, handwashing stations, and non-uniform cleaning and sanitation procedures create hygiene issues (Worsfold et al., 2004). Khouryieh et al. investigated consumers' awareness of safety in farmers' markets fresh produce in Kentucky; out of 239 responses, more than half $(65 \%)$ of the respondents expressed concerns about the safety of perishable farmers' market purchases, and $43 \%$ of respondents perceived farmers to be the most responsible to their products' safety (Khouryieh et al., 2019).

A detailed survey was conducted to study food safety practices of farmers and farmers' market managers from Georgia, Virginia, and South Carolina. Among 55 surveyed markets, 22 (49\%) markets consisted of more than 15 vendors at their peak season, while 7 markets had 5 or fewer vendors. More than half (128/226) of the surveyed small-to-medium-sized farmers used manure as fertilizers. Thirty-one percent (69/226) of the farmers used untested irrigation sources 
such as streams, ponds, untested wells, and rainwater. Only one-third (73/226) of the farmers always cleaned the produce transport containers. This lack of hygiene raises concerns of crosscontamination when reusing those containers during transport. Additionally, 35\% (79/226) of farmers did not control for temperature (refrigeration) during transportation of the goods, albeit placing produce in a portable refrigerator or storing in a large cooler was the most popular way to cool produce during transport to farmers' markets (125/226) (Harrison et al., 2013).

Harrison et al. (2013) found 19 out of 45 (42\%) of the surveyed farmers' market managers did not establish food safety standards for the market. Less than a quarter of the markets offered sanitation training to workers and vendors. Only 3 out of $45(6 \%)$ market managers asked if there were any sanitation training courses available to the vendors; this lack of interest by market managers regarding vendors' food safety practices coupled with the lack of food safety standards suggest a limited understanding of potential risks. Half of the markets surveyed revealed vulnerability to potential foodborne outbreaks and inability to address these risks (Harrison et al., 2013).

Norwood et al. (2019) surveyed 300 market managers and vendors in Houston, Texas to identify food safety practices and educational needs. A total of $66 \%$ of the 59 survey participants believed that food safety training was beneficial, and $48 \%$ did not have any previous experience food safety training or education. Fifty-four percent of participants reported that management required them to follow food safety practices but only $36 \%$ of the vendors received food safety training. Positive practices such as designated eating areas and booths equipped with tent covering were noted; however, researchers also observed high-risk behaviors including pets defecating near produce booths, produce box container reuse, and the presence of live farm animals (goats and chicken). 
Refrigeration at or below $41^{\circ} \mathrm{F}\left(5^{\circ} \mathrm{C}\right)$ during post-harvest procedures, transportation, and display are required for Temperature Control Safety (TCS foods), as listed in the FDA food code, to maintain microbial quality in produce including "raw seed sprouts, cut melons, cut leafy greens and cut tomatoes or mixtures of tomatoes that are not modified in any way so that they are unable to support pathogenic microorganism grow or toxin formation" (FDA, 2013).

\subsubsection{The Food Safety Modernization Act}

The Guide to Minimize Microbial Food Safety Hazards of Fresh-cut Fruits and Vegetables, published by the FDA, recommended implementing Good Agricultural Practices (GAPs) to reduce the risk of foodborne pathogen contamination of fresh produce (FDA, 2018).

The FSMA produce safety rule is part of the FDA Food Safety Modernization Act (FSMA) that was published in 2015; outlined in Section 105 of FSMA, this legislation establishes minimum standards for safe production and harvesting of fresh fruits and vegetables. These standards are based on a foundation of Good Agricultural Practices (GAPs). Standards include 1.) worker health, hygiene, and training; 2.) agricultural water used for production and post-harvest; 3.) biological soil amendments like compost and manure; 4.) animals, domesticated and wild; 5.) Equipment, tools, buildings, and sanitation; and 6.) Production of sprouts (FDA, 2020; Produce Safety Alliance, 2021a).

The FSMA produce safety rules went into effect 60 days after publication (November 27, 2015) in the Federal Register. Depending on size of businesses and farms, will be applied at different times: 1.) Large businesses, with a three year average annual gross produce sales greater than $\$ 500,000$, have 2 years from the effective date of the rule to comply; 2 .) small businesses, with a three year average annual gross produce sales between $\$ 250,000$ and $\$ 500,000$, have 3 years from the effective date of the rule to comply; 3 .) very small businesses, 
with a three year average annual gross produce sales between $\$ 25,000$ and $\$ 250,000$, have 4 years from the effective date of the rule to comply. Producers with a three-year average annual gross produce sales of less than $\$ 25,000$ are exempt from this rule (FDA, 2017; Produce Safety Alliance, 2021b).

Good Agricultural Practices (GAP) is used by multiple national and international organizations. The Food and Agriculture Organization of the United Nations (FAO) defined GAP as "a collection of principles to apply for on-farm production and postproduction processes, resulting in safe and healthy food and non-food agricultural products, while taking into account economic, social and environmental sustainability" (FAO, 2016). In the United States, Good Agricultural Practices is a voluntary audit that verifies that fruits and vegetables are produced, packed, handled, and stored to minimize risks of microbial food safety hazards, by adhering to the recommendations made in the U.S. Food and Drug Administration's (FDA) Guide to Minimize Microbial Food Safety Hazards for Fresh Fruits and Vegetables (FDA, 2020; Gravani, 2009).

Hultberg et al. (2012) accessed adherence to Good Agricultural Practices (GAPs) in vegetable growers from Minnesota in 2012 via survey by mail. Out of the 32\% response rate (274/855), over $65 \%$ of respondents reported compliance to proper worker hygiene practices, including 1.) harvest container and tool sanitization and cleaning, 2.) water treatment to reduce the potential for microbial contamination, and 3.) protection of growing and storing vegetables from contamination. The researchers concluded that Minnesota farmers believe they adhere to many recommended food safety best practices but are lagging in important areas such as 1.) treating wash and processing water, 2.) taking measures to keep animals out of production fields, and 3.) cleaning and disinfecting harvesting tools and containers on a scheduled basis. 
Inconsistency in adherence to GAPs was also observed from a recent survey of 160 Kentucky farmers. While $90 \%$ of respondents claimed to be familiar with GAPs, only $47 \%$ practiced water quality GAPs, and 55\% adhered to soil amendment GAPs. Farmers also lacked understanding of potential microbiological contamination sources, less than half $(41 \%)$ identified soil as a source of pathogenic contamination, and $51 \%$ recognized irrigation water as a potential source. Only $28 \%$ of participants recognized refrigeration and cooling to be a source of contamination (Sinkel et al., 2018).

\subsubsection{Pathogen survival on food contact surfaces}

Cross contamination has been identified as a major factor contributing to foodborne illness (Bloomfield \& Scott, 1997; Ross \& Guzewich, 1999). Kusumaningrum et al., (2003) tested the survival of Salmonella Enteritidis, Staphylococcus aureus, and Campylobacter jejuni at different inoculation levels $\left(50,12,119 \mathrm{CFU} / \mathrm{cm}^{2}\right.$ respectively) on stainless steel, and the transfer efficiency from stainless steel to cucumber and chicken fillets. Results showed that $S$. Enteritidis and $S$. aureus were able to survive for at least 2 days at a contamination level of 3 $\log _{10} \mathrm{CFU} / \mathrm{cm}^{2}$. C. jejuni was reduced to below detectable limits $\left(0.62 \mathrm{CFU} / 100 \mathrm{~cm}^{2} \log _{10}\right.$ unit $)$ within one to two hours, supporting its need for an microaerophilic environment to survive. Pathogens had transfer rates of $20-100 \%$ from stainless steel to cucumber and chicken fillets.

Pathogens adhere to different surfaces in different manners. Silva, et al. (2008) evaluated adherence of L. monocytogenes to eight materials found in kitchen environments, in addition to the viability of adhered cells. Stainless steel 304, marble, granite, glass, polypropylene from two sources, and two types of silestone were inoculated with 10 strains of L. monocytogenes after 48 hours of growth $\left(8 \log _{10}\right.$ cells $\left./ \mathrm{mL}\right)$. Adhesion assays were performed after 2 hours at $37^{\circ} \mathrm{C}$. Scanning electron microscopy revealed that L. monocytogenes strains adhere to every tested 
surface material; it adhered tightly to granite and marble and loosely on polypropylene. Although L. monocytogenes attached to polypropylene loosely, nearly $100 \%$ of its samples were viable compared to the silestone with the lowest recovery rate of $18.5 \%$.

Choi et al. (2012) studied survival of E. coli O157:H7, S. Typhimurium, and L. monocytogenes on stainless steel and concluded that tested pathogens could survive for seven days at conditions of $25{ }^{\circ} \mathrm{C}$ and approximately 70\% RH. E. coli $\mathrm{O} 157: \mathrm{H} 7$ reduction was between 2 to $5 \log _{10} \mathrm{CFU} / \mathrm{mL}$ during storage compared to 2 to $3 \log _{10} \mathrm{CFU} / \mathrm{mL}$ reduction for S. Typhimurium and 2 to $4 \log _{10} \mathrm{CFU} / \mathrm{mL}$ for L. monocytogenes.

Since pathogens can survive on numerous surfaces for a prolonged periods, effective sanitation methods that reduce cross-contamination between fresh produce and food contact surfaces are important to improve microbial safety in fresh produce.

\subsubsection{Sanitation on contact surfaces}

Potential presence of pathogens in farmers' markets should not be overlooked. Characterizing foodborne pathogens and selecting an effective sanitizing method for food contact surfaces to keep fresh produce from foodborne pathogens contamination is a priority. Pathogen control processes for post-harvest produce are important for small growers to reduce pathogens on produce surfaces.

Cleaning and sanitizing are essential to reducing risk of cross-contamination during postharvest processing and display of produce in farmers' markets (Alzamora et al., 2000; FDA, 2013). Cleaning removes germs, soil, and impurities from a surface, using detergent and water. Sanitizing reduces microorganisms on a surface to a safe level; cleaning and sanitizing the surface improves microbial quality and reduces the risk of infection (CDC, 2021b). Barker et al. (2003) demonstrated that using only detergent was not sufficient to restore food contact surfaces 
(workspace, chopping board, cloth) to a hygienic state by comparing the reduction of $S$. Enteritidis when treated with detergent and different concentration of chlorine solutions on 8 different surfaces. These surfaces included fingers, chopping boards, cloths, knife-handles, door handles and more. Detergent-based cleaning could not consistently restore the tested surfaced to a hygienic state, and $500 \mathrm{ppm}$ of hypochlorite was not satisfactory for food hygiene purposes. But a high concentration (5000ppm) of hypochlorite was effective.

In a study of farmers and farmers' market practices, Harrison et al. (2013) found few (88/226) farmers sanitized food contact surfaces at their farms. The majority of survey participants who claimed they sanitized surfaces could not identify the difference between a sanitizer and a detergent. Vinegar, detergent, soap, diluted bleach solutions, sulfur solutions, citric acid solutions, and ammonia-based solutions were chosen to sanitize food contact surfaces (Harrison et al., 2013). Detergents soften the food soils and promote their dispersion and removal, while sanitizers reduce the population of spoilage and pathogenic microorganisms without sterilizing the produce contact surfaces (Marriott \& Gravani, 2006).

Establishing proper sanitation processes is important for reducing risk of crosscontamination. Surfaces that include buckets and bins for harvesting and transport; utensils and benchtops for post-harvest production, tabletops and containers for display in the market have direct contact with fresh produce and should be made of surfaces that can be easily cleaned like non-porous plastic or metal. While stainless steel is commonly used in food processing, its usage is not commonly observed in the farmers' market environment. Wood and cardboard are commonly used in farmers' markets but these materials cannot be cleaned as easily due to the crevices on the surfaces that as hold soil and moisture. 
Biofilms have significant implications for microbial food contamination and transmission of foodborne diseases because pathogens can colonize surfaces, forming multicellular microbial communities that protect those pathogens from adverse conditions, therefore increasing their resilience (González-Rivas et al., 2018). Biofilm is a major problem in sanitation, it is more resistant to sanitation than single cells and requires physical removal; otherwise it could cause cross-contamination (Gupta et al., 2016). Bae, et al. (2012) evaluated survival of foodborne pathogens on stainless steel surfaces in various attached forms (adhered cells, biofilm produced in TSB, biofilm produced at RH 100\%) stored at a different relative humidity (RH 23\%, 43\%, $68 \%, 85 \%$, and $100 \%)$. Efficacy of chemical sanitizers on inhibition of different foodborne pathogen biofilms on stainless steel surfaces. A mixture of Escherichia coli O157:H7, Listeria monocytogenes, Salmonella Typhimurium, Staphylococcus aureus, and Cronobacter sakazakii was used to form different biofilms at different relative humidity levels on stainless steel coupons. Coupons were then treated with water, chlorine-based (Clean Shot, Chemical Leader Co., Seoul, Korea), and alcohol-based sanitizers (Alpet-F, Ildong Pharmaceutical Co., Seoul, Korea) for 1 or 5 minutes. The alcohol-based sanitizer was effective on E. coli in the biofilm, with 1 minute of treatment, it reduced the E. coli population from around $6 \log _{10} \mathrm{CFU} /$ coupon to undetectable $\left(\sim 5 \log _{10}\right.$ reduction). Alcohol treatment was less effective against $S$. aureus because it only produced an $\sim 4 \log _{10}$ reduction when treated for 1 minute; albeit, this treatment reduced $S$. aureus to undetectable $\left(\sim 5 \log _{10}\right.$ reduction) after 5 minutes of treatment. The chlorine sanitizer performed relatively poorly, reducing on $E$. coli and $\sim 1$ to $2 \log _{10}$ reductions on $S$. aureus by $\sim 4$ and $\sim 1$ to $2 \log _{10}$, respectively. In general, cells attached via adhesion were more susceptible to chemical sanitizers compared to biofilm counterparts. 
Presterl et al. (2007) enhanced the effects of alcohol-based, hydrogen peroxide-based, and povidone-iodine-based sanitizers on Staphylococcus epidermidis biofilm using the static microtitre plate model. They concluded that hydrogen peroxide (at 3\% and 5\%), and alcohols rapidly eradicate $S$. epidermidis biofilms achieving a $>5 \log$ reduction after 5 minutes; whereas, a $3 \log$ survival was observed in the 30 minutes povidone-iodine treatment.

While individual sanitizer treatments have some effect on biofilms, it is possible to combine a chemical treatment with a physical treatment like steam to improve biofilm inactivation. Ban and Kang (2016) studied inactivation of biofilms formed by $E$. coli $\mathrm{O} 157: \mathrm{H7}$, S. Typhimurium, and L. monocytogenes on stainless steel using sodium hypochlorite, hydrogen peroxide, iodophor, and benzalkonium chloride with steam. The use of steam resulted in an additional reduction of up to $2.78 \log _{10}$ units.

As part of the Food Safety Modernization Act, the Produce Safety Rule provided nationwide standards during growth, harvest, and handling of fresh produce as a measure to reduce associated foodborne outbreaks. However, growers with a three-year average annual gross produce sales of less than $\$ 25,000$ are exempt from this rule. Regardless of exemption, vendors providing fresh produce options should follow good agricultural practices to minimize microbial hazards.

\subsection{Sanitizers}

After effective cleaning with detergents, soil is removed, but this process does not ensure removal of pathogens. Sanitation is used to disinfect surfaces and reduce microbial load. Physical sanitizers disinfect by exposing surfaces to heat, including hot water, pressurized steam, hot air, or radiation. Chemical sanitizers are more commonly used than physical sanitizers; they differ in their general attributes, as well as their antimicrobial properties. Sanitizers are selected 
based on like stability, ease of use, non-toxicity, non-corrosiveness, impact on product quality, and cost (Lentsch et al., 1979).

\subsubsection{Chlorine}

Sodium hypochlorite is the active compound found in household beach. It is generally recognized as safe (GARS), fast-acting, low cost, and easy to use. However, chlorine-based sanitizers are unstable at higher temperatures, corrosive to metals, can oxidize food affecting its color and lipid, are less effective in hard water, and the reaction between free chlorine and organic matter promotes the formation of a small number of harmful by-products, including possible carcinogens like haloacetic acids (HAA) and trihalomethanes (THMs) (Alzamora et al., 2000; Shen et al., 2013).

Hypochlorous acid $(\mathrm{HOCl})$ is the most effective form of chlorine for sanitation, this form is present predominantly in a $\mathrm{pH}$ range of 4.0 to $6.0 ; \mathrm{pH}$ is commonly adjusted by addition of citric acid. (USDA-AMS, 2015). Hypochlorous acid is effective against vegetative cells of bacteria, yeasts and molds, spores, and viruses. It hydrolyzes cell membranes, reacts with amino acids, and interferes with metabolism and enzyme functions in cells (Estrela et al., 2002).

The FDA approved the use of chlorine in washing fresh produce, and this regulatory body recommended applying a 40-200mg/L solution for 1-2 minutes as sanitizing treatments for produce and equipment (U.S. FDA, 2014b, 2016b). It is typically used at levels of 200 ppm for food contact surfaces, and 400 ppm for non-food contact surfaces such as floors and walls (Alzamora et al., 2000).

Efficiency of chlorine-based sanitizers has been studied with different application methods and food product types. Chaidez et al. (2007) observed a $3 \log _{10}$ CFU/unit reduction in S. Typhimurium inoculated on fresh tomatoes by spraying chlorine solution $(200 \mathrm{mg} / \mathrm{L})$ holding 
for 30 seconds; a $3.61 \log _{10} \mathrm{CFU} /$ unit reduction was observed by immersing the tomatoes in the same chlorine solution. Another study on the dynamic effects of free-chlorine concentration, reported a 4 to $5 \log _{10} \mathrm{CFU} / \mathrm{mL}$ reduction for a mixture of Salmonella and E. coli strains at 30 seconds contact time in the presence of fresh produce extract (Shen et al., 2013).

Beuchat et al. (1998) tested efficiency of spraying as a chlorine application on apples, tomatoes, and lettuce compared to traditional dipping. E. coli O157:H7, L.monocytogenes, and Salmonella were inoculated onto produce samples. Sodium hypochlorite at 200 and 2000 ppm, room condition were applied at different times $(0,1,3,5$, or $10 \mathrm{~min})$ before analysis. A greater concentration of (2000ppm) chlorine yielded greater reduction, and inactivation by chlorine reached $0.35-2.30 \log _{10} \mathrm{CFU} / \mathrm{cm}^{2}$ ) after one minute of application. Results also suggested that spraying could be an alternative to immersion application because it generated similar reductions (Beuchat, et al., 1998).

\subsubsection{Peroxyacetic acid}

Peroxyacetic acid (PAA), or peracetic acid, is a colorless liquid, has a pungent odor and low $\mathrm{pH}$ similar to vinegar, is an oxidizer, and is generally recognized as safe (GRAS). It is synthesized from the reaction between acetic acid and hydrogen peroxide and is considered to be a stronger biocide than hydrogen peroxide (McDonnell \& Russell, 1999; USDA-AMS, 2016).

PAA is widely used in food and beverage and health care industries as an antimicrobial agent (USDA- FSIS, 2021). It can also be used for sanitizing produce, leafy greens, poultry, and meats. (FAO \& Ma. Patricia V. Azanza, 2004) PAA is an effective sanitizer against both grampositive and gram-negative bacteria, as well as yeasts and molds; it causes cell membrane disruption, and it oxidizes sulfhydral and sulfur bonds in proteins, enzymes, and other metabolites (CDC, 2019c). 
PAA is stable in the $100-200$ ppm range. It has a low tolerance to soil and is less compatible with hard water. It has higher organic material tolerance than chlorine-based sanitizers (Marriott \& Gravani, 2006; Omar A. Oyarzabal \& Steffen Backert, 2011). The FDA limits PAA use in wash water to no more than $80 \mathrm{ppm}$ when assisting the peeling of fruits and vegetables, followed by rinsing with potable water (U.S. FDA, 2016b). Concentrations of 100200ppm are permitted for sanitizing food-processing equipment or food contact articles (U.S. FDA, 2011).

The efficacy of PAA has been studied for different food products. Applying 500ppm PAA to almonds without agitation caused up to a $1.93 \log _{10} \mathrm{CFU} / \mathrm{g}$ reduction on Salmonella enterica (Pao et al., 2006). While combining 80ppm PAA with the rolling process for 60 seconds, Salmonella was reduced by up to $5.5 \log _{10} \mathrm{CFU} / \mathrm{mL}$ (Chang \& Schneider, 2012). Singh et al. (2018) reported that between 5-minute treatments of PAA, chlorine-based sanitizer, and lactic acid, PAA achieved the highest reduction on E. coli O157:H7 (lettuce, lemon, tomato, and blueberry at 2.2, 5.7, 5.5, and $6.7 \log _{10} \mathrm{CFU} / \mathrm{g}$, respectively), $S$. Typhimurium (lemon, tomato, cantaloupe, blueberry at 5.4, 6.8, 4.5, and 5.9 $\log \mathrm{CFU} / \mathrm{g}$, respectively), and L. monocytogenes (lettuce and cantaloupe at 2.4 and $4.4 \log _{10} \mathrm{CFU} / \mathrm{g}$, respectively).

\subsubsection{Lactic acid}

Organic acids are naturally found in fruit and food products as by-products of fermentation, examples are malic acid in apples, lactic acid from dairy products, tartaric acid from grapes, citric acid from lemon, and acetic acid from vinegar (Theron \& Lues, 2011). These acids are generally recognized as safe (GRAS) by the FDA, and they are used as preservatives, antioxidants, and flavorings. They can be found in soft drinks, desserts, salad dressings, and acidulants in low acid foods (Mircea Enachescu Dauthy, 1995; Theron \& Lues, 2011). 
Organic acids are effective sanitizers against gram-positive and negative bacteria, as well as yeasts and molds depending on concentration, $\mathrm{pH}$, and method of application (Theron \& Lues, 2011). They can cross the cell membrane in their undissociated form, dissociate into ions inside the cell, and disrupt the electron transport chain (ETC) and DNA synthesis (Doyle \& Buchanan, 2013; Gómez-García et al., 2019; Lambert \& Stratford, 1999). These effects have been shown to damaged the membrane of Escherichia coli, lengthened the lag phase, and decreased the growth rate of cells (Axe \& Bailey, 1995; Theron \& Lues, 2011).

Lactic acid is naturally produced by lactic acid bacteria through fermentation, it is primarily used to control pH and as flavoring to food products (Doyle \& Buchanan, 2013). Effectiveness of lactic acid was studied on multiple agricultural products with different foodborne pathogens. A 5-minute wash with $1 \%$ lactic acid reduced E. coli by $2.7 \log _{10} \mathrm{CFU} / \mathrm{g}$ on baby spinach (Huang \& Chen, 2011). A 10-minute treatment of $2 \%$ lactic acid reduced a cocktail of E. coli, $S$, Typhimurium, and L. monocytogenes by up to $3.42 \log _{10}$ unit on apples, and up to $2.54 \log _{10}$ CFU/units on lettuce (Park et al., 2011).

While acid-based sanitizers are generally effective on bacteria, strains like Salmonella Typhimurium and $S$. Enteritidis can adapt to acid stress and improve survival in lactic acid fermented foods and in the presence of common food preservatives like EDTA (Ethylenediaminetetraacetic acid), at low dosage (Leyer \& Johnson, 1992, 1997).

Lactic acid was shown to inhibit spore former including Clostridium butyricum (BRACKETT, 1987; Hirsch et al., 1952; Minor \& Marth, 1970). In a comparison of Bacillus coagulans inhibition in tomato juice, lactic acid was most effective compared to acetic, malic, and citric acids (Rice \& Pederson, 1954). Another study showed lactic, malic, and citric acids 
were more effective than acetic and propionic acids for inhibition of a mixture of $E$. coli, $S$.

Typhimurium, and L. monocytogenes (Park et al., 2011).

\section{Conclusion}

Foodborne disease outbreaks that originate from farmers' markets will negatively impact the perception of locally grown fresh produce and in turn reduce economic viability, whether produce is grown conventionally or organically. Food safety risks could be mitigated by incorporating proper safety and sanitation practices during production and in farmers' market operations. Effectiveness of different sanitation methods depends on microbial sensitivity, sanitizer used, and methods of application, resulting in variable reported outcomes. Further investigation on pathogen-produce combinations, effectiveness of sanitizing agent applications, and operating with verified sanitizing agents are needed. 


\section{References}

Acheson, D., \& Allos, B. M. (2001). Campylobacter jejuni Infections: Update on Emerging Issues and Trends. Clinical Infectious Diseases, 32(8), 1201-1206. https://doi.org/10.1086/319760

Ahvenainen, R. (1996). New approaches in improving the shelf life of minimally processed fruit and vegetables. Trends in Food Science \& Technology, 7(6), 179-187. https://doi.org/10.1016/0924-2244(96)10022-4

Alzamora, S. M., Tapia, M. S., \& López-Malo, A. (2000). Minimally processed fruits and vegetables. In Minimally processed fruits and vegetables: Fundamental aspects and applications (pp. 63-78). Aspen Publishers.

Axe, D. D., \& Bailey, J. E. (1995). Transport of lactate and acetate through the energized cytoplasmic membrane ofEscherichia coli. Biotechnology and Bioengineering, 47(1), 819. https://doi.org/10.1002/bit.260470103

Bae, Y.-M., Baek, S.-Y., \& Lee, S.-Y. (2012). Resistance of pathogenic bacteria on the surface of stainless steel depending on attachment form and efficacy of chemical sanitizers. International Journal of Food Microbiology, 153(3), 465-473. https://doi.org/10.1016/j.ijfoodmicro.2011.12.017

Ban, G.-H., \& Kang, D.-H. (2016). Effect of sanitizer combined with steam heating on the inactivation of foodborne pathogens in a biofilm on stainless steel. Food Microbiology, 55, 47-54. https://doi.org/10.1016/j.fm.2015.11.003

Barker, J., Naeeni, M., \& Bloomfield, S. f. (2003). The effects of cleaning and disinfection in reducing Salmonella contamination in a laboratory model kitchen. Journal of Applied Microbiology, 95(6), 1351-1360. https://doi.org/10.1046/j.1365-2672.2003.02127.x 
Bennett, J. E., Dolin, R., Blaser, M. J., Mandell, G. L., \& Douglas, R. G. (2015). Mandell, Douglas, and Bennett's principles and practice of infectious diseases. http://www.sciencedirect.com/science/book/9781455748013

Bennish, M. L., \& Ahmed, S. (2020). Shigellosis. In Hunter's Tropical Medicine and Emerging Infectious Diseases (pp. 492-499). Elsevier. https://doi.org/10.1016/B978-0-323-555128.00048-X

Berrang, M. E., Buhr, R. J., Cason, J. A., \& Dickens, J. A. (2001). Broiler Carcass Contamination with Campylobacter from Feces during Defeathering. Journal of Food Protection, 64(12), 2063-2066. https://doi.org/10.4315/0362-028X-64.12.2063

Bertoldi, B., Richardson, S., Schneider, R. G., Kurdmongkoltham, P., \& Schneider, K. R. (2015). Preventing Foodborne Illness: E. coli “The Big Six.” E. Coli, 7.

Beuchat, L. R., Nail, B. V., Adler, B. B., \& Clavero, M. R. S. (1998). Efficacy of Spray Application of Chlorinated Water in Killing Pathogenic Bacteria on Raw Apples, Tomatoes, and Lettuce. Journal of Food Protection, 61(10), 1305-1311. https://doi.org/10.4315/0362-028X-61.10.1305

Bianchini, A., Stratton, J., Weier, S., Hartter, T., Plattner, B., Rokey, G., Hertzel, G., Gompa, L., Martinez, B., \& Eskridge, K. M. (2014). Use of Enterococcus faecium as a surrogate for Salmonella enterica during extrusion of a balanced carbohydrate-protein meal. Journal of Food Protection, 77(1), 75-82. https://doi.org/10.4315/0362-028X.JFP-13-220

Bibek Ray \& Arun Bhunia. (2013). Fundamental Food Microbiology (Fifth Edition).

Bloomfield, S. F., \& Scott, E. (1997). Cross-contamination and infection in the domestic environment and the role of chemical disinfectants. Journal of Applied Microbiology, 83(1), 1-9. https://doi.org/10.1046/j.1365-2672.1997.00199.x 
BRACKETT, R. E. (1987). Effects of various acids on growth and survival of Yersinia enterocolitica. Journal of Food Protection, 50(7), 598-601.

Bucur, F. I., Grigore-Gurgu, L., Crauwels, P., Riedel, C. U., \& Nicolau, A. I. (2018). Resistance of Listeria monocytogenes to Stress Conditions Encountered in Food and Food Processing Environments. Frontiers in Microbiology, 9. https://doi.org/10.3389/fmicb.2018.02700

Busta, F. F., Suslow, T. V., Parish, M. E., Beuchat, L. R., Farber, J. N., Garrett, E. H., \& Harris, L. J. (2003). The Use of Indicators and Surrogate Microorganisms for the Evaluation of Pathogens in Fresh and Fresh-Cut Produce. Comprehensive Reviews in Food Science and Food Safety, 2(s1), 179-185. https://doi.org/10.1111/j.1541-4337.2003.tb00035.x

Caballero, S., Kim, S., Carter, R. A., Leiner, I. M., Sušac, B., Miller, L., Kim, G. J., Ling, L., \& Pamer, E. G. (2017). Cooperating Commensals Restore Colonization Resistance to Vancomycin-Resistant Enterococcus faecium. Cell Host \& Microbe, 21(5), 592-602.e4. https://doi.org/10.1016/j.chom.2017.04.002

Caniça, M., Manageiro, V., Abriouel, H., Moran-Gilad, J., \& Franz, C. M. A. P. (2018). Antibiotic resistance in foodborne bacteria. Trends in Food Science \& Technology. https://doi.org/10.1016/j.tifs.2018.08.001

CDC. (2012a). Pathogens-complete-list-01-12.pdf. https://www.cdc.gov/foodborneburden/PDFs/pathogens-complete-list-01-12.pdf

CDC. (2012b, August 27). Multistate Outbreak of Listeriosis Linked to Whole Cantaloupes from Jensen Farms, Colorado. https://www.cdc.gov/listeria/outbreaks/cantaloupes-jensenfarms/index.html 
CDC. (2015a). Notes from the Field: Campylobacteriosis Outbreak Associated with Consuming Undercooked Chicken Liver Pâté-Ohio and Oregon, December 2013-January 2014. https://www.cdc.gov/mmwr/preview/mmwrhtml/mm6414a7.htm

CDC. (2015b). Preliminary Incidence and Trends of Infection with Pathogens Transmitted Commonly Through Food-Foodborne Diseases Active Surveillance Network, 10 U.S. Sites, 2006-2014. https://www.cdc.gov/mmwr/preview/mmwrhtml/mm6418a4.htm?s_cid=mm6418a4_w\#T $a b$

CDC. (2015c, March 9). Serotypes and the Importance of Serotyping Salmonella|CDC. https://www.cdc.gov/salmonella/reportspubs/salmonella-atlas/serotypingimportance.html

CDC. (2016a). Escherichia coli (E. coli). https://www.cdc.gov/ecoli/pdfs/cdc-e.-colifactsheet.pdf

CDC. (2016b). Multistate Outbreak of Listeriosis Linked to Packaged Salads Produced at Springfield, Ohio Dole Processing Facility. https://www.cdc.gov/listeria/outbreaks/bagged-salads-01-16/

CDC. (2017, June 29). Learn about the symptoms of Listeria. Centers for Disease Control and Prevention. https://www.cdc.gov/listeria/symptoms.html

CDC. (2018a, November 16). Guide to Confirming an Etiology in Foodborne Disease Outbreak. https://www.cdc.gov/foodsafety/outbreaks/investigatingoutbreaks/confirming_diagnosis.html 
CDC. (2018b, December 3). Multistate Outbreak of Listeriosis Linked to Raw Milk Produced by Miller's Organic Farm in Pennsylvania. https://www.cdc.gov/listeria/outbreaks/rawmilk-03-16/index.html

CDC. (2018c, December 3). Multistate Outbreak of Listeriosis Linked to Soft Raw Milk Cheese Made by Vulto Creamery. https://www.cdc.gov/listeria/outbreaks/soft-cheese-0317/index.html

CDC. (2019a, January 17). Multistate Outbreak of E. coli O157:H7 Infections Linked to Romaine Lettuce (Final Update) | Investigation Notice: Multistate Outbreak of E. coli O157:H7 Infections April 2018| E. coli. https://www.cdc.gov/ecoli/2018/o157h7-0418/index.html

CDC. (2019b, January 17). Outbreak of E. coli Infections Linked to Romaine Lettuce | E. coli Infections Linked to Romaine Lettuce | November 2018. https://www.cdc.gov/ecoli/2018/o157h7-11-18/index.html

CDC. (2019c, April 4). Peracetic Acid Sterilization | Disinfection \& Sterilization Guidelines. https://www.cdc.gov/infectioncontrol/guidelines/disinfection/sterilization/peraceticacid.html

CDC. (2019d, May 24). Outbreak of Salmonella Infections Linked to Pre-Cut Melons. https://www.cdc.gov/salmonella/carrau-04-19/index.html

CDC. (2019e, June 17). Prevent Listeria. Centers for Disease Control and Prevention. https://www.cdc.gov/listeria/prevention.html

CDC. (2019f, October 3). Outbreak of Listeria Infections Linked to Deli-Sliced Meats and Cheeses | Outbreak of Listeria Infections Linked to Deli-Sliced Products | April 2019. https://www.cdc.gov/listeria/outbreaks/deliproducts-04-19/index.html 
CDC. (2019g, December 20). Outbreaks Involving Campylobacter |CDC.

https://www.cdc.gov/campylobacter/outbreaks/outbreaks.html

CDC. (2019h, December 30). Questions and Answers | Campylobacter |CDC.

https://www.cdc.gov/campylobacter/faq.html

CDC. (2020a, January 15). Outbreak of E. coli Infections Linked to Romaine Lettuce.

https://www.cdc.gov/ecoli/2019/o157h7-11-19/index.html

CDC. (2020b, January 23). Outbreaks Involving Salmonella.

https://www.cdc.gov/salmonella/outbreaks.html

CDC. (2020c, February 18). Outbreak of Salmonella Infections Linked to Cut Fruit.

https://www.cdc.gov/salmonella/javiana-12-19/index.html

CDC. (2020d, April 17). Outbreak of Listeria Infections Linked to Enoki Mushrooms $\mid$ Outbreak of Listeria Infections Linked to Enoki Mushrooms | March 2020| Listeria.

https://www.cdc.gov/listeria/outbreaks/enoki-mushrooms-03-20/index.html

CDC. (2020e, October 8). Outbreak of Salmonella Newport Infections Linked to Onions $\mid$ CDC.

https://www.cdc.gov/salmonella/newport-07-20/index.html

CDC. (2020f, October 15). Questions \& Answers | Shigella-Shigellosis.

https://www.cdc.gov/shigella/general-information.html

CDC. (2020g, October 16). Outbreak of Salmonella Enteritidis Infections Linked to Peaches. https://www.cdc.gov/salmonella/enteritidis-08-20/index.html

CDC. (2021a, January 28). CDC: Listeria Outbreak Linked to Deli Meats. Centers for Disease Control and Prevention. https://www.cdc.gov/listeria/outbreaks/delimeat-1020/index.html 
CDC. (2021b, May 6). How To Clean and Disinfect Schools To Help Slow the Spread of Flu. https://www.cdc.gov/flu/school/cleaning.htm

Center for Food Safety and Applied Nutrition. (2020, February 8). Guidance for Industry: Guide to Minimize Microbial Food Safety Hazards for Fresh Fruits and Vegetables. U.S. Food and Drug Administration; FDA. https://www.fda.gov/regulatory-information/search-fdaguidance-documents/guidance-industry-guide-minimize-microbial-food-safety-hazardsfresh-fruits-and-vegetables

Ceylan, E., \& Bautista, D. A. (2015). Evaluating Pediococcus acidilactici and Enterococcus faecium NRRL B-2354 as Thermal Surrogate Microorganisms for Salmonella for InPlant Validation Studies of Low-Moisture Pet Food Products. Journal of Food Protection, 78(5), 934-939. https://doi.org/10.4315/0362-028X.JFP-14-271

Chaidez, C., Lopez, J., Vidales, J., \& Campo, N. C.-D. (2007). Efficacy of chlorinated and ozonated water in reducing Salmonella typhimurium attached to tomato surfaces. International Journal of Environmental Health Research, 17(4), 311-318. https://doi.org/10.1080/09603120701417063

Chan, Y. C., \& Wiedmann, M. (2009). Physiology and genetics of Listeria monocytogenes survival and growth at cold temperatures. Critical Reviews in Food Science and Nutrition, 49(3), 237-253. https://doi.org/10.1080/10408390701856272

Chang, A. S., \& Schneider, K. R. (2012). Evaluation of Overhead Spray-Applied Sanitizers for the Reduction of?Salmonella?on Tomato Surfaces. Journal of Food Science, 77(1), M65M69. https://doi.org/10.1111/j.1750-3841.2011.02486.x 
Chantarapanont, W., Berrang, M., \& Frank, J. F. (2003). Direct Microscopic Observation and Viability Determination of Campylobacter jejuni on Chicken Skin. Journal of Food Protection, 66(12), 2222-2230. https://doi.org/10.4315/0362-028X-66.12.2222

Chaudhuri, D., Roy Chowdhury, A., Biswas, B., \& Chakravortty, D. (2018). Salmonella Typhimurium Infection Leads to Colonization of the Mouse Brain and Is Not Completely Cured With Antibiotics. Frontiers in Microbiology, 9. https://doi.org/10.3389/fmicb.2018.01632

Choi, N.-Y., Baek, S.-Y., Yoon, J.-H., Choi, M.-R., Kang, D.-H., \& Lee, S.-Y. (2012). Efficacy of aerosolized hydrogen peroxide-based sanitizer on the reduction of pathogenic bacteria on a stainless steel surface. Food Control, 27(1), 57-63. https://doi.org/10.1016/j.foodcont.2012.02.027

Coburn, B., Grassl, G. A., \& Finlay, B. B. (2007). Salmonella, the host and disease: A brief review. Immunology and Cell Biology, 85(2), 112-118. https://doi.org/10.1038/sj.icb.7100007

Colás-Medà, P., Viñas, I., Alegre, I., \& Abadias, M. (2017). The impact of a cold chain break on the survival of Salmonella enterica and Listeria monocytogenes on minimally processed 'Conference' pears during their shelf life. Journal of the Science of Food and Agriculture, 97(9), 3077-3080. https://doi.org/10.1002/jsfa.8127

D'aoust, J.-Y., Warburton, D. W., \& Sewell, A. M. (1985). Salmonella typhimurium phage-type 10 from cheddar cheese implicated in a major Canadian foodborne outbreak. Journal of Food Protection, 48(12), 1062-1066. 
Davis, K. R. (2016). Campylobacter jejuni Infections Associated with Raw Milk ConsumptionUtah, 2014. MMWR. Morbidity and Mortality Weekly Report, 65. https://doi.org/10.15585/mmwr.mm6512a1

de Oliveira Elias, S., Noronha, T. B., \& Tondo, E. C. (2019). Salmonella spp. And Escherichia coli O157:H7 prevalence and levels on lettuce: A systematic review and meta-analysis. Food Microbiology, 84, 103217. https://doi.org/10.1016/j.fm.2019.05.001

Devirgiliis, C., Barile, S., \& Perozzi, G. (2011). Antibiotic resistance determinants in the interplay between food and gut microbiota. Genes \& Nutrition, 6(3), 275-284. https://doi.org/10.1007/s12263-011-0226-X

Dewey-Mattia, D., Manikonda, K., Hall, A. J., Wise, M. E., \& Crowe, S. J. (2018). Surveillance for Foodborne Disease Outbreaks—United States, 2009-2015. MMWR Surveillance Summaries, 67(10), 1-11. https://doi.org/10.15585/mmwr.ss6710a1

Doyle, M. P., \& Buchanan, R. (Eds.). (2013). Food microbiology: Fundamentals and frontiers (4th ed). ASM Press.

Enache, E., Kataoka, A., Black, D. G., Napier, C. D., Podolak, R., \& Hayman, M. M. (2015). Development of a Dry Inoculation Method for Thermal Challenge Studies in LowMoisture Foods by Using Talc as a Carrier for Salmonella and a Surrogate (Enterococcus faecium). Journal of Food Protection, 78(6), 1106-1112. https://doi.org/10.4315/0362028X.JFP-14-396

Estrela, C., Estrela, C. R. A., Barbin, E. L., Spanó, J. C. E., Marchesan, M. A., \& Pécora, J. D. (2002). Mechanism of action of sodium hypochlorite. Brazilian Dental Journal, 13(2), $113-117$. 
FAO. (2016). A Scheme and Training Manual on Good Agricultural Practices (GAP) for Fruits and Vegetables. http://www.fao.org/3/i6677e/i6677e.pdf

FAO \& Ma. Patricia V. Azanza. (2004). Hydrogen Peroxide, Peroxyacetic Acid, Octanoic Acid, Peroxyoctanoic Acid, And 1-Hydroxyethylidene-1,1-Diphosphonic Acid (Hedp) As Components Of Antimicrobial Washing Solution. http://www.fao.org/fileadmin/templates/agns/pdf/jecfa/cta/63/Antimicrobials.pdf

FAO, \& WHO (Eds.). (2008). Microbiological hazards in fresh leafy vegetables and herbs: Meeting report. World Health Organization; Food and Agriculture Organization of the United Nations.

Farber, J. M., \& Peterkin, P. I. (1991). Listeria monocytogenes, a food-borne pathogen. Microbiological Reviews, 55(3), 476-511.

FDA. (2012). Bad Bug Book, Foodborne Pathogenic Microorganisms and Natural Toxins. https://www.fda.gov/media/83271/download

FDA. (2013). Food Code. https://www.fda.gov/media/87140/download

FDA. (2017). Compliance with and Recommendations for Implementation of the Standards for the Growing, Harvesting, Packing, and Holding of Produce for Human Consumption for Sprout Operations: Guidance for Industry. https://www.fda.gov/media/102430/download

FDA. (2018). Guide to Minimize Food Safety Hazards of Fresh-cut Produce: Draft Guidance for Industry. 71.

FDA. (2020). FSMA Final Rule on Produce Safety. FDA. https://www.fda.gov/food/food-safetymodernization-act-fsma/fsma-final-rule-produce-safety

FDA-NSTA. (2009, January 17). FDA/CFSAN - Food Safety A to Z Reference Guide. https://web.archive.org/web/20090117202535/http://www.cfsan.fda.gov/ dms/a2z-s.html 
Food Safety News. (2011, August 9). Did Deer Cause Oregon's Strawberry Outbreak? Food Safety News. http://www.foodsafetynews.com/2011/08/epis-pinpoint-strawberries-in-ore-coli-outbreak/

Food Safety News. (2015, September 4). Update: 9 Confirmed, 1 Probable Case in Seattle E. Coli Outbreak. Food Safety News. http://www.foodsafetynews.com/2015/09/6-e-colicases-linked-to-mexican-food-sold-at-washington-farmers-markets/

Foulquié Moreno, M. R., Sarantinopoulos, P., Tsakalidou, E., \& De Vuyst, L. (2006). The role and application of enterococci in food and health. International Journal of Food Microbiology, 106(1), 1-24. https://doi.org/10.1016/j.ijfoodmicro.2005.06.026

Franz, C. M. A. P., Holzapfel, W. H., \& Stiles, M. E. (1999). Enterococci at the crossroads of food safety? International Journal of Food Microbiology, 47(1-2), 1-24. https://doi.org/10.1016/S0168-1605(99)00007-0

Gardner, T. J., Fitzgerald, C., Xavier, C., Klein, R., Pruckler, J., Stroika, S., \& McLaughlin, J. B. (2011). Outbreak of Campylobacteriosis Associated With Consumption of Raw Peas. Clinical Infectious Diseases, 53(1), 26-32. https://doi.org/10.1093/cid/cir249

Garner, D., \& Kathariou, S. (2016). Fresh Produce-Associated Listeriosis Outbreaks, Sources of Concern, Teachable Moments, and Insights. Journal of Food Protection, 79(2), 337-344. https://doi.org/10.4315/0362-028X.JFP-15-387

Gaschignard, J., Levy, C., Romain, O., Cohen, R., Bingen, E., Aujard, Y., \& Boileau, P. (n.d.). Neonatal Bacterial Meningitis: 444 Cases in 7 Years. The Pediatric Infectious Disease Journal, 30(3), 212-217. 
Gerba, C. P. (2009). Chapter 22 -Environmentally Transmitted Pathogens. In R. M. Maier, I. L. Pepper, \& C. P. Gerba (Eds.), Environmental Microbiology (Second Edition) (pp. 445484). Academic Press. https://doi.org/10.1016/B978-0-12-370519-8.00022-5

Giannella, R. A. (1996). Salmonella. In S. Baron (Ed.), Medical Microbiology (4th ed.). University of Texas Medical Branch at Galveston. http://www.ncbi.nlm.nih.gov/books/NBK8435/

Gombas, D., Luo, Y., Brennan, J., Shergill, G., Petran, R., Walsh, R., Hau, H., Khurana, K., Zomorodi, B., Rosen, J., Varley, R., \& Deng, K. (2017). Guidelines To Validate Control of Cross-Contamination during Washing of Fresh-Cut Leafy Vegetables. Journal of Food Protection, 80(2), 312-330. https://doi.org/10.4315/0362-028X.JFP-16-258

Gómez-García, M., Sol, C., de Nova, P. J. G., Puyalto, M., Mesas, L., Puente, H., Mencía-Ares, Ó., Miranda, R., Argüello, H., Rubio, P., \& Carvajal, A. (2019). Antimicrobial activity of a selection of organic acids, their salts and essential oils against swine enteropathogenic bacteria. Porcine Health Management, 5. https://doi.org/10.1186/s40813-019-0139-4

González-Rivas, F., Ripolles-Avila, C., Fontecha-Umaña, F., Ríos-Castillo, A. G., \& RodríguezJerez, J. J. (2018). Biofilms in the Spotlight: Detection, Quantification, and Removal Methods. Comprehensive Reviews in Food Science and Food Safety, 17(5), 1261-1276. https://doi.org/10.1111/1541-4337.12378

Gravani, R. B. (2009). The Role of Good Agricultural Practices in Produce Safety. In X. Fan, B. A. Niemira, C. J. Doona, F. E. Feeherry, \& R. B. Gravani (Eds.), Microbial Safety of
Fresh Produce (pp. 101-117). Wiley-Blackwell.
https://doi.org/10.1002/9781444319347.ch5 
Gupta, P., Sarkar, S., Das, B., Bhattacharjee, S., \& Tribedi, P. (2016). Biofilm, pathogenesis and prevention - a journey to break the wall: A review. Archives of Microbiology, 198(1), 115. https://doi.org/10.1007/s00203-015-1148-6

Gurtler, J. B., Doyle, M. P., \& Kornacki, J. L. (Eds.). (2017). Foodborne Pathogens. Springer International Publishing. https://doi.org/10.1007/978-3-319-56836-2

Hara-Kudo, Y., \& Takatori, K. (2011). Contamination level and ingestion dose of foodborne pathogens associated with infections. Epidemiology and Infection, 139(10), 1505-1510. https://doi.org/10.1017/S095026881000292X

Harrison, J. A., Gaskin, J. W., Harrison, M. A., Cannon, J. L., Boyer, R. R., \& Zehnder, G. W. (2013). Survey of Food Safety Practices on Small to Medium-Sized Farms and in Farmers Markets. Journal of Food Protection, 76(11), 1989-1993. https://doi.org/10.4315/0362-028X.JFP-13-158

Hirsch, A., McClintock, M., \& Mocquot, G. (1952). 476. Observations on the influence of inhibitory substances produced by the lactobacilli of Gruyere cheese on the development of anaerobic spore-formers. Journal of Dairy Research, 19(02), 179. https://doi.org/10.1017/S0022029900006427

Hitchins, A. D. (1996). Assessment of alimentary exposure to Listeria monocytogenes. International Journal of Food Microbiology, 30(1-2), 71-85.

Huang, Y., \& Chen, H. (2011). Effect of organic acids, hydrogen peroxide and mild heat on inactivation of Escherichia coli O157:H7 on baby spinach. Food Control, 22(8), 11781183. https://doi.org/10.1016/j.foodcont.2011.01.012 
Hultberg, A., Schermann, M., \& Tong, C. (2012). Results from a Mail Survey to Assess Minnesota Vegetable Growers' Adherence to Good Agricultural Practices. HortTechnology, 22(1), 83-88. https://doi.org/10.21273/HORTTECH.22.1.83

IFSAC. (2015). Foodborne Illness Source Attribution Estimates for Salmonella, Escherichia coli O157 (E. coli O157), Listeria monocytogenes (Lm), and Campylobacter using Outbreak Surveillance Data. https://www.cdc.gov/foodsafety/pdfs/ifsac-project-report-508c.pdf IFSAC. (2020). Foodborne illness source attribution estimates for 2018 for Salmonella, Escherichia coli O157, Listeria monocytogenes, and Campylobacter using multi-year outbreak surveillance data, United States. 15.

Iturriaga, M. H., Tamplin, M. L., \& Escartín, E. F. (2007). Colonization of Tomatoes by Salmonella Montevideo Is Affected by Relative Humidity and Storage Temperature. Journal of Food Protection, 70(1), 30-34. https://doi.org/10.4315/0362-028X-70.1.30

Jackson, B. R., Zegarra, J. A., López-Gatell, H., Sejvar, J., Arzate, F., Waterman, S., Núñez, A. S., López, B., Weiss, J., Cruz, R. Q., Murrieta, D. Y. L., Luna-Gierke, R., Heiman, K., Vieira, A. R., Fitzgerald, C., Kwan, P., Zárate-Bermúdez, M., Talkington, D., Hill, V. R., \& Mahon, B. (2014). Binational outbreak of Guillain-Barré syndrome associated with Campylobacter jejuni infection, Mexico and USA, 2011. Epidemiology \& Infection, 142(5), 1089-1099. https://doi.org/10.1017/S0950268813001908

James M., J., Martin J., L., \& David A., G. (2006a). Foodborne Gastroenteritis Caused by Salmmonella and Shigella. In Mordern Food Microbiology (Seventh Edition). Springer.

James M., J., Martin J., L., \& David A., G. (2006b). Foodbrone Listeriosis. In Mordern Food Microbiology (Seventh Edition). Springer. 
Jang, J., Hur, H.-G., Sadowsky, M. J., Byappanahalli, M. N., Yan, T., \& Ishii, S. (2017).

Environmental Escherichia coli: Ecology and public health implications-a review. Journal of Applied Microbiology, 123(3), 570-581. https://doi.org/10.1111/jam.13468

Jay, J. M., Loessner, M. J., \& Golden, D. A. (2005). Foodborne Gastroenteritis Caused by Escherichia coli. In Modern food microbiology (7th ed, pp. 637-656). Springer.

Jeong, S., Marks, B. P., \& Ryser, E. T. (2011). Quantifying the performance of Pediococcus sp. (NRRL B-2354: Enterococcus faecium) as a nonpathogenic surrogate for Salmonella Enteritidis PT30 during moist-air convection heating of almonds. Journal of Food Protection, 74(4), 603-609. https://doi.org/10.4315/0362-028X.JFP-10-416

Johannes, L., \& Römer, W. (2010). Shiga toxins-From cell biology to biomedical applications. Nature Reviews Microbiology, 8(2), 105-116. https://doi.org/10.1038/nrmicro2279

Khan, A., Davlieva, M., Panesso, D., Rincon, S., Miller, W. R., Diaz, L., Reyes, J., Cruz, M. R., Pemberton, O., Nguyen, A. H., Siegel, S. D., Planet, P. J., Narechania, A., Latorre, M., Rios, R., Singh, K. V., Ton-That, H., Garsin, D. A., Tran, T. T., ... Arias, C. A. (2019). Antimicrobial sensing coupled with cell membrane remodeling mediates antibiotic resistance and virulence in Enterococcus faecalis. Proceedings of the National Academy of Sciences, 116(52), 26925-26932. https://doi.org/10.1073/pnas.1916037116

Khan, W. A., Griffiths, J. K., \& Bennish, M. L. (2013). Gastrointestinal and Extra-Intestinal Manifestations of Childhood Shigellosis in a Region Where All Four Species of Shigella Are Endemic. PLoS ONE, 8(5). https://doi.org/10.1371/journal.pone.0064097

Khouryieh, M., Khouryieh, H., Daday, J. K., \& Shen, C. (2019). Consumers' perceptions of the safety of fresh produce sold at farmers' markets. Food Control, 105, 242-247. https://doi.org/10.1016/j.foodcont.2019.06.003 
Kopit, L. M., Kim, E. B., Siezen, R. J., Harris, L. J., \& Marco, M. L. (2014). Safety of the Surrogate Microorganism Enterococcus faecium NRRL B-2354 for Use in Thermal Process Validation. Applied and Environmental Microbiology, 80(6), 1899-1909. https://doi.org/10.1128/AEM.03859-13

Kusumaningrum, H. D., Riboldi, G., Hazeleger, W. C., \& Beumer, R. R. (2003). Survival of foodborne pathogens on stainless steel surfaces and cross-contamination to foods. International Journal of Food Microbiology, 85(3), 227-236. https://doi.org/10.1016/S0168-1605(02)00540-8

Lambert, R. J., \& Stratford, M. (1999). Weak-acid preservatives: Modelling microbial inhibition and response. Journal of Applied Microbiology, 86(1), 157-164. https://doi.org/10.1046/j.1365-2672.1999.00646.x

Laughlin, M. E., Chatham-Stephens, K., \& Geissler, A. L. (2019). Campylobacteriosis-Chapter 4-2020 Yellow Book| Travelers' Health | CDC. https://wwwnc.cdc.gov/travel/yellowbook/2020/travel-related-infectiousdiseases/campylobacteriosis

Le Minor, L., \& Popoff, M. Y. (1987). Designation of Salmonella enterica sp. nov., nom. rev., as the Type and Only Species of the Genus Salmonella: Request for an Opinion. International Journal of Systematic and Evolutionary Microbiology, 37(4), 465-468.

Lentsch, S., Division, K., \& Paul, S. (1979). Sanitizers for an effective cleaning program. Economics Laboratories.

Levy, D. J., Beck, N. K., Kossik, A. L., Patti, T., Meschke, J. S., Calicchia, M., \& Hellberg, R. S. (2015). Microbial safety and quality of fresh herbs from Los Angeles, Orange County 
and Seattle farmers' markets. Journal of the Science of Food and Agriculture, 95(13), 2641-2645. https://doi.org/10.1002/jsfa.6996

Leyer, G. J., \& Johnson, E. A. (1992). Acid adaptation promotes survival of Salmonella spp. In cheese. Applied and Environmental Microbiology, 58(6), 2075-2080.

Leyer, G. J., \& Johnson, E. A. (1997). Acid adaptation sensitizes Salmonella typhimurium to hypochlorous acid. Applied and Environmental Microbiology, 63(2), 461-467.

Ma, L., Kornacki, J. L., Zhang, G., Lin, C.-M., \& Doyle, M. P. (2011). Development of Thermal Surrogate Microorganisms in Ground Beef for In-Plant Critical Control Point Validation Studies. J. Food Prot., 70(4), 6.

Marriott, N. G., \& Gravani, R. B. (2006). Principles of food sanitation (5th ed). Springer.

McDonnell, G., \& Russell, A. D. (1999). Antiseptics and Disinfectants: Activity, Action, and Resistance. Clinical Microbiology Reviews, 12(1), 147-179.

Melton-Celsa, A. R. (2014). Shiga Toxin (Stx) Classification, Structure, and Function. Microbiology Spectrum, 2(2). https://doi.org/10.1128/microbiolspec.EHEC-0024-2013

Minor, T. E., \& Marth, E. H. (1970). Growth of Staphylococcus aureus in acidified pasteurized milk. Journal of Milk and Food Technology, 33(11), 516-520.

Mircea Enachescu Dauthy. (1995). Fruit and vegetable processing—Contents. http://www.fao.org/docrep/V5030E/V5030E00.htm

Morris, J. G., \& Potter, M. E. (Eds.). (2013). Foodborne infections and intoxications (4th ed). Academic.

Norwood, H. E., Neal, J. A., \& Sirsat, S. A. (2019). Food Safety Resources for Managers and Vendors of Farmers Markets in Texas. Journal of Environmental Health, 82(2), 8-12. 
Okike, I. O., Lamont, R. F., \& Heath, P. T. (2013). Do We Really Need to Worry About Listeria in Newborn Infants?: The Pediatric Infectious Disease Journal, 32(4), 405-406. https://doi.org/10.1097/INF.0b013e3182867fa0

Omar A. Oyarzabal \& Steffen Backert. (2011). Microbial Food Safety: An Introduction. Springer.

Oprea, S. F., \& Zervos, M. J. (2007). Enterococcus and its Association with Foodborne Illness. In S. Simjee (Ed.), Foodborne Diseases (pp. 157-174). Humana Press. https://doi.org/10.1007/978-1-59745-501-5_6

Oyarzabal, O. A., \& Backert, S. (2017). Varying Pathogenicity of Campylobacter jejuni Isolates. In J. B. Gurtler, M. P. Doyle, \& J. L. Kornacki (Eds.), Foodborne Pathogens (pp. 41-60). Springer International Publishing. https://doi.org/10.1007/978-3-319-56836-2_2

Painter, J. A., Hoekstra, R. M., Ayers, T., Tauxe, R. V., Braden, C. R., Angulo, F. J., \& Griffin, P. M. (2013). Attribution of Foodborne Illnesses, Hospitalizations, and Deaths to Food Commodities by using Outbreak Data, United States, 1998-2008. Emerging Infectious Diseases, 19(3), 407-415. https://doi.org/10.3201/eid1903.111866

Pao, S., Kalantari, A., \& Huang, G. (2006). Utilizing Acidic Sprays for Eliminating Salmonella enterica on Raw Almonds. Journal of Food Science, 71(1), M14-M19. https://doi.org/10.1111/j.1365-2621.2006.tb12394.x

Park, S.-H., Choi, M.-R., Park, J.-W., Park, K.-H., Chung, M.-S., Ryu, S., \& Kang, D.-H. (2011). Use of Organic Acids to Inactivate Escherichia coli O157:H7, Salmonella Typhimurium, and Listeria monocytogenes on Organic Fresh Apples and Lettuce. Journal of Food Science, 76(6), M293-M298. https://doi.org/10.1111/j.17503841.2011.02205.x 
Pires, A. F. A., Stover, J., Kukielka, E., Haghani, V., Aminabadi, P., de MELO RAMOS, T., \& Jay-Russell, M. T. (2020). Salmonella and Escherichia coli Prevalence in Meat and Produce Sold at Farmers' Markets in Northern California. Journal of Food Protection, 83(11), 1934-1940. https://doi.org/10.4315/JFP-20-079

Poh, C. H., Oh, H. M. L., \& Tan, A. L. (2006). Epidemiology and clinical outcome of enterococcal bacteraemia in an acute care hospital. The Journal of Infection, 52(5), 383386. https://doi.org/10.1016/j.jinf.2005.07.011

Presterl, E., Suchomel, M., Eder, M., Reichmann, S., Lassnigg, A., Graninger, W., \& Rotter, M. (2007). Effects of alcohols, povidone-iodine and hydrogen peroxide on biofilms of Staphylococcus epidermidis. Journal of Antimicrobial Chemotherapy, 60(2), 417-420. https://doi.org/10.1093/jac/dkm221

Produce Safety Alliance. (2021a). Produce Safety Rule. https://producesafetyalliance.cornell.edu/food-safety-modernization-act/produce-safetyrule/

Produce Safety Alliance. (2021b). Produce Safety Rule Compliance Dates \& Timeline. https://producesafetyalliance.cornell.edu/food-safety-modernization-act/produce-safetyrule-compliance-dates-timeline/

Rice, A. C., \& Pederson, C. S. (1954). Chromatographic Analysis Of Organic Acids In Canned Tomato Juice, Including The Identification Of Pyrrolidonecarboxylic Acid. Journal of Food Science, 19(1-6), 106-114. https://doi.org/10.1111/j.1365-2621.1954.tb17428.x

RJ Gilbert, J de Louvois, T Donovan, C Little, K Nye, CD Ribeiro, J Richards, D Roberts, \& FJ Bolton. (2000). Guidelines for the microbiological quality of some ready-to-eat foods 
sampled at the point of sale. Communicable Disease and Public Health, 3: 163-7. http://mb-labs.com/wp-content/uploads/2014/08/Micro-Limits-Ready-to-Eat-Foods.pdf

Robins-Browne, R. M., Holt, K. E., Ingle, D. J., Hocking, D. M., Yang, J., \& Tauschek, M. (2016). Are Escherichia coli Pathotypes Still Relevant in the Era of Whole-Genome Sequencing? Frontiers in Cellular and Infection Microbiology, 6. https://doi.org/10.3389/fcimb.2016.00141

Ross, M., \& Guzewich, J. (1999). Evaluation of risks related to microbiological contamination of ready-to-eat food by food preparation workers and the effectiveness of interventions to minimize those risks. FDA White Paper, FDA, CFSAN.

Roth, L., Simonne, A., House, L., \& Ahn, S. (2018). Microbiological analysis of fresh produce sold at Florida farmers' markets. Food Control, 92, 444-449. https://doi.org/10.1016/j.foodcont.2018.05.030

Sánchez, G., Elizaquível, P., \& Aznar, R. (2012). A single method for recovery and concentration of enteric viruses and bacteria from fresh-cut vegetables. International Journal of Food Microbiology, 152(1), 9-13. https://doi.org/10.1016/j.ijfoodmicro.2011.10.002

São José, J. F. B. de, Medeiros, H. S. de, Bernardes, P. C., \& Andrade, N. J. de. (2014). Removal of Salmonella enterica Enteritidis and Escherichia coli from green peppers and melons by ultrasound and organic acids. International Journal of Food Microbiology, 190(Supplement C), 9-13. https://doi.org/10.1016/j.jffoodmicro.2014.08.015

Scallan, E., Hoekstra, R. M., Angulo, F. J., Tauxe, R. V., Widdowson, M.-A., Roy, S. L., Jones, J. L., \& Griffin, P. M. (2011). Foodborne Illness Acquired in the United States-Major 
Pathogens. Emerging Infectious Diseases, 17(1), 7-15.

https://doi.org/10.3201/eid1701.P11101

Scheinberg, J. A., Dudley, E. G., Campbell, J., Roberts, B., DiMarzio, M., DebRoy, C., \& Cutter, C. N. (2017). Prevalence and Phylogenetic Characterization of Escherichia coli and Hygiene Indicator Bacteria Isolated from Leafy Green Produce, Beef, and Pork Obtained from Farmers' Markets in Pennsylvania. Journal of Food Protection, 80(2), 237-244. https://doi.org/10.4315/0362-028X.JFP-16-282

Scheutz, F., Teel, L. D., Beutin, L., Piérard, D., Buvens, G., Karch, H., Mellmann, A., Caprioli, A., Tozzoli, R., Morabito, S., Strockbine, N. A., Melton-Celsa, A. R., Sanchez, M., Persson, S., \& O’Brien, A. D. (2012). Multicenter Evaluation of a Sequence-Based Protocol for Subtyping Shiga Toxins and Standardizing Stx Nomenclature. Journal of Clinical Microbiology, 50(9), 2951-2963. https://doi.org/10.1128/JCM.00860-12

Schlech, W. F. I., Lavigne, P. M., Bortolussi, R. A., Allen, A. C., Haldane, E. V., Wort, A. J., Hightower, A. W., Johnson, S. E., King, S. H., Nicholls, E. S., \& Broome, C. V. (1983). Epidemic Listeriosis—Evidence for Transmission by Food. New England Journal of Medicine, 308(4), 203-206. https://doi.org/10.1056/NEJM198301273080407

Schuchat, A., Swaminathan, B., \& Broome, C. V. (1991). Epidemiology of human listeriosis. Clinical Microbiology Reviews, 4(2), 169-183.

Schüller, S. (2011). Shiga Toxin Interaction with Human Intestinal Epithelium. Toxins, 3(6), 626-639. https://doi.org/10.3390/toxins3060626

Shen, C., Luo, Y., Nou, X., Wang, Q., \& Millner, P. (2013). Dynamic Effects of Free Chlorine Concentration, Organic Load, and Exposure Time on the Inactivation of Salmonella, 
Escherichia coli O157:H7, and Non-O157 Shiga Toxin-Producing E. coli. Journal of Food Protection, 76(3), 386-393. https://doi.org/10.4315/0362-028X.JFP-12-320

Silk, B. J., Date, K. A., Jackson, K. A., Pouillot, R., Holt, K. G., Graves, L. M., Ong, K. L., Hurd, S., Meyer, R., Marcus, R., Shiferaw, B., Norton, D. M., Medus, C., Zansky, S. M., Cronquist, A. B., Henao, O. L., Jones, T. F., Vugia, D. J., Farley, M. M., \& Mahon, B. E. (2012). Invasive Listeriosis in the Foodborne Diseases Active Surveillance Network (FoodNet), 2004-2009: Further Targeted Prevention Needed for Higher-Risk Groups. Clinical Infectious Diseases, 54(suppl_5), S396-S404. https://doi.org/10.1093/cid/cis268

Silva, J., Leite, D., Fernandes, M., Mena, C., Gibbs, P. A., \& Teixeira, P. (2011). Campylobacter spp. as a Foodborne Pathogen: A Review. Frontiers in Microbiology, 2. https://doi.org/10.3389/fmicb.2011.00200

Silva, S., Teixeira, P., Oliveira, R., \& Azeredo, J. (2008). Adhesion to and Viability of Listeria monocytogenes on Food Contact Surfaces. Journal of Food Protection, 71(7), 13791385. https://doi.org/10.4315/0362-028X-71.7.1379

Singh, P., Hung, Y.-C., \& Qi, H. (2018). Efficacy of Peracetic Acid in Inactivating Foodborne Pathogens on Fresh Produce Surface. Journal of Food Science, 83(2), 432-439. https://doi.org/10.1111/1750-3841.14028

Sinkel, D., Khouryieh, H., Daday, J. K., Stone, M., \& Shen, C. (2018). Knowledge and Implementation of Good Agricultural Practices among Kentucky Fresh Produce Farmers. Food Protection Trends, 38(2), 111-121.

Su, L., \& Chiu, C. (2007). Salmonella: Clinical importance and evolution of nomenclature. Chang Gung Medical Journal, 30(3), 210. 
Theron, M. M., \& Lues, J. F. R. (2011). Organic acids and food preservation. CRC Press, Taylor \& Francis Group.

Trias, R., Bañeras, L., Badosa, E., \& Montesinos, E. (2008). Bioprotection of Golden Delicious apples and Iceberg lettuce against foodborne bacterial pathogens by lactic acid bacteria. International Journal of Food Microbiology, 123(1), 50-60. https://doi.org/10.1016/j.ijfoodmicro.2007.11.065

Tuttle, J., Gomez, T., Doyle, M. P., Wells, J. G., Zhao, T., Tauxe, R. V., \& Griffin, P. M. (1999). Lessons from a large outbreak of Escherichia coli O157[ratio ]H7 infections: Insights into the infectious dose and method of widespread contamination of hamburger patties. Epidemiology \& Infection, 122(2), 185-192.

https://doi.org/10.1017/S0950268898001976

U.S. FDA. (2004, January 23). U.S. DEPARTMENT OF HEALTH AND HUMAN SERVICES FOOD AND DRUG ADMINISTRATION ) ) Amending 21 C.F.R. Part 109 ) to Establish a Reg. https://google2.fda.gov/search?q=cache:XRN_9azhVhcJ:www.fda.gov/ohrms/dockets/da ilys/03/dec03/122403/03p-0574-cp00001-02vol1.pdf+zero+tolerance+listeria\&client=FDAgov\&site=FDAgov\&lr=\&proxystylesheet =FDAgov\&output=xml_no_dtd\&ie=UTF-8\&access=p\&oe=UTF-8

U.S. FDA. (2011). 40 CFR 180.1196-Peroxyacetic acid; exemption from the requirement of a tolerance. LII / Legal Information Institute. https://www.law.cornell.edu/cfr/text/40/180.1196

U.S. FDA. (2014a). Laboratory Methods - BAM: Salmonella [WebContent]. https://www.fda.gov/food/foodscienceresearch/laboratorymethods/ucm070149.htm 
U.S. FDA. (2014b). Science \& Research (Food)_Chapter V. Methods to Reduce/Eliminate Pathogens from Produce and Fresh-Cut Produce [WebContent]. https://www.fda.gov/Food/FoodScienceResearch/ucm091363.htm

U.S. FDA. (2016a). Food Safety Modernization Act (FSMA)_Produce Safety Standards [WebContent]. https://www.fda.gov/Food/GuidanceRegulation/FSMA/ucm304045.htm\#prevention

U.S. FDA. (2016b). Sec. 173.315 Chemicals used in washing or to assist in the peeling of fruits and vegetables. https://www.accessdata.fda.gov/SCRIPTs/cdrh/cfdocs/cfcfr/CFRSearch.cfm?fr=173.315 $\&$ SearchTerm $=$ chemicals

USDA ERS. (2020). Food Availability (Per Capita) Data System. https://www.ers.usda.gov/data-products/food-availability-per-capita-data-system

USDA ERS. (2021). USDA ERS - Economic Cost of Major Foodborne Illnesses Increased \$2 Billion From 2013 to 2018. https://www.ers.usda.gov/amber-waves/2021/april/economiccost-of-major-foodborne-illnesses-increased-2-billion-from-2013-to-2018/

USDA- FSIS. (2021). HEALTH HAZARD INFORMATION SHEET Peroxyacetic Acid (PAA). 4. USDA-AMS. (2015). Hypochlorous Acid TR 0813 15.pdf. https://www.ams.usda.gov/sites/default/files/media/Hypochlorous\%20Acid\%20TR\%200 $8 \% 2013 \% 2015 . p d f$

USDA-AMS. (2016). Peracetic Acid Handling/Processing. https://www.ams.usda.gov/sites/default/files/media/Peracetic\%20Acid\%20TR\%203_3_2 016\%20Livestock.pdf 
USFDA. (2016). Consumers - Foodborne Illnesses: What You Need to Know [WebContent]. https://www.fda.gov/food/resourcesforyou/consumers/ucm103263.htm

Wood, J. L., Chen, J. C., Friesen, E., Delaquis, P., \& Allen, K. J. (2015). Microbiological Survey of Locally Grown Lettuce Sold at Farmers' Markets in Vancouver, British Columbia. Journal of Food Protection, 78(1), 203-208. https://doi.org/10.4315/0362-028X.JFP-14199

Worsfold, D., Worsfold, P. M., \& Griffith, C. J. (2004). An assessment of food hygiene and safety at farmers' markets. International Journal of Environmental Health Research, 14(2), 109-119. https://doi.org/10.1080/0960312042000209507

Yeni, F., Yavaş, S., Alpas, H., \& Soyer, Y. (2016). Most Common Foodborne Pathogens and Mycotoxins on Fresh Produce: A Review of Recent Outbreaks. Critical Reviews in Food Science and Nutrition, 56(9), 1532-1544. https://doi.org/10.1080/10408398.2013.777021

Yi, J., Huang, K., Young, G. M., \& Nitin, N. (2020). Quantitative analysis and influences of contact dynamics on bacterial cross-contamination from contaminated fresh produce. Journal of Food Engineering, 270, 109771.

https://doi.org/10.1016/j.jfoodeng.2019.109771

Zhu, Q., Gooneratne, R., \& Hussain, M. (2017). Listeria monocytogenes in Fresh Produce: Outbreaks, Prevalence and Contamination Levels. Foods, 6(3), 21. https://doi.org/10.3390/foods6030021 


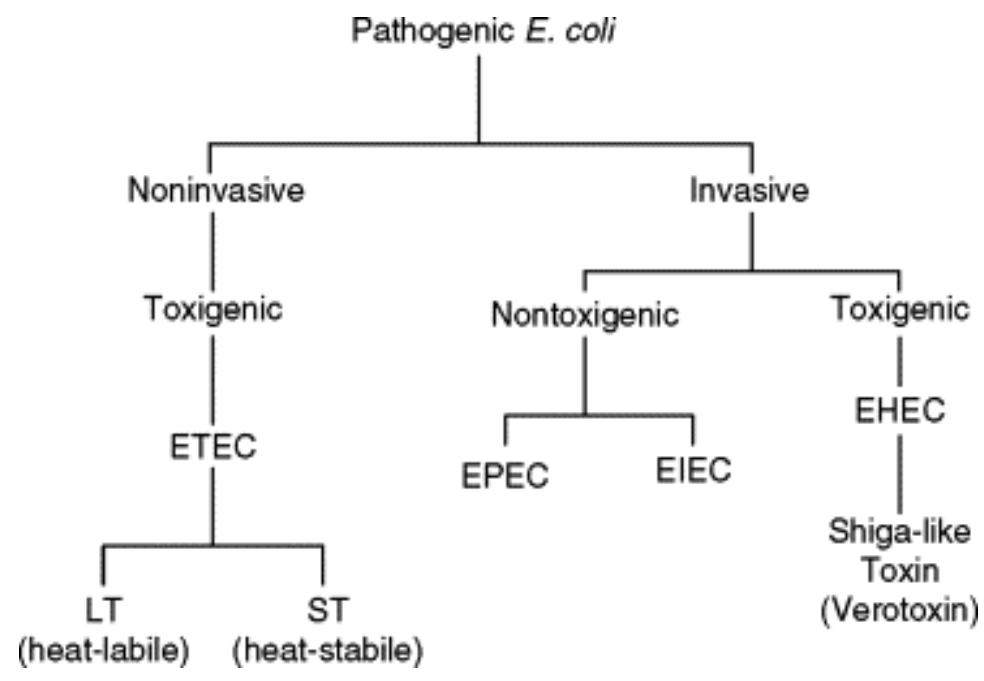

Figure 2.1: Relationship between different pathotypes of Escherichia coli. (Gerba, 2009, p. 22)

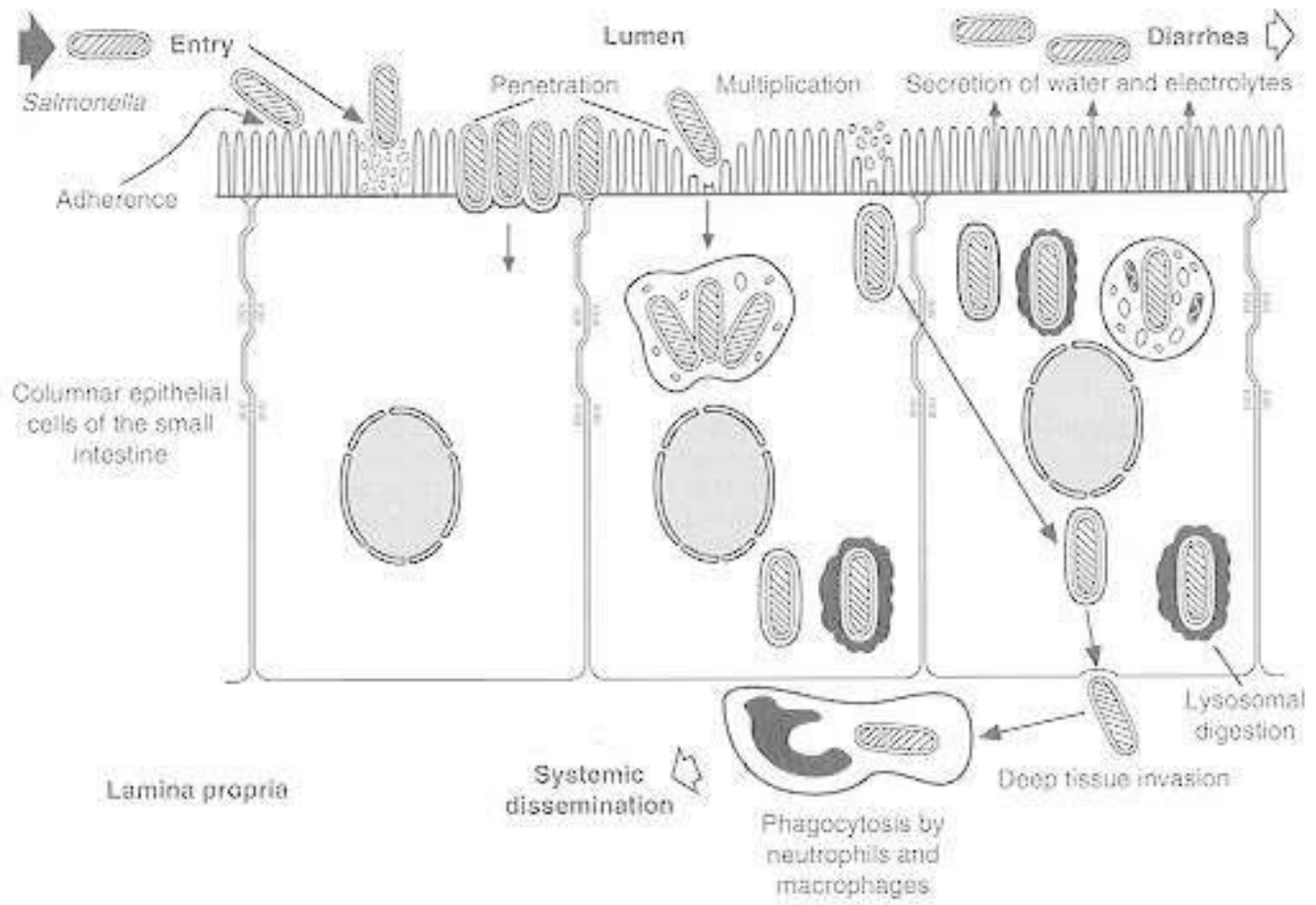

Figure 2.2: Salmonella invading intestinal mucosa (Giannella, 1996). 


\section{CHAPTER 3}

Compare the Efficacy of Two Triple-Wash Procedures with Sodium Hypochlorite, LacticCitric Acid Blend, and Mixer of Peroxyacetic Acid and Hydrogen Peroxide to Inactivate Salmonella, Listeria monocytogenes, and surrogate Enterococcus faecium on Cucumbers and Tomatoes

This study aimed to evaluate the two triple-wash procedures with commercial antimicrobials to inactivate foodborne pathogens and surrogate bacteria on cucumbers and tomatoes. Fresh West Virginia locally grown cucumbers and tomatoes were dip-inoculated with Salmonella Typhimurium and Tennessee, Listeria monocytogenes (3-strain), and Enterococcus faecium. Produce were washed through two triple-wash steps (10 s each) including water dip, antimicrobial dip, and water dip (WAW), or water dip, water dip, and antimicrobial dip (WWA), followed by draining ( $2 \mathrm{~min}$ ) on aluminum foil paper. The WWW process was also included as water-only control. Tested treatments were 1) water, 2) sodium hypochlorite ( $\mathrm{SH} ; 100 \mathrm{ppm}, \mathrm{pH}$ 8.2 or ASH pH-6.8 adjusted by citric acid); 3) lactic and citric acid blend (LCA; 2.5\%); and 4) an $\mathrm{H}_{2} \mathrm{O}_{2}$-peroxyacetic-acid mixer (SaniDate-5.0, SD-0.0064, 0.25 and 0.50\%). Surviving bacteria were recovered on XLT-4 (Salmonella), MOX (L. monocytogenes), and bile esculin agar (E. faecium). Data (2 replicates/4 samples/replicate) were analyzed using the Mixed Model Procedure of SAS $(P=0.05)$. Counts of Salmonella, L. monocytogenes, and E. faecium on unwashed cucumbers and tomatoes were 5.42 to $6.23,6.31$ to 6.92 , and $6.05 \log _{10} \mathrm{CFU} /$ produce, respectively. Triple-wash with water only reduced all three tested bacteria by 0.45 to 1.36 $\log _{10} \mathrm{CFU} /$ fruit. Triple-wash by WWA with antimicrobials achieved additional reductions (LsMeans) of $0.38 \log _{10} \mathrm{CFU} /$ cucumber (Salmonella), $0.56 \log _{10} \mathrm{CFU} /$ cucumber (E. faecium), $1.48 \log _{10}$ CFU/tomato (Salmonella), $1.09 \log _{10}$ CFU/tomato (L. monocytogenes), and 0.71 
$\log _{10} \mathrm{CFU} /$ tomato than the WAW procedure. Applying SD- $0.25 \%$ and SD- $0.50 \%$ solutions in triple-washing cucumbers and tomatoes indicates similar $(P>0.05)$ reductions to ASH and greater $(P<0.05)$ reductions than SH and LCA. E. faecium behaved less susceptible $(P<0.05)$ or no difference $(P>0.05)$ to Salmonella in most cases except for tomatoes in the WWA process. Results of this study indicate that SD could be used as an alternative antimicrobial agent for chlorine water in triple-wash processing at locally small produce plants. Future pilot plant validation studies and cost-effectiveness analysis are needed for applying SD solutions in triplewash by WV locally small produce growers.

Keywords: Postharvest wash, Triple-wash, Antimicrobials, Pathogens, Surrogate, Cucumbers, Tomatoes 


\subsection{Introduction}

Among common foodborne pathogens, Salmonella is the second common cause of foodborne illnesses (Dewey-Mattia et al., 2018). A multi-state outbreak of Salmonella Poona on sliced cucumber from 2015 to 2016 caused more than 900 infected cases, six deaths recorded according to the Center for Disease Control and Prevention (CDC) (CDC, 2019). In 2006, an outbreak across 21 states in the United States caused 183 people ill, of which 22 patients were hospitalized (CDC, 2006). In 2017, Denmark, Finland, Germany, Ireland, and the United Kingdom were affected by the outbreak of Salmonella on cucumbers (EFSA and ECDC, 2018). Another popular fresh produce commodity, tomatoes, has been associated with Salmonella outbreaks as well. Tomatoes were also inked to a recent Salmonella outbreak in Sweden, with 71 identified infections/illnesses (Colombe et al., 2019). In 2015, tomatoes served at Chipotle restaurants in Minnesota were reported to be contaminated with Salmonella (Minnesota Department of Health, 2015).

Listeria monocytogenes is another pathogen of concern reported by the United Fresh Produce Association (UFPA) due to the higher fatality rate of listeriosis (UFPA, 2018). In Iran, the prevalence of Listeria monocytogenes was reported to be $18 \%$ of sampled cucumbers (Hossein et al., 2013). Depending on the area, the prevalence of L. monocytogenes was ranged from $3.78 \%$ (Li et al., 2017b) to $17.5 \%$ (Strawn et al., 2013) on cucumber sampled from the Farmers' market. Although outbreaks caused by L. monocytogenes on tomatoes are uncommon, tomatoes were recognized as a common food crop that susceptible to food pathogens (Honjoh et al., 2016).

The consumption of fresh produce (fresh vegetables and fruits) has increased to 345 pounds (per capita availability) in 2017 (USDA ERS - Food Availability (Per Capita) Data 
System, 2019) In the United Sates; however, there has been increasing concern regarding the microbial safety of farmers' market sold produce (Scheinberg et al., 2017). Fresh produce was accounted for $46 \%$ of foodborne illnesses according to a comprehensive analysis by CDC (Painter et al., 2013). A recent study in West Virginia and Kentucky farmers' markets showed that $18.6 \%$ of spinach, $10.9 \%$ of tomatoes, $18.5 \%$ of peppers, and $56.3 \%$ of cantaloupes were tested positive for Salmonella, and 3.78\% of the produce samples were positive for Listeria spp. (Li et al., 2017b). Fresh produce may be eaten without further processing, therefore, crosscontamination during transportation or handling becomes a serious issue to ensure produce safety. As the demand for locally produced foods has increased nationwide, estimating to achieve the $\$ 20$ billion target by 2019 (USDA, 2015), produce safety becomes a recurring problem especially in regions where raw consumption of fresh produce is common practice.

In 1998, the United States Food and Drug Administration (FDA) published the "Guide to Minimize Microbial Food Safety Hazards for Fresh Fruits and Vegetables" as the main guidelines for Good Agricultural Practices (GAP), which identified that antimicrobial chemicals in processing water may reduce microbial load on the surface of produce (U.S.-FDA, 1998). The West Virginia University (WVU) Extension Service Small Farm Center encourages small produce growers to apply a triple-wash process during their post-harvest processing if their produce is eaten raw or grown on the ground (Strohbehn et al., 2013). Although more evidence suggests washing is more a cross-contamination resource than a pathogen reduction step, the triple-wash process (water rinse, water rinse, and final antimicrobials dip) is still recommended for removing pathogens from food surfaces and improving on-farm food safety with the assumption of clean water being used in each wash step (Strohbehn et al., 2013). The effectiveness of the triple-wash depends critically on the antimicrobial solutions used. Sodium 
hypochlorite (referred to as chlorine water) has been well recognized and used extensively as an effective and low-cost sanitizer during the post-harvest washing process (Shen et al., 2013). The antimicrobial effect of chlorinated water against Salmonella was observed when spraying 200 ppm chlorinated water onto tomato surfaces (Bari et al., 2003). However, chlorinated water has obvious disadvantages including easily being degraded by organic matter and generating chlorine by-products (Shen et al., 2016). Therefore, local produce growers are interested in learning the efficacy of new antimicrobial solutions. For example, Preston County Workshop Inc., a local small produce processor, is currently using SaniDate-5.0 (a mixer of peroxyacetic acid and $\mathrm{H}_{2} \mathrm{O}_{2}$ ) in their triple-wash tanks to control foodborne pathogens of their produce. According to our recent internal survey from locally small produce growers at 2018, West Virginia, Small Farm Conference produce safety training workshop, approximately half of the participants (9/20) currently choose water dip-antimicrobial dip-water dip (WAW) and the other half (10/20) pick water dip-water dip-antimicrobial dip (WWA) procedure. Recently, there is growing recognition that post-harvest washing reduces cross-contamination with no expectation of achieving $\log _{10}$ count reductions of pathogens on produce (Gombas et al, 2017). Therefore, the concentration level to be used and the antimicrobial efficacy of the triple-wash procedures is needed to be investigated.

The efficacy of antimicrobial solutions during triple-wash should be tested in real local small produce commercial settings because the dynamics of processing conditions applied by local produce growers could be less controlled than laboratory conditions. Almost no local small produce plants want to use a real pathogen in their processing lines, instead, they usually apply alternative methods such as ensuring a sufficient active sanitizer within the wash tank. The use of a pathogen surrogate is a possible valid approach and the target surrogate needs to be validated in 
the laboratory conditions first (Hu and Gurtler, 2017). Enterococcus faecium, a Gram-positive chain shape coccus, has been studied in our WVU poultry farm as a safer alternative for Salmonella during steam conditioning, antimicrobial inclusion, standard/thermal aggressive pelleting during broiler feeds manufacture (Boney et al., 2018; Boltz et al., 2019). E. faecium has also been validated as a surrogate for Salmonella in almond pasteurization (Jeong et al., 2011). However, this Salmonella surrogate has not been validated on fresh produce and no publications identified the ideal surrogate for Salmonella during the post-harvest produce washing process. As the outbreaks associated with Salmonella and L. monocytogenes are of concern among fresh produce, a more comprehensive evaluation of the washing procedure should be carried to fulfill the requirement of produce microbial safety. Therefore, the objectives of this study were to evaluate two triple-wash procedures with three commercial antimicrobials to inactivate Salmonella, L. monocytogenes, and the surrogate E. faecium on WV locally grown cucumbers and tomatoes.

\subsection{Materials and Methods}

\subsubsection{Fresh produce sample preparation and background microflora elimination}

Fresh cucumbers and tomatoes were purchased from WV Morgantown Farmers' market and then overnight stored in the refrigerated cooler. Before the experiment, the population of natural microflora on produce surfaces were determined by adding one cucumber or tomato into $200 \mathrm{ml}$ buffered peptone water (BPW) with shaking $30 \mathrm{~s}$ following by spread-plating onto tryptic soy agar after 10 -fold serial dilution and incubated at $35^{\circ} \mathrm{C}$ for $48 \mathrm{~h}$. Results indicated that there were approximately 5-6 $\log _{10} \mathrm{CFU} /$ produce of background microflora on cucumbers and tomatoes surfaces. It was noticed that the microflora on cucumbers interfered with the results of the E. faecium experiment as the selective media used for the E. faecium experiment was not 
selective enough. Therefore, cucumber samples were decontaminated before subjected to $E$. faecium inoculation. To reduce microflora on cucumber in E. faecium experiment, a pre-wash procedure was conducted. Fresh cucumbers were first rinsed with tap water and then submerged in chlorinated solution ( $40 \mathrm{~mL}$ bleach in $2 \mathrm{~L}$ water) for a minute, followed by submerged in boiling water for 5 seconds. This surface disinfection method was verified by showing no colonies on bile esculin agar after shaking cucumbers with $200 \mathrm{ml}$ BPW following by spreadplating. The decontaminated cucumber samples were air-dried in a biosafety cabinet before inoculation.

\subsubsection{Preparation of inoculum}

Salmonella Typhimurium ATCC 14028, Salmonella Tennessee ATCC 10722, L. monocytogenes strains L2624 and L2625 (cantaloupe outbreak serotype 1/2b, donated by Dr. Joshua Gurtler, USDA-ARS, Wyndmoor, PA), and surrogate E. faecium ATCC 8459 were used in this study. Both Salmonella and L. monocytogenes strains were used in the previous related farmers' market produce safety projects (Li et al., 2017b, 2018), and the strain of E. faecium has been studied on poultry meat projects (Lemonakis et al., 2017; Boltz et al., 2019). Salmonella, $L$. monocytogenes, and E. faecium retrieved from frozen stock cultures were streak-plated onto Xylose Lysine Tergitol-4 (XLT-4), Modified Oxford (MOX), and bile esculin (BEA) agar, respectively, and then incubated at $35^{\circ} \mathrm{C}$ for $48 \mathrm{~h}$ to generate single colonies. Before the experiment, a single colony picked from XLT-4 (Salmonella), MOX (L. monocytogenes), and BEA (E. faecium) agar of each strain were enriched in $10 \mathrm{~mL}$ tryptic soy broth (TSB; Alpha Biosciences, Baltimore, MD, USA) at $35^{\circ} \mathrm{C}$ for $24 \mathrm{~h}$. Then, the individual cultured strain was centrifuged $(5,000 \times \mathrm{g})$ for 15 min (VWR Symphony 4417, VWR International, Radnor, PA). Each centrifuged strain was then washed triplicate in $0.1 \% \mathrm{BPW}$ followed by re-suspending in 
$10 \mathrm{ml}$ of $0.1 \%$ BPW. Inoculum of Salmonella and L. monocytogenes were made from the combination of the four-strain cocktail, where two Salmonella strains and two L. monocytogenes strains were combined (Li et al., 2017b; 2018). After a four-strain cocktail was made, the inoculum with approximately $6 \log _{10} \mathrm{CFU} / \mathrm{mL}$ was made by adding the mixed $40 \mathrm{ml}$ of the cocktail into $3 \mathrm{~L}$ 0.1\% BPW solution for the dip inoculation process. The inoculum level of $E$. faecium was $6.5 \log _{10} \mathrm{CFU} / \mathrm{mL}$ by adding $40 \mathrm{ml}$ of triplicate washed strains into $3 \mathrm{~L} 0.1 \% \mathrm{BPW}$ solutions.

\subsubsection{Inoculation of fresh produce samples}

Tomatoes and cucumbers were inoculated by placing the product in a metal bowl containing $3 \mathrm{~L}$ of Salmonella or Listeria inoculum with gentle stirring for $5 \mathrm{~min}$, followed by placement in a biosafety cabinet for 15 mins to allow for the pathogen attachment. According to our preliminary studies, E. faecium was inoculated onto tomato and cucumber samples by pipetting $1 \mathrm{~mL}$ of inoculum onto the samples and fully covering the surface using food-grade plastic wrap for 30 seconds, then air-dried in a biosafety cabinet for 15 mins.

\subsubsection{Triple-wash produce with antimicrobials}

Before the triple-washing process, the Inoculated produce (cucumbers and tomatoes) were tested the surface temperatures using a scan thermometer, and the surface temperatures of both products were $46.76 \pm 0.6^{\circ} \mathrm{F}\left(8.2^{\circ} \mathrm{C}\right)$. Then, inoculated samples were left unwashed (control) or triple washed in three metal containers with 3L of solution each. Each treatment contained 6 samples randomly and evenly split into 2 groups, each sample contains either one tomato or one cucumber. Two triple-wash procedures were applied to the samples, including WAW or WWA. Each step in the triple wash procedure was completed by dipping the samples into the solutions with manual rotation for $10 \mathrm{~s}$ with agitation at $200 \mathrm{rpm}$ (Li et al., 2017). Treatments tested 
include: i) tap water only $\left(\mathrm{pH}=6.9,15.4^{\circ} \mathrm{C}\right)$; ii) sodium hypochlorite (free available chlorine 100 $\pm 0.6 \mathrm{ppm}, \mathrm{pH}=8.2-\mathrm{SH}$, or $\mathrm{pH}=6.8$-adjusted by $10 \%$ citric acid- $\mathrm{ASH}, 14.4^{\circ} \mathrm{C}$; Birko, Henderson, CO, USA, iii) a lactic/citric acid blend (LCA, Veggiexide ${ }^{\circledR}, 2.5 \%, \mathrm{pH}=5.1,15.4^{\circ} \mathrm{C}$, Birko), and iv) a $\mathrm{H}_{2} \mathrm{O}_{2}$-peroxyacetic-acid mixer (SaniDate-5.0, SD, $15.2^{\circ} \mathrm{C}$; Arbico Organics, Tucson, AZ, USA) with the concentrations of $0.0064(\mathrm{pH} 6.25), 0.25(\mathrm{pH} 5.52)$ and $0.50 \%(\mathrm{pH} 3.75)$. Free chlorine concentration was measured using the $\mathrm{N}, \mathrm{N}$ diethyl-1,4 phenylenediamine sulfate method with a chlorine photometer (CP-15, HF Scientific, Inc., Ft. Myers, FL). Temperatures of all wash solutions were ranged from 57.92 to $59.72^{\circ} \mathrm{F}\left(14.4\right.$ to $\left.15.4^{\circ} \mathrm{C}\right)$, which meets the U.S. FDA advisory that wash water needs to be $10^{\circ} \mathrm{F}$ higher than the produces $\left(46.76^{\circ} \mathrm{F}\right)$ being washed (U.S.-FDA, 2018). After triple-wash procedures, samples were drained and dried on aluminum foil paper for $2 \mathrm{~min}$.

\subsubsection{Microbiological analysis}

Each unwashed and washed produce sample was placed into a sterile sample bag (Nasco, Fort Atkinson, WI, USA) and rinsed in $200 \mathrm{ml}$ of BPW, followed by vigorously shaking for $60 \mathrm{~s}$ to detach microorganisms from the surface. Sample rinse solutions were then 10-fold or 100-fold serially diluted in $0.1 \%$ BPW and then spread-plated (adding $0.1 \mathrm{ml}$ onto 1 plate or $1.0 \mathrm{ml}$ equally split onto 3 plates) on XLT-4, MOX, and BEA agar to enumerate Salmonella, $L$. monocytogenes, and E. faecium cells, respectively. All agar plates were then incubated at $35^{\circ} \mathrm{C}$ for $24 \mathrm{~h}$ (XLT-4) or $48 \mathrm{~h}$ (MOX and BEA) and were manually counted for colony-formingunites (CFU) after the incubation period. Three different dilutions were used for the spreadplating of each sample including " 0 " dilution by adding $1 \mathrm{ml}$ of $200 \mathrm{ml}$ BPW diluent equally split onto 3 agar plates $(0.33 \mathrm{ml}$ each). Colonies from each of the three plates were added together after incubation, therefore the detection limit is $2.3 \log _{10} \mathrm{CFU} /$ fruit $\left(=\log _{10} 200\right.$ 
CFU/fruit). The presumptive positive colonies were confirmed by using an Oxoid latex agglutination test kit (Oxoid Ltd, Basingstoke, Hampshire, UK).

\subsubsection{Data analysis}

The triple-wash studies were duplicated with 4 cucumbers and 4 tomatoes per treatment per repeat with a total of 8 samples per treatment for each bacterium. The experimental design is a randomized $2 \times 6$ factorial design with 2 triple-wash procedures (WAW or WWA) and 6 antimicrobial treatments. The survival and reduction of Salmonella, L. monocytogenes, and E. faecium was analyzed using the mixed model procedure of SAS (version 9.2, SAS Institute, Cary, NC), including individual factors of triple-wash procedures, antimicrobial treatments, and their interactions. The comparison of reductions between Salmonella and the surrogate $E$. faecium was also analyzed using the mixed model procedure. The reduction data were determined by a reduction ratio of $\log _{10}\left(\mathrm{~N}_{0} / \mathrm{N}\right)$, which includes $\mathrm{N}_{0}$, the average control plate counts, and N, the plate count of each antimicrobial treated sample (Adler et al., 2016). The means were determined by Tukey HSD at an $\alpha=0.05$ significance level.

\subsection{Results and Discussion}

\subsubsection{Comparison of WAW and WWA procedures}

In general, the least-squares mean (LsMean) values across the 6 tested antimicrobial treatments (water only wash were not included) indicate that triple-wash with WWA procedure is more effective $(P<0.05)$ than WAW in reducing Salmonella $\left(2.39\right.$ vs $2.01 \log _{10}$ $\mathrm{CFU} /$ cucumber) and E. faecium (2.16 vs $1.60 \log _{10} \mathrm{CFU} /$ cucumber) on cucumbers, and reducing Salmonella (2.82 vs $1.34 \log _{10}$ CFU/tomato), L. monocytogenes (2.35 vs $1.26 \log _{10}$ CFU/tomato), and E. faecium ( 2.81 vs $2.10 \log _{10}$ CFU/tomato) on tomatoes. Although there is a statistical difference between WWA and WAW process, the $\log _{10}$ reductions of the difference are ranged 
from 0.38 to $1.44 \log _{10} \mathrm{CFU} /$ fruit, which is still relatively low. Applying WWA or WAW procedures on cucumbers showed no difference in reductions (1.39 vs $1.35 \log _{10}$ CFU/cucumber) for L. monocytogenes.

\subsubsection{Efficacy of triple-wash with antimicrobials against Salmonella}

Survivals and reductions of Salmonella on cucumbers are shown in Table 3.1. All 6 antimicrobial treatments were more effective $(P<0.05)$ in reducing Salmonella than the wateronly wash (1.26 to $1.36 \log _{10} \mathrm{CFU} /$ cucumber, Table 3.1). Compared to SH, ASH increased reductions of the pathogen by $0.41(P<0.05$, WAW $)$ and $0.32 \log _{10}$ CFU/cucumber $(P=0.06$, WWA). As expected, antimicrobials applied in the WAW procedure for cucumbers significantly $(P<0.05)$ reduced the Salmonella population (survivals of 3.36 to $4.17 \log _{10} \mathrm{CFU} /$ cucumber) than the untreated control $\left(5.80 \log _{10} \mathrm{CFU} /\right.$ cucumber $)$, with the reductions ranging from 1.63 (SD-0.0064\%) to 2.44 (SD-0.50\%) $\log _{10}$ CFU/cucumber (Table 3.1). Compared to the WAW, $\mathrm{SH}, \mathrm{SD}-0.0064 \%$, and SD-0.25\% applied in the WWA process achieved an additional $(P<0.05)$ reduction of Salmonella by 0.4 to $0.5 \log _{10}$ CFU/cucumber (Table 3.1). However, no significant $(P>0.05)$ difference of reductions between WAW and WWA in ASH, LCA, and SD-0.50\% washed samples (Table 3.1). Compared to SH and LCA, adding SD $(0.0064,0.25,0.50 \%)$ into triple-wash process showed similar or greater $(P<0.05)$ reductions $\left(1.63-2.44\right.$ vs $1.82-2.00 \log _{10}$ CFU/cucumber for WAW; 2.09-2.66 vs 2.14-2.43 $\log _{10}$ CFU/cucumber for WWA, Table 3.1). Compared to ASH, SD-0.25\% and SD-0.50\% showed similar $(P>0.05)$ reductions ranging from 2.18 to $2.44 \log _{10}$ CFU/cucumber (WAW) and 2.43 to $2.75 \log _{10}$ CFU/cucumber (WWA).

As shown in Table 3.2, triple-washing tomatoes in antimicrobials by WAW process significantly $(P<0.05)$ reduced Salmonella with the survival populations ranging from 3.72 to $4.80 \log _{10} \mathrm{CFU} /$ tomato compared to $5.70 \log _{10} \mathrm{CFU} /$ tomato (unwashed control). All 6 tested 
antimicrobials were more effective $(P<0.05)$ for reducing the pathogen than the water only wash, except for LCA. Again, ASH achieved additional $(P<0.05)$ reduction of $0.66 \log _{10}$ CFU/tomato than SH washed samples. SD- $0.25 \%$ and $-0.50 \%$ treated samples showed similar $(P$ $>0.05$ ) reductions (1.63 to $1.98 \log _{10} \mathrm{CFU} /$ tomato) compared to $\mathrm{ASH}$ (1.98 $\log _{10} \mathrm{CFU} /$ tomato), and greater $(P<0.05)$ reductions than $\mathrm{SH}\left(1.32 \log _{10} \mathrm{CFU} /\right.$ tomato $)$ and LCA $\left(0.90 \log _{10}\right.$ CFU/tomato). The reduction of SD-0.0064\% is similar $(P>0.05)$ to $\mathrm{SH}$ and LCA, but less $(P<0.05)$ than ASH. Compared to the WAW, applying WWA process increased $(P<0.05)$ the reduction levels from 1.32 to $3.14,1.98$ to $3.30,0.90$ to $3.28,1.13$ to $1.72,1.98$ to 3.35 , and 1.63 to $3.26 \log _{10} \mathrm{CFU} /$ tomato for $\mathrm{SH}, \mathrm{ASH}, \mathrm{LCA}, \mathrm{SD}-0.0064 \%$, SD-0.25\%, and SD-0.50\%, respectively (Table 3.2).

\subsubsection{Efficacy of triple-wash with antimicrobials against $L$. monocytogenes}

Survivals and reductions of L. monocytogenes on cucumbers and tomatoes are shown in Tables 3 and 4, respectively. As shown in Table 3.3, triple-washing cucumbers in 6 antimicrobials by WAW process significantly $(P<0.05)$ reduced $L$. monocytogenes with the survival populations ranging from 4.44 to $5.55 \log _{10} \mathrm{CFU} /$ cucumber compared to the $6.31 \log _{10}$ CFU/cucumber of the control (Table 3.3). For the WAW process, reductions of SH, ASH, LCA, SD- $0.25 \%$, and SD-50\% are greater than the water control (0.59 $\log _{10}$ CFU/cucumber) except for SD-0.0064\% showing a similar reduction (0.76 $\log _{10} \mathrm{CFU} /$ cucumber). Among the tested antimicrobial treatments, no difference $(P>0.05)$ was found between the reductions $(1.56$ to $1.87 \log _{10} \mathrm{CFU} /$ cucumber) caused by SH, ASH, SD-0.25\%, and SD-0.50\%, which are greater $(P$ $<0.05)$ than LCA (1.23 $\log _{10} \mathrm{CFU} /$ cucumber) and SD-0.0064\% (0.76 $\log _{10} \mathrm{CFU} /$ cucumber) treatments. Applying WWA process increased $(P<0.05)$ reductions from 1.64 to $2.25,1.87$ to 2.41, and 0.76 to $1.30 \log _{10} \mathrm{CFU} /$ cucumber for $\mathrm{SH}, \mathrm{ASH}$, and SD-0.0064\% washed samples, 
respectively (Table 3.3). However, the WWA process did not increase reductions of the pathogen on cucumbers washed in LCA, SD- $0.25 \%$ and SD- $0.50 \%$ as compared to the WAW process (Table 3.3).

The efficacy of antimicrobials to inactivate L. monocytogenes on tomatoes has not been widely studied. As shown in Table 3.4, significantly lower survivals (4.42-5.46 $\log _{10}$ CFU/tomato) were observed on tomatoes washed in 6 antimicrobials using the WAW process than the untreated control (6.39 $\left.\log _{10} \mathrm{CFU} / \mathrm{g}\right)$ and water wash control $\left(5.96 \log _{10} \mathrm{CFU} / \mathrm{g}\right)$. SD$0.25 \%$ and SD- $0.50 \%$ reduced the pathogen counts by 1.51 to $1.72 \log _{10}$ CFU/tomato, which were slightly $(P>0.05)$ lower than ASH $\left(1.97 \log _{10}\right.$ CFU/tomato $)$ and greater $(P<0.05)$ than the reductions of $\mathrm{SH}$ (0.93 $\log _{10} \mathrm{CFU} /$ tomato), LCA (1.18 $\log _{10} \mathrm{CFU} /$ tomato), and SD-0.0064\% (0.94 $\log _{10} \mathrm{CFU} /$ tomato, Table 3.4). Compared to the WAW process, applying WWA procedures $(P<0.05)$ increased reductions of all 6 tested antimicrobial treatments by 0.49 to $1.40 \log _{10}$ CFU/tomato (Table 3.4).

\subsubsection{Comparison of Salmonella verse Surrogate E. faecium}

The response of surrogate E. faecium to antimicrobials on cucumbers and tomatoes is shown in Tables 3.5 and 3.6, respectively. Triple-wash with only water reduced $(P<0.05)$ the surrogate by $0.56 \log _{10} \mathrm{CFU} /$ cucumber and $0.45 \log _{10} \mathrm{CFU} /$ tomato compared to the unwashed control. ASH showed greater $(P<0.05)$ and similar $(P \geq 0.05)$ reductions than $\mathrm{SH}$ for cucumbers and tomatoes, respectively. For the WAW process, reductions obtained after washing in SH, ASH, LCA, SD-0.0064\%, SD-0.25\%, and SD-0.50\% ranged from 0.80 to $2.27 \log _{10}$ CFU/cucumber (Table 3.5) and from 1.34 to $2.90 \log _{10}$ CFU/tomatoes (Table 3.6). Like Salmonella, the application of the WWA process with 6 tested antimicrobials resulted in additional $(P<0.05)$ reductions of 0.25 to $0.83 \log _{10} \mathrm{CFU} /$ cucumber and 0.49 to $1.22 \log _{10}$ 
CFU/tomato, respectively, compared to the WAW process. For cucumbers, the application of SD- $0.0064 \%,-0.25 \%$ and $-0.50 \%$ solutions showed similar $(P>0.05)$ reductions $(1.82-2.27$ $\log _{10} \mathrm{CFU} /$ cucumber for WAW, 2.48-2.96 $\log _{10} \mathrm{CFU} /$ cucumber for WWA) compared to ASH (2.08 $\log _{10} \mathrm{CFU} /$ cucumber for WAW, $2.39 \log _{10} \mathrm{CFU} /$ cucumber for WWA $)$, but better $(P<$ $0.05)$ reductions than $\mathrm{SH}$ and LCA treatments in both WAW (0.80-0.92 $\log _{10} \mathrm{CFU} /$ cucumber) and WWA (1.05-1.63 $\log _{10} \mathrm{CFU} /$ cucumber) process (Table 3.5). For tomatoes, SD-0.25\% and $0.50 \%$ indicated greater $(P<0.05)$ reductions $\left(2.48-2.90 \log _{10}\right.$ CFU/tomato $)$ than $\mathrm{SH}\left(1.88 \log _{10}\right.$ CFU/tomato), ASH (1.37 $\log _{10} \mathrm{CFU} /$ tomato), and LCA (1.34 $\log _{10} \mathrm{CFU} /$ tomato) treated samples using WAW process. Applying the WWA process, SD- $0.50 \%$ was the most effective $(P<0.05)$ in reducing the pathogen surrogate from tomatoes (3.53 $\log _{10}$ CFU/tomato, Table 3.6) followed by $\mathrm{SD}-0.25 \%, \mathrm{SH}, \mathrm{LCA}$, and $\mathrm{ASH}$, which showed similar reductions of 2.50 to $2.97 \log _{10}$ CFU/tomato.

In this study, the mixed model procedure was applied to compare the reductions of Salmonella verse the surrogate E. faecium as shown in Tables 7 (cucumbers) and 8 (tomatoes). For cucumbers, the reductions of E. faecium after the application of WAW or WWA process with the 6 tested antimicrobial treatments were less (LsMeans 1.60 vs $2.01 \log _{10}$ CFU/cucumber for WAW, $P<0.05$ ) or not different (LsMeans 2.16 vs $2.39 \log _{10}$ CFU/cucumber for WWA, $P>$ 0.05) than Salmonella. Specifically, application of SH, ASH, and LCA indicated lower $(P<$ 0.05) reductions, which ranged from 0.80 to $2.08 \log _{10} \mathrm{CFU} /$ cucumber (WAW) and 1.05 to 2.39 $\log _{10} \mathrm{CFU} /$ cucumber (WWA) for E. faecium compared to Salmonella reduced by WAW (1.82 to $2.41 \log _{10} \mathrm{CFU} /$ cucumber) and WWA (2.14 to $2.75 \log _{10} \mathrm{CFU} /$ cucumber) process (Table 3.7). SD- $0.25 \%$ and SD-50\% reduced E. faecium by 1.82 to $2.27 \log _{10}$ CFU/cucumber (WAW) and 
2.65 to $2.96 \log _{10} \mathrm{CFU} / \mathrm{cucumber}(\mathrm{WWA})$, which were similar $(P>0.05)$ to the reductions of Salmonella (Table 3.7).

For tomatoes, the reductions for E. faecium from WAW with antimicrobials were greater $(P<0.05)$ than the Salmonella results (LsMeans 2.10 vs $1.39 \log _{10}$ CFU/tomato), but they were the same $(P>0.05)$ to the reductions of Salmonella in WWA processed samples (LsMeans 2.80 vs $2.81 \log _{10} \mathrm{CFU} /$ tomato). Specifically, E. faecium on tomatoes washed through WWA with SD- $0.0064 \%, 0.25 \%$, and $0.50 \%$ behaved no significant difference $(P>0.05)$ to Salmonella with reductions of 2.19 to $3.53 \log _{10} \mathrm{CFU} /$ tomato (E. faecium) compared to the reductions of 1.72 to $3.35 \log _{10}$ CFU/tomato (Salmonella) (Table 3.8).

\subsubsection{Discussion}

Results from this study suggest that apply WWA produce during triple-wash is a better approach than WAW in reducing foodborne pathogens. This conclusion could be possibly explained by the that the residual sanitizers after the WWA process further inactivate pathogens on the product samples since the neutralization step was absent from this study. benefits the final antimicrobial wash. The WWW control showed reductions of 0.5 to $1.2 \log _{10} \mathrm{CFU} /$ fruit across all tested pathogens on cucumbers and tomatoes in this study, which are similar to Wang and Ryser (2014) reporting that $1.0 \log _{10} \mathrm{CFU} / \mathrm{g}$ reduction of Salmonella yielded by water wash for $15 \mathrm{~s}$ in a pilot-scale processing line.

As the physiochemical properties of cucumbers and tomatoes' surface are greatly different, it is plausible that the same sanitizer may not result in the same level of antimicrobial effect. Our results suggest it is critical to consider the types of fresh produce when choosing the sanitizer to reduce the foodborne pathogens, as the antimicrobial effect of one sanitizer may 
vary. Plus, the amount of organic matter such as dust, soil, and debris of produce surfaces could impact the washing process.

Chlorine is a common sanitizer used in fresh produce due to the economic feasibility and strong antimicrobial ability (Shen et al., 2013). When chlorinated water is used as a sanitizer in fresh produce, the maximum concentration regulated by U.S.-FDA is 200 ppm. However, even $100 \mathrm{ppm}$ chlorinated water demonstrates strong antimicrobial activity. An earlier study reported that tomatoed dipped in $100 \mathrm{ppm}$ chlorinated water for $30 \mathrm{~s}$ showed significant reduction against Salmonella, and the level of reduction was not different between $30 \mathrm{~s}, 1 \mathrm{~min}$, or $2 \mathrm{~min}$ (Wei et al., 1995). A recent study by Sreedharan et al. (2017) showed that $100 \mathrm{ppm}$ of free chlorine reduced Salmonella by $>4.5 \log _{10} \mathrm{CFU} /$ tomato in a model flume water for $30 \mathrm{~s}$. It suggested that a longer treatment time of chlorinated water was not necessary on fresh produce against Salmonella, which is beneficial in a real production pipeline. When immersing tomatoes into 200 ppm chlorinated water, its activity was significantly higher than 1 or 2 ppm ozonated water on Salmonella under different levels of turbidity of the water (Chaidez et al., 2007). Currently, there are no small produce growers (contacted with 8 local growers in WV) that acidified $\mathrm{pH}$ of chlorine water before triple-washing their produce in WV (personal communication with Dr. Tom McConnell, Program Leader of the WV Small Farm Center). However, during the large industry scale produce washing process, adjusting the $\mathrm{pH}$ of chlorine solutions to 6.8 with citric acid is recognized to ensure the protonated form of hypochlorite predominates in the wash solution (Luo et al., 2012). Therefore, chlorine solution with near-neutral $\mathrm{pH}$ at 6.8 adjusted by citric acid was included as a test treatment in this study. Results of this study suggest that the antimicrobial efficacy of chlorinated water in the concentration of $100 \mathrm{ppm}$ was significant against Salmonella, and the reductions were improved when the $\mathrm{pH}$ of $\mathrm{SH}$ was adjusted to 6.8 in 
most cases in this study except for E. faecium on tomatoes. A previous study by Wang and Ryser (2014) also reported that chlorine plus citric acid ( $\mathrm{pH}$ 6.0) yielding a greater reduction $\left(3.1 \log _{10}\right.$ $\mathrm{CFU} / \mathrm{g}$ ) for Salmonella on tomatoes than chlorine at alkaline status $\left(2.1 \log _{10} \mathrm{CFU} / \mathrm{g}\right)$. This is because hypochlorous acid, the most effective antimicrobial component, predominates in chlorine water at near-neutral $\mathrm{pH}$, whereas the hypochlorite would be in the ionic form rather than the antimicrobial protonated state at alkali pH solution (White, 2010). The antimicrobial effect of SH- or ASH-100 ppm can also be maximized when the WWA triple wash procedure was used on cucumbers and tomatoes, as the reduction of Salmonella was significantly higher in WWA than WAW process.

The antimicrobial activity of chlorinated water is not limited to Salmonella. L. monocytogenes., another common food pathogen, was also sensitive to chlorinated water treatment on the surface of fresh produce. On cucumbers, 1 min and 2 min of $200 \mathrm{ppm}$ chlorinated water bath demonstrated the same level of Salmonella reduction (Yuk et al., 2006). Spraying 200 ppm chlorinated water on tomatoes significantly reduces L. monocytogenes on tomatoes (Beuchat et al., 1998; Bari et al., 2003). Surprisingly, although L. monocytogenes outbreak was reported on cucumber before (Meldrum et al., 2009; Ponniah et al., 2012; Hossein et al., 2013), the antimicrobial effect of chlorine water against L. monocytogenes is relatively lacking in the current literature. Considering the easy accessibility of chlorinated water, chlorinated water without or with neutralizing $\mathrm{pH}$ was included in this study to better contribute to the current database of antimicrobial effect against L. monocytogenes on cucumbers (Table 3.3). Our results suggest that $100 \mathrm{ppm}$ chlorinated water $(\mathrm{SH})$ is an effective antimicrobial against L. monocytogenes on cucumbers, and neutralizing $\mathrm{pH}$ to 6.8 by citric acid and the WWA procedure maximizes the antimicrobial effect of chlorinated water as the significant higher 
reduction was observed. On tomatoes, although $\mathrm{SH}-100 \mathrm{ppm}$ is still an effective sanitizer (Table 3.4), the antimicrobial efficacy of SH against L. monocytogenes was significantly increased when the $\mathrm{pH}$ was adjusted to 6.8 (ASH), which is similar to SD-0.25 and SD-0.50\% and greater than SD-0.0064\% and LCA.

Recently, there is a growing interest for produce processors to apply other antimicrobial chemicals for replacing chlorinated water since chlorine water easily reacts with water constituents and generates chlorine byproducts after repeated replenish with new chlorine solutions (López-Gálvez et al., 2012; Shen et al., 2016). Local small produce growers in WV are also losing interest in chlorine use due to the concern of natural and organic processes of fresh produce (personal communication with Dr. Tom McConnell, Program Leader of the WV Small Farm Center). LCA, a buffered mixture of the lactic and citric acid solution, was introduced by the food chemical industry about a decade ago and reported to effectively reduce Salmonella on poultry carcasses and avoid discoloration of chicken meat caused by lactic acid solution (Laury et al., 2009). The only study of LCA on produce demonstrated that spraying $2.5 \%$ LCA onto Jalapeno peppers through commercial cabinet reduced the natural flora, Salmonella, and the surrogate generic Escherichia coli by $1.3,1.1$, and $0.8 \log _{10} \mathrm{CFU} / \mathrm{g}$, respectively (Adler et al., 2016). The mechanism of LCA to inhibit bacteria survival is the combined effect of lactic and citric acid. Lactic acid decreases the ionic concentration within the bacterial cell membrane of its exterior cell wall and citric acid can diffuse through the cell membrane and penetrate the weak non-dissociated acid. The combination of both acids leads to an accumulation of the acid within the cell cytoplasm, acidification of the cytoplasm, disruption of the proton motive force, and inhibition of substrate transport (Vasseur et al., 1999). Results showed that similar reductions $\left(<0.5 \log _{10} \mathrm{CFU} / \mathrm{g}\right)$ were achieved by LCA compared to the SH for against Salmonella, L. 
monocytogenes, and the surrogate E. faecium for most tests in this study. However, LCA was less effective than ASH for inactivating Salmonella on tomatoes and E. faecium on cucumbers.

SaniDate-5.0 is a mixed antimicrobial solution composed of $23 \% \mathrm{H}_{2} \mathrm{O}_{2}, 5.3 \%$ peroxyacetic acid (PAA), and 70\% unknown ingredients (likely water), which has been recommended by the WV Small Farm Center to wash fresh produce processed from local small farms (Li et al., 2017b) since the major wholesale buyer in WV Appalachian Harvest require the use of SaniDate-5.0 as part of the post-harvest protocol for growers selling to their business especially for an organic farming process (personal communication with Dr. Tom McConnell, Program Leader of the WV Small Farm Center). Like other oxidizing chemicals, SaniDate-5.0 oxidizes bacterial cells, denatures protein, and further disrupts cell wall structure to kill or inhibit bacteria (Block, 2011). A previous study by Brinez et al. (2006) reported that the mixer of $\mathrm{H}_{2} \mathrm{O}_{2}$ and PAA reduced non-pathogenic strains of Staphylococcus, Listeria spp. and E. coli by more than $5 \log _{10} \mathrm{CFU} / \mathrm{ml}$ after 10 -min contact even with the organic matter present in solutions (Briñez et al., 2006). Results of this study suggested similar $(P>0.05)$ reductions of Salmonella, L. monocytogenes, and E. faecium on cucumbers and tomatoes achieved by SD- $0.25 \%$ and SD$50 \%$ as compared to ASH, which was greater $(P<0.05)$ than the reductions of SH and LCA solutions. The market price of a 5-gallon pallet is $\$ 330$ for SaniDate-5.0 compared to $\$ 12$ for SH and $\$ 108.5$ for LCA, therefore agricultural economic cost-effectiveness analysis is needed to verify that SaniDate-5.0 is economically feasible for locally small produce growers as an alternative antimicrobial solution to chlorine water.

E. faecium has been previously studied and validated as a potential Salmonella surrogate in almonds (Jeong et al., 2011), a balanced carbohydrate protein meal (Bianchini et al., 2014), and pet foods (Ceylan and Bautista, 2015) during the thermal activation process. Our recent 
study also confirmed that E. faecium could be a nonpathogenic surrogate of Salmonella for inplant antimicrobial validation studies on broiler carcasses (Lemonakis et al., 2017). To evaluate the suitability of choosing surrogate microorganisms for foodborne pathogens when exposed to antimicrobials, the surrogate needs to be behaved equally well or better (resistant to interventions) than the target pathogen in challenge studies (Adler et al., 2016). Therefore, sideby-side comparisons of reduced levels of Salmonella and E. faecium after a triple wash through WAW or WWA with antimicrobials on cucumbers and tomatoes were presented in Tables 7 and 8. Results indicate that the E. faecium strain used in this study could potentially be a surrogate of Salmonella for validating triple-wash with commercial antimicrobials on cucumbers in locally small produce processing settings, however, more studies are still needed to confirm its use on tomatoes as a Salmonella surrogate since opposite results generated from WAW verse WWA process. Other nonpathogenic bacteria such as generic Escherichia coli (ATCC BAA-1427, ATCC BAA-1428, ATCC BAA-1429, ATCC BAA-1430, and ATCC BAA-1431) could be surrogates for Salmonella on different produce commodities including tomatoes (Adler et al., 2016). Because our previous pilot plant trial study showed that spraying $50 \mathrm{ppm} \mathrm{SH}$ or $1.0 \%$ LCA reduced the generic E. coli on jalapeno peppers by 0.8 to $1.0 \log _{10} \mathrm{CFU} / \mathrm{g}$ and were not different from the reductions (0.5 to $1.1 \log _{10} \mathrm{CFU} / \mathrm{g}$ ) of Salmonella (Adler et al., 2016).

\subsection{Conclusions}

Under the condition of this study, the triple-wash WWA procedure is better than the WAW to inactivate Salmonella, L. monocytogenes, and E. faecium on cucumbers and tomatoes. SaniDate-5.0 at the concentration of $0.25 \%$ and $0.50 \%$ indicates similar or better antimicrobial efficacy than chlorine water without or with $\mathrm{pH}$ adjustment. E. faecium could be a potential Salmonella surrogate used for validation studies of antimicrobial treatments during the post- 
harvest washing process on produce. Results from this study provide important information for local small produce growers who are interested to adopt the triple-wash during postharvest processing. Future studies are needed to validate the same procedure in commercial pilot plant settings and cost-effectiveness is necessary to evaluate whether SaniDate-5.0 is economically feasible for locally small produce processors.

\section{Limitations of this study}

The authors are recognizing the following limitations of this study. First, this extension validation study is valuable for locally very small produce growers in $\mathrm{WV}$, which is not representing/stimulating large industry commercial-scale produce processing. Second, the extent of cross-contamination in the different wash regimes of the triple-wash process was not reported in this study. It is well established that preventing cross-contamination is more critical than the reduction of pathogens during the produce washing process (Gombas et al, 2017). The crosscontamination study of triple-wash in three washing tanks with or without antimicrobials should be included in our future related studies. Third, the cucumbers tested for E. faecium were pretreated to remove background microorganisms, which may not be well representing the cucumbers' surface characteristics. An antibiotic marker should be introduced into E. faecium to solve this issue in our future related studies. Fourth, the absence of a neutralization step from the WWA process may further reduce the pathogens by the residual sanitizer on produce samples. We realize that D/E neutralizing broth with a more general neutralizing effect should be included in our studies. 


\section{Acknowledgment}

This research was funded by the United States Department of Agriculture, the National Institute of Food and Agriculture, the AFRI-Critical Agricultural Research and Extension (CARE) (Grant \# 2019-68008-29828). 


\section{References}

Adler, J. M., Cain-Helfrich, E. D., and Shen, C. (2016). Reductions in Natural Microbial Flora, Nonpathogenic Escherichia coli, and Pathogenic Salmonella on Jalapeno Peppers Processed in a Commercial Antimicrobial Cabinet: A Pilot Plant Trial. Journal of Food Protection 79, 1854-1859. doi:10.4315/0362-028X.JFP-16-222.

Bari, M. L., Sabina, Y., Isobe, S., Uemura, T., and Isshiki, K. (2003). Effectiveness of Electrolyzed Acidic Water in Killing Escherichia coli O157:H7, Salmonella Enteritidis, and Listeria monocytogenes on the Surfaces of Tomatoes. Journal of Food Protection 66, 542-548. doi:10.4315/0362-028X-66.4.542.

Beuchat, L. R., Nail, B. V., Adler, B. B., and Clavero, M. R. S. (1998). Efficacy of Spray Application of Chlorinated Water in Killing Pathogenic Bacteria on Raw Apples, Tomatoes, and Lettuce. Journal of Food Protection 61, 1305-1311. doi:10.4315/0362028X-61.10.1305.

Bianchini, A., Stratton, J., Weier, S., Hartter, T., Plattner, B., Rokey, G., et al. (2014). Use of Enterococcus faecium as a Surrogate for Salmonella enterica during Extrusion of a Balanced Carbohydrate-Protein Meal. Journal of Food Protection 77, 75-82. doi:10.4315/0362-028X.JFP-13-220.

Block, S. S. (2011). Disinfection, Sterilization, and Preservation. Lippincott Williams \& Wilkins.

Boltz, T. P., Boney, J. W., Shen, C., Jaczynski, J., and Moritz, J. S. (2019). The Effect of Standard Pelleting and More Thermally Aggressive Pelleting Utilizing a Hygieniser on Feed Manufacture and Reduction of Enterococcus faecium, a Salmonella Surrogate. $J$ Appl Poult Res 28, 1226-1233. doi:10.3382/japr/pfz088. 
Boney, J. W., Jaczynski, J., Weidhaas, J. L., Bergeron, A. N., and Moritz, J. S. (2018). The effects of steam conditioning and antimicrobial inclusion on feed manufacturing and inactivation of Enterococcus faecium, a Salmonella surrogate. J Appl Poult Res 27, 472482. doi:10.3382/japr/pfy052.

Briñez, W. J., Roig-Sagués, A. X., Hernández Herrero, M. M., López-Pedemonte, T., and Guamis, B. (2006). Bactericidal efficacy of peracetic acid in combination with hydrogen peroxide against pathogenic and non pathogenic strains of Staphylococcus spp., Listeria spp. and Escherichia coli. Food Control 17, 516-521.

doi:10.1016/j.foodcont.2005.02.014.

CDC (2006). Salmonella Typhimurium Infections Linked to Tomatoes - Salmonella. Centers for Disease Control and Prevention. Available at: https://www.cdc.gov/salmonella/2006/tomatoes-11-2006.html [Accessed December 11, 2019].

CDC (2019). Multistate Outbreak of Salmonella Poona Infections Linked to Imported Cucumbers (Final Update) | Multistate Outbreak of Salmonella Poona Infections Linked to Imported Cucumbers | September 2015 | Salmonella | CDC. Centers for Disease Control and Prevention. Available at: https://www.cdc.gov/salmonella/poona-0915/index.html [Accessed December 11, 2019].

Ceylan, E., and Bautista, D. A. (2015). Evaluating Pediococcus acidilactici and Enterococcus faecium NRRL B-2354 as Thermal Surrogate Microorganisms for Salmonella for InPlant Validation Studies of Low-Moisture Pet Food Products. Journal of food protection 78, 934-939. doi:10.4315/0362-028X.JFP-14-271. 
Colombe, S., Jernberg, C., Löf, E., Angervall, A. L., Mellström-Dahlgren, H., Dotevall, L., ... Rehn, M. (2019). Outbreak of unusual $\mathrm{H}_{2} \mathrm{~S}$-negative monophasic Salmonella Typhimurium strain likely associated with small tomatoes, Sweden, August to October 2019. Euro surveillance, 24, 1900643. doi:10.2807/1560-7917.ES.2019.24.47.1900643

Dewey-Mattia, D., Manikonda, K., Hall, A.J., Wise, M.E., and Crowe, S.J. (2018). Surveillance for Foodborne Disease Outbreaks — United States, 2009-2015.

EFSA (European Food Safety Authority) and ECDC (European Centre for Disease Prevention and Control). (2018). Multi-country outbreak of Salmonella Agona infections possibly linked to ready-to-eat food. EFSA supporting publication 2018: 15, EN-1465. 15 pp. doi: $10.2903 /$ sp.efsa.2018.EN-1465

Gombas, D., Luo, Y., Brennan, J., Shergill, G., Petran, R., Walsh, R., Hau, H., Khurana, K., Zomorodi, B., Rosen, J., Varley, R., and Deng, K. (2017). Guidelines to validate control of cross-contamination during washing of fresh-cut leafy vegetables. Journal of Food Protection 80, 312-330. doi:10.4315/0362-028X.JFP-16-258.

Ho, J. L., Shands, K. N., Friedland, G., Eckind, P., and Fraser, D. W. (1986). An Outbreak of Type 4b Listeria monocytogenes Infection Involving Patients From Eight Boston Hospitals. Arch Intern Med 146, 520-524. doi:10.1001/archinte.1986.00360150134016.

Honjoh, K., Iwaizako, Y., Lin, Y., Kijima, N., and Miyamoto, T. (2016). Possibilities for Contamination of Tomato Fruit by Listeria monocytogenes during Cultivation. Food Science and Technology Research 22, 349-357. doi:10.3136/fstr.22.349.

Hossein, J., Mohammadjavad, P., Chung, Y. L., and Won, F. W. (2013). Prevalence of Listeria species and Listeria monocytogenes serotypes in ready mayonnaise salads and salad vegetables in Iran. Afr. J. Microbiol. Res. 7, 1903-1906. doi:10.5897/AJMR2013.5658. 
Hu, M., and Gurtler, J. B. (2017). Selection of Surrogate Bacteria for Use in Food Safety

Challenge Studies: A Review. Journal of Food Protection 80, 1506-1536. doi:10.4315/0362-028X.JFP-16-536.

Jeong, S., Marks, B. P., and Ryser, E. T. (2011). Quantifying the Performance of Pediococcus sp. (NRRL B-2354: Enterococcus faecium) as a Nonpathogenic Surrogate for Salmonella Enteritidis PT30 during Moist-Air Convection Heating of Almonds. Journal of Food Protection 74, 603-609. doi:10.4315/0362-028X.JFP-10-416.

Laury, A. M., Alvarado, M. V., Nace, G., Alvarado, C. Z., Brooks, J. C., Echeverry, A., et al. (2009). Validation of a Lactic Acid- and Citric Acid-Based Antimicrobial Product for the Reduction of Escherichia coli O157:H7 and Salmonella on Beef Tips and Whole Chicken Carcasses. Journal of Food Protection 72, 2208-2211. doi:10.4315/0362-028X72.10 .2208 .

Lemonakis, L., Li, K., Adler, J. M., and Shen, C. (2017). Microbiological quality assessment and validation of antimicrobials against unstressed or cold-stress adapted Salmonella and surrogate Enterococcus faecium on broiler carcasses and wings. Poult Sci 96, 4038-4045. doi:10.3382/ps/pex195.

Li, K., Khouryieh, H., Jones, L., Etienne, X., and Shen, C. (2018). Assessing farmers market produce vendors' handling of containers and evaluation of the survival of Salmonella and Listeria monocytogenes on plastic, pressed-card, and wood container surfaces at refrigerated and room temperature. Food Control 94, 116-122. doi:10.1016/j.foodcont.2018.06.036.

Li, K., Lemonakis, L., Glover, B., Moritz, J., and Shen, C. (2017a). Impact of Built-up-Litter and Commercial Antimicrobials on Salmonella and Campylobacter Contamination of Broiler 
Carcasses Processed at a Pilot Mobile Poultry-Processing Unit. Front. Vet. Sci. 4. doi:10.3389/fvets.2017.00088.

Li, K., Weidhaas, J., Lemonakis, L., Khouryieh, H., Stone, M., Jones, L., et al. (2017b). Microbiological quality and safety of fresh produce in West Virginia and Kentucky farmers' markets and validation of a post-harvest washing practice with antimicrobials to inactivate Salmonella and Listeria monocytogenes. Food Control 79, 101-108. doi:10.1016/j.foodcont.2017.03.031.

López-Gálvez, F., Posada-Izquierdo, G. D., Selma, M. V., Pérez-Rodríguez, F., Gobet, J., Gil, M. I., et al. (2012). Electrochemical disinfection: An efficient treatment to inactivate Escherichia coli O157:H7 in process wash water containing organic matter. Food Microbiology 30, 146-156. doi:10.1016/j.fm.2011.09.010.

Meldrum, R. J., Little, C. L., Sagoo, S., Mithani, V., McLauchlin, J., and de Pinna, E. (2009). Assessment of the microbiological safety of salad vegetables and sauces from kebab takeaway restaurants in the United Kingdom. Food Microbiology 26, 573-577. doi:10.1016/j.fm.2009.03.013.

Minnesota Department of Health. (2015). UPDATE: Tomatoes identified as source of Salmonella outbreak in restaurant chain. Available at: https://www.health.state.mn.us/news/pressrel/2015/salmonella091615.html [Accessed January 20, 2020].

Painter, J. A., Hoekstra, R. M., Ayers, T., Tauxe, R. V., Braden, C. R., Angulo, F. J., et al. (2013). Attribution of Foodborne Illnesses, Hospitalizations, and Deaths to Food Commodities by using Outbreak Data, United States, 1998-2008. Emerging Infectious Diseases, 407-415. doi:10.3201/eid1903.111866. 
Ponniah, J., Robin, T. D., Paie, M. S., Chai, L. C., Radu, S., Ghazali, F. M., et al. (2012). Assessment of Listeria monocytogenes in salad vegetables through kitchen simulation study. Journal of tropical agriculture and food science.

Scheinberg, J., Dudley E., Campbell, J., Roberts, B., DImarzio, M., DeBroy, C., and Cutter, C. (2017). Prevalence and phylogenetic characterization of Escherichia coli and hygiene indicator bacteria isolated from leafy green produce, beef, and pork obtained from farmers' markets in Pennsylvania. Journal of Food Protection 80, 237-244. doi:10.4315/0362-028X.JFP-16-282.

Shen, C., Luo, Y., Nou, X., Wang, Q., and Millner, P. (2013). Dynamic Effects of Free Chlorine Concentration, Organic Load, and Exposure Time on the Inactivation of Salmonella, Escherichia coli O157:H7, and Non-O157 Shiga Toxin-Producing E. coli. Journal of Food Protection 76, 386-393. doi:10.4315/0362-028X.JFP-12-320.

Shen, C., Norris, P., Williams, O., Hagan, S., and Li, K. (2016). Generation of chlorine byproducts in simulated wash water. Food Chemistry 190, 97-102. doi:10.1016/j.foodchem.2015.04.146.

Sreedharan, A., Li, Y., De, J., Gutierrez, A., Silverberg, R., and Schneider, K. R. (2017). Determination of optimum sanitizer levels for prevention of Salmonella crosscontamination of mature round tomatoes in a laboratory model flume system. Journal Food Protection 80, 1436-1442. doi: 10.4315/0362-028X.JFP-17-032

Strawn, L. K., Gröhn, Y. T., Warchocki, S., Worobo, R. W., Bihn, E. A., and Wiedmann, M. (2013). Risk Factors Associated with Salmonella and Listeria monocytogenes Contamination of Produce Fields. Appl. Environ. Microbiol. 79, 7618-7627. doi:10.1128/AEM.02831-13. 
Strohbehn, C., Mendonca, A., Wilson, L., Domoto, P., and Smith, M. (2013). On-farm Food Safety: Cleaning and Sanitizing Guide. Human Sciences Extension and Outreach Publications. Available at: https://lib.dr.iastate.edu/extension_families_pubs/102 [Accessed December 9, 2019].

United Fresh Produce Association. (2018). Guidance on environmental monitoring and control of listeria for the fresh produce industry. Available at: https://www.unitedfresh.org/content/uploads/2019/03/FINAL-UFPA-ListeriaGuidance.pdf. [Accessed December 9, 2019].

USDA. (2015). Trends in U.S. Local and Regional Food Systems: A Report to Congress. Available at: https://www.ers.usda.gov/webdocs/publications/42805/51173_ap068.pdf. [Accessed December 9, 2019].

USDA ERS - Food Availability (Per Capita) Data System. (2019). Available at: https://www.ers.usda.gov/data-products/food-availability-per-capita-data-system/ [Accessed December 9, 2019].

U.S.-Food and Drug Administration. (1998). Guidance for industry: Guide to minimize microbial food safety hazards for fresh fruits and vegetables. Available at: https://www.fda.gov/regulatory-information/search-fda-guidance-documents/guidanceindustry-guide-minimize-microbial-food-safety-hazards-fresh-fruits-and-vegetables. [Accessed January 24, 2020].

U.S.-Food and Drug Administration. (2018). Program Information Manual: Retail Food Protection Storage and Handling of Tomatoes. Available at: https://www.fda.gov/food/retail-food-industryregulatory-assistance-training/program- 
information-manual-retail-food-protection-storage-and-handling-tomatoes. [Accessed January 24, 2020].

Vasseur, C., Beverel, L., Hebraud, M., and Labadie, J. (1999). Effect of osmotic, alkaline, acid, or thermal stresses on the growth and inhibition of Listeria monocytogenes. Journal of Applied Microbiology 86, 469-476. doi: 10.1046/j.1365-2672.1999.00686.x

Wang, H., and Ryser, E. (2014). Efficacy of Various Sanitizers against Salmonella during Simulated Commercial Packing of Tomatoes. Journal of Food Protection 77, 1868-1875. doi:10.4315/0362-028X.JFP-14-213

Wei, C. I., Huang, T. S., Kim, J. M., Lin, W. F., Tamplin, M. 1., and Bartz, J. A. (1995). Growth and Survival of Salmonella montevideo on Tomatoes and Disinfection with Chlorinated Water. Journal of Food Protection 58, 829-836. doi:10.4315/0362-028X-58.8.829.

White, G. C. (2010). White's handbook of chlorination and alternative disinfectants, 5th ed. Black and Veach Corporation. John Wiley and Sons, Inc., Hoboken, NJ

Yuk, H.-G., Bartz, J. A., and Schneider, K. R. (2006). The Effectiveness of Sanitizer Treatments in Inactivation of Salmonella spp. from Bell Pepper, Cucumber, and Strawberry. Journal of Food Science 71, M95-M99. doi:10.1111/j.1365-2621.2006.tb15638.x. 


\section{Ch.3 Tables}

Table 3.1. Survival and reduction of Salmonella Typhimurium and Tennessee on cucumbers $\left(\log _{10}\right.$ CFU/cucumber) by triple wash procedure water dip-antimicrobial dip-water dip (WAW) or water dip-water dip-antimicrobial dip (WWA) in water, sodium hypochlorite (SH, 100 ppm, pH 8.2), ASH (SH, 100 ppm, pH 6.8 adjusted by citric acid), lactic and citric acid blend (LCA, Veggiexide®, $2.5 \%$ ), a PAA and hydrogen peroxide mixer (SD, SaniDate-5.0, 0.0064, 0.25 and 0.50\%).

\begin{tabular}{|c|c|c|c|c|}
\hline \multicolumn{3}{|c|}{ Survival } & \multicolumn{2}{|c|}{ Reduction } \\
\hline Treatment & WAW & WWA & WAW & WWA \\
\hline Control & $5.80 \pm 0.28 a$ & $5.42 \pm 0.33 a$ & -* & -* \\
\hline Water & $4.54 \pm 0.05 b$ & $4.06 \pm 0.05 b$ & $1.26 \pm 0.05 \mathrm{cA}$ & $1.36 \pm 0.05 \mathrm{cA}$ \\
\hline SH-100 ppm & $3.80 \pm 0.44 \mathrm{~cd}$ & $3.00 \pm 0.23 \mathrm{~cd}$ & $2.00 \pm 0.44 \mathrm{bA}$ & $2.43 \pm 0.23 \mathrm{abB}$ \\
\hline ASH-100 ppm & $3.39 \pm 0.38 \mathrm{e}$ & $2.67 \pm 0.42 \mathrm{~d}$ & $2.41 \pm 0.38 \mathrm{aA}$ & $2.75 \pm 0.42 \mathrm{aA}$ \\
\hline LCA- $2.5 \%$ & $3.98 \pm 0.54 \mathrm{~cd}$ & $3.28 \pm 0.26 c$ & $1.82 \pm 0.54 \mathrm{bA}$ & $2.14 \pm 0.26 \mathrm{bA}$ \\
\hline SD-0.0064\% & $4.17 \pm 0.55 b c$ & $3.33 \pm 0.43 c$ & $1.63 \pm 0.55 b c A$ & $2.09 \pm 0.43 b B$ \\
\hline SD- $0.25 \%$ & $3.62 \pm 0.73 \mathrm{de}$ & $2.76 \pm 0.12 \mathrm{~d}$ & $2.18 \pm 0.73 \mathrm{abA}$ & $2.66 \pm 0.20 \mathrm{aB}$ \\
\hline SD- $0.50 \%$ & $3.36 \pm 0.59 \mathrm{e}$ & $2.79 \pm 0.19 d$ & $2.44 \pm 0.59 \mathrm{aA}$ & $2.63 \pm 0.19 \mathrm{aA}$ \\
\hline
\end{tabular}

—* indicates reduction data are not available

Mean values with different letters within a column are significantly different $(P<0.05)$

Mean values with different capital letters within a row are significantly different $(P<0.05)$ 
Table 3.2. Survival and reduction of Salmonella Typhimurium and Tennessee on tomatoes $\left(\log _{10}\right.$ CFU/tomato) by triple wash procedure water dip-antimicrobial dip-water dip (WAW) or water dip-water dip-antimicrobial dip (WWA) in water, sodium hypochlorite (SH, 100 ppm, pH 8.2), ASH (SH, 100 ppm, pH 6.8 adjusted by citric acid), lactic and citric acid blend (LCA, Veggiexide ${ }^{2}, 2.5 \%$ ), a PAA and hydrogen peroxide mixer (SD, SaniDate-5.0, 0.0064, 0.25 and 0.50\%).

\begin{tabular}{|c|c|c|c|c|}
\hline \multicolumn{3}{|c|}{ Survival } & \multicolumn{2}{|c|}{ Reduction } \\
\hline Treatment & WAW & WWA & WAW & WWA \\
\hline Control & $5.70 \pm 0.19 a$ & $6.23 \pm 0.42 \mathrm{a}$ & —* & —* \\
\hline Water & $4.96 \pm 0.08 b$ & $5.45 \pm 0.05 b$ & $0.74 \pm 0.08 \mathrm{eA}$ & $0.78 \pm 0.05 \mathrm{cA}$ \\
\hline SH-100 ppm & $4.38 \pm 0.31 \mathrm{~cd}$ & $3.09 \pm 0.50 \mathrm{~d}$ & $1.32 \pm 0.31 \mathrm{bcA}$ & $3.14 \pm 0.50 \mathrm{aB}$ \\
\hline ASH-100 ppm & $3.72 \pm 0.44 d$ & $2.93 \pm 0.73 d$ & $1.98 \pm 0.44 \mathrm{aA}$ & $3.30 \pm 0.73 \mathrm{aB}$ \\
\hline LCA-2.5\% & $4.80 \pm 0.15 b$ & $2.95 \pm 0.12 \mathrm{~d}$ & $0.90 \pm 0.15 \mathrm{deA}$ & $3.28 \pm 0.12 \mathrm{aB}$ \\
\hline SD-0.0064\% & $4.57 \pm 0.25 b c$ & $4.51 \pm 0.20 c$ & $1.13 \pm 0.25 \mathrm{cdA}$ & $1.72 \pm 0.20 \mathrm{bB}$ \\
\hline SD- $0.25 \%$ & $3.72 \pm 0.39 d$ & $2.88 \pm 0.28 \mathrm{~d}$ & $1.98 \pm 0.39 \mathrm{aA}$ & $3.35 \pm 0.28 \mathrm{aB}$ \\
\hline SD- $0.50 \%$ & $4.07 \pm 0.1 \mathrm{~d}$ & $2.97 \pm 0.32 \mathrm{~d}$ & $1.63 \pm 0.13 \mathrm{abA}$ & $3.26 \pm 0.32 \mathrm{aB}$ \\
\hline
\end{tabular}

- indicates reduction data are not available

Mean values with different letters within a column are significantly different $(P<0.05)$

Mean values with different capital letters within a row are significantly different $(P<0.05)$ 
Table 3.3. Survival and reduction of Listeria monocytogenes on cucumbers ( $\left.\log _{10} \mathrm{CFU} / \mathrm{cucumber}\right)$ by triple wash procedure water dipantimicrobial dip-water dip (WAW) or water dip-water dip-antimicrobial dip (WWA) in water, sodium hypochlorite (SH, 100 ppm, pH 8.2), ASH (SH, 100 ppm, pH 6.8 adjusted by citric acid), lactic and citric acid blend (LCA, Veggiexide®, 2.5\%), a PAA and hydrogen peroxide mixer (SD, SaniDate-5.0, 0.0064, 0.25 and $0.50 \%$ ).

\begin{tabular}{|c|c|c|c|c|}
\hline \multicolumn{3}{|c|}{ Survival } & \multicolumn{2}{|c|}{ Reduction } \\
\hline Treatment & WAW & WWA & WAW & WWA \\
\hline Control & $6.31 \pm 0.28 \mathrm{a}$ & $6.92 \pm 0.44 a$ & —* & —* \\
\hline Water & $5.72 \pm 0.37 b$ & $6.20 \pm 0.13 b$ & $0.59 \pm 0.37 \mathrm{cA}$ & $0.72 \pm 0.13 \mathrm{cA}$ \\
\hline SH-100 ppm & $4.67 \pm 0.46 c$ & $5.87 \pm 0.49 c$ & $1.64 \pm 0.46 \mathrm{abA}$ & $1.05 \pm 0.46 \mathrm{bcB}$ \\
\hline ASH-100 ppm & $4.44 \pm 0.72 c$ & $4.52 \pm 0.43 d$ & $1.87 \pm 0.72 \mathrm{aA}$ & $2.41 \pm 0.43 \mathrm{aB}$ \\
\hline LCA- $2.5 \%$ & $5.08 \pm 0.40 c$ & $6.17 \pm 0.43 c$ & $1.23 \pm 0.40 \mathrm{bA}$ & $0.75 \pm 0.43 \mathrm{cB}$ \\
\hline SD-0.0064\% & $5.55 \pm 0.46 b$ & $5.62 \pm 0.39 c$ & $0.76 \pm 0.46 \mathrm{~A}$ & $1.30 \pm 0.39 \mathrm{bB}$ \\
\hline $\mathrm{SD}-0.25 \%$ & $4.56 \pm 0.49 c$ & $5.64 \pm 0.35 c$ & $1.75 \pm 0.49 \mathrm{aA}$ & $1.28 \pm 0.35 \mathrm{bA}$ \\
\hline SD- $0.50 \%$ & $4.75 \pm 0.49 c$ & $5.76 \pm 0.40 c$ & $1.56 \pm 0.49 \mathrm{abA}$ & $1.16 \pm 0.40 \mathrm{bA}$ \\
\hline
\end{tabular}

_* indicates reduction data are not available

Mean values with different letters within a column are significantly different $(P<0.05)$

Mean values with different capital letters within a row are significantly different $(P<0.05)$ 
Table 3.4. Survival and reduction of Listeria monocytogenes on tomatoes ( $\log _{10}$ CFU/tomato) by triple wash procedure water dipantimicrobial dip-water dip (WAW) or water dip-water dip-antimicrobial dip (WWA) in water, sodium hypochlorite (SH, 100 ppm, $\mathrm{pH}$ 8.2), ASH (SH, 100 ppm, pH 6.8 adjusted by citric acid), lactic and citric acid blend (LCA, Veggiexide®, 2.5\%), a PAA and hydrogen peroxide mixer (SD, SaniDate-5.0, 0.0064, 0.25 and $0.50 \%$ ).

\begin{tabular}{|c|c|c|c|c|}
\hline \multicolumn{3}{|c|}{ Survival } & \multicolumn{2}{|c|}{ Reduction } \\
\hline Treatment & WAW & WWA & WAW & WWA \\
\hline Control & $6.39 \pm 0.16 \mathrm{a}$ & $6.41 \pm 0.16 a$ & -* & —* \\
\hline Water & $5.96 \pm 0.03 b$ & $5.99 \pm 0.03 b$ & $0.43 \pm 0.03 \mathrm{dA}$ & $0.42 \pm 0.03 \mathrm{cA}$ \\
\hline SH-100 ppm & $5.21 \pm 0.30 \mathrm{c}$ & $3.74 \pm 0.39 d$ & $1.18 \pm 0.30 \mathrm{bcA}$ & $2.67 \pm 0.39 \mathrm{aB}$ \\
\hline ASH-100 ppm & $4.42 \pm 0.14 \mathrm{~d}$ & $4.03 \pm 0.54 \mathrm{~d}$ & $1.97 \pm 0.14 \mathrm{aA}$ & $2.38 \pm 0.54 \mathrm{aA}$ \\
\hline LCA- $2.5 \%$ & $5.46 \pm 0.15 c$ & $4.08 \pm 0.20 \mathrm{~d}$ & $0.93 \pm 0.15 \mathrm{Ac}$ & $2.33 \pm 0.20 \mathrm{aB}$ \\
\hline SD-0.0064\% & $5.45 \pm 0.97 c$ & $4.79 \pm 0.16 c$ & $0.94 \pm 0.97 \mathrm{Abc}$ & $1.62 \pm 0.16 b B$ \\
\hline SD- $0.25 \%$ & $4.88 \pm 0.19 \mathrm{~d}$ & $3.76 \pm 0.40 \mathrm{~d}$ & $1.51 \pm 0.19 \mathrm{abA}$ & $2.65 \pm 0.40 \mathrm{aB}$ \\
\hline SD- $0.50 \%$ & $4.67 \pm 0.06 \mathrm{~d}$ & $3.93 \pm 0.41 d$ & $1.72 \pm 0.06 \mathrm{aA}$ & $2.48 \pm 0.41 \mathrm{aB}$ \\
\hline
\end{tabular}

- indicates reduction data are not available

Mean values with different letters within a column are significantly different $(P<0.05)$

Mean values with different capital letters within a row are significantly different $(P<0.05)$ 
Table 3.5. Survival and reduction of Enterococcus faecium on cucumbers ( $\log _{10}$ CFU/cucumber) by triple wash procedure water dipantimicrobial dip-water dip (WAW) or water dip-water dip-antimicrobial dip (WWA) in water, sodium hypochlorite (SH, $100 \mathrm{ppm}$, $\mathrm{pH}$ 8.2), ASH (SH, 100 ppm, pH 6.8 adjusted by citric acid), lactic and citric acid blend (LCA, Veggiexide®, 2.5\%), a PAA and hydrogen peroxide mixer (SD, SaniDate-5.0, 0.0064, 0.25 and 0.50\%).

\begin{tabular}{|c|c|c|c|c|}
\hline \multicolumn{3}{|c|}{ Survival } & \multicolumn{2}{|c|}{ Reduction } \\
\hline Treatment & WAW & WWA & WAW & WWA \\
\hline Control & $6.05 \pm 0.59 a$ & $6.05 \pm 0.71 \mathrm{a}$ & —* & —* \\
\hline Water & $5.49 \pm 0.27 b$ & $5.49 \pm 0.27 b$ & $0.56 \pm 0.27 \mathrm{cA}$ & $0.56 \pm 0.27 \mathrm{eA}$ \\
\hline SH-100 ppm & $5.25 \pm 0.39 b$ & $5.00 \pm 0.26 c$ & $0.80 \pm 0.39 b c A$ & $1.05 \pm 0.26 \mathrm{dA}$ \\
\hline ASH-100 ppm & $3.97 \pm 0.49 d$ & $3.66 \pm 0.41 \mathrm{e}$ & $2.08 \pm 0.49 \mathrm{aA}$ & $2.39 \pm 0.41 \mathrm{bA}$ \\
\hline LCA- $2.5 \%$ & $5.13 \pm 0.19 b$ & $4.42 \pm 0.41 d$ & $0.92 \pm 0.19 \mathrm{bA}$ & $1.63 \pm 0.41 \mathrm{cB}$ \\
\hline SD-0.0064\% & $3.86 \pm 0.52 \mathrm{~d}$ & $3.57 \pm 0.60 \mathrm{e}$ & $2.19 \pm 0.52 \mathrm{aA}$ & $2.48 \pm 0.60 \mathrm{bA}$ \\
\hline SD- $0.25 \%$ & $4.23 \pm 0.30 c$ & $3.40 \pm 0.57 \mathrm{ef}$ & $1.82 \pm 0.30 \mathrm{aA}$ & $2.65 \pm 0.57 \mathrm{abB}$ \\
\hline SD- $0.50 \%$ & $3.78 \pm 0.51 \mathrm{~d}$ & $3.09 \pm 0.44 \mathrm{f}$ & $2.27 \pm 0.51 \mathrm{aA}$ & $2.96 \pm 0.44 \mathrm{aB}$ \\
\hline
\end{tabular}

-* indicates reduction data are not available

Mean values with different letters within a column are significantly different $(P<0.05)$

Mean values with different capital letters within a row are significantly different $(P<0.05)$ 
Table 3.6. Survival and reduction of Enterococcus faecium on tomatoes ( $\log _{10}$ CFU/tomato) by triple wash procedure water dipantimicrobial dip-water dip (WAW) or water dip-water dip-antimicrobial dip (WWA) in water, sodium hypochlorite (SH, 100 ppm, $\mathrm{pH}$ 8.2), ASH (SH, 100 ppm, pH 6.8 adjusted by citric acid), lactic and citric acid blend (LCA, Veggiexide®, 2.5\%), a PAA and hydrogen peroxide mixer (SD, SaniDate-5.0, 0.0064, 0.25 and $0.50 \%$ ).

\begin{tabular}{|c|c|c|c|c|}
\hline \multicolumn{3}{|c|}{ Survival } & \multicolumn{2}{|c|}{ Reduction } \\
\hline Treatment & WAW & WWA & WAW & WWA \\
\hline Control & $6.05 \pm 0.36 \mathrm{a}$ & $6.05 \pm 0.51 \mathrm{a}$ & —* & -* \\
\hline Water & $5.60 \pm 0.05 b$ & $5.60 \pm 0.05 b$ & $0.45 \pm 0.05 \mathrm{e}$ & $0.45 \pm 0.05 \mathrm{e}$ \\
\hline SH-100 ppm & $4.17 \pm 0.75 d$ & $3.27 \pm 0.46 \mathrm{de}$ & $1.88 \pm 0.75 \mathrm{cA}$ & $2.78 \pm 0.46 \mathrm{cA}$ \\
\hline ASH-100 ppm & $4.68 \pm 0.23 c$ & $3.55 \pm 0.12 \mathrm{~cd}$ & $1.37 \pm 0.23 \mathrm{dA}$ & $2.50 \pm 0.12 \mathrm{cdB}$ \\
\hline LCA- $2.5 \%$ & $4.71 \pm 0.82 c$ & $3.49 \pm 0.39 \mathrm{~cd}$ & $1.34 \pm 0.82 \mathrm{dA}$ & $2.56 \pm 0.39 \mathrm{cdB}$ \\
\hline SD-0.0064\% & $4.12 \pm 0.47 d$ & $3.86 \pm 0.62 c$ & $1.93 \pm 0.47 \mathrm{cA}$ & $2.19 \pm 0.62 \mathrm{dA}$ \\
\hline SD- $0.25 \%$ & $3.57 \pm 0.50 \mathrm{e}$ & $3.08 \pm 0.41 \mathrm{e}$ & $2.48 \pm 0.50 \mathrm{bA}$ & $2.97 \pm 0.41 \mathrm{bB}$ \\
\hline SD- $0.50 \%$ & $3.15 \pm 0.67 f$ & $2.52 \pm 0.44 f$ & $2.90 \pm 0.67 \mathrm{aA}$ & $3.53 \pm 0.20 \mathrm{aB}$ \\
\hline
\end{tabular}

- indicates reduction data are not available

Mean values with different letters within a column are significantly different $(P<0.05)$

Mean values with different capital letters within a row are significantly different $(P<0.05)$ 
Table 3.7. A comparison of the reduction of Salmonella and surrogate Enterococcus faecium on cucumbers (log ${ }_{10}$ CFU/cucumber) by triple wash procedure water dip-antimicrobial dip-water dip (WAW) or water dip-water dip-antimicrobial dip (WWA) in water, sodium hypochlorite (SH, 100 ppm, pH 8.2), ASH (SH, 100 ppm, pH 6.8 adjusted by citric acid), lactic and citric acid blend (LCA, Veggiexide ${ }^{2}, 2.5 \%$ ), a PAA and hydrogen peroxide mixer (SD, SaniDate-5.0, 0.0064, 0.25 and 0.50\%).

\begin{tabular}{|c|c|c|c|c|}
\hline \multicolumn{3}{|c|}{ WAW } & \multicolumn{2}{|c|}{ WWA } \\
\hline Treatment & Salmonella & E. faecium & Salmonella & E. faecium \\
\hline Water & $1.26 \pm 0.05 \mathrm{~A}$ & $0.56 \pm 0.27 \mathrm{~B}$ & $1.36 \pm 0.05 \mathrm{~A}$ & $0.56 \pm 0.27 \mathrm{~B}$ \\
\hline SH-100 ppm & $2.00 \pm 0.44 \mathrm{~A}$ & $0.80 \pm 0.39 \mathrm{~B}$ & $2.43 \pm 0.23 \mathrm{~A}$ & $1.05 \pm 0.26 \mathrm{~B}$ \\
\hline ASH-100 ppm & $2.41 \pm 0.38 \mathrm{~A}$ & $2.08 \pm 0.49 B$ & $2.75 \pm 0.42 \mathrm{~A}$ & $2.39 \pm 0.41 \mathrm{~A}$ \\
\hline LCA-2.5\% & $1.82 \pm 0.54 \mathrm{~A}$ & $0.92 \pm 0.19 \mathrm{~B}$ & $2.14 \pm 0.26 \mathrm{~A}$ & $1.63 \pm 0.41 B$ \\
\hline SD- $0.0064 \%$ & $1.63 \pm 0.55 \mathrm{~A}$ & $2.19 \pm 0.52 B$ & $2.09 \pm 0.43 \mathrm{~A}$ & $2.48 \pm 0.60 \mathrm{~A}$ \\
\hline SD- $0.25 \%$ & $2.18 \pm 0.73 \mathrm{~A}$ & $1.82 \pm 0.30 \mathrm{~A}$ & $2.66 \pm 0.20 \mathrm{~A}$ & $2.65 \pm 0.57 \mathrm{~A}$ \\
\hline SD- $0.50 \%$ & $2.44 \pm 0.59 \mathrm{~A}$ & $2.27 \pm 0.51 \mathrm{~A}$ & $2.63 \pm 0.19 \mathrm{~A}$ & $2.96 \pm 0.44 \mathrm{~A}$ \\
\hline
\end{tabular}

Mean values with different capital letters within a row under WAW or WWA column are significantly different $(P<0.05)$ 
Table 3.8. A comparison of the reduction of Salmonella and surrogate Enterococcus faecium on tomatoes (log 10 CFU/tomato) by triple wash procedure water dip-antimicrobial dip-water dip (WAW) or water dip-water dip-antimicrobial dip (WWA) in water, sodium hypochlorite (SH, 100 ppm, pH 8.2), ASH (SH, 100 ppm, pH 6.8 adjusted by citric acid), lactic and citric acid blend (LCA, Veggiexide ${ }^{2}, 2.5 \%$ ), a PAA and hydrogen peroxide mixer (SD, SaniDate-5.0, 0.0064, 0.25 and 0.50\%).

\begin{tabular}{|c|c|c|c|c|}
\hline \multicolumn{3}{|c|}{ WAW } & \multicolumn{2}{|c|}{ WWA } \\
\hline Treatment & Salmonella & E. faecium & Salmonella & E. faecium \\
\hline Water & $0.74 \pm 0.08 \mathrm{~A}$ & $0.45 \pm 0.05 \mathrm{~B}$ & $0.78 \pm 0.05 \mathrm{~A}$ & $0.45 \pm 0.05 \mathrm{~B}$ \\
\hline SH-100 ppm & $1.32 \pm 0.31 \mathrm{~A}$ & $1.88 \pm 0.75 \mathrm{~B}$ & $3.14 \pm 0.50 \mathrm{~A}$ & $2.78 \pm 0.46 \mathrm{~B}$ \\
\hline ASH-100 ppm & $1.98 \pm 0.44 \mathrm{~A}$ & $1.37 \pm 0.23 \mathrm{~B}$ & $3.30 \pm 0.73 \mathrm{~A}$ & $2.50 \pm 0.12 B$ \\
\hline LCA- $2.5 \%$ & $0.90 \pm 0.15 \mathrm{~A}$ & $1.34 \pm 0.82 \mathrm{~A}$ & $3.28 \pm 0.12 \mathrm{~A}$ & $2.56 \pm 0.39 B$ \\
\hline SD-0.0064\% & $1.13 \pm 0.25 \mathrm{~A}$ & $1.93 \pm 0.47 \mathrm{~B}$ & $1.72 \pm 0.20 \mathrm{~A}$ & $2.19 \pm 0.62 \mathrm{~A}$ \\
\hline SD- $0.25 \%$ & $1.98 \pm 0.39 \mathrm{~A}$ & $2.48 \pm 0.50 \mathrm{~A}$ & $3.35 \pm 0.28 \mathrm{~A}$ & $2.97 \pm 0.41 \mathrm{~A}$ \\
\hline SD- $0.50 \%$ & $1.63 \pm 0.13 \mathrm{~A}$ & $2.90 \pm 0.67 \mathrm{~B}$ & $3.26 \pm 0.32 \mathrm{~A}$ & $3.53 \pm 0.20 \mathrm{~A}$ \\
\hline
\end{tabular}

Mean values with different capital letters within a row under WAW or WWA column are significantly different $(P<0.05)$ 


\section{CHAPTER 4}

\section{Inactivation of Foodborne Pathogens (Salmonella and Listeria monocytogenes) on Locally Processed Spinaches by Three-Step Wash with Antimicrobials}

A three-step wash with commercial antimicrobials including an $\mathrm{H}_{2} \mathrm{O}_{2}$-peroxyacetic-acid mix, chlorine water, and a lactic/citric acid blend was conducted to inactivate foodborne pathogens on spinaches. Fresh spinaches from West Virginia small growers were artificially contaminated with a 4-strain mixture of Salmonella and Listeria monocytogenes. Inoculated spinaches were threestep washed in water, antimicrobial, and water (WAW) or water, water, and antimicrobial (WWA) with $10 \mathrm{~s}$ of each step. Antimicrobial treatments are sodium hypochlorite (SH; 100 ppm, pH-6.8), lactic/citric acid blend (LCA; 2.5\%), and a $\mathrm{H}_{2} \mathrm{O}_{2}$-peroxyacetic-acid mixer (SaniDate5.0, 0.0064, 0.25 and 0.50\%). Microbial populations were analyzed on XLT-4 (Salmonella) and MOX agars (L. monocytogenes) with a total of 9 samples (3 replicates) followed by analysis using SAS (Mixed Model Procedure, $P=0.05$ ). Unwashed spinaches recovered 4.57-5.10 and 6.68-6.73 $\log _{10} \mathrm{CFU} / \mathrm{g}$ of Salmonella and L. monocytogenes, respectively. WWA procedure obtained additional reductions of the pathogens by $0.35-1.07 \log _{10} \mathrm{CFU} / \mathrm{g}$ (LsMeans) than the WAW procedure. Three-step wash in $0.25 \%$ and $0.50 \%$ of SaniDate-5.0 solution showed at least similar or even greater $(P<0.05)$ reductions of the pathogens on spinaches than those of SH and LCA treated samples. Results suggested that SaniDate-5.0 is a promising antimicrobial agent that could be suggested to WV small spinach growers during the post-harvest three-step wash process.

Keywords: Three-step wash, Antimicrobials, Salmonella, Listeria monocytogenes, Spinach 


\subsection{Introduction}

Locally grown/processed food products are growing dramatically in the recent 20 years with the number of farmers' markets nationwide reaching 8,268 in 2014 which increased by almost 5 folds than the amount in 1994 (1,755) (USDA-ERS, 2020). In the state of West Virginia (WV), 93 farmers' markets are over 112 locations statewide creating annual sales valued at \$9.1 million (Li et al., 2018) and providing the average annual income for full-time and parttime produce farmers ranged from $\$ 20,000$ to $\$ 41,200$ (Scheinberg, 2012). The increasing requirement for locally produced foods is partially due to the fresh produce from the farmers' market is believed to be more "organic" and safer than conventional wholesale stores (Scheinberg, 2012; Scheinberg et al., 2017). This is typically for WV, a state with a high obesity rate, the push to increase fresh produce consumption for healthier lifestyles triggers the importance of safe processing of locally grown produce.

Although purchasing fresh produce from local farmers' markets is very popular among residents in WV, food safety of produce from farmers' market is a major concern since a recent study of 5 locally grown produce commodities selling at WV and KY farmers' markets showed $10.9-56.3 \%$ of tested produce samples were positive for Salmonella and 3.8\% of tested samples are positive for Listeria (Li et al., 2017b). The population of aerobic plate counts and total coliforms on spinach is more than $5 \log _{10} \mathrm{CFU} / \mathrm{g}$ and greater than those on tomatoes, peppers, cucumbers, cantaloupes. Plus, $22.6 \%$ of spinach samples obtained from WV Morgantown farmers' market were tested for the presence of Salmonella enterica spp. (Li et al., 2017b). The production of produce, including leafy greens, typically requires some form of irrigation water during the growing process. For the locally small-scale growers, irrigation water sometimes comes from rainwater, groundwater, and well water, which provides a good opportunity for 
foodborne pathogens such as Salmonella and Listeria from soil to be contaminated onto produce surfaces (Leifert et al., 2008). To maintain the confidence of local consumers regarding the microbial safety of produce purchased from farmers' markets, a three-step wash process is highly recommended for WV locally small produce growers to implement during post-harvest processing if their produce is grown from the soil or uncooked (Li et al., 2018; 2020a; 2020b). The types of antimicrobial agents play an important role in the effectiveness of the three-step wash. Large industry scale post-harvest processing usually adds chlorine water in the washing tanks to inactivate foodborne pathogens on the surfaces of produce since chlorine water is easy to be prepared (dissolving Clorox or calcium-hypochlorite into waters) and low cost with only \$12/per 5-gallon pallet (Shen et al., 2013). However, locally small produce growers are preferring to use other antimicrobial chemical agents due to the concerns of chlorine by-products (Shen et al., 2016) and may not be approving for the organic process.

Small produce growers in WV are very interested to apply a mixture of peroxyacetic acid and $\mathrm{H}_{2} \mathrm{O}_{2}$ (referred to as SaniDate-5.0) during their post-harvest processing. Our recent studies demonstrated that SaniDate-5.0 effectively reduce Salmonella and Listeria monocytogenes counts on cucumbers, tomatoes (Li et al., 2020a), and butternut squashes (Leifert et al., 2008) from WV Morgantown Farmers' market and increase the shelf life period of butternut squash during a pilot plant trial study ( $\mathrm{Li}$ et al., 2020b). In our three-step wash training workshops for local small produce growers at the 2019 and 2020 WV Small Farm Conference, five participants are interested to know the antimicrobial efficacy of SaniDate-5.0 on leafy greens such as spinach, since there is a growing recognition among produce growers that washing process should be effective to decreased rates of cross-contamination but with no expectation to dramatically reduce foodborne microbial pathogens on surfaces of leafy greens (Gombas et al., 
2017). Therefore, this study was designed to evaluate the efficacy of two three-step wash procedures (water + water + antimicrobial agents vs water + antimicrobial agents + water) to decrease microbial populations of Salmonella and L. monocytogenes on WV locally grown spinaches.

\subsection{Materials and Methods}

\subsubsection{Preparation of inoculum}

Bacterial strains used in this study are the same ones in our previous triple-wash validation studies (Li et al., 2020a; 2020b) including two Salmonella strains which are Salmonella Typhimurium ATCC 14028 and Tennessee ATCC 10722 and two L. monocytogenes strains L2624 and L2625. The two L. monocytogenes are both serotype 1/2b isolated from cantaloupe outbreaks and donated from Dr. Joshua Gurtler, Senior Microbiologist from United States Department of Agriculture-Agricultural Research and Services at Wyndmoor, Pennsylvania. All 4 bacterial strains were maintained as frozen stock cultures and activated by streak-plating onto the selective medium Xylose-Lysine-Tergitol-4 (XLT-4, Hardy Diagnostics, MD, U.S.A) and Modified Oxford (MOX, Hardy Diagnostics) agar to generate single colonies (pure cultures) of Salmonella and L. monocytogenes, respectively, after incubating at $35^{\circ} \mathrm{C}$ for 24-48 hours. On the day of the experiment, two single colonies of each strain were picked from XLT-4 and MOX agars followed by cultivating in $10 \mathrm{~mL}$ pre-manufactured sterile tryptic soy broth (Hardy Diagnostics) at $35^{\circ} \mathrm{C}$ for $24 \mathrm{~h}$. The individual $24 \mathrm{~h}$ fresh cultured strain was then duplicate-washed in diluted $0.1 \%$ buffered peptone water (BPW, Hardy Diagnostics) by centrifuging with the moderate speed of 5,000 $\times \mathrm{g}$ for $15 \mathrm{~min}$ (VWR Symphony 4417, VWR International, Radnor, PA) and re-suspending by vertexing in a $15 \mathrm{ml}$ tube containing $10 \mathrm{ml}$ of new sterile $0.1 \%$ BPW solutions. After that, all four $10 \mathrm{ml}$ of re-suspended Salmonella and $L$. 
monocytogenes solutions were then combined to make a total of $40 \mathrm{ml}$ of a four-strain cocktail inoculum (Li et al., 2017b; 2018; 2020a; 2020b). The final inoculum solution used for spinaches was prepared by adding the $40 \mathrm{ml}$ prepared mixture into a fresh sterile $3 \mathrm{~L}$ of $0.1 \% \mathrm{BPW}$ solution in a $5 \mathrm{~L}$ autoclaved metal bowl. The microbial population of Salmonella and $L$. monocytogenes in the inoculum was approximately 5-6 $\log _{10} \mathrm{CFU} / \mathrm{ml}$ based on the counts from XLT-4 and MOX agars, respectively.

\subsubsection{Inoculation of spinach samples}

Fresh spinach samples were obtained from Morgantown Farmers' market every Saturday at noon and stored at a walk-in refrigerator $\left(5^{\circ} \mathrm{C}\right)$ for $18-24 \mathrm{~h}$. Before inoculation, spinach leaves were first weighted to create 20 batches with 300 grams of each batch. Inoculation was conducted by placing each batch of spinach (300 gram) into a pre-autoclaved 5 L volume metal bowl with $3 \mathrm{~L}$ of the aforementioned inoculum of Salmonella and Listeria with gentle stirring with a magnetic stir ( $100 \mathrm{rpm})$ for $5 \mathrm{~min}$. After that, the 300-gram inoculated spinach samples were allowed to air-dry for $1 \mathrm{~h}$ in a biosafety cabinet to allow for the attachment of the pathogens before the three-step washing experiment. The $3 \mathrm{~L}$ inoculum solution was re-prepared after the triplicate was used.

\subsubsection{Triple-wash produce with antimicrobials}

After inoculation, each 300 gram of inoculated spinach leaves was randomly picked and washing by three steps in another three fresh pre-autoclaved metal containers. Each container was filled with $3 \mathrm{~L}$ of the solutions (tap water or antimicrobial agents) to create a wash ratio of 10:1 for the wash solution verse spinach leaves. Two different three-step wash procedures were conducted in this study. They are first water dip, second antimicrobial agent dip, and final water dip referred to as WAW; or first water dip, second water dip, and final antimicrobial dip referred 
to as WWA. Every step was conducted by completely immersing inoculated spinaches into the solutions with manual rotation by hands with gloves for $10 \mathrm{~s}$ with agitation speed at approximately $200 \mathrm{rpm}$ ( $\mathrm{Li}$ et al., 2020a; 2020b) and continued for the three bowls referred to as three-step wash. Details of the wash solutions without or with commercial antimicrobials including tap water (WVU campus municipal), sodium hypochlorite ( $\mathrm{SH}$, Birko, Henderson, $\mathrm{CO}$, USA), a lactic/citric acid blend (LCA, Veggiexide®, Birko), and SaniDate-5.0 (Arbico Organics, Tucson, AZ, USA) solutions are described in Table 4.1. Temperatures of all wash solutions were $10^{\circ} \mathrm{F}$ higher than the spinach sample $\left(46.76^{\circ} \mathrm{F}\right)$ which followed the recommendation from the U.S. Food and Drug Administration (FDA) advisory board (Center for Food Safety and Applied Nutrition, 2020). After a three-step wash, spinach leaves were placed on aluminum foil papers in a biohazard for 5 min to drain out the extra water.

\subsubsection{Microbiological analysis}

Three 25-g of unwashed or washed spinach samples were randomly picked and weighted from the whole $300-\mathrm{g}$ of each batch. Every $25-\mathrm{g}$ sample was aseptically transferred into a food sample bag (Nasco, Fort Atkinson, WI, USA) which was pre-added with $200 \mathrm{ml}$ of BPW. The sample bag was then homogenizing for $1 \mathrm{~min}$ in a Masticator (Microbiology International, Frederick, MD, U.S.A). The homogenizer was then appropriately diluted in several 9.0 (10-fold) or $9.9 \mathrm{ml}$ (100-fold) of $0.1 \%$ BPW solutions followed by plating onto XLT-4 and MOX agar for analyzing cell counts of Salmonella and L. monocytogenes, respectively. XLT-4 agar plates were incubated at $35^{\circ} \mathrm{C}$ for $24 \mathrm{~h}$ and MOX agar plates were incubated at $35^{\circ} \mathrm{C}$ for $48 \mathrm{~h}$. Agar plates for Salmonella and L. monocytogenes in the range of 20-200 colony-forming-unites (CFU) were picked and used the Oxoid latex agglutination test kit (Oxoid Ltd, Basingstoke, Hampshire, UK) to test and confirm 2 presumptive positive Salmonella and L. monocytogenes colonies from 
every plate. Then all plates were manually counting for CFU with the detection limit is 0.9 $\log _{10} \mathrm{CFU} / \mathrm{g}$.

\subsubsection{Data analysis}

This three-step study was conducted triplicate with the sample unit of $25 \mathrm{~g}$ of spinach $\times 3$ in each treatment of each repeat with a total of 3 repeats. Therefore, there were 9 samples in each treatment for Salmonella or L. monocytogenes. The design of the experiment in this study is a randomized $2 \times 6$ factorial design with 2 types of three-step wash procedures (WAW or WWA) and 6 treatments of water or antimicrobial agents. The mixed model procedure of SAS (version 9.2, SAS Institute, Cary, NC) was used to analyze the difference among the survival and reduction of the pathogens, including individual factors of three-step wash procedures, antimicrobial treatments, and their interactions. Data of pathogen reductions of each treatment were calculated in the Excel spread sheet by a reduction ratio of $\log _{10}\left(\mathrm{~N}_{0} / \mathrm{N}\right)$, which includes $\mathrm{N}_{0}$ (the average CFU counts of the untreated control samples) and $\mathrm{N}$ (the CFU counts of each sample treated by different antimicrobials) based on our previous study (Adler et al., 2016). Comparison of means of various treatments was determined by Tukey HSD with significance level set at $\alpha=0.05$.

\subsection{Results and Discussion}

\subsubsection{Three-step wash by WAW verse WWA procedures}

Analysis from the mixed model procedure showed that the antimicrobial efficacy of triple-wash against Salmonella and L. monocytogenes was determined by the three-step wash procedures (WAW or WWA, $P<0.05)$ and types of antimicrobial agents $(P<0.05)$. The interaction between wash procedures and antimicrobials was also significant $(P<0.05)$. In this study, the least-squares mean (LsMean) values of the 5 tested antimicrobial treatments (not 
including the water-only treatment) were calculated to compare the overall antimicrobial efficacy between WAW and WWA procedures. Results indicate that applying the WWA procedure in a three-step wash is better $(P<0.05)$ than WAW in decreasing the cell counts of Salmonella and L. monocytogenes on spinaches with LsMeans of 1.86 vs $0.79 \log _{10} \mathrm{CFU} / \mathrm{g}$ and $1.37 \mathrm{vs} 1.02$ $\log _{10} \mathrm{CFU} / \mathrm{g}$, respectively.

\subsubsection{Three-step wash with antimicrobials against Salmonella}

Data in Figure 4.1 shows the survivals and reductions of Salmonella on spinaches without or after triple-wash treatments. Triple-wash with tap water without antimicrobials only slightly $(P>0.05)$ reduces Salmonella of spinach samples by 0.15 to $0.28 \log _{10} \mathrm{CFU} / \mathrm{g}$ compared to the control (unwashed samples). Three-step washing spinach samples in 5 different antimicrobial treatments showed greater $(P<0.05)$ reductions of the pathogen than the WWW treatment regardless of WAW or WWA procedures except for SaniDate-5.0-0.0064\% in WWA showing similar reductions ( 0.44 vs $\left.0.28 \log _{10} \mathrm{CFU} / \mathrm{g}\right)$ than the only water washed samples. As expected, three-step wash with antimicrobials in the WAW procedure significantly $(P<0.05)$ decreased the cell counts of Salmonella (survivals of 3.15 to $4.24 \log _{10} \mathrm{CFU} / \mathrm{g}$ ) than the control (4.57 $\log _{10} \mathrm{CFU} / \mathrm{g}$ ), and the reductions were ranged from 0.33 (SaniDate-5.0-0.25\%) to 1.42 (LCA$2.5 \%) \log _{10} \mathrm{CFU} / \mathrm{g}$ (Figure 4.1). Compared to the WAW procedure, SH-100 ppm, SaniDate-5.00.25\% and SaniDate-5.0-0.50\% in WWA procedure achieved an additional $(P<0.05)$ reduction of $0.25,1.48$, and $1.28 \log _{10} \mathrm{CFU} / \mathrm{g}$, respectively (Figure 4.1 ). However, LCA-2.5\% and SaniDate 5.0-0.0064\% did not show a difference $(P>0.05)$ of the pathogen reductions when the wash procedure was switched from WAW to WWA (Figure 4.1). For WAW procedure, adding SaniDate-5.0-0.0064, -0.25 , or $-0.50 \%$ into triple-wash solutions showed less $(P<0.05)$ reductions than those of SH-100 and LCA-2.5\% (0.33-0.52 vs 1.19-1.42 $\log _{10}$ CFU/g, Figure 
4.1). For WWA procedure, samples washed in SaniDate-5.0-0.25\% and -0.50\% solution showed similar $(P>0.05)$ reductions of the pathogen than LCA-2.5\% (1.76-1.81 vs $\left.1.86 \log _{10} \mathrm{CFU} / \mathrm{g}\right)$ and greater $(P<0.05)$ reductions than those from SH-100 ppm $\left(1.76-1.81\right.$ vs $\left.1.44 \log _{10} \mathrm{CFU} / \mathrm{g}\right)$.

\subsubsection{Three-step wash with antimicrobials against $L$. monocytogenes}

Figure 4.2 shows the reductions of L. monocytogenes on spinaches after a three-step wash. After inoculation, the population of L. monocytogenes on unwashed spinach was 6.68 to $6.73 \log _{10} \mathrm{CFU} / \mathrm{g}$. Three-step wash without antimicrobials (only tap water) decreased $(P<0.05)$ the pathogen populations by 0.42 to $0.47 \log _{10} \mathrm{CFU} / \mathrm{g}$ than the untreated control (Figure 4.2). Applying triple-wash for spinach with WAW procedure with 5 antimicrobials dramatically $(P<$ 0.05 ) decreased the counts of L. monocytogenes than the control (survivals of 5.56 to 5.75 vs $6.68 \log _{10} \mathrm{CFU} / \mathrm{g}$, Figure 4.2). Applying the WAW process with all 5 tested antimicrobial treatments reduced L. monocytogenes by 0.93 to $1.12 \log _{10} \mathrm{CFU} / \mathrm{g}$, which is greater $(P<0.05)$ than the water-only treatment $\left(0.47 \log _{10} \mathrm{CFU} / \mathrm{g}\right)$ but similar $(P>0.05)$ after comparison with each other (Figure 4.2). Compared to the WAW process, the WWA procedure enhanced $(P<$ 0.05 ) reductions of the pathogen in the treatments of LCA-2.5\%, SaniDate-5.0-0.25\%, and $0.50 \%$ by $0.36,0.65$, and $0.74 \log _{10} \mathrm{CFU} / \mathrm{g}$, respectively (Figure 4.2 ). However, applying the WWA process with SH-100 ppm and SaniDate 5.0-0.0064\% did not increase $(P>0.05)$ reductions of the pathogen on spinaches after switching to the WAW procedure (Figure 4.2). Among the tested concentrations of SaniDate-5.0, reductions of SaniDate-5.0-0.25\% (1.67 $\left.\log _{10} \mathrm{CFU} / \mathrm{g}\right)$ and $-0.50 \%\left(1.65 \log _{10} \mathrm{CFU} / \mathrm{g}\right)$ were greater $(P<0.05)$ than those of SH-100 ppm $\left(1.17 \log _{10} \mathrm{CFU} / \mathrm{g}\right)$ and LCA-2.5\% (1.35 $\left.\log _{10} \mathrm{CFU} / \mathrm{g}\right)$; the reduction of SaniDate-5.0-0.0064\% is close $(P>0.05)$ to those of SH-100 ppm but less $(P<0.05)$ than the LCA-2.5\% treated samples (Figure 4.2). 


\subsubsection{Discussion}

Results from the present study suggest that three-step wash procedure with WWA or WAW play an important role to determine the efficacy of inactivating Salmonella and $L$. monocytogenes on spinaches, which suggest that applying the WWA procedure in the three-step wash is more effective than the WAW for the control of the pathogens. This result agrees with the findings from our previous study reporting that WWA increased the reductions of Salmonella by $0.7 \log _{10} \mathrm{CFU} /$ product and L. monocytogenes by $1.6 \log _{10} \mathrm{CFU} /$ product on butternut squashes compared to the WAW process (Li et al., 2020b). Another related study also found that the threestep wash with WWA procedure is better than WAW in decreasing Salmonella on cucumber and tomatoes and reducing L. monocytogenes on tomatoes with the enhancement of the reductions by 0.4 to $1.5 \log _{10} \mathrm{CFU} /$ product (Li et al., 2020a). These results could be possibly explained by the residual antimicrobial agents applied through WWA continued to inactivate bacterial pathogens on the surface of the produce, since no further neutralization step was applied in these studies. The tap water-only treatment referred to as WWW in this study showed slight reductions of 0.2 to $0.5 \log _{10} \mathrm{CFU} / \mathrm{g}$ against Salmonella and L. monocytogenes on spinach. A recent study found that immersion inoculated spinach leaves into sterile distilled water only slightly decreased Salmonella Saintpaul by $0.4 \log _{10} \mathrm{CFU} / \mathrm{cm}^{2}$ than the unwashed control (Ruengvisesh et al., 2019). These results suggest that physical removing only has a very limited impact on reducing pathogens on spinach and the antimicrobial efficacy of the three-step wash relied on the choice of antimicrobial agents.

Chlorine is widely used during the post-harvest washing process of fresh produce including spinach due to its ease to prepare, strong antimicrobial capability, and economic feasibility (Luo et al., 2012; Shen et al., 2013) with the maximum concentration of $200 \mathrm{ppm}$ on 
fresh produce and food contact surfaces (Nutrition, 2020). Chorine water has very strong antimicrobial activity as shown in our previous study that $0.5 \mathrm{ppm}$ of free chlorine with exposure time $\geq 30$ s reduced three Salmonella strains by $>4.5 \log _{10}$ CFU/ml (Shen et al., 2013). A recent study suggested that free chlorine at the concentration of $100 \mathrm{ppm}$ reduced Salmonella by more than $4.5 \log _{10} \mathrm{CFU} /$ per sample in a model flume water with a contact time of $30 \mathrm{~s}$ (Sreedharan et al., 2017). Although there are no locally small produce growers in WV that adjust the $\mathrm{pH}$ of sodium chlorite prepared water before washing their products (personal communication with Dr. Tom McConnell, Program Leader of the WV Small Farm Center), chlorine water is needed to adjusting $\mathrm{pH}$ to 6.8 with prepared $10 \%$ citric acid to ensure the most effective form of hypochlorite acid ( $\mathrm{HClO}$ ) dominate in the washing solution (Luo et al., 2012). Therefore, same to our recent three-step wash studies (Li et al., 2020a; 2020b), chlorine solution with a pH of 6.8 was included as an antimicrobial treatment in the current study. Results indicate that adding 100 ppm of chlorine water into a three-step wash process was effective against Salmonella and $L$. monocytogenes with the reductions of 1.1 to $1.4 \log _{10} \mathrm{CFU} / \mathrm{g}$ regardless of the WAW or WWA procedure. These results are the same as the previous study reported that the Salmonella reduction of minimally processed spinach was 1.2 to $1.4 \log _{10}$ after washing in $125 \mathrm{ppm}$ of chlorine solution ( $\mathrm{pH}$ 7.0) for 8 min with various water: produce ratios (Pirovani et al., 2000). A recent study reported that L. monocytogenes on chlorine (100 ppm, pH 7.3) treated spinach surfaces decreased by $2.14 \log _{10} \mathrm{CFU} / \mathrm{cm}^{2}$ with a contact time of $15 \mathrm{~min}$ (Chhetri et al., 2019). These results verified that HCLO as the most effective antimicrobial ingredient would be dominant in chlorine wash solutions with $\mathrm{pH}$ values close to 7.0 (Black \& Veatch Corporation, 2009), therefore the training and practicing of correct preparation of chlorine water before triplewash should be included in our future extension/outreach workshops in our WV local 
community. In this study, it was also noticed that the anti-Salmonella effect of chlorine water can be improved when the WWA procedure was applied during triple-wash of spinach, as the reduction of Salmonella was greater in WWA than WAW process, which agrees with our previous triple-wash tests of Salmonella on cucumber and tomatoes (Li et al., 2020a). Three-step wash with chlorine water using the WWA process did not improve the reductions of $L$. monocytogenes on spinach samples, which is also similar to our previous study on cucumbers (Li et al., 2020a).

According to our recent personal communication with Dr. Tom McConnell, Program Leader of the WV Small Farm Center, WV small produce growers are not interested in including chlorine water in their three-step wash tanks due to the concern of certifying of organic processes of their products. Plus, studies have indicated that chlorine water is easy to lose the effective level of hypochlorous acid after reacting with organic matters in wash waters (López-Gálvez et al., 2012; Luo et al., 2012; Shen et al., 2013) and repeatedly replenish with fresh chlorine solution could form the carcinogenic halogenated disinfection by-products including trihalomethanes (Shen et al., 2016). There are growing interests among local small produce growers to apply other antimicrobial chemicals instead of chlorine. In 2009, a new chemical formula of the lactic and citric acid buffered solution, referred to as LCA, was generated by food chemists in Birko Corporation (Henderson, CO, USA) to prevent discoloration (red to yellow color) of poultry products caused by lactic acid (Laury et al., 2009). Previous studies showed that applying LCA during the post-harvest process of poultry products through dip solution (Li et al., 2017a), nozzle sprayer (Laury et al., 2009), or electronic static sprayer (Jiang et al., 2018), significantly reduce Salmonella or Campylobacter on poultry carcasses and eggs. Regarding fresh produce, a study of LCA on Jalapeno peppers conducted by microbiologists at Birko 
corporation verified that $2.5 \%$ LCA decreased cell counts of natural background flora, Salmonella, and generic Escherichia coli by $0.8-1.3 \log _{10} \mathrm{CFU} / \mathrm{g}$ through a commercial cabinet sprayer (Adler et al., 2016). The inactivation of LCA to bacterial cells is the synergistic effect of lactic and citric acid leads to acid accumulation in the cell cytoplasm to acidify cytoplasm, disrupt proton motive force, and prevent nutrient transport (Vasseur et al., 1999). Results of this study indicated that applying LCA in a three-step wash achieved approximately 1.0-1.9 $\log _{10}$ CFU/g reductions of Salmonella and L. monocytogenes on spinach which are close $\left(<0.5 \log _{10}\right.$ $\mathrm{CFU} / \mathrm{g}$ ) to the reductions of chlorine water. In our previous studies, triple-wash with LCA reduced Salmonella by 1.1-2.7, 1.8-2.1, and 0.9-3.3 $\log _{10}$ CFU/product, and L. monocytogenes by 0.5-2.3, 0.8-1.2, and 0.9-2.3 $\log _{10} \mathrm{CFU} /$ product on butternut squashes (Li et al., 2020b), cucumber, and tomatoes (Li et al., 2020a), respectively, which also showed that similar reductions of Salmonella and L. monocytogenes were achieved by LCA compared to chlorine water.

The WV Small Farm Center recently recommended WV locally small growers to use SaniDate-5.0 in the triple-wash if their produce is grown directly from the soil because the largest WV wholesale buyer named Appalachian Harvest require it to be used during the postharvest process especially for the organic farming process (Li et al., 2020a). SaniDate-5.0 is composed by the ingredients of $23 \% \mathrm{H}_{2} \mathrm{O}_{2}, 5.3 \%$ peroxyacetic acid (PAA), and $70 \%$ unknown components (likely water), which reported can oxidize cells of bacteria, denatures protein and disrupts cell wall structure to inactivate bacterial cells (McDonnell, et al. 2021). A study reported that the combination of $\mathrm{H}_{2} \mathrm{O}_{2}$ and PAA in a solution with high organic matter is still able to reduce bacteria cells including Staphylococcus, Listeria, and E. coli by more than $5 \log _{10} \mathrm{CFU} / \mathrm{ml}$ with a contact time of 10-min (Briñez et al., 2006). Results of the current study suggested similar 
$(P>0.05)$ reductions (1.6 to $1.8 \log _{10} \mathrm{CFU} / \mathrm{g}$ ) of Salmonella and L. monocytogenes on spinach were achieved by SaniDate 5.0-0.25\% and SaniDate $5.0-50 \%$ as compared to chlorine water and LCA. In this study, the better antimicrobial effect of SaniDate-5.0 than chlorine and acids could be explained by the combination of $\mathrm{H}_{2} \mathrm{O}_{2}$ and PAA in SaniDate-5.0 provide an additional synergistic impact for the oxidation of bacterial cells, although the detail of its antimicrobial mechanism remains unclear. Our previous study also found that applying SaniDate 5.0-0.25\% and SaniDate $5.0-50 \%$ in three-step wash process reduced Salmonella by 2.7-2.9, 2.6, and 3.3 $\log _{10} \mathrm{CFU} /$ product, and L. monocytogenes by $2.4-2.9,1.1-1.3$, and $2.5-2.7 \log _{10}$ CFU/product on butternut squashes (Li et al., 2020b), cucumber, and tomatoes (Li et al., 2020a), respectively, which were same or greater than the reductions of chlorine water or LCA treated samples. Results from the present and previous studies of triple-wash all suggested that SaniDate-5.0 is a good replacement for chlorine water to be used as an antimicrobial agent during the post-harvest washing process. Starting in 2019, the Preston Workshop, a small produce processor located in Reedsville, WV has already used the triple-wash with SaniDate-5.0 in their produce (butternut squashes, peppers, cucumbers, etc.) processing line, and their triple-washing facilities are expected to be updated by the end of 2021. However, for very small spinach growers, SaniDate5.0 is needed to be verified of cost-effectiveness as a replacement of chlorine water by various agricultural economic models taking consideration of food safety risks, since the market price value for SaniDate-5.0 is $\$ 330$ (5-gallon pallet) compared to $\$ 12$ for Clorox $^{\circledR}$ (chlorine water).

\subsection{Conclusions}

Results of this study suggested that applying the WWA procedure is better than the WAW in a three-step wash to inactivate Salmonella and L. monocytogenes on WV locally grown spinaches. SaniDate-5.0, especially at the concentrations of $0.25 \%$ and $0.50 \%$, indicates similar 
or better antimicrobial efficacy than chlorine water and LCA on spinach. Results from this study provide validated academic laboratory results for WV locally small produce growers to adopt the three-step wash in their post-harvest process lines. Future studies are needed to evaluate whether SaniDate-5.0 is economically feasible for locally small produce growers and whether it will cause side-effect of sensory qualities of washed fresh produce. Future studies should also include a cross-contamination test of three-step wash with or without antimicrobials since it has now been well recognized that the washing of produce is more important for preventing crosscontamination than reducing foodborne pathogens (Gombas et al., 2017).

\section{Acknowledgment}

This research was finally supported by the United States Department of Agriculture, the National Institute of Food and Agriculture, the AFRI-Critical Agricultural Research and Extension (CARE) (Grant \# 2019-68008-29828). 


\section{References}

Adler, J. M., Cain-Helfrich, E. D., \& Shen, C. (2016). Reductions in Natural Microbial Flora, Nonpathogenic Escherichia coli, and Pathogenic Salmonella on Jalapeno Peppers Processed in a Commercial Antimicrobial Cabinet: A Pilot Plant Trial. Journal of Food Protection, 79(11), 1854-1859. https://doi.org/10.4315/0362-028X.JFP-16-222

Black \& Veatch Corporation. (2009). White's Handbook of Chlorination and Alternative Disinfectants. John Wiley \& Sons, Inc. https://doi.org/10.1002/9780470561331

Briñez, W. J., Roig-Sagués, A. X., Hernández Herrero, M. M., López-Pedemonte, T., \& Guamis, B. (2006). Bactericidal efficacy of peracetic acid in combination with hydrogen peroxide against pathogenic and non-pathogenic strains of Staphylococcus spp., Listeria spp. And Escherichia coli. Food Control, 17(7), 516-521. https://doi.org/10.1016/j.foodcont.2005.02.014

Center for Food Safety and Applied Nutrition. (2020). Program Information Manual: Retail Food Protection Storage and Handling of Tomatoes. FDA. https://www.fda.gov/food/retailfood-industryregulatory-assistance-training/program-information-manual-retail-foodprotection-storage-and-handling-tomatoes

Chhetri, V. S., Janes, M. E., King, J. M., Doerrler, W., \& Adhikari, A. (2019). Effect of residual chlorine and organic acids on survival and attachment of Escherichia coli O157: H7 and Listeria monocytogenes on spinach leaves during storage. $L W T, 105,298-305$. https://doi.org/10.1016/j.lwt.2019.02.019

Gombas, D., Luo, Y., Brennan, J., Shergill, G., Petran, R., Walsh, R., Hau, H., Khurana, K., Zomorodi, B., Rosen, J., Varley, R., \& Deng, K. (2017). Guidelines To Validate Control 
of Cross-Contamination during Washing of Fresh-Cut Leafy Vegetables. Journal of Food Protection, 80(2), 312-330. https://doi.org/10.4315/0362-028X.JFP-16-258

Jiang, W., Etienne, X., Li, K., \& Shen, C. (2018). Comparison of the Efficacy of Electrostatic versus Conventional Sprayer with Commercial Antimicrobials To Inactivate Salmonella, Listeria monocytogenes, and Campylobacter jejuni for Eggs and Economic Feasibility Analysis. Journal of Food Protection, 81(11), 1864-1870. https://doi.org/10.4315/0362028X.JFP-18-249

Laury, A. M., Alvarado, M. V., Nace, G., Alvarado, C. Z., Brooks, J. C., Echeverry, A., \& Brashears, M. M. (2009). Validation of a Lactic Acid- and Citric Acid-Based Antimicrobial Product for the Reduction of Escherichia coli O157:H7 and Salmonella on Beef Tips and Whole Chicken Carcasses. Journal of Food Protection, 72(10), 22082211. https://doi.org/10.4315/0362-028X-72.10.2208

Leifert, C., Ball, K., Volakakis, N., \& Cooper, J. M. (2008). Control of enteric pathogens in ready-to-eat vegetable crops in organic and 'low input' production systems: A HACCPbased approach. Journal of Applied Microbiology, 105(4), 931-950. https://doi.org/10.1111/j.1365-2672.2008.03794.x

Li, K., Chiu, Y.-C., Jiang, W., Jones, L., Etienne, X., \& Shen, C. (2020a). Comparing the Efficacy of Two Triple-Wash Procedures With Sodium Hypochlorite, a Lactic-Citric Acid Blend, and a Mix of Peroxyacetic Acid and Hydrogen Peroxide to Inactivate Salmonella, Listeria monocytogenes, and Surrogate Enterococcus faecium on Cucumbers and Tomatoes. Frontiers in Sustainable Food Systems, 4, 19. https://doi.org/10.3389/fsufs.2020.00019 
Li, K., Etienne, X., Chiu, Y.-C., Jones, L., Khouryieh, H., Jiang, W., \& Shen, C. (2020b). Validation of triple-wash procedure with a $\mathrm{H} 2 \mathrm{O} 2$-peroxyacetic acid mixer to improve microbial safety and quality of butternut squashes and economic feasibility analysis. Food Control, 112, 107146. https://doi.org/10.1016/j.foodcont.2020.107146

Li, K., Khouryieh, H., Jones, L., Etienne, X., \& Shen, C. (2018). Assessing farmers market produce vendors' handling of containers and evaluation of the survival of Salmonella and Listeria monocytogenes on plastic, pressed-card, and wood container surfaces at refrigerated and room temperature. Food Control, 94, 116-122. https://doi.org/10.1016/j.foodcont.2018.06.036

Li, K., Lemonakis, L., Glover, B., Moritz, J., \& Shen, C. (2017a). Impact of Built-up-Litter and Commercial Antimicrobials on Salmonella and Campylobacter Contamination of Broiler Carcasses Processed at a Pilot Mobile Poultry-Processing Unit. Frontiers in Veterinary Science, 4. https://doi.org/10.3389/fvets.2017.00088

Li, K., Weidhaas, J., Lemonakis, L., Khouryieh, H., Stone, M., Jones, L., \& Shen, C. (2017b). Microbiological quality and safety of fresh produce in West Virginia and Kentucky farmers' markets and validation of a post-harvest washing practice with antimicrobials to inactivate Salmonella and Listeria monocytogenes. Food Control, 79, 101-108. https://doi.org/10.1016/j.foodcont.2017.03.031

López-Gálvez, F., Posada-Izquierdo, G. D., Selma, M. V., Pérez-Rodríguez, F., Gobet, J., Gil, M. I., \& Allende, A. (2012). Electrochemical disinfection: An efficient treatment to inactivate Escherichia coli O157:H7 in process wash water containing organic matter. Food Microbiology, 30(1), 146-156. https://doi.org/10.1016/j.fm.2011.09.010 
Luo, Y., Nou, X., Millner, P., Zhou, B., Shen, C., Yang, Y., Wu, Y., Wang, Q., Feng, H., \& Shelton, D. (2012). A pilot plant scale evaluation of a new process aid for enhancing chlorine efficacy against pathogen survival and cross-contamination during produce wash. International Journal of Food Microbiology, 158(2), 133-139. https://doi.org/10.1016/j.ijfoodmicro.2012.07.008

McDonnell, G. E., Hansen, J. M. (Eds.). (2021). Block's disinfection, sterilization, and preservation (Sixth edition). Wolters Kluwer.

Nutrition, C. for F. S. and A. (2020, January 9). Guidance for Industry: Guide to Minimize Microbial Food Safety Hazards of Fresh-cut Fruits and Vegetables. U.S. Food and Drug Administration; FDA. https://www.fda.gov/regulatory-information/search-fda-guidancedocuments/guidance-industry-guide-minimize-microbial-food-safety-hazards-fresh-cutfruits-and-vegetables

Pirovani, M. E., Guemes, D. R., Di Pentima, J. H., \& Tessi, M. A. (2000). Survival of Salmonella hadar after washing disinfection of minimally processed spinach. Letters in Applied Microbiology, 31(2), 143-148. https://doi.org/10.1046/j.13652672.2000.00770.x

Ruengvisesh, S., Kerth, C. R., \& Taylor, T. M. (2019). Inhibition of Escherichia coli O157:H7 and Salmonella enterica Isolates on Spinach Leaf Surfaces Using Eugenol-Loaded Surfactant Micelles. Foods, 8(11), 575. https://doi.org/10.3390/foods8110575

Scheinberg, J. A. (2012). A MICROBIOLOGICAL COMPARISON OF POULTRY PRODUCTS OBTAINED FROM FARMERS' MARKETS AND SUPERMARKETS IN PENNSYLVANIA. https://etda.libraries.psu.edu/files/final_submissions/7455 
Scheinberg, J. A., Dudley, E. G., Campbell, J., Roberts, B., DiMarzio, M., DebRoy, C., \& Cutter, C. N. (2017). Prevalence and Phylogenetic Characterization of Escherichia coli and Hygiene Indicator Bacteria Isolated from Leafy Green Produce, Beef, and Pork Obtained from Farmers' Markets in Pennsylvania. Journal of Food Protection, 80(2), 237-244. https://doi.org/10.4315/0362-028X.JFP-16-282

Shen, C., Luo, Y., Nou, X., Wang, Q., \& Millner, P. (2013). Dynamic Effects of Free Chlorine Concentration, Organic Load, and Exposure Time on the Inactivation of Salmonella, Escherichia coli O157:H7, and Non-O157 Shiga Toxin-Producing E. coli. Journal of Food Protection, 76(3), 386-393. https://doi.org/10.4315/0362-028X.JFP-12-320

Shen, C., Norris, P., Williams, O., Hagan, S., \& Li, K. (2016). Generation of chlorine byproducts in simulated wash water. Food Chemistry, 190, 97-102. https://doi.org/10.1016/j.foodchem.2015.04.146

Sreedharan, A., Li, Y., De, J., Gutierrez, A., Silverberg, R., \& Schneider, K. R. (2017). Determination of Optimum Sanitizer Levels for Prevention of Salmonella CrossContamination of Mature Round Tomatoes in a Laboratory Model Flume System. Journal of Food Protection, 80(9), 1436-1442. https://doi.org/10.4315/0362-028X.JFP$17-032$

USDA-ERS. (2020). Food Availability (Per Capita) Data System. https://www.ers.usda.gov/data-products/food-availability-per-capita-data-system Vasseur, C., Baverel, L., Hebraud, M., \& Labadie, J. (1999). Effect of osmotic, alkaline, acid or thermal stresses on the growth and inhibition of Listeria monocytogenes. Journal of Applied Microbiology, 86(3), 469-476. https://doi.org/10.1046/j.13652672.1999.00686.x 


\section{Chapter 4 Tables and Figures}

Table 4.1. Physical and chemical parameters of antimicrobial treatments in this study

\begin{tabular}{cccc}
\hline Name & Concentration & $\mathrm{pH}$ & Temperature $\left({ }^{\circ} \mathrm{C}\right)$ \\
\hline Tap Water & $\sim 2$ ppm of free chlorine & 6.8 & 15.4 \\
Sodium hypochlorite & $100 \pm 1 \mathrm{ppm}^{\mathrm{a}}$ & $6.8^{\mathrm{b}}$ & 14.4 \\
Lactic/citric acid blend & $2.5 \%$ & 5.1 & 15.4 \\
SaniDate-5.0 & $0.0064 \%$ & 6.25 & 15.2 \\
SaniDate-5.0 & $0.25 \%$ & 3.75 & 15.1 \\
SaniDate-5.0 & $0.50 \%$ & 15.4 \\
\hline Note: ${ }^{\text {a }}$ The free chlorine concentration tested by DPD method using a chlorine photometer (CP-15, HF Scientific, Inc., Ft. Myers, FL); \\
b adjusted by 10\% citric acid
\end{tabular}




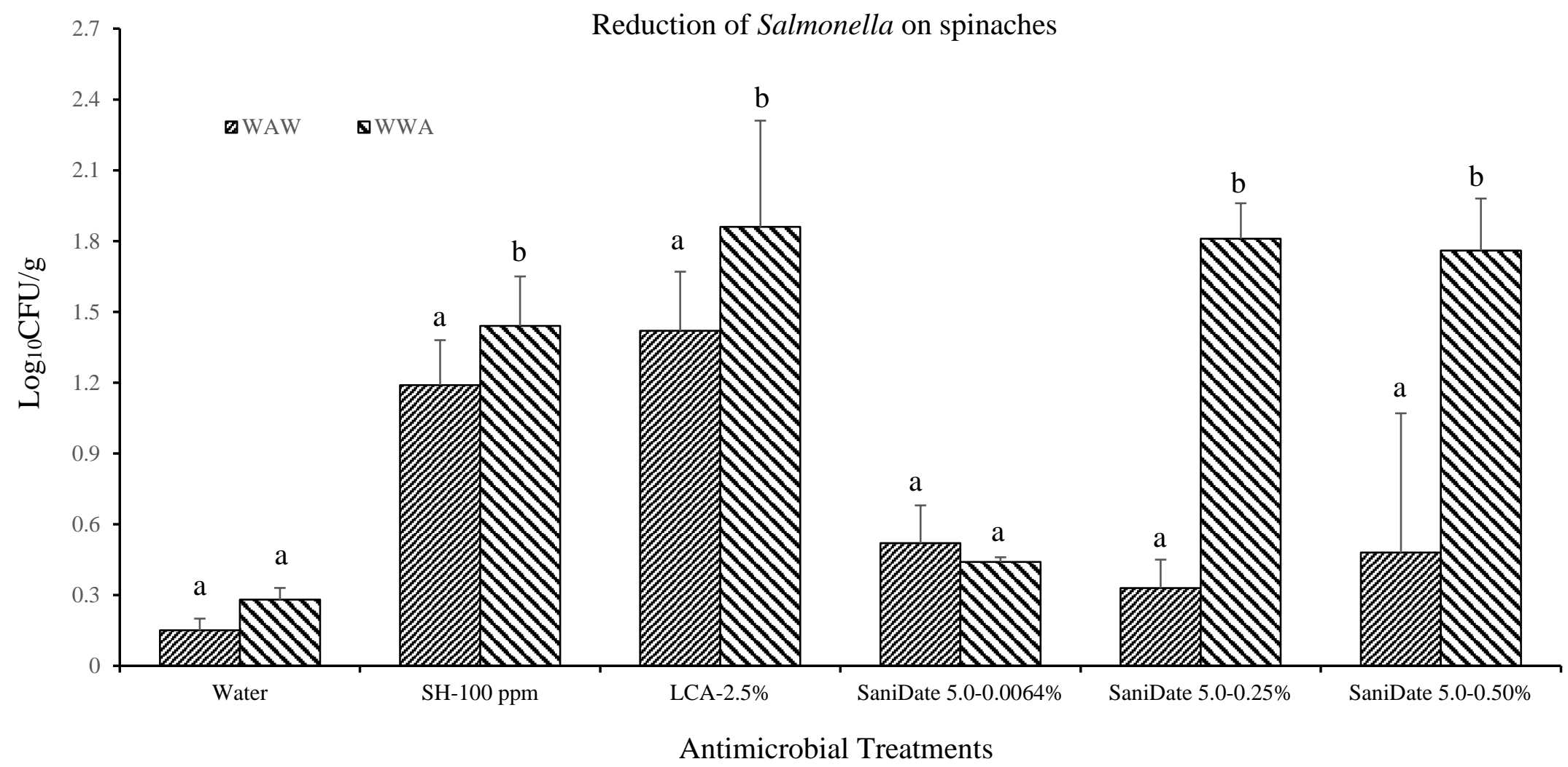

Figure 4.1. Reductions of Salmonella Typhimurium and Tennessee on spinaches $\left(\log _{10} \mathrm{CFU} / \mathrm{g}\right)$ after three-step washing using the procedure of WAW (water dip + antimicrobial dip + water dip) or WWA (water dip + water dip + antimicrobial dip) with or without antimicrobials of sodium hypochlorite (SH-100 ppm), lactic/citric acid blend (LCA, 2.5\%), and a mixture of hydrogen peroxide and peroxyacetic acid (SaniDate-5.0, 0.0064, 0.25 and 0.50\%).

Note: Mean values with different letters on the standard deviation bar are statistically different $(\mathrm{P}<0.05)$. 


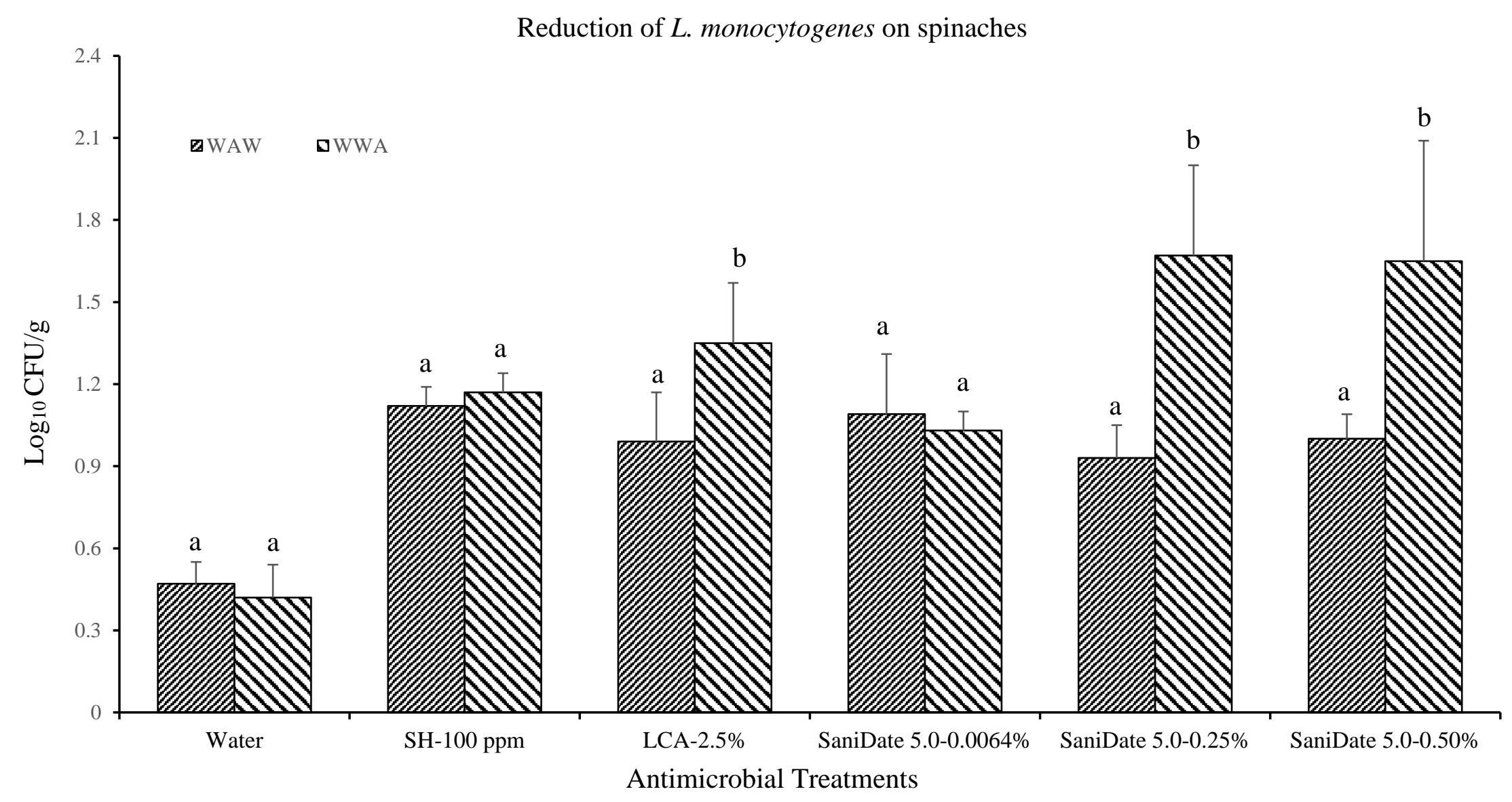

Figure 4.2. Reductions of Listeria monocytogenes on spinaches $\left(\log _{10} \mathrm{CFU} / \mathrm{g}\right)$ after the three-step washing using the procedure of WAW (water dip + antimicrobial dip + water dip) or WWA (water dip + water dip + antimicrobial dip) with or without antimicrobials of sodium hypochlorite (SH-100 ppm), lactic/citric acid blend (LCA, 2.5\%), and a mixture of hydrogen peroxide and peroxyacetic acid (SaniDate-5.0, 0.0064, 0.25 and 0.50\%).

Note: Mean values with different letters on the standard deviation bar are statistically different $(\mathrm{P}<0.05)$. 


\section{CHAPTER 5}

\section{Validation of Triple-Wash Procedure with $\mathrm{A}_{2} \mathrm{O}_{2}$-Peroxyacetic Acid Mixer to Improve Microbial Safety and Quality of Butternut Squashes and Economic Feasibility Analysis}

This study aims to i) evaluate two triple-wash procedures with an $\mathrm{H}_{2} \mathrm{O}_{2}$-peroxyacetic-acid mixer (SaniDate-5.0) to improve microbial safety and quality of butternut squashes and ii) determine the feasibility of the triple-wash application in a processing plant. In study I, fresh squashes were dip-inoculated with a mixture of Salmonella and Listeria monocytogenes, followed by two triplewash steps including water dip-antimicrobial dip-water dip (WAW) or water dip-water dipantimicrobial dip (WWA). Tested antimicrobials were i) lactic/citric acid blend (LCA; 2.5\%); ii) sodium hypochlorite (SH; $100 \mathrm{ppm})$; and iii) SaniDate-5.0, 0.0064, 0.25 and 0.50\%. Surviving bacteria were recovered using XLT-4 agar for Salmonella and MOX agar for L. monocytogenes. In study II, freshly harvested squashes were either left unwashed or triple-washed using WWA in water and SaniDate-5.0 (0.0071 and $0.45 \%)$ at a processing plant followed by storage at $9^{\circ} \mathrm{C}$ for 70 days. Aerobic Plate Counts (APCs), coliforms/Escherichia coli, lactic-acid-bacteria, and psychrotrophs on squashes were tested every seven days. Counts of Salmonella and $L$. monocytogenes on unwashed squash were 5.0-5.3 and 5.4-6.0 $\log _{10} \mathrm{CFU} / \mathrm{squash}$, respectively. WWA wash was more effective $(P<0.05)$ in reducing Salmonella $\left(2.5 \log _{10} \mathrm{CFU} / \mathrm{squash}\right)$ and $L$. monocytogenes (2.3 $\left.\log _{10} \mathrm{CFU} / \mathrm{squash}\right)$ than WAW (1.8 $\log _{10} \mathrm{CFU} / \mathrm{squash}$ for Salmonella and $0.3 \log _{10} \mathrm{CFU} / \mathrm{squash}$ for L. monocytogenes). Antimicrobials caused different degrees in reduction of Salmonella (1.7-2.6 $\left.\log _{10} \mathrm{CFU} / \mathrm{squash}\right)$ and L. monocytogenes (1.2-1.8 $\log _{10}$ CFU/squash) on squashes, while the highest was achieved with SantiDate-5.0 (0.25 or 0.5\%). During storage, SaniDate-5.0 treated squashes showed lower $(P<0.05)$ counts of APCs, 
coliforms, lactic-acid-bacteria, and psychrotrophs than the unwashed and water-treated samples on days 50 to 70 . The estimated annual operating cost of the triple-wash process with SaniDate5.0 ranges from $\$ 487.05$ to $\$ 1,977.33$ for growers producing $1,000-5,000$ squashes. The WWA procedure with SaniDate-5.0 appears to be an economically feasible way for local small producers to improve microbial safety and quality of squashes during postharvest processing.

Keywords: Triple-wash, Antimicrobials, Foodborne Pathogens, Surrogate, Butternut-Squash, Cost-effectiveness Analysis 


\subsection{Introduction}

In West Virginia, there are 93 farmers' markets at over 112 locations (West Virginia Farmers' market Association, 2018), generating approximately \$9.1 million in annual sales with an average annual income of $\$ 41,200$ for full-time produce farmers and $\$ 20,000$ for part-time farmers (Li et al., 2018). As the farmers' markets have become more popular in WV, there has been increasing concern regarding the microbial safety and quality of the available produce. Our most recent study of farmers' markets in WV and Kentucky showed a high prevalence of Salmonella spp. (18.6\% of spinach, $10.9 \%$ of tomatoes, $18.5 \%$ of peppers, and $56.3 \%$ of cantaloupes), and relatively high presence of Listeria spp. (3.78\% of the samples) on locally grown produce surfaces (Li et al., 2017a). Ensuring the safety of fresh produce sold at farmers' markets is essential for the continuing growth of the burgeoning local foods sector in WV.

In 2017, the West Virginia Small Farm Center suggested produce growers use a threestep wash to remove pathogens from produce surfaces if their produce is eaten raw or grown close to the ground. The triple-washing process (water rinse, water rinse, and final antimicrobials dip) has been recognized as an effective tool for removing pathogens from food surfaces and improving on-farm food safety (Strohbehn et al., 2013). The effectiveness of this procedure largely depends on the types of antimicrobial solutions used. Commercial antimicrobials including chlorine water have been studied extensively as an effective and low-cost sanitizer (Shen et al., 2013); however, chlorinated water could be easily degraded by organic matters generated in a produce washing tank and create chlorine by-products (López-Gálvez et al., 2012; Shen et al., 2016). Therefore, produce growers are interested in learning the efficacy of new antimicrobial solutions. For example, SaniDate-5.0, a mix of peroxyacetic acid and $\mathrm{H}_{2} \mathrm{O}_{2}$, is considered by WV local produce processors as an organic sanitizer during post-harvest 
processing. Validating this new antimicrobial solution during postharvest produce processing and storage, as well as the comparison of this strategy to other antimicrobial solutions, are important steps for providing scientific information toward improved food safety for locally grown produce in $\mathrm{WV}$.

Butternut squashes, belonging to winter squashes (Cucurbita spp. L.), are very popular food and ornamental crops in WV. Butternut squashes are weighed from a few ounces to several hundred pounds and are high in vitamin A and fiber and low in calories (Jett, 2014). Although butternut squash has not been associated with any Salmonella outbreaks, in July 2019, Southern Specialties Inc. issued a recall notice for Marketside bagged fresh pre-cut butternut squash because of possible contamination with Listeria spp. (News Desk, 2019). Therefore, butternut squashes can be regarded as a previously unrecognized, under-researched, and emerging food vehicle possibly contaminated with foodborne pathogens.

Although the triple-wash is presumed to reduce foodborne pathogens effectively, the efficacy of antimicrobial solutions should be tested in the laboratory as well as in the real produce farm setting, where the dynamic processing conditions are more complex than the laboratory setting. In addition, an economic feasibility analysis with cost data from real plant settings is also needed to determine the potential of popularizing the proposed sanitizing procedure among small produce growers in WV. Therefore, the objectives of this study were to 1) evaluate two triple-wash procedures with antimicrobials to reduce Salmonella and Listeria monocytogenes on butternut squashes in the laboratory, 2) evaluate the shelf-life stability of washed squashes in a real processing plant, and 3) evaluate the economic feasibility of adopting the triple-wash process through cost-benefit analyses. 


\subsection{Materials and Methods}

\subsubsection{Preparation of inoculum and inoculation of squashes}

In this study, two Salmonella strains (Salmonella Typhimurium ATCC 14028 and Salmonella Tennessee ATCC 10722), and two L. monocytogenes strains (L2624 and L2625cantaloupe outbreak serotype 1/2b, donated by Dr. Joshua Gurtler, USDA-ARS, Wyndmoor, PA) were used in the laboratory triple-wash validation studies. Each Salmonella or L. monocytogenes strain was prepared separately. In each experiment, only one cocktail (Salmonella or L. monocytogenes) was used, and thus, no combination of bacteria inoculum occurred in this study.

Pure cultures of Salmonella and L. monocytogenes were generated by streak-plating frozen stock cultures onto Xylose-Lysine-Tergitol-4 (XLT-4, Hardy Diagnostics, Santa Maria, CA, USA) and Modified Oxford (MOX) agar (Hardy Diagnostics, Santa Maria, CA, USA), respectively, and then incubating at $35^{\circ} \mathrm{C}$ for 24 (XLT-4) or $48 \mathrm{~h}$ (MOX) to form single colonies. On the day of the experiment, two single colonies picked from XLT-4 (Salmonella) and MOX Agar (L. monocytogenes) of each strain were cultured in $10 \mathrm{~mL}$ of tryptic soy broth (TSB, Alpha Biosciences, Baltimore, MD, USA) and incubated at $35^{\circ} \mathrm{C}$ for $24 \pm 2 \mathrm{~h}$. The initial concentration was $7.41 \log _{10}$ CFU/mL for Salmonella Typhimurium, $7.96 \log _{10}$ CFU/mL for Salmonella Tennessee, $8.59 \log _{10} \mathrm{CFU} / \mathrm{mL}$ for L. monocytogenes 2624 , and $8.77 \log _{10} \mathrm{CFU} / \mathrm{mL}$ for $L$. monocytogenes 2625. Each Salmonella and L. monocytogenes culture was centrifuged at a speed of 5,000 $\times \mathrm{g}$ for $15 \mathrm{~min}$ (VWR Symphony 4417, VWR International, Radnor, PA), and then triplicate washed in $0.1 \%$ buffered peptone water (BPW, Alpha Biosciences, Baltimore, MD, USA), followed by re-suspending in $10 \mathrm{~mL}$ of $0.1 \%$ BPW. After washing, the initial concentration of Salmonella and L. monocytogenes cells in the re-suspended solution was 7.6 and $8.7 \log _{10} \mathrm{CFU} / \mathrm{mL}$, respectively. To make a similar initial inoculum level of Salmonella and 
L. monocytogenes (difference $\leq 0.5 \log _{10} \mathrm{CFU} / \mathrm{mL}$ ), each Salmonella strain was prepared in duplicate based on the preliminary studies. Inoculum of Salmonella and L. monocytogenes were made from the above-mentioned two-strain cocktail separately, where two Salmonella strains were combined, or two L. monocytogenes strains were combined. The volume of $40 \mathrm{~mL}$ (Salmonella) or $20 \mathrm{~mL}$ (L. monocytogenes) prepared cocktails were then added into $3 \mathrm{~L} 0.1 \%$ BPW solution to yield an inoculum solution with a target concentration of $6.2-6.7 \log _{10} \mathrm{CFU} / \mathrm{ml}$, which was used for the following dip inoculation process. Each butternut squash, obtained from Preston County Workshop Inc., was inoculated by placing the product in a plastic tub containing $3 \mathrm{~L}$ of the inoculum with manual stir for $5 \mathrm{~min}$, followed by placement in a biosafety cabinet for 30 min to allow for pathogen attachment.

\subsubsection{Triple wash squashes with antimicrobials in lab condition}

Inoculated squashes were left unwashed (control) or triple washed in three large plastic tubs with $10 \mathrm{~L}$ solution in each. For each treatment, 6 squashes were randomly split into two groups ( 3 samples each), followed by two triple-wash procedures including a water dipantimicrobial dip-water dip (WAW), or a water dip-water dip-antimicrobial dip (WWA), followed by draining for 2 min on fresh paper towel. Each wash step was $10 \mathrm{~s}$ of dip time with manual rotation. The triple-wash process was conducted by three workers, each carrying and washing one squash into each $10 \mathrm{~L}$ solution tub followed by WAW or WWA procedure at the same time. After washing three squashes, old solutions were added with $500 \mathrm{ppm}$ chlorine for 30 min followed by autoclaving. The tubs were sanitized, refreshed with new water or new antimicrobial solutions to prevent cross-contamination from the previous treatment. Tested antimicrobials were i) sodium hypochlorite $(\mathrm{SH}$; free available chlorine $100 \mathrm{ppm}, \mathrm{pH}=6.8$ adjusted by $10 \%$ citric acid, $14.4^{\circ} \mathrm{C}$; Birko, Henderson, CO, USA), ii) a lactic/citric acid blend 
(LCA, Veggiexide ${ }^{\circledR}, 2.5 \%, \mathrm{pH}=5.1,15.4^{\circ} \mathrm{C}$, Birko); and iii) an $\mathrm{H}_{2} \mathrm{O}_{2}$-peroxyacetic-acid mixer (SaniDate-5.0, $15.2^{\circ} \mathrm{C}$; Arbico Organics, Tucson, AZ, USA) with the concentrations of 0.0064 (pH 6.25), $0.25(\mathrm{pH} 5.52)$ and $0.50 \%(\mathrm{pH} 3.75)$.

\subsubsection{Triple wash squashes in a processing plant}

The onsite plant shelf-life validation studies were conducted at Preston County Workshop, Reedsville, WV, from September to December 2018. Freshly harvested butternut squashes without any brown rust color (visible Fusarium Wilt contamination), animal bites, and large punctures on their skin were picked. The triple-wash was processed in three commercial washing tanks, each containing 175 gallons of water. Based on the laboratory test results, the WWA procedure was applied in this onsite plant study. The first step was dipping squashes into a water solution $\left(\mathrm{pH} 7.02,13.3^{\circ} \mathrm{C}\right)$ and manually brushing with a produce brusher for $15 \mathrm{sec}$ (Figure 5.1A); then the brushed samples were dipped into the second water tank $(\mathrm{pH} 7.05$, $14.3^{\circ} \mathrm{C}$ ) and with soft cloth towels scrubbed for $15 \mathrm{sec}$ (Figure 5.1B). Finally, the samples were placed into a melt rinse container with mesh and completely immersed in the SaniDate-5.0 solutions for $45 \mathrm{sec}$ (Figure 5.1C). The antimicrobial treatments tested in the third tank were 1) water, 2) SaniDate-5.0-0.0071\% (pH 5.88, $\left.15.1^{\circ} \mathrm{C}\right)$ and 3) SaniDate-5.0-0.45\% (pH 3.79, $15.2^{\circ} \mathrm{C}$ ). The unwashed squashes were included as the controls. After triple-washing, the squashes were dried in front of a fan for $30 \mathrm{~min}$, followed by storage in a cooler at $9^{\circ} \mathrm{C}$ for 70 days. The temperatures $\left(9.1 \pm 0.59^{\circ} \mathrm{C}\right)$ and relative humidity values $(\mathrm{RH} 72.04 \pm 2.68 \%)$ of the cooler were monitored and recorded during the whole experiment period. Squash samples were collected every 7 days and transferred to the Food Science Laboratory at West Virginia University to conduct microbial quality analysis. 


\subsubsection{Microbiological analysis}

Each squash was placed into a sterile chicken-rinse bag (Nasco, Fort Atkinson, WI, USA) and rinsed in $200 \mathrm{ml}$ of BPW, followed by vigorously shaking for $60 \mathrm{~s}$ to detach microorganisms from the surface. For laboratory studies, the squash rinse solutions were 10-fold serially diluted in $0.1 \%$ BPW and then spread-plated on XLT-4 and MOX agar to enumerate Salmonella and $L$. monocytogenes cells, respectively, followed by incubating agar plates at $35^{\circ} \mathrm{C}$ for $24 \mathrm{~h}$ (XLT-4) or $48 \mathrm{~h}(\mathrm{MOX})$. For onsite plant studies, squash rinse solutions for counting the total aerobic bacteria, coliform, and Escherichia coli populations were surface-plated onto $3 \mathrm{M}^{@}$ APCs, E. coli/coliforms petrifilm (3M Microbiology Products, St. Paul, MN, USA) following manufacturer instructions and incubated at $35^{\circ} \mathrm{C}$ for $72 \mathrm{~h}$ (APCs) or $48 \mathrm{~h}$ (E. coli/coliforms). Samples for lactic acid bacteria (LAB) were spread-plated onto Man-Rogosa-Sharpe (MRS) agar (Hardy Diagnostics, MD, USA) and incubated in an anaerobic jar (Hardy Diagnostics) at $30^{\circ} \mathrm{C}$ for 3 days. Samples for psychrotrophs (PSY) were spread-plated onto tryptic soy agar and incubated at $4^{\circ} \mathrm{C}$ for 10 days. All agar plates and petrifilms were manually counted colonies after the incubation period.

\subsubsection{Economic feasibility analysis}

To examine the economic feasibility of the triple wash process, we calculated its operating cost for three types of growers, according to their production scale. In conducting the analysis, we assumed that (1) a 200-gallon water tank costs $\$ 250$ and lasts for 10 years; (2) scrub brush and microfiber towels are replaced annually at $\$ 5$ and $\$ 1$ each, respectively; (3) labor cost is $\$ 10 /$ hour; (4) water, including sewage, costs $\$ 10$ per 1,000 gallons $(3,784 \mathrm{~L})$; (5) each triple wash section takes three hours; (6) 500 squashes can be processed in each section with the help of four workers. The costs of antimicrobials (SaniDate-5.0 at $0.0071 \%$ and $0.45 \%$ ) and the mixed 
solutions are listed in Table 5.1. The market cost of SaniDate-5.0 is $\$ 62.20 /$ gallon. The amount needed for preparing a 175 -gallon water solution with $0.0071 \%$ and $0.45 \%$ SaniDate-5.0 is 47.03 and $2981.01 \mathrm{~mL}$, respectively. Therefore, the costs for 175 -gallon mixed solution is $\$ 2.52$ $(0.0071 \%)$ and $\$ 50.73(0.45 \%)$. For simplicity, we focus our discussion on the extra cost that would be incurred by farmers had they adopted the triple wash process, without considering the cost associated with other post-harvest procedures.

\subsubsection{Data analysis}

The laboratory study was triple-repeated with 3 squashes per treatment per repeat with a total of 9 samples per treatment. It was conducted with a completely randomized $2 \times 5$ factorial design for the 2 triple-wash procedures (WAW or WWA) and 5 antimicrobial treatments. The survival and reduction of Salmonella and L. monocytogenes were analyzed using the mixed model procedure of SAS (version 9.2, SAS Institute, Cary, NC), with the individual factors being the wash procedure, the antimicrobial treatment, and their interactions. The reduction data were determined by a reduction ratio of $\log 10\left(\mathrm{~N}_{0} / \mathrm{N}\right)$, which includes $\mathrm{N}_{0}$, the average control plate counts, and N, the plate count of each antimicrobial treated sample (Adler et al., 2016). The means were compared at an $\alpha=0.05$ significance level as determined by Tukey HSD. The plant onsite shelf-life studies were repeated twice, and for each replication, 3 individual samples per treatment at each sampling time were analyzed $(n=6)$. The Mixed Model Procedure in SAS $®$ was used to analyze the counts of APCs, coliforms/E. coli, LAB, and PSY on squash surfaces, and the individual factors are the antimicrobial used, time period, and their interaction. A statistical significance level of $0.05(P<0.05)$ as determined by LSD was used. 


\subsection{Results and Discussion}

\subsubsection{Laboratory study: antimicrobial effect of treatments during the triple-wash process}

The microbial population of unwashed and triple-washed inoculated squash was obtained on XLT-4 and MOX for Salmonella and L. monocytogenes, respectively. Initial levels of inoculated Salmonella and L. monocytogenes on unwashed squash surfaces were 5.0 to $5.3 \log _{10}$ $\mathrm{CFU} / \mathrm{squash}$ and 5.4 to $6.0 \log _{10} \mathrm{CFU} / \mathrm{squash}$, respectively. According to the mixed model procedure of SAS, for Salmonella the antimicrobial efficacy of triple wash was determined by the wash process $(P<0.05)$, and the type of antimicrobial agent $(P<0.05)$. For $L$. monocytogenes, the triple-wash process was also significant $(P<0.05)$, but the type of antimicrobial agent was not the main effect $(P>0.05)$. No interactions $(P>0.05)$ were significant for either Salmonella and L. monocytogenes.

Our internal survey during the produce wash short course at the 2018 WV Small Farm Conference showed that small produce growers applied two triple-wash processes. i.e., WAW and WWA, in WV. In this laboratory test, the least squares means (LS means) across the tested antimicrobials indicate that WWA is more effective $(P<0.05)$ than WAW in reducing Salmonella (2.54 versus $\left.1.84 \log _{10} \mathrm{CFU} / \mathrm{squash}\right)$ and L. monocytogenes $\left(2.30\right.$ versus $0.72 \log _{10}$ $\mathrm{CFU} /$ squash) on squash surfaces. No previous studies have been conducted to compare the reductions from these two triple wash procedures. For WWA, the first two water wash steps removed the organic matter from the squash surfaces and possibly lowered the initial population on squashes by physical removal which benefits the final antimicrobial wash.

Antimicrobials applied in triple-wash WAW procedure onto butternut squashes significantly reduced the Salmonella population (survival of 2.5 to $3.9 \log _{10} \mathrm{CFU} / \mathrm{squash}$ ) compared to the unwashed control $\left(5.0 \log _{10} \mathrm{CFU} / \mathrm{squash}\right)$, with the reductions ranging from 1.1 
(SH) to 2.5 (SD-0.50\%) $\log _{10} \mathrm{CFU} / \mathrm{squash}$ (Table 5.2). Compared with the WAW, squashes washed through the WWA procedure in SH, LCA, SaniDate-5.0-0.0064\%, and $-0.25 \%$ achieved a significant additional reduction $(P<0.05)$ of Salmonella by $1.6,0.8,0.4$, and $0.6 \log _{10}$ CFU/squash, respectively (Table 5.1). However, no significant difference $(P>0.05)$ between WAW and WWA was found for reductions in SaniDate-5.0-0.5\% washed samples.

L. monocytogenes is a possible emerging and under-researched pathogen on butternut squashes. Similar to the results for Salmonella, triple-washing following a WAW process with antimicrobials significantly reduced $L$. monocytogenes $(P<0.05)$ on squashes, resulting in a surviving population of 4.8 (SH and LCA) to $5.5 \log _{10} \mathrm{CFU} / \mathrm{squash}$ (SaniDate-5.0-0.5\%) compared to $6.0 \log _{10} \mathrm{CFU} / \mathrm{squash}$ of the unwashed control. Squashes washed in $0.5 \%$ of SaniDate-5.0 achieved the highest $(P<0.05)$ reduction $\left(1.2 \log _{10}\right.$ CFU/squash $)$ among the five tested antimicrobial treatments, and no significant difference $(P>0.05)$ was observed among the reductions (0.5 to $0.8 \log _{10} \mathrm{CFU} / \mathrm{squash}$ ) resulting from SH, LCA, SaniDate-5.0-0.0064\% and SaniDate-5.0-0.25\% (Table 5.2). Similarly, the WWA procedure significantly enhanced $(P<$ 0.05) the reduction levels by 1.6 to $1.8 \log _{10} \mathrm{CFU} / \mathrm{squash}$ for all tested antimicrobial solutions as compared to the WAW (Table 5.2). However, there was no difference $(P>0.05)$ in reductions among these five treatments applied by the WWA procedure.

Chlorine water, primarily composed of hypochlorous acid $(\mathrm{HOCl})$, is currently the most commonly used sanitizer during fresh produce processing due to its strong ability to kill microorganisms in solutions, minimal impact on produce quality, and economic feasibility (Shen et al., 2013). Chlorine was found to have significantly reduced the Salmonella population on cantaloupe (Fan, Annous, Keskinen, \& Mattheis, 2009) and the antimicrobial effect was observed throughout the 6-day storage period at $4{ }^{\circ} \mathrm{C}$ (Ukuku \& Sapers, 2001). Results from this 
study showed that reductions of 1.1 to 2.7 and 0.5 to $2.3 \log _{10} \mathrm{CFU} / \mathrm{squash}$ were achieved by $\mathrm{SH}$ to inactivate Salmonella and L. monocytogenes, respectively, on squashes, which are similar to previous results of SH on other fresh produce (Gil et al., 2009). Recently, fresh produce processors, including local small produce processors, have become more interested in evaluating the efficacy of alternative antimicrobials during the post-harvest washing process (Adler et al., 2016) due to certain disadvantages of chlorine, such as fast degradation and the generation of byproducts (Shen, Luo, Nou, Wang, \& Millner, 2013; Shen, Norris, Williams, Hagan, \& Li, 2016). LCA, a buffered mixture of the lactic and citric acid solution, can reduce the bacterial intracellular $\mathrm{pH}$ and disrupts the transmembrane proton motive force (Raybaudi-Massilia et al., 2009; Ricke, 2003). A recent study suggested that cabinet spraying 2.5\% LCA onto Jalapeno peppers reduced the natural flora, generic Escherichia coli, and Salmonella counts by 1.3, 0.8, and $1.1 \log _{10}$ CFU/g, respectively (Adler et al., 2016). Results from the present study showed that LCA achieved very similar reductions compared to the SH for both Salmonella (1.1-2.7 vs. 1.3 to $2.1 \log _{10} \mathrm{CFU} / \mathrm{squash}$ ) and L. monocytogenes (same at 0.5 to $2.3 \log _{10} \mathrm{CFU} / \mathrm{squash}$ ), regardless of applying a WAW or WWA procedure. Hydrogen peroxide $\left(\mathrm{H}_{2} \mathrm{O}_{2}\right)$ is another common sanitizer, which has been reported to effectively reduce the Salmonella population on produce surface in the postharvest washing process (Ukuku \& Sapers, 2001; Ukuku \& Fett, 2004). SaniDate-5.0, mainly composed of $23 \% \mathrm{H}_{2} \mathrm{O}_{2}$ and $5.3 \%$ peroxyacetic acid, has been recommended by the WV Small Farm Center to treat fresh produce from small produce farms in WV (Li et al., 2017b). The mechanism of SaniDate-5.0 to inactivate pathogens is to oxidize bacterial cells, denature protein and further disrupt cell wall structure (Block, 2011). Results of the present study indicate a similar or greater $(P<0.05)$ reduction of Salmonella and $L$. monocytogenes by SaniDate-5.0 as compared to SH, especially for the $0.5 \%$ concentration level. 
Therefore, SaniDate-5.0 could be potentially used by locally small produce processors as an alternative antimicrobial solution to $\mathrm{SH}$.

\subsubsection{Plant onsite study: evaluate the shelf-life stability of washed squashes}

Validation of a new antimicrobial solution that can be readily adopted by the food processing industry often requires test conditions that match as closely as possible the commercial operation setting (Luo et al., 2012). Therefore, a plant onsite shelf life study was conducted in fall 2018 at our project stakeholder, Preston County Workshop, Reedsville, WV, a squash processing plant. Since the stakeholder is currently applying SaniDate-5.0 during its triple-wash process, this study only focussed on SaniDate-5.0 solutions with concentrations of $0.0071 \%$ (currently used by the stakeholder) and $0.45 \%$ as compared to the water-washed and unwashed samples.

Overall, no significant $(P>0.05)$ growth of the tested APCs, coliforms/ E. coli, PSY, and LAB counts on squash surfaces was detected during the storage period (70 days) due to the relatively low storage temperature of $9^{\circ} \mathrm{C}$ (Figure 5.2). The fluctuation of the microbial counts on squash surfaces during storage was attributed to inconsistent initial microbial loads among freshly harvested squashes. It is also noticed that a reduction of APCs, coliforms, PSY, and LAB counts started for almost all treated samples including the water and control group on day 49 , which could be explained by the metabolic injury to bacteria at the low temperature. The death of bacteria slowly starts during extended storage at low temperature which begins with nonlethal physical or metabolic injury and further developed to progressively cold injury requiring additional nutrition to survive (Straka and Stokes, 1959). Squashes treated by SaniDate-5.0 with $0.0071 \%$ or $0.45 \%$ had lower $(P<0.05)$ counts of APCs, coliforms, LAB, and PSY than the unwashed and water-treated samples typically from days 49 to 70 (Figure 5.2) due to the use of 
antimicrobials. In contrast to the laboratory tests, no difference $(P<0.05)$ between the $0.0071 \%$ and $0.45 \%$ of SaniDate-5.0 was observed in the onsite plant studies, which is possibly due to the dipping time of $10 \mathrm{~s}$ (laboratory test) verse $45 \mathrm{~s}$ (onsite plant studies) in each washing step. The dipping time was limited to $10 \mathrm{~s}$ in the laboratory test because this test was focused on the impact of antimicrobial treatments and the triple-wash processes (WAW vs. WWA). The 45s washing time used in the onsite plant test because the triple-wash process needs to be conducted the same as the stakeholder did for their commercial products. This result also suggests that 1) simply using a higher concentration of antimicrobials is not necessary to improve microbial quality of squashes; 2) the reduction efficacy is often lower than expected in commercial-scale processing plants because operational and storage conditions are much less controlled in the real commercial-scale implementation than under academic laboratory conditions.

Initial APCs on unwashed fresh raw butternut squashes were $7.3 \pm 0.2 \log _{10} \mathrm{CFU} / \mathrm{squash}$ (Figure 5.2). After the squashes were triple-washed and dried, APCs on squash decreased by 0.5, 0.3, and $0.7 \log _{10} \mathrm{CFU} / \mathrm{squash}$ to $4.5,4.7$, and $4.4 \log _{10} \mathrm{CFU} / \mathrm{squash}$ for water, SaniDate-5.0$0.0071 \%$ and $-0.45 \%$ treatment samples, respectively, which were not significantly different $(P>$ 0.05) (Figure 5.2). During storage, APCs remained between 6.6 to $7.9 \log _{10}$ CFU/squash and 6.2 to $8.0 \log _{10} \mathrm{CFU} / \mathrm{squash}$ on unwashed and water-washed samples, respectively (Figure 5.2). In the final 21 days of storage (days 49 to 70), compared to the unwashed control, APC declines $(P<0.05)$ of 0.5 to $1.2 \log _{10} \mathrm{CFU} / \mathrm{squash}$ were observed for the SaniDate-5.0-0.0071\% and $0.45 \%$ washed squashes, which were greater $(P<0.05)$ than the water treatment reductions of 0.1 to $0.4 \log _{10} \mathrm{CFU} /$ squash (Figure 5.2).

Although no studies have reported the APCs on butternut squashes, the APCs on similar crops such as cantaloupes and tomatoes treated by antimicrobials are well documented. In a 
previous study (Fan, Annous, Keskinen, \& Mattheis, 2009), the results suggested that $180 \mathrm{ppm}$ chlorine and $80 \mathrm{ppm}$ peroxyacetic acid (PAA) reduced APCs on cantaloupes by 0.8 and $0.7 \log _{10}$ $\mathrm{CFU} / \mathrm{cm}^{2}$; however, the reduction effect was not statistically significant. Moreover, 80 ppm PAA treatment significantly reduced the aroma score at $4^{\circ} \mathrm{C}$ storage, which negatively affected the postharvest quality of cantaloupes. Another alternative sanitizer $5 \%$ acetic acid at $25^{\circ} \mathrm{C}$ also had no significant effect on APCs reduction on cantaloupe surfaces (Fouladkhah \& Avens, 2010), a result similar to those found in Fan's study. Inconsistent results were reported for $\mathrm{H}_{2} \mathrm{O}_{2}$ as antimicrobials against APCs on cantaloupe. Although $2.5 \% \mathrm{H}_{2} \mathrm{O}_{2}$ significantly reduced total mesophilic aerobes on cantaloupe and honeydew melon surfaces (Ukuku, Bari, Kawamoto, \& Isshiki, 2005), $5 \% \mathrm{H}_{2} \mathrm{O}_{2}$ at $50^{\circ} \mathrm{C}$ was reported to have no significant effect against $\mathrm{APCs}$ on shelf-life of fresh-cut cantaloupes (Sapers, Miller, Pilizota, \& Mattrazzo, 2001). Heated sanitizer, even hot water, showed a better antimicrobial effect against APCs. APCs were significantly reduced on cantaloupe surfaces when water and $5 \%$ acetic acid were used at $95^{\circ} \mathrm{C}$ (Fouladkhah \& Avens, 2010). As the surface of cantaloupes was highly uneven and rough, the antimicrobial effect of many sanitizers may be restricted without surfactants. For example, $150 \mathrm{ppm}$ chlorine treatment on tomatoes was reported to have a significant effect against APCs (Sibomana, Ziena, Schmidt, \& Workneh, 2017) while 180 ppm chlorine did not have a significant effect on cantaloupes (Fan, Annous, Keskinen, \& Mattheis, 2009).

The initial population of PSY on unwashed squashes was $6.0 \log _{10} \mathrm{CFU} / \mathrm{squash}$. Triplewashing squashes in water reduced $(P<0.05)$ the PSY counts by $0.9 \log _{10} \mathrm{CFU} / \mathrm{squash}$ on day 0 , and the reductions increased to $1.2(P=0.05)$ and $1.5 \log _{10} \mathrm{CFU} / \mathrm{g}(P<0.05)$ when SaniDate-5.0-0.0071\% and 0.45\% solution was applied, respectively (Figure 5.3). Between 14 and 49 days in storage, the levels of PSY among treatments did not change significantly $(P>$ 
0.05, Figure 5.2). Towards the end of the storage, from days 56 to 70, SaniDate-5.0-0.0071\% (3.9 to $4.5 \log _{10} \mathrm{CFU} / \mathrm{squash}$ ) and $0.45 \%$ (3.1 to $4.4 \log _{10} \mathrm{CFU} / \mathrm{squash}$ ) treated samples showed significantly $(P<0.05)$ lower survivals of PSY, as compared to the unwashed control (5.1 to $5.4 \log _{10} \mathrm{CFU} / \mathrm{squash}$ ) and water-treated samples (4.7 to $5.7 \log _{10} \mathrm{CFU} / \mathrm{squash}$ ) (Figure 5.2). Initial total coliform counts on butternut squashes from unwashed and water-treated samples were 5.1 and $4.7 \log _{10} \mathrm{CFU} / \mathrm{squash}$, respectively (Figure 5.3). A significant lower $(P<$ 0.05) count of coliforms of $3.0 \log _{10} \mathrm{CFU} / \mathrm{squash}$ was obtained on SaniDate-5.0-0.45\% treated samples on day-0 and SaniDate-5.0-0.0071\% treated samples on day 7, compared to the unwashed control and water treated samples (Figure 5.3). Similar to the APCs and PSYs, no significant $(P>0.05)$ difference in coliforms counts among all treatments were found on days 14-42 in storage. However, during the last three weeks of storage (days 49-70), coliforms ranged from 4.3 to $4.9 \log _{10} \mathrm{CFU} / \mathrm{squash}$ and 3.7 to $4.7 \log _{10} \mathrm{CFU} / \mathrm{squash}$ for samples washed in SaniDate-5.0-0.0071\% and SaniDate-5.0-0.45\% solutions, respectively, which were significantly lower than the samples of the unwashed control (5.1 to $6.0 \log _{10} \mathrm{CFU} / \mathrm{squash}$ ) and those receiving water treatment only (5.3 to $5.8 \log _{10} \mathrm{CFU} / \mathrm{squash}$ ) (Figure 5.2). For the E. coli counts, SaniDate-5.0-0.0071\% and $-0.45 \%$ solution did not cause significant reductions during the storage period except for days 56-63, with a very low survival of 0.0-0.3 $\log _{10} \mathrm{CFU} / \mathrm{squash}$ (Data not shown in tabular form).

LAB is Gram-positive, acid-tolerant, and lactic acid-producing bacteria, which usually grows well in an environment rich in $\mathrm{CO}_{2}$ and low in $\mathrm{O}_{2}$ (Luo, 2007). In this study, the squashes were stored aerobically. Therefore the LAB counts on unwashed control samples ranged from 5.1 to $6.3 \log _{10} \mathrm{CFU} / \mathrm{squash}$ with no significant growth. On day 0, the SaniDate-5.0-0.45\% washed samples resulted in lower $(P<0.05) \mathrm{LAB}$ populations $\left(5.2 \log _{10} \mathrm{CFU} / \mathrm{g}\right)$ than the 
control (5.8 $\left.\log _{10} \mathrm{CFU} / \mathrm{squash}\right)$ and the water treated samples $\left(6.2 \log _{10} \mathrm{CFU} / \mathrm{squash}\right)$ (Figure 5.2). From days 7 to 14 , the washed samples showed lower $(P<0.05)$ survival of LABs than the unwashed control; however, no significant difference $(P<0.05)$ between SaniDate-5.0 and water treated samples were found. Similar to the aforementioned microbial quality results, from days 49 to 70, the SD washed samples indicated significantly lower $(P<0.05)$ LAB counts on squash surfaces than the control and water treated samples. For example, the LAB survival on SaniDate-5.0-0.45\% remained as 3.9 to $4.4 \log _{10}$ CFU/squash, which is lower $(P<0.05)$ than the other three treatments.

The antimicrobial effects of chlorine and $\mathrm{H}_{2} \mathrm{O}_{2}$ were tested previously on LAB (Ukuku, 2006; Ukuku \& Fett, 2004). Among the tested sanitizers, chlorine at 200 ppm or $\mathrm{H}_{2} \mathrm{O}_{2}$ at $2.5 \%$ and $5 \%$ were reported to be significantly effective at reducing the population of LAB when

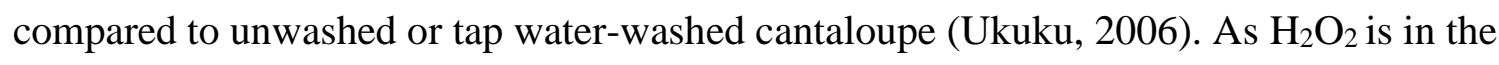
formula of SaniDate-5.0, the antimicrobial effect of SaniDate-5.0 was expected on squashes.

\subsubsection{The operating cost of triple-wash on squashes}

Our previous economic analysis calculated the cost of implementing triple wash for typical produce farmers in WV, finding only a modest increase to operating cost when applying the triple-wash procedure with chlorine and a slightly higher increase when using SaniDate-5.0 (Scarcioffololo et al., 2018). Even though earlier analysis showed that triple-wash could be considered a low-cost sanitizing procedure, more detailed analyses, in conjunction with the cost data obtained from real plant settings are needed to determine the economic feasibility of the triple-wash procedure for local small producers.

Table 5.4 lists the operating cost of triple-wash for squash growers of the small, medium, and large scales when the water and antimicrobial solution are re-used throughout each section. 
The triple-wash process requires minimal initial set-up cost, and its fixed cost only includes the cost for the water tanks, hand brushes, microfiber, and annualized maintenance expenditure. Growers may choose to harvest squashes multiple times throughout the harvest window and conduct a triple-wash section when a total of 500 squashes have been harvested. Since the process is labor-intensive, it is not surprising to see in Table 5.2 that most of the operating cost comes from labor, especially for larger-scale growers. For SaniDate-5.0-0.0071\%, labor cost accounts for $49.3 \%, 64.9 \%$, and $80.3 \%$ of the added processing cost for growers producing $1,000,2,000$, and 5,000 squashes, respectively.

As shown in Table 5.4, when water and treatments are reused in the same section, the annual operating cost of the triple wash process ranges between $\$ 487.05$ and $\$ 1,977.33$ for growers producing 1,000-5,000 squashes using SaniDate-5.0 at two levels of concentration. As compared to the lower-concentration antimicrobial solution, it costs $20 \%$ extra to apply the solution with the higher SaniDate-5.0 concentration for two sections per year (1,000 squashes), which rises to $32 \%$ for 10 sections per year (5,000 squashes). Overall, it costs around 3 times more to apply 10 sections of triple-wash on squashes as compared to 2 sections.

Since the effectiveness of antimicrobials may decrease when the level of organic load increases, farmers may choose to process fewer squashes in each triple wash section. The shortened wash section also allows farmers more flexibility in deciding when to harvest squash during the harvest window as they can conduct the sections on different days. We compute the operating cost for the triple-wash process when 60 and 180 squashes are processed in each section, the results of which are presented in Table 5.5. Compared to the 500-squash section, it costs $20-220 \%$ more for the 60 -squash section depending on the production scale and the antimicrobial concentration level (Table 5.5). For the 180-squash section, the cost would 
increase by $5-55 \%$ compared to the baseline case of processing 500 squashes per section (Table 5.5). The increased operating cost is attributed to the extra cost required for more water and antimicrobial solutions which are replaced at the end of each section. Since the triple-wash procedure can be applied to a variety of produce, the fixed cost is expected to decrease when the system is operated more frequently.

In conclusion, applying the triple-wash process with the WWA procedure showed better bacterial pathogen reductions than the WAW procedure. SaniDate 5.0 indicates similar or better antimicrobial efficacy against Salmonella and L. monocytogenes compared to chlorine water and LCA solutions. SaniDate-5.0 treated squashes showed lower microbial counts than the unwashed and water-treated samples typically during the later storage period. The annual operating cost of the triple-wash using SaniDate-5.0 is approximately $\$ 500$ to $\$ 2,000$ for producing 1,000 to 5,000 squashes. An extra 5-220\% cost will be added if the water is refreshed in each tank. Results from this study provide important information for local small produce growers who are interested in adopting the triple-wash procedure with SaniDate-5.0 during postharvest processing.

\section{Acknowledgment}

This research was supported by the United States Department of Agriculture, the National Institute of Food and Agriculture, the AFRI-Critical Agricultural Research and Extension (CARE) (Grant \# 2019-68008-29828), and the Non-Land Grant Colleges of Agriculture (NLGCA) Capacity Building Program (Grant \# 2017-70001-25993). The authors appreciate the WVU Extension Service Small Farm Center for their generous assistance during the project period. We also appreciate Dr. Peter V. Schaeffer, Professor of Resource Economics \& Management, Interim Director, Division of Animal and Nutritional Sciences, WVU, for the critical reading of this manuscript. 


\section{References}

Adler, J. M., Cain-Helfrich, E. D., \& Shen, C. (2016). Reductions in Natural Microbial Flora, Nonpathogenic Escherichia coli, and Pathogenic Salmonella on Jalapeno Peppers Processed in a Commercial Antimicrobial Cabinet: A Pilot Plant Trial. Journal of Food Protection, 79, 1854-1859.

Block, S. S. (Ed.). (2001). Peroxygen compounds. In Disinfection, sterilization, and preservation (5th ed, pp. 185-204). Philadelphia, PA: Lippincott Williams \& Wilkins.

Fan, X., Annous, B. A., Keskinen, L. A., \& Mattheis, J. P. (2009). Use of Chemical Sanitizers To Reduce Microbial Populations and Maintain Quality of Whole and Fresh-Cut Cantaloupe. Journal of Food Protection, 72(12), 2453-2460.

Fouladkhah, A., \& Avens, J. S. (2010). Effects of Combined Heat and Acetic Acid on Natural Microflora Reduction on Cantaloupe Melons. Journal of Food Protection, 73(5), 981984.

Gil, M. I., Selma, M. V., López-Gálvez, F., \& Allende, A. (2009). Fresh-cut product sanitation and wash water disinfection: problems and solutions. International Journal of Food Microbiology, 134, 37-45.

Jett, L. (2014). Growing Pumpkins and Winter Squash in West Virginia. West Virginia University Extension Service fact sheet.

Li, K., Lemonakis, L., Glover, B., Moritz, J., \& Shen, C. (2017a). Impact of Built-up-Litter and Commercial Antimicrobials on Salmonella and Campylobacter Contamination of Broiler Carcasses Processed at a Pilot Mobile Poultry-Processing Unit. Frontiers in Veterinary Science, 4. 
Li, K., Weidhaas, J., Lemonakis, L., Khouryieh, H., Stone, M., Jones, L., \& Shen, C. (2017b). Microbiological quality and safety of fresh produce in West Virginia and Kentucky farmers' markets and validation of a post-harvest washing practice with antimicrobials to inactivate Salmonella and Listeria monocytogenes. Food Control, 79, 101-108.

Li, K., Khouryieh, H., Jones, L., Etienne, X.L., \& Shen, C. (2018). Assessing farmers market produce vendors' handling of containers and evaluation of the survival of Salmonella and Listeria monocytogenes on plastic, pressed-card, and wood container surfaces at refrigerated and room temperature. Food Control, 94, 116-122.

López-Gálvez, F., Posada-Izquierdo, G. D., Selma, M. V., Pérez-Rodríguez, F., Gobet, J., Gil, M. I., \& Allende, A. (2012). Electrochemical disinfection: An efficient treatment to inactivate Escherichia coli O157:H7 in process wash water containing organic matter. Food Microbiology, 30, 146-156.

Luo, Y. 2007. Fresh-cut produce wash water reuse affects water quality and packaged product quality and microbial growth in romaine lettuce. HortScience, 42, 1413-1419.

Luo, Y., Nou, X., Millner, P., Zhou, B., Shen, C., Yang, Y., Wu, Y., Wang, Q., Feng, H., \& Shelton, D. (2012). A pilot plant scale evaluation of a new process aid for enhancing chlorine efficacy against pathogen survival and cross-contamination during produce wash. International Journal of Food Microbiology, 158, 133-139.

News Desk. (2019, February 27). Walmart's bagged fresh green beans and squash recalled for Listeria risk. From Food Safety News website: https://www.foodsafetynews.com/2019/02/walmarts-bagged-fresh-green-beans-andsquash-recalled-for-listeria-risk/. Accessed October 15, 2019. 
Raybaudi-Massilia, R. M., Mosqueda-Melgar, J., Soliva-Fortuny, R., \& Martín-Belloso, O. (2009). Control of Pathogenic and Spoilage Microorganisms in Fresh-cut Fruits and Fruit Juices by Traditional and Alternative Natural Antimicrobials. Comprehensive Reviews in Food Science and Food Safety, 8, 157-180.

Ricke, S. C. (2003). Perspectives on the use of organic acids and short chain fatty acids as antimicrobials. Poultry Science, 82, 632-639.

Sapers, G. M., Miller, R. L., Pilizota, V., \& Mattrazzo, A. M. (2001). Antimicrobial Treatments for Minimally Processed Cantaloupe Melon. Journal of Food Science, 66, 345-349.

Scarcioffolo, A., Shen, C., \& Etienne, X. (2018). Economic Feasibility of Three-Step Wash Process to Improve Produce Microbial Safety. Presented at the Food Microbiology Symposium 2018 Annual Meeting of Institute of Food Technologists. July 15-18. Chicago, IL.

Sibomana, M. S., Ziena, L. W., Schmidt, S., \& Workneh, T. S. (2017). Influence of Transportation Conditions and Postharvest Disinfection Treatments on Microbiological Quality of Fresh Market Tomatoes (cv. Nemo-Netta) in a South African Supply Chain. Journal of Food Protection, 80, 345-354.

Shen, C., Luo, Y., Nou, X., Wang, Q., \& Millner, P. (2013). Dynamic effects of free chlorine concentration, organic load, and exposure time on the inactivation of Salmonella, Escherichia coli O157:H7, and non-O157 Shiga toxin-producing E. coli. Journal of Food Protection, 76, 386-393.

Shen, C., Norris, P., Williams, O., Hagan, S., \& Li, K. (2016). Generation of chlorine byproducts in simulated wash water. Food Chemistry, 190, 97-102. 
Straka, R. P., \& Stokes, J. L. (1959). Metabolic injury to bacteria at low temperatures. Journal of Bacteriology, 78, 181-185.

Strohbehn, C., Mendonca, A., Wilson, L., Domoto, P., Smith, M., Brehm-Stecher, B., \& Shaw, A. (2013). On-farm Food Safety: Cleaning and Sanitizing Guide. Human Sciences Extension and Outreach Publications. Available at: https://lib.dr.iastate.edu/extension_families_pubs/102. Accessed 15 October 2019.

Ukuku, D. O., \& Sapers, G. M. (2001). Effect of Sanitizer Treatments on Salmonella Stanley Attached to the Surface of Cantaloupe and Cell Transfer to Fresh-Cut Tissues during Cutting Practices. Journal of Food Protection, 64, 1286-1291.

Ukuku, D. O., \& Fett, W. F. (2004). Method of Applying Sanitizers and Sample Preparation Affects Recovery of Native Microflora and Salmonella on Whole Cantaloupe Surfaces. Journal of Food Protection, 67, 999-1004.

Ukuku, D. O., Bari, M. L., Kawamoto, S., \& Isshiki, K. (2005). Use of hydrogen peroxide in combination with nisin, sodium lactate and citric acid for reducing transfer of bacterial pathogens from whole melon surfaces to fresh-cut pieces. International Journal of Food Microbiology, 104, 225-233.

Ukuku, D. O. (2006). Effect of sanitizing treatments on removal of bacteria from cantaloupe surface, and re-contamination with Salmonella. Food Microbiology, 23, 289-293.

West Virginia Farmers Market Association. (2018). Member Markets. Available at: http://www.wvfarmers.org/members-2/market/. Accessed 15 October 2019. 


\section{Chapter 5 Tables and Figures}

Table 5.1. Cost of SaniDate-5.0 at different concentrations

\begin{tabular}{lcc}
\hline & \multicolumn{2}{c}{ SaniDate-5.0 } \\
& $0.0071 \%$ & $0.45 \%$ \\
\hline Gallon price (\$) & 62.20 & 62.20 \\
Amount needed for 175 Gallons of water (mL) & 47.03 & 2981.01 \\
Mixed solution cost, at 175 gallons (\$) & 2.52 & 50.73 \\
\hline
\end{tabular}


Table 5.2. Reduction of Salmonella Typhimurium and Tennessee on butternut squashes ( $\left.\log _{10} \mathrm{CFU} / \mathrm{squash}\right)$ by triple-wash procedure water dip-antimicrobial dip-water dip (WAW) or water dip-water dip-antimicrobial dip (WWA) in sodium hypochlorite (SH, 100 ppm), lactic and citric acid blend (LCA, Veggiexide ${ }^{\circledR}, 2.5 \%$ ), a PAA and hydrogen peroxide mixer (SaniDate-5.0, 0.0064, 0.25 and $0.50 \%)$.

\begin{tabular}{lcr}
\hline Treatment & WAW & WWA \\
\hline Control & $-*$ & - $^{*}$ \\
Sodium hypochlorite (SH-100 ppm) & $1.1 \pm 0.7 \mathrm{cA}$ & $2.7 \pm 0.4 \mathrm{aB}$ \\
Lactic and citric acid blend (LCA-2.5\%) & $1.3 \pm 0.4 \mathrm{cA}$ & $2.1 \pm 1.1 \mathrm{cB}$ \\
SaniDate-5.0-0.0064\% & $2.0 \pm 0.6 \mathrm{baA}$ & $2.4 \pm 0.5 \mathrm{bcB}$ \\
SaniDate-5.0-0.25\% & $2.3 \pm 0.5 \mathrm{aA}$ & $2.7 \pm 0.4 \mathrm{aB}$ \\
SaniDate-5.0-0.50\% & $2.5 \pm 0.4 \mathrm{aA}$ & \\
\hline
\end{tabular}

\footnotetext{
—* indicates reduction data are not available
}

Mean values with different letters within a column are significantly different $(P<0.05)$

Mean values with different capital letters within a row are significantly different $(P<0.05)$ 
Table 5.3. Reduction of Listeria monocytogenes on butternut squashes ( $\left.\log _{10} \mathrm{CFU} / \mathrm{squash}\right)$ by triple-wash procedure water dipantimicrobial dip-water dip (WAW) or water dip-water dip-antimicrobial dip (WWA) in sodium hypochlorite (SH, $100 \mathrm{ppm}$ ), lactic and citric acid blend (LCA, Veggiexide ${ }^{\circledR}, 2.5 \%$ ), a PAA and hydrogen peroxide mixer (SaniDate-5.0, 0.0064, 0.25 and 0.50\%).

\begin{tabular}{lcc}
\hline Treatment & WAW & WWA \\
\hline Control & - - $^{*}$ & $2.3 \pm 0.3 \mathrm{aB}$ \\
Sodium hypochlorite (SH-100 ppm) & $0.5 \pm 0.8 \mathrm{aA}$ & $2.3 \pm 0.8 \mathrm{aB}$ \\
Lactic and citric acid blend (LCA-2.5\%) & $0.5 \pm 0.5 \mathrm{aA}$ & $2.4 \pm 0.4 \mathrm{aB}$ \\
SaniDate-5.0-0.0064\% & $0.8 \pm 0.5 \mathrm{aA}$ & $2.4 \pm 0.4 \mathrm{aB}$ \\
SaniDate-5.0-0.25\% & $0.6 \pm 0.5 \mathrm{aA}$ & $2.9 \pm 0.7 \mathrm{bB}$
\end{tabular}

- * indicates reduction data are not available

Mean values with different letters within a column are significantly different $(P<0.05)$

Mean values with different capital letters within a row are significantly different $(P<0.05)$ 
Table 5.4. Cost comparison of triple wash at different production scales. Total cost is calculated by assuming water and treatments are reused throughout the whole washing section.

\begin{tabular}{|c|c|c|c|c|c|c|}
\hline & \multicolumn{2}{|c|}{$\begin{array}{l}\text { 1,000 Squashes } \\
\text { ( } 2 \text { sections) }\end{array}$} & \multicolumn{2}{|c|}{$\begin{array}{l}\text { 2,000 Squashes } \\
\text { (4 sections) }\end{array}$} & \multicolumn{2}{|c|}{$\begin{array}{l}5,000 \text { Squashes } \\
\text { (10 sections) }\end{array}$} \\
\hline Water tank (annualized) & $\$$ & 75.00 & $\$$ & 75.00 & $\$$ & 75.00 \\
\hline Hand brush & $\$$ & 50.00 & $\$$ & 50.00 & $\$$ & 50.00 \\
\hline Microfiber cloth & $\$$ & 10.00 & $\$$ & 10.00 & $\$$ & 10.00 \\
\hline Maintenance (annualized) & $\$$ & 100.00 & $\$$ & 100.00 & $\$$ & 100.00 \\
\hline \multicolumn{7}{|l|}{ Variable cost } \\
\hline Labor & $\$$ & 240.00 & $\$$ & 480.00 & $\$$ & $1,200.00$ \\
\hline \multicolumn{7}{|l|}{ SaniDate-5.0 } \\
\hline $0.0071 \%$ & $\$$ & 1.55 & $\$$ & 3.09 & $\$$ & 7.73 \\
\hline $0.45 \%$ & $\$$ & 97.97 & $\$$ & 195.93 & $\$$ & 489.83 \\
\hline Water & $\$$ & 10.50 & $\$$ & 21.00 & $\$$ & 52.50 \\
\hline \multicolumn{7}{|l|}{ Total cost } \\
\hline \multicolumn{7}{|l|}{ SaniDate-5.0 } \\
\hline $0.0071 \%$ & $\$$ & 487.05 & $\$$ & 739.09 & $\$$ & $1,495.23$ \\
\hline $0.45 \%$ & $\$$ & 583.47 & $\$$ & 931.93 & $\$$ & $1,977.33$ \\
\hline
\end{tabular}


Table 5.5. Cost comparison of triple wash at different production scales when water and antimicrobial treatments are refreshed every 60 or 180 squashes.

\begin{tabular}{|c|c|c|c|c|c|c|c|}
\hline \multirow{2}{*}{$\begin{array}{l}\text { Refresh frequency } \\
\text { Every } 60 \text { squashes }\end{array}$} & \multirow{2}{*}{$\frac{\text { Total cost }}{\text { SaniDate-5.0 }}$} & \multicolumn{2}{|c|}{ 1,000 Squashes } & \multicolumn{2}{|c|}{ 2,000 Squashes } & \multicolumn{2}{|c|}{ 5,000 Squashes } \\
\hline & & & & & & & \\
\hline & $0.0071 \%$ & $\$$ & 583.41 & $\$$ & 931.82 & $\$$ & $1,977.06$ \\
\hline & $0.45 \%$ & $\$$ & $1,451.19$ & $\$$ & $2,667.37$ & $\$$ & $6,315.93$ \\
\hline \multirow[t]{3}{*}{ Every 180 squashes } & SaniDate-5.0 & & & & & & \\
\hline & $0.0071 \%$ & $\$$ & 511.14 & $\$$ & 787.27 & $\$$ & $1,615.69$ \\
\hline & $0.45 \%$ & $\$$ & 800.40 & $\$$ & $1,365.79$ & $\$$ & $3,061.98$ \\
\hline
\end{tabular}




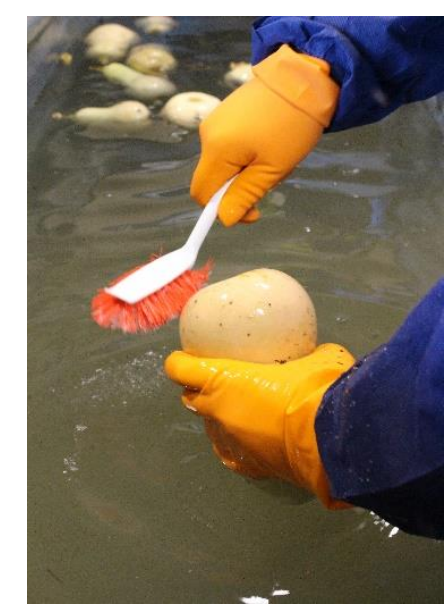

(A)

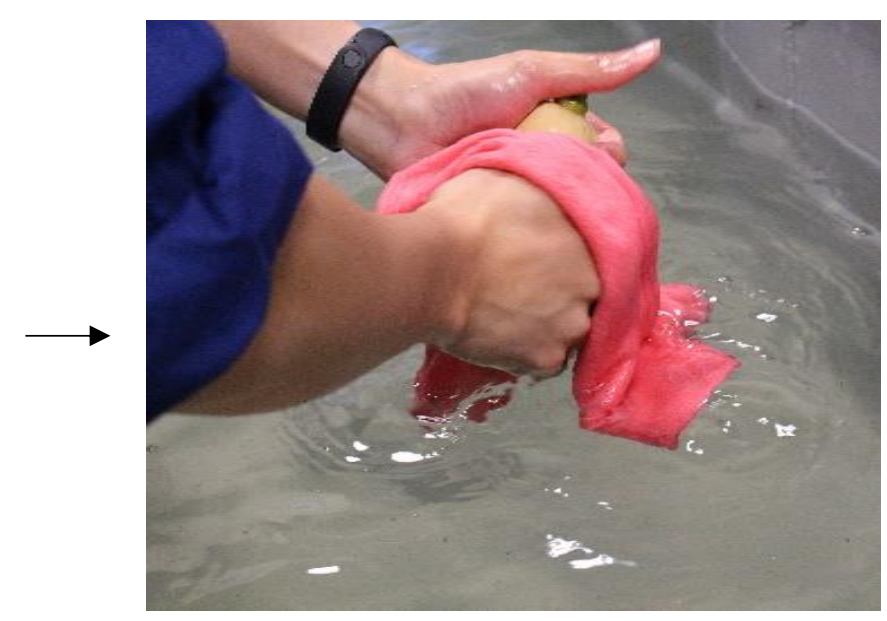

(B)

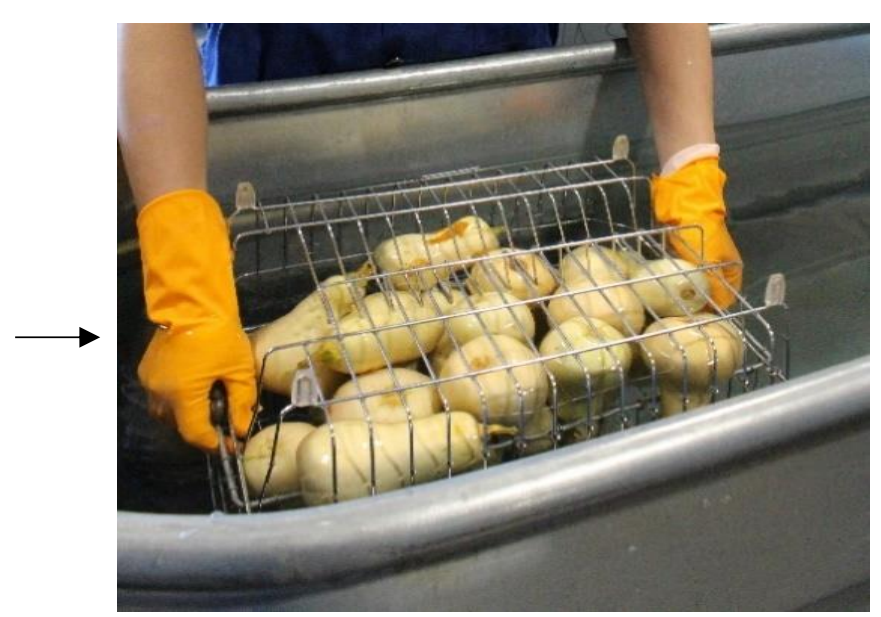

(C)

Figure 5.1. Triple-wash process inlucding step 1-manually brush with produce bursher (A), step 2-soft cloth towlers scrub (B), step 3melt rinse container with mesh and immerse into the SaniDate-5.0 solution (C). 
Aerobic Plate Count

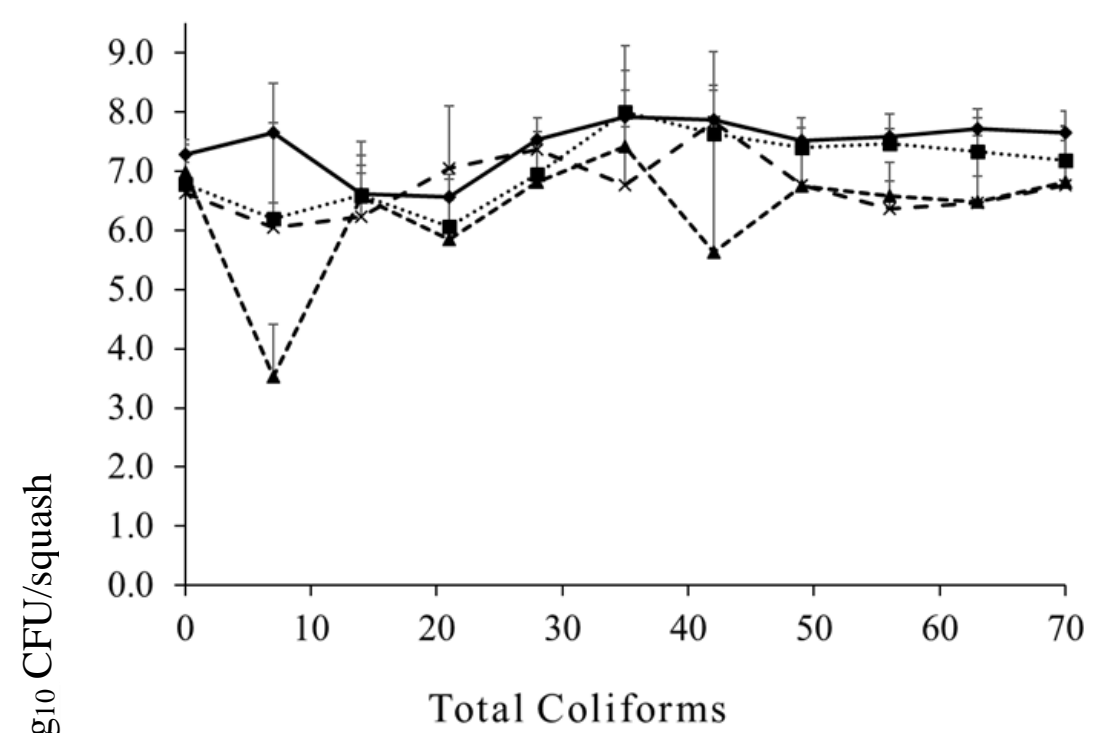

$\stackrel{0}{\perp}$

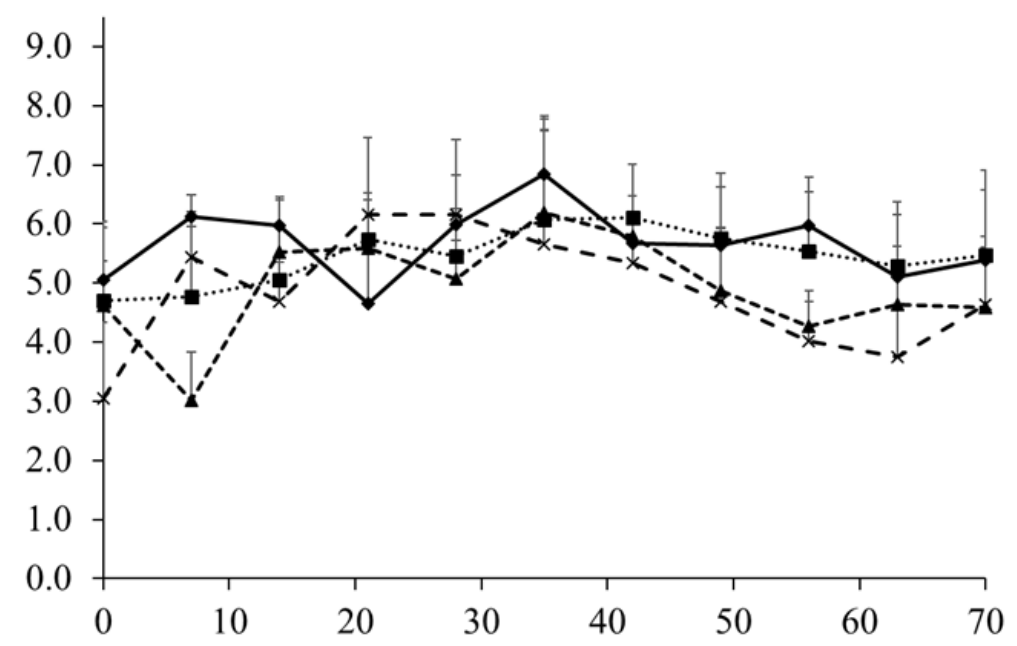

Psychrophile
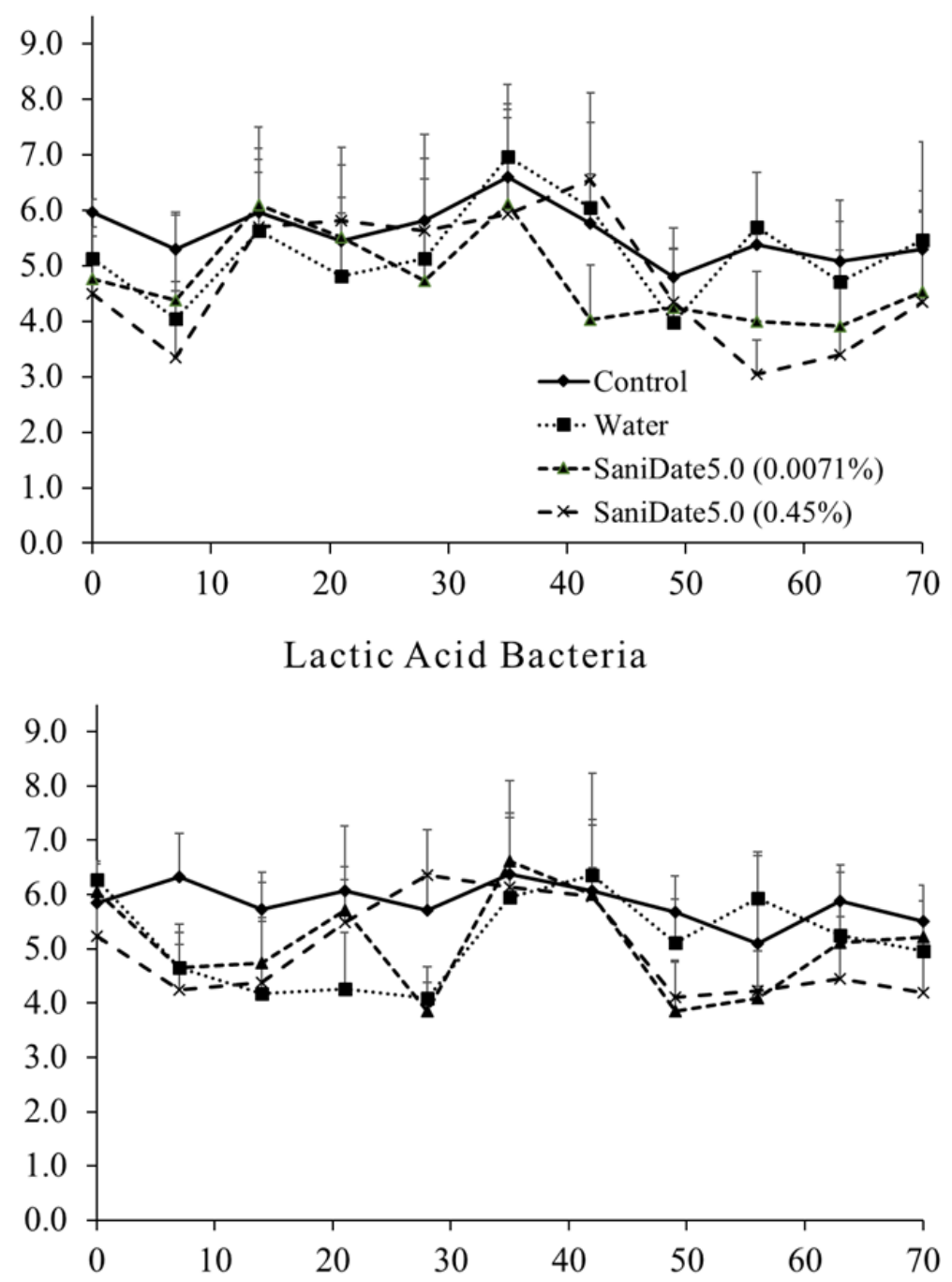

Figure 5.2. Average and standard deviation of microbial populations ( $\left.\log _{10} \mathrm{CFU} / \mathrm{squash}\right)$ measured as aerobic plate counts, psychrophiles, total coliforms, and lactic acid bacteria on butternut squashes after triple-wash in water and SaniDate-5.0 (SD, $0.0071 \%$ and $0.45 \%$ ) solutions followed by storage at $9^{\circ} \mathrm{C}$ for 70 days. 


\section{CHAPTER 6}

\section{Assessing Farmers' market Produce Vendors' Handling of Containers and Evaluation of the Survival of Salmonella and Listeria monocytogenes on Plastic, Pressed-Card, and Wood Container Surfaces at Refrigerated and Room Temperature}

This study aims to assess how small produce growers handle containers and evaluate the survival of Salmonella and Listeria monocytogenes on various produce container surfaces commonly used at farmers' markets, under storage conditions both at refrigerated and room temperature. In Study I, an anonymous survey was conducted to assess the practices of handling produce containers from 28 vendors at farmers' markets in Morgantown, WV, and 141 vendors from farmers' markets in Kentucky. In Study II, plastic, pressed-card, and wood containers were trimmed $\left(25 \mathrm{~cm}^{2}\right)$ and inoculated with $S$. Typhimurium and Tennessee, and two strains of $L$. monocytogenes, stored at $3.2^{\circ} \mathrm{C}(22.19 \% \mathrm{RH})$ and $22.5^{\circ} \mathrm{C}(50.40 \% \mathrm{RH})$, respectively, for 21 days and periodically analyzed for microbial populations on XLT-4 (Salmonella) and ModifiedOxford (L. monocytogenes) agars. The survey results showed that plastic, paper, and wood containers are the top three choices for small produce growers to transport and present produce at farmers' markets. The pathogens decreased slower $(P<0.05)$ at $3.2^{\circ} \mathrm{C}$ and on pressed-card and wood surfaces than at $22.5^{\circ} \mathrm{C}$ and a plastic surface. At $3.2^{\circ} \mathrm{C}$, Salmonella counts decreased $(P<$ 0.05) from 5.27-5.53 to 2.63-2.84 $\log _{10} \mathrm{CFU} / \mathrm{cm}^{2}$, and L. monocytogenes decreased $(P<0.05)$ from 6.39-6.93 to $4.89-5.46 \log _{10} \mathrm{CFU} / \mathrm{cm}^{2}$ on the three material surfaces by the end of the storage period, with the lowest $(P<0.05)$ survival on a plastic surface. At $22.5^{\circ} \mathrm{C}$, Salmonella populations decreased $(P<0.05)$ from $4.94-5.38$ to $<1.30 \log _{10} \mathrm{CFU} / \mathrm{cm}^{2}$ (the detection limit) after 3, 9 and 12 days on plastic, pressed-card and wood surfaces, respectively. $L$. monocytogenes decreased $(P<0.05)$ from 6.39-6.93 to $\leq 1.30 \log _{10} \mathrm{CFU} / \mathrm{cm}^{2}$ after 12,12 , and 21 
days on plastic, wood, and pressed-card surfaces, respectively. These results were confirmed by different mathematical survival models for analyzing pathogen inactivation rates. Vendors at farmers' markets should choose plastic containers to store fresh produce and avoid storing containers at refrigerated temperature

Keywords: Container Surfaces, Salmonella, Listeria monocytogenes, Farmers' market 


\subsection{Introduction}

The demand for "locally-grown" food in the United States has risen dramatically in the past two decades (Scheinberg et al., 2013; 2017). The surge in demand for locally produced food has created jobs and opportunities for small agribusinesses throughout the nation, especially through local farmers' markets. According to the U.S. Department of Agriculture (USDA) Economic Research Service (ERS), the number of farmers' markets in the U.S. has more than quadrupled since 1994 (USDA-Economic Research Service, 2017). Consumers often consider fresh produce sold at farmers' markets to be healthier and safer than produce in conventional stores. Yet, information on whether these foods are indeed safer to consume is rather limited. Several outbreaks related to fresh produce from farmers' markets were reported in the U.S. over the past decade, raising concerns on the safety of food sold at farmers' markets (Food Safety News, 2011, 2015; Gardner et al., 2011; Levy et al., 2014).

Currently, there are 93 farmers' markets at over 112 locations throughout West Virginia (West Virginia Farmers' market Association, 2018). Farmers' markets generated an estimated \$9.1 million in annual sales and served over half a million customers in WV in 2017. Farmers' markets play an important role in West Virginia's economy, creating an average annual revenue of $\$ 41,200$ for full-time produce farmers and approximately $\$ 20,000$ for part-time farmers (internal unpublished data, personal communication with Mr. Thomson Gross, GIS Analyst, WV FOODLINK). In Kentucky, there are more than 159 farmers' markets providing locally grown fresh produce to consumers across the state (Kentucky Department of Agriculture, 2016). Our recent Good Agriculture Practices (GAP) survey of 160 small-scale produce growers in $21 \mathrm{KY}$ counties indicated that participants failed to identify many sources of potential microbiological contamination, including soil, ice, and cooling and refrigeration (only $28-41 \%$ recognition, 
Sinkel et al., 2018). Our most recent study of farmers' markets in WV and KY showed a high prevalence of Salmonella spp. (18.6\% of spinach, $10.9 \%$ of tomatoes, $18.5 \%$ of peppers, and $56.3 \%$ of cantaloupes), and the relatively high presence of Listeria spp. (3.78\% of the samples) on locally grown produce surfaces (Li et al., 2017). Levy et al. (2014) reported that 1 of 133 tested fresh herbs (basil, cilantro, and parsley) from Los Angeles and Seattle farmers' markets were positive for Salmonella spp. Scheinberg et al. (2017) found that 3.9\% (6/152) of fresh produce samples contained Listeria spp., including 2\% (1/54) of kale, 4\% (2 of 52) of lettuce, and 7\% (3 of 46) of spinach samples from 25 farmers' markets in Pennsylvania. As farmers' markets become increasingly popular over time, it is important to assess and understand the risks of foodborne pathogen contamination during the produce handling process and evaluate relevant strategies to mitigate such risks.

During post-harvest storage of produce, tree fruits such as apples, oranges, and peaches, in particular, are stored in unsanitized containers, which could serve as a potential reservoir for numerous plant pathogens (Cossentine et al., 2004; Higbee, et al., 2001; Randall, et al., 2011) and potentially harbor and transfer foodborne pathogens such as Salmonella spp. and $L$. monocytogenes (Killinger, 2014). One factor affecting post-harvest food safety risks is the material makeup of these storage containers, which can be wood, pressed-card, or plastic. Wood containers are subject to weathering. Pressed-card buckets with green molded pulp material often have rough surfaces that can harbor various pathogens. By contrast, plastic bins are easier to clean and sanitize due to their flat and smooth surfaces (Waelti, 1992).

Currently, little information exists regarding the role of storage container material as a potential source of pathogen contamination at local farmers' markets, especially the pathogen survival rate on various material surfaces. We aim to fill this data gap in the literature. The 
objectives of this study were to 1) assess the knowledge and practices around the use of produce storage containers of farmers' market vendors in Kentucky and Morgantown, WV, and 2) evaluate and model the survival rate of Salmonella and L. monocytogenes on various storage material surfaces at refrigerated and room temperature.

\subsection{Materials and Methods}

\subsubsection{Survey of handling produce containers at KY and WV farmers' markets}

The survey questionnaire was developed by the authors after several group meetings and then distributed to selected industry professionals, extension agents, and academic faculty at Western Kentucky University (WKU) and West Virginia University (WVU) for review and comments. The wording of the survey questionnaire was reviewed and revised based on the comments from Dr. Jerry Daday, Professor of Sociology, WKU. The questionnaire was approved by WVU (IRB/IBC\#15-04-07) and WKU's Institutional Review Board (IRB). Before the collection of formal data, the questionnaire was pre-tested at two farmers' markets in Nashville, TN (just across the KY state line) to ascertain whether the farmers clearly understood the survey questions contained on the survey instrument. The questionnaire was finalized after data analysis from the pre-test trials. The survey questionnaire consisted of 6 questions regarding the practices of handling produce storage containers: 1) the type of containers the vendor uses to present produce at farmers' markets; 2) the type of containers the vendor uses for storing/transporting produce; 3) whether the vendor washes the containers between visits to farmers' markets; 4) whether the vendor sanitizes the containers; 5) where the vendor stores the containers before selling at farmers' market; and 6) the vendor's awareness/knowledge of foodborne pathogens transmitted to fresh produce. The specific survey questions were included in the results of Tables 6.1 to 6.4 . 
The survey questionnaire was distributed by the face-to-face method at KY and WV farmers' markets. Produce growers who sold produce at farmers' markets during the data collection visits were recruited. A five-dollar gift card was provided as an incentive gift for the completion and return of the questionnaire. All survey participants were required to sign informed consent documents before answering the questionnaire. The consent document informed the respondents that the survey was voluntary and anonymous and that they are free to withdraw from the survey at any point in time. The recruiting of produce vendors at the Morgantown Farmers' market, Morgantown, WV, was coordinated with Ms. Lisa Jones, Program Coordinator, WVU Extension Service Small Farm Center. The survey questionnaire was sent to 600 farmers' market produce vendors in 21 counties in KY between April and August 2014. The counties in KY were selected to represent different regions of the state, including large cities such as Louisville, Lexington, and Bowling Green, and middle-sized cities such as Elizabethtown, Paducah, and Owensboro. There were a total of $141(141 / 600,23.5 \%)$ survey responses completed and returned, and the response rate of each question ranged from 19.5 to $23.5 \%$ (Tables $6.1-6.4$ ). The same survey questionnaire was later distributed to 40 farmers' market produce vendors from July to Oct 2015 in Morgantown Farmers' Market, Morgantown WV, where WVU is located, with 28 (28/40, 70\%) completed and returned questionnaires, and the response rate of each question ranged from 37.5 to $70.0 \%$ (Tables $6.1-$ 6.4).

\subsubsection{Preparation of inoculum}

Salmonella Typhimurium ATCC 14028 and Salmonella Tennessee ATCC 10722, and two L. monocytogenes strains, L2624 and L2625 [cantaloupe outbreak serotype 1/2b], donated by Dr. Joshua Gurtler (USDA-ARS, Wyndmoor, PA), were used in this study. Frozen stock cultures 
were streak-plated onto XLT-4 and Modified Oxford (MOX) agar followed by incubation at $35^{\circ} \mathrm{C}$ for $48 \mathrm{~h}$ to generate pure cultures. Single colonies from XLT-4 (Salmonella) and MOX Agar (L. monocytogenes) were cultured and sub-cultured in $10 \mathrm{ml}$ of tryptic soy broth (TSB; Alpha Biosciences, Baltimore, MD, USA) at $35^{\circ} \mathrm{C}$ for $24 \pm 2 \mathrm{~h}$. Each Salmonella and $L$. monocytogenes culture was centrifuged (VWR Symphony 4417, VWR International, Radnor, $\mathrm{PA} ; 5,000 \times \mathrm{g}, 15 \mathrm{~min})$, triplicate washed in $0.1 \%$ buffered peptone water $(\mathrm{BPW})$, and then resuspended in $0.1 \%$ BPW. The two Salmonella and two L. monocytogenes strains were then combined (Li et al., 2017) to yield an inoculation level of 4-6 $\log _{10} \mathrm{CFU} / \mathrm{cm}^{2}$ when $0.2 \mathrm{ml}$ of inoculum was applied to material surfaces.

\subsubsection{Storage material inoculation and microbiological analysis}

Plastic, pressed-card, and wood containers obtained were the same as what is used at the farmers' markets in Morgantown, WV. The plastic container is made of polyethylene board (donated by a produce grower at Morgantown Farmers' Market, Morgantown, WV, USA), the pressed-card container was the green molded pulp produce basket (donated by Whole Foods Market, Pittsburgh, PA, USA), and the wood container (purchased from Texas Basket Co., Inc., Jacksonville, TX, USA) was manufactured by a mixture of sweet gum, elm, and cottonwood. The inner bottom surfaces of each container were manually trimmed and cut into $5 \mathrm{~cm} \times 5 \mathrm{~cm}$ square areas $\left(25 \mathrm{~cm}^{2}\right)$ and inoculated with the aforementioned four-strain mixture of Salmonella and L. monocytogenes in a biosafety hood. Before inoculation, each trimmed material surface was exposed to UV light in a biosafety hood for $1 \mathrm{~h}$ to sanitize the surfaces. The inoculum $(0.2$ ml) was spread uniformly onto the material surfaces using a sterilized spreader, and the inoculated surfaces were left for 30 min under the hood for attachment. All inoculated materials were then stored at $3.2^{\circ} \mathrm{C}(22.9 \% \mathrm{RH})$ and $22.5^{\circ} \mathrm{C}(50.4 \% \mathrm{RH})$ for 21 days. On days $0,0.13$, 
$0.25,0.5,1,3,6,9,12,15,18$, and 21, individual samples were placed in a sterile Whirl-Pak ${ }^{@}$ bag (Whirl-Pak, Nasco, Modesto, CA, USA) containing $50 \mathrm{ml}$ of $0.1 \% \mathrm{BPW}$, shaken and massaged for $30 \mathrm{~s}$, and stomached for $5 \mathrm{~min}$ in a masticator (IUL Instruments, Barcelona, Spain). Samples were then 10 -fold serially diluted in $0.1 \%$ BPW, followed by spread-plating onto XLT4 (Salmonella) and MOX agar (L. monocytogenes). Microbial colonies of Salmonella and L. monocytogenes were counted manually after incubation at $35^{\circ} \mathrm{C}$ for $24 \mathrm{~h}$ and $48 \mathrm{~h}$, respectively. Samples below the detectable limit $\left(1.3 \log _{10} \mathrm{CFU} / \mathrm{cm}^{2}\right)$ by spread-plating were enriched in BPW at $35^{\circ} \mathrm{C}$ for $24 \mathrm{~h}$ and then streak-plated onto XLT-4 (Salmonella) and MOX agar ( $L$. monocytogenes) to verify the presence/absence of pathogens on surfaces.

\subsubsection{Data analysis}

Survey answers were analyzed using the Chi-Square test on SAS (version 9.2, SAS Institute, Cary, NC) to examine the bivariate relationships between categorical variables, with statistical significance set at an alpha level of 0.05 . The studies for testing the microbial survival on various material surfaces during storage were repeated twice, and for each replication, 4 individual samples per material surface (plastic, pressed-card, or wood) at each sampling time were analyzed $(n=8)$. The Mixed Model Procedure in SAS was used to analyze the survival population of Salmonella and L. monocytogenes on container surfaces, with the individual factors of storage material, temperature, time period, and the interaction terms between them using a statistical significance level of $0.05(P<0.05)$. GInaFit software (Geeraerd et al., 2006) was used to estimate pathogen survival kinetic parameters on container surfaces. The root means square error (RMSE) and $\mathrm{R}^{2}$ were used to determine the best survival model that fit the data. The lower the RMSE is, the better the model (Ratkowsky, 2002). 


\subsection{Results and Discussion}

\subsubsection{Assessing vendor's handling of produce containers}

All of our survey results from Tables 6.1 to 6.4 reflect self-reported behaviors of farmers' market vendors from Morgantown WV and KY. According to our survey results shown in Table 6.1, plastic containers were the most $(P<0.05)$ common choice by 22 of 27 respondents $(81 \%)$ in Morgantown, WV, and by 111 of $140(79 \%)$ respondents in KY to present produce at local farmers' markets, followed by paper (43-52\%) and wood containers (33-48\%). At least $80 \%$ of paper containers were green molded pulp produce baskets (data not shown in tabular form). Only $15-24 \%$ of vendors interviewed used metal containers. Out of 28 respondents, three used containers made of other materials, including mesh bags, natural fiber baskets, and wicker baskets. Instead of allowing consumers to take the containers, as is common in wholesale markets, almost all farmers' market vendors reused the containers to save cost. This practice of reusing produce display containers raises the concern of microbial cross-contamination between products. Similarly, as shown in Table 6.1 , the vast majority $(P<0.05)$ of respondents in Morgantown, WV (96\%), and KY (89\%) used plastic containers to transport produce to local farmers' markets. Approximately $25-30 \%$ and $21-40 \%$ of respondents used paper and wood containers, respectively, followed by only $4-16 \%$ who used metal containers. Two out of the 28 respondents in Morgantown, WV used containers made of other materials such as cardboard and plastic-lined disposable bags. According to Siroli et al. (2017), cardboard material is better at reducing microbial cross-contamination than plastic.

In order to assist West Virginia locally small produce growers and farmers' market produce vendors in preventing cross-contamination of pathogens from food contact surfaces (i.e., storage containers) to produce, the three-step washing process (water rinse, antimicrobial 
application, final water rinse) has been suggested by the WV Small Farm Center as an effective tool for removing pathogens from food surfaces (Strohbehn et al., 2013). When asked whether the farmers' wash/sanitize produce containers between visits from farmers' markets, $85 \%$ and 93\% of vendors surveyed in Morgantown, WV, and KY farmers' markets, respectively, responded with a "Yes" (Table 6.2). However, in the follow-up question, approximately 30-40\% of them did not apply any sanitizers in the wash water (Table 6.2). Among the respondents who replied that they use sanitizers, chlorine water, and Lysol ${ }^{\circledR}$ disinfection wipes were indicated as the top choices (data not shown in tabular form).

Effective temperature control is a critical component of the post-harvest practice of produce storage. Sixty-two (62\%) percent (KY) to 67\% (Morgantown, WV) of respondents indicated that they stored produce containers at refrigerated temperature, and 63\% (Morgantown, WV) to $84 \%(\mathrm{KY})$ stored containers at room temperature. This suggests that some vendors store containers at both refrigerated and room temperatures (Table 6.3). As expected, no vendors store containers in freezers (Table 6.3). At the end of the survey questionnaire, vendors were given a list of four microbiological foodborne pathogens and asked to select what they believe were food safety risks for fresh produce; 15 of 28 (Morgantown, WV) and 117 of 140 (KY) vendors surveyed answered this question. The results suggest that Shiga toxin-producing Escherichia coli (83-87\%), Salmonella (80-91\%), and Listeria (71-87\%) were well recognized by respondents as potential foodborne pathogens contaminated on produce. However, $46 \%$ of respondents failed to identify Staphylococcus aureus as a pathogen on produce.

\subsubsection{Salmonella and L. monocytogenes survival on various container surfaces}

The microbial survival curves of Salmonella and L. monocytogenes on plastic, pressedcard, and wood surfaces during storage at 3.2 and $22.5^{\circ} \mathrm{C}$ are shown in Figure 6.1. As expected, 
both Salmonella and L. monocytogenes populations on the three material surfaces decreased $(P<$ 0.05) during storage due to drying and desiccation of the surface condition and the limited nutrition available for bacteria. The decrease in pathogen populations during the storage period was significantly affected by the bacterial strain $(P<0.05)$, storage temperatures $(P<0.05)$, and surface materials $(P<0.05)$. In general, the decrease in pathogen populations was faster $(P<$ $0.05)$ at $22.5^{\circ} \mathrm{C}$ than $3.2^{\circ} \mathrm{C}$ and, in most cases, faster $(P<0.05)$ on plastic surfaces than pressedcard or wood. In addition, $L$. monocytogenes was more resistant $(P<0.05)$ to environmental conditions on the surfaces tested than Salmonella.

The initial populations of Salmonella on plastic, pressed-card and wood surfaces were 5.27-5.53 $\log _{10} \mathrm{CFU} / \mathrm{cm}^{2}$ and 4.94-5.38 $\log _{10} \mathrm{CFU} / \mathrm{cm}^{2}$ for storage at 3.2 and $22.5^{\circ} \mathrm{C}$, respectively (Figure 6.1). For samples stored at $3.2^{\circ} \mathrm{C}$, Salmonella counts on surfaces decreased linearly by $1.11,1.25$, and $2.60 \log _{10} \mathrm{CFU} / \mathrm{cm}^{2}$ on plastic, pressed-card, and wood container surfaces, respectively, on the first day (Figure 6.1). From day one to day 21 (the end of the storage period), Salmonella counts declined gradually, though larger fluctuations were observed on several sampling days. The surviving population of Salmonella ranged from 2.63 to $3.03 \log _{10}$ $\mathrm{CFU} / \mathrm{cm}^{2}$ across three material surfaces by the end of the 21-day storage period (Figure 6.1). Compared to $3.2^{\circ} \mathrm{C}$, samples stored at $22.5^{\circ} \mathrm{C}$ were more detrimental to Salmonella on all three material surfaces. At $22.5^{\circ} \mathrm{C}$, Salmonella levels decreased from approximately $5.0 \log _{10}$ $\mathrm{CFU} / \mathrm{cm}^{2}$ to below the detection limit $\left(1.30 \log _{10} \mathrm{CFU} / \mathrm{cm}^{2}\right)$ at days 3,9 , and 12 on plastic, wood, and pressed-card surfaces, respectively. The previous study by McEldowney and Fletcher (1988) reported that bacterial survival on glass surfaces was shorter at $22.5^{\circ} \mathrm{C}$ than at $3.2^{\circ} \mathrm{C}$. However, the pathogen was still present on all three material surfaces by the end of storage (day 21) as detected by the enrichment for recovering bacterial populations below detectable limits. These 
results indicate that Salmonella on dry produce container surfaces could remain viable and present a contamination hazard for a considerably long time.

The initial population of L. monocytogenes recovered from the three material surfaces was higher than Salmonella, ranging from 6.39 to $6.93 \log _{10} \mathrm{CFU} / \mathrm{cm}^{2}$ for 3.2 and $22.5^{\circ} \mathrm{C}$ (Figure 6.1). At $3.2^{\circ} \mathrm{C}$, L. monocytogenes levels declined significantly by $1.09,0.52$, and $2.26 \log _{10}$ $\mathrm{CFU} / \mathrm{cm}^{2}$ on pressed-card, wood, and plastic surfaces, respectively, within the first day (Figure 6.1). After that, the pathogen populations maintained a constant level or declined only slightly during the 21-day storage period. The L. monocytogenes population remaining on pressed-card, wood, and plastic surfaces were as high as 4.89 to $5.73 \log _{10} \mathrm{CFU} / \mathrm{cm}^{2}$, respectively, by the end of storage. Similar to Salmonella, the survival rates of L. monocytogenes decreased dramatically at $22.5^{\circ} \mathrm{C}$. It took 21 days for L. monocytogenes counts to decrease below the detectable limit on wood and plastic surfaces (still present on surfaces after enrichment), whereas there were 2.03 $\log _{10} \mathrm{CFU} / \mathrm{cm}^{2}$ of the pathogen remaining on pressed-card surfaces by the end of storage. The reduction rate of L. monocytogenes was slower and its residual pathogen population was higher than Salmonella regardless of the surface material and the storage temperature. Our results are consistent with the previous study by Siroli et al. (2017), who found that Salmonella Enteritidis (inoculation level $\sim 5 \log _{10} \mathrm{CFU} / \mathrm{cm}^{2}$ ) decreased to below detectable limits after 8 and $48 \mathrm{~h}$ on cardboard and plastic surfaces $\left(22.5^{\circ} \mathrm{C}\right)$, whereas $1-3 \log _{10} \mathrm{CFU} / \mathrm{cm}^{2}$ of L. monocytogenes remained on both surfaces by the end of the 48-h storage. In this study, the relative humidity (RH) level was $22.9 \%$ at $3.2^{\circ} \mathrm{C}$ and $50.4 \%$ at $22.5^{\circ} \mathrm{C}$; therefore, our results could be explained by the fact that Gram-positive bacteria (L. monocytogenes) are more resistant to external dry and desiccation conditions than Gram-negative bacteria (Salmonella) (Siroli et al., 2017). The heavy 
layers (peptidoglycan) in the cell wall of Gram-positive bacteria compared to that of Gramnegative bacteria could protect the former against desiccation (Milling et al., 2005).

According to our previous survey results, more than $60 \%$ of surveyed produce growers store produce containers with produce at refrigerated temperatures. However, the results of this study indicated that the survival of foodborne pathogens decreased faster at room temperature than at refrigerated temperature, which suggested that small local produce growers should avoid putting the containers with produce at cooler or refrigerated temperatures. This important information should be mentioned in future extension/outreach short courses regarding postharvest practices for produce to improve the microbial safety of locally grown produce at farmers' markets.

\subsubsection{Modeling of pathogen survival during storage}

The seven bacterial survival models in the Ginafit software were used to predict the pathogen-inactivating kinetics of cells on the three material surfaces and the two storage temperatures. The appropriateness of each model was evaluated using the $\mathrm{R}^{2}$ and RMSE values. Except for Salmonella at $3.2^{\circ} \mathrm{C}$, the estimated parameters from various models were consistent with the visual patterns in the survival curves (Figure 6.1).

For Salmonella at $3.2^{\circ} \mathrm{C}$, the kinetic survival parameters can be determined by the linear model with tail $\left(\mathrm{R}^{2}=0.79-0.92, \mathrm{RMSE}=0.32-0.43\right)$, Weibull $\left(\mathrm{R}^{2}=0.75-0.92, \mathrm{RMSE}=0.17-0.56\right)$, and biphasic models $\left(\mathrm{R}^{2}=0.80-0.98, \mathrm{RMSE}=0.11-0.38\right)$ (Table 6.5). According to the linear with tail and biphasic model, the inactivation rate of Salmonella on pressed-card was 14.68-14.19, which was greater $(P<0.05)$ than on plastic $(5.95)$ and wood $(3.76-12.79)$ surfaces. According to Peleg (2006), the Weibull model can indicate the failure of tested microorganisms to resist the harsh conditions with the smaller $\mathrm{k}$ value, suggesting a greater inactivation rate. In this study, the 
$\mathrm{k}$ values for plastic $(0.04)$ and pressed-card $(0.01)$ samples were similar $(P>0.05)$ and less $(P<$ 0.05) than the wood samples (0.33), suggesting that Salmonella was more sensitive (vulnerable) on plastic and pressed-card than on wood surfaces, a result that differs from the linear with tail and biphasic models. The discrepancies between the results could be explained by the fluctuation of the pathogen survival on surfaces during the storage period (day one to 21). For example, on plastic surfaces, the Salmonella population decreased from 2.67 to $2.33 \log _{10} \mathrm{CFU} / \mathrm{cm}^{2}$ from day one to three but increased to $3.25 \log _{10} \mathrm{CFU} / \mathrm{cm}^{2}$ on day six and declined to $2.52 \log _{10} \mathrm{CFU} / \mathrm{cm}^{2}$ on day nine. Similarly, Salmonella counts on wood surfaces decreased from 3.42 to $3.12 \log _{10}$ $\mathrm{CFU} / \mathrm{cm}^{2}$ from day one to three but returned to 3.38 and $3.32 \log _{10} \mathrm{CFU} / \mathrm{cm}^{2}$ from day three to day six and nine (Figure 6.1). The $\alpha$ value of the Weibull model indicated that the shape of the survival curves with $\alpha>1$ showed downward concavity, $\alpha=1$ showed a linear curve, and $\alpha<1$ showed an upward concavity with residual cells adapting to stresses (Geeraerd et al., 2006). The $\alpha$ values of the three material surfaces ranged from $0.11-0.21$, indicating that the inactivated curves show a similar upward concavity and that the remaining cells on all three material surfaces were resistant to dry, desiccated, and poor nutrition conditions at $3.2^{\circ} \mathrm{C}$ (Lopez-Galvez et al., 2012).

For Salmonella at $22.5^{\circ} \mathrm{C}$, the linear $\left(\mathrm{R}^{2}=0.50-0.69, \mathrm{RMSE}=0.61-0.92\right)$ model indicated a greater $(P<0.05)$ inactivation rate on plastic surfaces $(\mathrm{Kmax}=2.47)$ than the pressed-card $(\mathrm{Kmax}=0.55)$ and wood surfaces $(\mathrm{Kmax}=0.45)$ (Table 6.6). This result is consistent with the pattern observed in Figure 6.1 in which the pathogen population declined faster on plastic surfaces than pressed-card or wood samples.

As shown in Tables 6.7 and 6.8, both the linear with tail and biphasic models provide a good fit for L. monocytogenes survival on three material surfaces at 3.2 and $22.5^{\circ} \mathrm{C}$, and the 
Weibull model fits the pathogen survival at $22.5^{\circ} \mathrm{C}$ best. At $3.2^{\circ} \mathrm{C}$, the inactivation rate of samples on plastic surfaces $(\mathrm{Kmax}=7.10, \mathrm{Kmax} 1=6.04)$ was greater $(P<0.05)$ than on pressed-card $(\mathrm{Kmax}=2.16, \mathrm{Kmax} 1=2.44)$ and wood surfaces $(\mathrm{Kmax}=0.83, \mathrm{Kmax} 1=2.24)$ as indicated by the linear with tail (Kmax value) and biphasic models (Kmax1 value), respectively (Table 6.7).

The biphasic model has been developed as an alternative to the linear model to explain whether there is a subpopulation of the initial population that is resistant (less sensitive) to thermal or non-thermal stress conditions (Geeraerd et al., 2006). The f value of the biphasic model explains the fraction of the initial population in a major subpopulation, and (1-f) is the fraction of the initial population in a minor subpopulation, and kmax 1 and $k m a x 2$ each represent the specific inactivation rates of the two subpopulations (Geeraerd et al., 2006). In this study, the f value for the pressed card was 0.9062 and 0.7168 for wood (Table 6.7), suggesting that approximately $10 \%$ (1-0.9062) and 29\% of (1-0.7168) the subpopulation of L. monocytogenes on pressed-card and wood surfaces were adapted and resistant to the surface conditions at $3.2^{\circ} \mathrm{C}$. The Kmax 2 values of pressed-card and wood surfaces were close to zero. These results were visually confirmed by the pathogen survival curve in Figure 6.1, which shows a long "tail" of $L$. monocytogenes $\left(5-6 \log _{10} \mathrm{CFU} / \mathrm{cm}^{2}\right)$ surviving on pressed-card and wood surfaces from day one to 21 . The f value on a plastic surface was 0.9889 and the Kmax2 value was zero, suggesting that only $1.2 \%$ (1-0.9889) of the subpopulation from the initial population was resistant to the dry and desiccated surface conditions. This result was also consistent with Figure 6.1 in that the "tail" of L. monocytogenes remaining on plastic surfaces was $4-5 \log _{10} \mathrm{CFU} / \mathrm{cm}^{2}$, down from the $6.93 \log _{10} \mathrm{CFU} / \mathrm{cm}^{2}$ of the initial population. 
At $22.5^{\circ} \mathrm{C}$, the Kmax value of the linear with tail model and the Kmax 1 value of the biphasic model both showed a larger $(P<0.05)$ inactivation rate of $L$. monocytogenes on plastic surfaces $(\mathrm{Kmax}=6.71, \mathrm{Kmax} 1=17.94)$ than on pressed $\operatorname{card}(\mathrm{Kmax}=0.86, \mathrm{Kmax} 1=3.70)$ and wood surfaces $(\mathrm{Kmax}=2.24$, Kamx1=3.50, Table 6.8). The Kmax2 value (0.29-0.41) of the biphasic model was similar $(P>0.05)$ between plastic, pressed-card, and wood surfaces, which was again consistent with the survival curve observed in Figure 6.1. As shown in Figure 6.1, the pathogen level for samples on all three material surfaces dramatically declined within day one, followed by a slow reduction afterward. According to the Weibull model, the lowest $(P<0.05) \mathrm{k}$ value was from plastic samples $(0.01)$, followed by wood (0.23) and pressed-card ones (0.97) (Table 6.8), again suggesting that L. monocytogenes was easier to be inactivated on plastic than on wood and pressed-card surfaces at room temperature. The results agree with those from the linear with tail and biphasic models.

In this study, both microbial survival curves and data modeling indicate that the pathogen counts decreased faster on plastic surfaces compared to pressed-card and wood surfaces during storage. Plastic surfaces used in this study were fresh, new, clean, and have smooth, plane, and homogeneous surfaces without holes and pores to entrap bacteria. As the water dried out in the first 30 min after inoculation, the only available nutrient source for the attached bacterial cells on plastic surfaces was the absorbed organic macromolecules, which can be exhausted rapidly during storage. In contrast, the microstructure of pressed-card and wood surfaces contains pores and niches that can absorb water for bacterial use and favor bacteria forming biofilms over time during storage. The bacteria matrix on pressed-card and wood surfaces could obtain fresh nutrients from the cell lysis of neighboring cells. The detailed mechanism would need to be 
examined using scanning or transmitting electronic microscopy to determine the entrapment of pathogens on various material surfaces during different storage conditions.

The results of this study indicated that plastic containers could potentially reduce the cross-contamination of foodborne pathogens to produce during storage, transport, and display at farmers' markets due to a faster viability loss of pathogenic microorganisms compared to pressed-card or wood ones. At farmers' markets, storage containers are typically owned by the vendors, who are viewed as having the primary responsibility for cleaning and sanitation practices. Plastic containers with smooth surfaces are easier cleaned and sanitized than pressedcard and wood containers, which contain hard-to-reach areas and usually are damaged after exposure to water solutions. In agreement with the aforementioned survey results, plastic containers should be the choice for small local produce growers to improve the microbial safety of produce.

\subsection{Conclusions}

In conclusion, based on the results from this study, it is suggested that local, small, fresh produce farmers should choose plastic containers to present fresh produce at farmers' markets and avoid putting containers directly into a cooler with unsold produce. Future studies are needed to validate the efficacy of the three-step wash with sanitizers to decontaminate foodborne pathogens on various container surfaces. The results of this study will be of interest to the states included in the study, West Virginia and Kentucky, as well as the county extension specialists/agents who are developing and implementing produce safety training programs, such as the new "Writing Your Food Safety Plan" short course for produce growers offered by the WVU Extension Service Small Farm Center in coordination with the WV Food Safety Training 
Team. These research results can also contribute to the development of training materials for farmers' market managers and vendors by local farmers' market associations.

\section{Acknowledgment}

This research was supported by the United States Department of Agriculture, the National Institute of Food and Agriculture, the AFRI-Food Safety Program (Grant \# 201469003-21583), and the Non-Land Grant Colleges of Agriculture (NLGCA) Capacity Building Program (Grant \# 2017-70001-25993). The authors appreciate the Morgantown and Bowling Green Farmers' Market Associations and the WVU Extension Service Small Farm Center for their generous assistance during the project period. 


\section{References}

Cossentine, J. E., Sholberg, P. L., Jensen, L. B. J., Bedford, K. E., \& Shephard, T. C. (2004). Fumigation of empty fruit bins with carbon dioxide to control diapausing codling moth larvae and Penicillium expansum link. ex thom spores. Hortscience. 39, 429-432.

Food Safety News. (2011). Did Deer Cause Oregon's Strawberry Outbreak? http://www.foodsafetynews.com/2011/08/epis-pinpoint-strawberries-in-or-e-colioutbreak/\#.VMBe89J0zIW Accessed April 14th, 2018.

Food Safety News. (2015). Update: 9 Confirmed, 1 Probable Case in Seattle E. coli Outbreak. http://www.foodsafetynews.com/2015/09/6-e-coli-cases-linked-to-mexican-food-sold-atwashington-farmers-markets/\#.WKSjnk0zWMQ. Accessed April 14th, 2018.

Gardner, T.J., Fitzgerald, C., Xavier, C., Klein, R., Pruckler, J., Stroika, S., \& McLaughlin, J. B. (2011). Outbreak of campylobacteriosis associated with consumption of raw peas. Clinical Infectious Diseases, 53, 26-32.

Geeraerd, A. H., Valdramidis, V. P., \& Van Impe, J. F. (2005). GInaFiT, a freeware tool to assess non-log-linear microbial survivor curves. International Journal of Food Microbiology, 102, 95-105.

Higbee, B. S., Calkins, C. O., \& Temple, C. A. (2001). Overwintering of codling moth (Lepidoptera: Tortricidae) larvae in apple harvest bins and subsequent moth emergence. Journal of Economic Entomology, 94, 1511-1517.

Kentucky Department of Agriculture. (2016). Farmers' market. http://www.kyagr.com/marketing/farmers-market.html. Accessed April 14th, 2018. 
Killinger, K. (2014). Assessment of sanitation techniques for tree fruit storage bins.

https://www.centerforproducesafety.org/amass/documents/researchproject/345/CPS\%20F inal\%20Report\%20Killinger.pdf. Accessed April 14th, 2018.

Levy, D., Beck, N., Kossik, A., Patti, T., Meschke, J., Calicchia, M., \& Hellberg, R. (2014). Microbial safety and quality of fresh herbs from Los Angeles, Orange County and Seattle farmers' markets. Journal of the Science of Food and Agriculture, 95, 2641-2645.

Li, K., Weidhaas, J., Lemonakis, L., Khouryieh, H., Stone, M., Jones, L., \& Shen, C. (2017). Microbiological Quality and Safety of Fresh Produce in West Virginia and Kentucky Farmers' Markets and Validation of a Post-harvest Washing Practice with Antimicrobials to Inactivate Salmonella and Listeria monocytogenes. Food Control. 79, 101-108.

López-Gálvez, F., Posada-Izquierdo, G. D., Selma, M. V., Pérez-Rodríguez, F., Gobet, J., Gil, M. I., \& Allende, A. (2012). Electrochemical disinfection: An efficient treatment to inactivate Escherichia coli $\mathrm{O} 157: \mathrm{H} 7$ in process wash water containing organic matter. Food Microbiology, 30, 146-156.

McEldowney, S. and Fletcher, M. (1988). The effect of temperature and relative humidity on the survival of bacteria attached to dry solid surfaces. Letters in Applied Microbiology, 7, 8386.

Milling, A., Kehr, R., Wulf, A., \& Smalla, K. (2005). Survival of bacteria on wood and plastic particles: Dependence on wood species and environmental conditions. Holzforschung, $59,72-81$.

Peleg, M., (2006). Advanced Quantitative Microbiology for Food and Biosystems: Models for Predicting Growth and Inactivation. CRC Press, Boca Raton, FL. 
Randall, P., Sholberg, P., Judd, G., \& Cossentine, J. (2011). Acetic acid fumigation of fruit storage bins to control diapausing codling moth larvae. Hortscience. 46, 1634-1639.

Ratkowsky, D.A., (2002). Some examples of, and problems with, the use of nonlinear logistic regression in predictive food microbiology. International Journal of Food Microbiology, $73,119-125$.

Scheinberg, J., Doores, S., \& Cutter, C. (2013). A Microbiological Comparison of Poultry Products Obtained from Farmers' Markets and Supermarkets in Pennsylvania. Journal of Food Safety, 33, 259-264.

Scheinberg, J., Dudley E., Campbell, J., Roberts, B., Dimarzio, M., DeBroy, C., \& Cutter, C. (2017). Prevalence and phylogenetic characterization of Escherichia coli and hygiene indicator bacteria isolated from leafy green produce, beef, and pork obtained from farmers' markets in Pennsylvania. Journal of Food Protection, 80, 237-244.

Sinkel, D., Khouryieh, H., Daday, J. K., Stone, M., \& Shen, C. (2018). Knowledge and implementation of Good Agricultural Practices among Kentucky fresh produce farmers. Food Protection Trends, 38, 111-121.

Siroli, L., Patrignani, F., Serrazanetti, D. I., Chiavari, C., Benevelli, M., Grazia, L., \& Lanciotti, R. (2017). Survival of Spoilage and Pathogenic Microorganisms on Cardboard and Plastic Packaging Materials. Frontiers in Microbiology, 8, 2606.

Strohbehn, C., Mendonca, A., Wilson, L., Domoto, P., Smith, M., Brehm-Stecher, B., \& Shaw, A. M. (2013) On-farm Food Safety: Cleaning and Sanitizing Guide. Human Sciences Extension and Outreach Publications. http://lib.dr.iastate.edu/extension_families_pubs/102. Accessed April 14th, 2018. 
USDA-Economic Research Service. (2017). National count of farmers market directory listings.https://www.ams.usda.gov/sites/default/files/media/NationalCountofFMDirectory 17.JPG Accessed April 14th, 2018.

Waelti, H. (1992). Should We Use Plastic Bins? Retrieved April 14, 2018, from http://postharvest.tfrec.wsu.edu/pages/J3I4C

West Virginia Farmers Market Association. (2018). http://wvfarmers.org/members-2/market/. Accessed June 7th, 2018. 


\section{Chapter 6 Tables and Figures}

Table 6.1. Type of containers for presenting and transporting produce at farmers' market

\begin{tabular}{|c|c|c|c|c|}
\hline $\begin{array}{l}\text { Survey } \\
\text { questions }\end{array}$ & \multicolumn{2}{|c|}{$\begin{array}{l}\text { What kind(s) of containers do you use to present your } \\
\text { produce at the market? (check all that apply) } \\
\text { 1. Wood } \\
\text { 2. Plastic } \\
\text { 3. Metal } \\
\text { 4. Paper } \\
\text { 5. Other (please specify) }\end{array}$} & \multicolumn{2}{|c|}{$\begin{array}{l}\text { What kind(s) of containers do you use for } \\
\text { storage/transport of your produce? (check all that apply) } \\
\text { 1. Wood } \\
\text { 2. Plastic } \\
\text { 3. Metal } \\
\text { 4. Paper } \\
\text { 5. Other (please specify) }\end{array}$} \\
\hline \multirow{3}{*}{ Type $^{\mathrm{a}}$} & Containers for pr & g produce & Containers for tra & g produce \\
\hline & $\begin{array}{c}\text { Morgantown, WV }(\mathrm{N}=27, \\
\left.67.5 \%{ }^{\mathrm{b}}\right)\end{array}$ & $\begin{array}{c}\mathrm{KY} \\
(\mathrm{N}=140,23.3 \%)\end{array}$ & $\begin{array}{c}\text { Morgantown, WV }(\mathrm{N}=28, \\
70.0 \%)\end{array}$ & $\begin{array}{c}\mathrm{KY} \\
(\mathrm{N}=138,23.0 \%)\end{array}$ \\
\hline & $\mathrm{n}(\%)$ & $\mathrm{n}(\%)$ & $\mathrm{n}(\%)$ & $\mathrm{n}(\%)$ \\
\hline Wood & $9(33) \mathrm{a}$ & $67(48) a$ & $6(21) \mathrm{a}$ & $55(40) \mathrm{a}$ \\
\hline Plastic & $22(81) b$ & $111(79) b$ & $27(96) b$ & $123(89) b$ \\
\hline Metal & $4(15) c$ & $33(24) c$ & $1(4) c$ & $22(16) c$ \\
\hline Paper & $14(52) \mathrm{d}$ & $60(43) a$ & $7(25) \mathrm{a}$ & $44(32) \mathrm{a}$ \\
\hline Others $^{c}$ & $3(11) c$ & N/A & $2(7) c$ & N/A \\
\hline
\end{tabular}

${ }^{a}$ Respondents were allowed to indicate more than one choice.

${ }^{\mathrm{b}}$ Response rate of total distributed questionnaires (WV: 40; KY: 600)

${ }^{c}$ Others include basket-natural fiber, mesh bags, wicker bags, cardboard, plastic-lined with disposable bag.

Mean values with different letters within each column are significantly different $(P<0.05$, LSD test) 
Table 6.2. Wash and/or sanitize produce containers between farmers' market visits

\begin{tabular}{|c|c|c|c|c|}
\hline $\begin{array}{l}\text { Survey } \\
\text { questions }\end{array}$ & \multicolumn{2}{|c|}{$\begin{array}{l}\text { Do you wash your storage containers between visits to } \\
\text { the farmers' market? } \\
1 \text {. No } \\
\text { 2. Yes }\end{array}$} & \multicolumn{2}{|c|}{$\begin{array}{l}\text { If yes, do you sanitize your containers? } \\
1 . \text { No } \\
\text { 2. Yes (If yes, please specify the type(s) of sanitizer you } \\
\text { use) }\end{array}$} \\
\hline \multirow{3}{*}{ Answers } & \multicolumn{2}{|c|}{ Wash containers between visits } & \multicolumn{2}{|c|}{ If yes, do you sanitize ${ }^{\mathrm{a}}$} \\
\hline & $\begin{array}{c}\text { Morgantown, WV }(\mathrm{N}=27, \\
\left.67.5 \% \%^{\mathrm{b}}\right)\end{array}$ & $\begin{array}{c}\mathrm{KY} \\
(\mathrm{N}=137,22.8 \%)\end{array}$ & $\begin{array}{c}\text { Morgantown, WV }(\mathrm{N}=22, \\
\left.95.6 \%^{c}\right)\end{array}$ & $\begin{array}{c}\mathrm{KY} \\
(\mathrm{N}=121,94.5 \%)\end{array}$ \\
\hline & $\mathrm{n}(\%)$ & $\mathrm{n}(\%)$ & $\mathrm{n}(\%)$ & $\mathrm{n}(\%)$ \\
\hline No & $4(15) \mathrm{a}$ & $9(7) \mathrm{a}$ & $9(41) \mathrm{a}$ & $35(29) \mathrm{a}$ \\
\hline Yes & $23(85) b$ & $128(93) b$ & $13(59) \mathrm{a}$ & $86(71) b$ \\
\hline
\end{tabular}

${ }^{a}$ Sanitizer includes chlorine, soapy water, Lysol, and vinegar water

${ }^{\mathrm{b}}$ Response rate of total distributed questionnaires (WV: 40; KY: 600)

${ }^{c}$ Response rate among those who answered "yes" (WV: 23; KY: 128)

Mean values with different letters within each column are significantly different $(P<0.05$, LSD test) 
Table 6.3. Temperature of storing containers with produce before transport to farmers' market

\begin{tabular}{|c|c|c|}
\hline Survey question & $\begin{array}{l}\text { How do you store your produce containers } \\
\text { before transporting them to the farmers' } \\
\text { market? (check all that apply) }\end{array}$ & $\begin{array}{l}\text { 1. I freeze my produce containers } \\
\text { 2. I store my produce containers at } \\
\text { refrigerated temperatures } \\
\text { 3. I store my produce containers at room } \\
\text { temperature }\end{array}$ \\
\hline Temperature $^{\mathrm{a}}$ & $\begin{array}{c}\text { Morgantown, WV } \\
\left(\mathrm{N}=27,67.5 \%{ }^{\mathrm{b}}\right)\end{array}$ & $\begin{array}{c}\mathrm{KY} \\
(\mathrm{N}=141,23.5 \%)\end{array}$ \\
\hline & $\mathrm{n}(\%)$ & $\mathrm{n}(\%)$ \\
\hline Freeze & $0(0) \mathrm{a}$ & $0(0) \mathrm{a}$ \\
\hline Refrigerated temperature & $18(67) b$ & $87(62) b$ \\
\hline Room temperature & $17(63) \mathrm{b}$ & $119(84) \mathrm{c}$ \\
\hline
\end{tabular}

${ }^{\mathrm{a}}$ Respondents were allowed to indicate more than one response.

${ }^{\mathrm{b}}$ Response rate of total distributed questionnaires (WV: 40; KY: 600)

Mean values with different letters within each column are significantly different $(P<0.05$, LSD test) 
Table 6.4. Awareness of foodborne pathogens contaminated on fresh produce

\begin{tabular}{|c|c|c|c|c|}
\hline Survey question & \multicolumn{2}{|c|}{$\begin{array}{l}\text { Are the following bacteria transmitted from } \\
\text { fresh fruits and vegetables? }\end{array}$} & \multicolumn{2}{|c|}{$\begin{array}{l}\text { 1. Shiga Toxin Producing E. coli (No, Yes) } \\
\text { 2. Salmonella (No, Yes) } \\
\text { 3. Listeria monocytogenes (No, Yes) } \\
\text { 4. Staphylococcus aureus (No, Yes) }\end{array}$} \\
\hline \multirow[t]{3}{*}{ Pathogens } & \multicolumn{2}{|c|}{$\begin{array}{l}\text { Morgantown, WV } \\
\left(\mathrm{N}=15,37.5 \%^{\mathrm{a}}\right)\end{array}$} & \multicolumn{2}{|c|}{$\begin{array}{c}\mathrm{KY} \\
(\mathrm{N}=117,19.5 \%) \\
\end{array}$} \\
\hline & Yes & No & Yes & No \\
\hline & $\mathrm{n}(\%)$ & $\mathrm{n}(\%)$ & $\mathrm{n}(\%)$ & $\mathrm{n}(\%)$ \\
\hline $\begin{array}{l}\text { Shiga-Toxin Producing } E \text {. } \\
\text { coli }\end{array}$ & $13(87) \mathrm{a}$ & $2(13) b$ & $97(83) \mathrm{a}$ & $20(17) b$ \\
\hline Salmonella & $12(80) a$ & $3(20) b$ & 107 (91)a & $10(9) b$ \\
\hline Listeria monocytogenes & $13(87) \mathrm{a}$ & $2(13) b$ & $83(71) \mathrm{a}$ & $34(29) b$ \\
\hline Staphylococcus aureus & $8(53) \mathrm{a}$ & $7(47) \mathrm{a}$ & $63(54) \mathrm{a}$ & $54(46) \mathrm{a}$ \\
\hline
\end{tabular}

${ }^{a}$ Response rate of total distributed questionnaires (WV: 40; KY: 600)

Mean values with different letters within each row are significantly different $(P<0.05$, LSD test) 
Table 6.5. Parameters (mean \pm standard error) of models estimated for the survival of Salmonella on plastic, pressed-card, and wood surfaces after storage at $3.2^{\circ} \mathrm{C}(22.9 \% \mathrm{RH})$ for 21 days.

\begin{tabular}{llccc}
\hline Model & Parameters & Plastic & Pressed-card & Wood \\
\hline Linear + Tail & RMSE & 0.3259 & 0.4331 & 0.1762 \\
& $\mathrm{R}^{2}$ & 0.9203 & 0.7903 & 0.9454 \\
& Kmax & $5.95 \pm 1.48 \mathrm{a}$ & $14.19 \pm 5.93 \mathrm{~b}$ & $3.76 \pm 1.64 \mathrm{a}$ \\
\hline Weibull & RMSE & 0.5690 & 0.3275 & 0.1762 \\
& $\mathrm{R}^{2}$ & 0.7572 & 0.8801 & 0.9454 \\
& $\mathrm{k}$ & $0.04 \pm 0.12 \mathrm{a}$ & $0.01 \pm 0.01 \mathrm{a}$ & $0.33 \pm 0.30 \mathrm{~b}$ \\
& $\alpha$ & $0.18 \pm 0.07$ & $0.11 \pm 0.03$ & $0.21 \pm 0.03$ \\
\hline Biphasic & $\mathrm{RMSE}$ & 0.3456 & 0.3757 & 0.1173 \\
& $\mathrm{R}$ & 0.9203 & 0.8072 & 0.9824 \\
& $\mathrm{f}$ & $0.9972 \pm 0.002 \mathrm{a}$ & $0.9839 \pm 0.014 \mathrm{a}$ & $0.9557 \pm 0.012 \mathrm{a}$ \\
& Kmax1 & $5.95 \pm 1.62 \mathrm{a}$ & $14.68 \pm 6.46 \mathrm{~b}$ & $12.79 \pm 2.34 \mathrm{~b}$ \\
& Kmax2 & $0.00 \pm 0.05 \mathrm{a}$ & $0.12 \pm 0.04 \mathrm{~b}$ & $0.13 \pm 0.01 \mathrm{~b}$ \\
\hline
\end{tabular}

Mean values with different letters within each row are significantly different $(P<0.05$, LSD test) 
Table 6.6. Parameters (mean \pm standard error) of models estimated for the survival of Salmonella on plastic, pressed-card, and wood surfaces after storage at $22.5^{\circ} \mathrm{C}(50.4 \% \mathrm{RH})$ for 21 days.

\begin{tabular}{llccc}
\hline Model & Parameters & Plastic & Pressed-card & Wood \\
\hline Linear & RMSE & 0.9215 & 0.7341 & 0.6190 \\
& $\mathrm{R}^{2}$ & 0.6837 & 0.5040 & 0.6947 \\
& Kmax & $2.47 \pm 0.84 \mathrm{a}$ & $0.55 \pm 0.19 \mathrm{~b}$ & $0.45 \pm 0.11 \mathrm{~b}$ \\
\hline
\end{tabular}

Mean values with different letters within each row are significantly different $(P<0.05$, LSD test) 
Table 6.7. Parameters (mean \pm standard error) of models estimated for the survival of Listeria monocytogenes on plastic, pressed-card, and wood surfaces after storage at $3.2^{\circ} \mathrm{C}(22.9 \% \mathrm{RH})$ for 21 days.

\begin{tabular}{llccc}
\hline Model & Parameters & Plastic & Pressed-card & Wood \\
\hline Linear + Tail & RMSE & 0.2268 & 0.2677 & 0.2624 \\
& $\mathrm{R}^{2}$ & 0.9286 & 0.7879 & 0.4999 \\
& Kmax & $7.10 \pm 1.68 \mathrm{a}$ & $2.16 \pm 1.13 \mathrm{~b}$ & $0.83 \pm 0.96 \mathrm{~b}$ \\
\hline Biphasic & RMSE & 0.2572 & 0.2790 & 0.2783 \\
& $\mathrm{R}^{2}$ & 0.9183 & 0.7952 & 0.4999 \\
& $\mathrm{f}$ & $0.9889 \pm 0.007 \mathrm{a}$ & $0.9062 \pm 0.064 \mathrm{~b}$ & $0.7168 \pm 0.224 \mathrm{c}$ \\
& Kmax1 & $6.04 \pm 1.75 \mathrm{a}$ & $2.44 \pm 1.47 \mathrm{~b}$ & $0.83 \pm 1.22 \mathrm{~b}$ \\
& Kmax2 & $0.00 \pm 0.03 \mathrm{a}$ & $0.02 \pm 0.04 \mathrm{a}$ & $0.00 \pm 0.05 \mathrm{a}$ \\
\hline
\end{tabular}

Mean values with different letters within each row are significantly different $(P<0.05$, LSD test $)$ 
Table 6.8. Parameters (mean \pm standard error) of models estimated for the survival of Listeria monocytogenes on plastic, pressed-card, and wood surfaces after storage at $22.5^{\circ} \mathrm{C}(50.4 \% \mathrm{RH})$ for 21 days.

\begin{tabular}{llccc}
\hline Model & Parameters & Plastic & Pressed-card & Wood \\
\hline Linear + Tail & RMSE & 0.6623 & 0.5040 & 0.5414 \\
& $\mathrm{R}^{2}$ & 0.8992 & 0.9370 & 0.9218 \\
& Kmax & $6.71 \pm 2.04 \mathrm{a}$ & $0.86 \pm 0.15 \mathrm{~b}$ & $2.24 \pm 0.59 \mathrm{c}$ \\
\hline Weibull & RMSE & 0.5962 & 0.3599 & 0.4118 \\
& $\mathrm{R}^{2}$ & 0.9183 & 0.9655 & 0.9579 \\
& $\mathrm{k}$ & $0.01 \pm 0.01 \mathrm{a}$ & $0.23 \pm 0.20 \mathrm{~b}$ & $0.97 \pm 0.66 \mathrm{c}$ \\
& $\alpha$ & $0.22 \pm 0.06$ & $0.39 \pm 0.08$ & $0.52 \pm 0.11$ \\
\hline Biphasic & RMSE & 0.4843 & 0.3734 & 0.3702 \\
& $\mathrm{R}$ & 0.9551 & 0.9639 & 0.9695 \\
& $\mathrm{f}$ & $0.9996 \pm 0.004 \mathrm{a}$ & $0.9943 \pm 0.005 \mathrm{a}$ & $0.9928 \pm 0.008 \mathrm{a}$ \\
& Kmax1 & $17.94 \pm 1.75 \mathrm{a}$ & $3.70 \pm 1.21 \mathrm{~b}$ & $3.50 \pm 1.20 \mathrm{~b}$ \\
& Kmax2 & $0.34 \pm 0.12 \mathrm{a}$ & $0.29 \pm 0.05 \mathrm{a}$ & $0.41 \pm 0.13 \mathrm{~b}$ \\
\hline
\end{tabular}

Mean values with different letters within each row are significantly different $(P<0.05$, LSD test) 

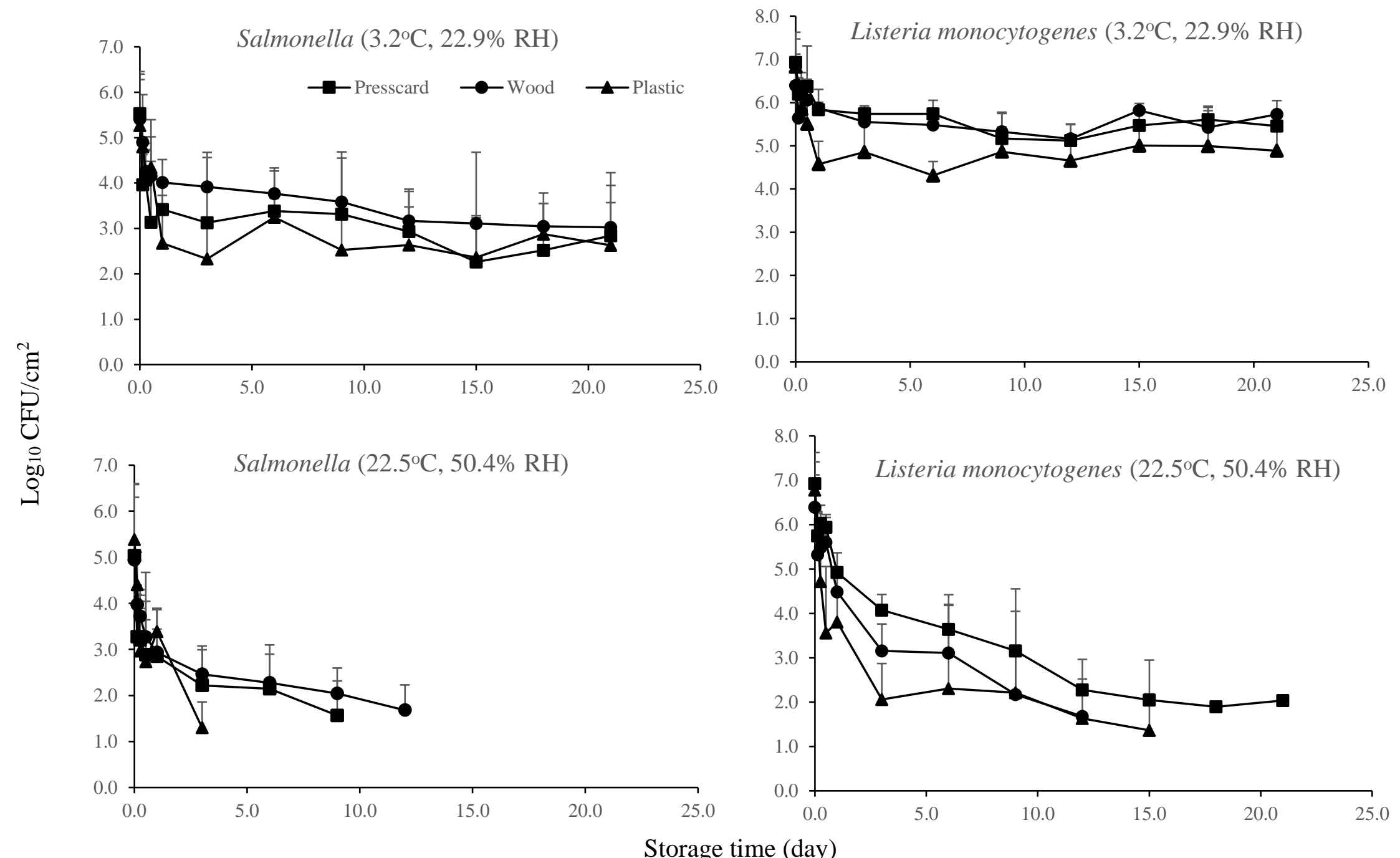

Figure 6.1. Survival of Salmonella and Listeria monocytogenes on plastic, pressed-card, and wood surfaces during storage at $3.2^{\circ} \mathrm{C}$ $(22.9 \% \mathrm{RH})$ and $22.5^{\circ} \mathrm{C}(50.4 \% \mathrm{RH})$ for 21 day 


\section{CHAPTER 7}

\section{Summary and Future Directions}

\section{Summary}

The microbial quality and safety of local produce can be improved with the triple wash process. Study one assessed the two triple-wash procedures in inactivating foodborne pathogens and surrogate bacteria on cucumbers and tomatoes. Results showed the WWA procedure better at inactivating Salmonella, L. monocytogenes, and E. faecium on cucumbers and tomatoes. SaniDate-5.0 at the concentration of $0.25 \%$ and $0.50 \%$ had similar or better antimicrobial efficacy than chlorine water without or with $\mathrm{pH}$ adjustment. E. faecium also showed potential for Salmonella surrogate used for validation studies of antimicrobial treatments during post-harvest washing process on produce. Study two assessed the two triple-wash procedures on spinach. Results are similar to the first study. A procedure was the better performer to inactivate Salmonella and L. monocytogenes on locally grown spinaches. SaniDate-5.0 at the concentrations of $0.25 \%$ and $0.50 \%$, indicates similar or better antimicrobial efficacy than chlorine water and LCA on spinach. Study three evaluated the two triple-wash procedures with SaniDate-5.0 to improve microbial safety and quality of butternut squashes, results indicate the WWA procedure performs better pathogen reductions than the WAW procedure on squashes against Salmonella and L. monocytogenes. Squashes treated with SaniDate-5.0 showed lower microbial counts than the unwashed and water-treated samples typically during the later storage period. This study also determined the feasibility of the triple-wash application in a processing plant. The annual operating cost of the triple-wash using SaniDate-5.0 is approximately $\$ 500$ to $\$ 2,000$ for producing 1,000 to 5,000 squashes. Refreshing water in each tank adds an extra cost of 5-220\%. Study four evaluated the survival of Salmonella and Listeria monocytogenes on 
various produce container surfaces commonly used at farmers' markets, under storage conditions both at refrigerated and room temperature. Results indicate produce farmers should choose plastic containers to present fresh produce at farmers' markets and avoid storing unsold produce in containers inside a cooler.

\section{Future Direction}

Further studies are needed to investigate cross-contamination of the triple-wash process in three washing tanks with or without antimicrobials. An antibiotic marker should be introduced into E. faecium to filter out background microflora. In addition, the residual effects on sanitizers applied on produce samples need to be compared, to determine if a neutralization step is needed after the WWA process. Sensory evaluations are needed to investigate the side-effect of sensory qualities of washed fresh produce. Finally, the efficacy of the triple-wash process with sanitizers to decontaminate foodborne pathogens on various container surfaces needs to be validated. 